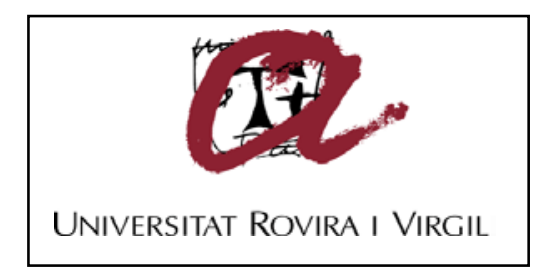

\title{
DROUGHT VARIABILITY AND CHANGE ACROSS THE IBERIAN PENINSULA
}

\author{
Joan Ramon Coll Benages
}

Dipòsit Legal: T 955-2014

ADVERTIMENT. L'accés als continguts d'aquesta tesi doctoral i la seva utilització ha de respectar els drets de la persona autora. Pot ser utilitzada per a consulta o estudi personal, així com en activitats o materials d'investigació i docència en els termes establerts a l'art. 32 del Text Refós de la Llei de Propietat Intel.lectual (RDL 1/1996). Per altres utilitzacions es requereix l'autorització prèvia i expressa de la persona autora. En qualsevol cas, en la utilització dels seus continguts caldrà indicar de forma clara el nom i cognoms de la persona autora i el títol de la tesi doctoral. No s'autoritza la seva reproducció o altres formes d'explotació efectuades amb finalitats de lucre ni la seva comunicació pública des d'un lloc aliè al servei TDX. Tampoc s'autoritza la presentació del seu contingut en una finestra o marc aliè a TDX (framing). Aquesta reserva de drets afecta tant als continguts de la tesi com als seus resums i índexs.

ADVERTENCIA. El acceso a los contenidos de esta tesis doctoral y su utilización debe respetar los derechos de la persona autora. Puede ser utilizada para consulta o estudio personal, así como en actividades o materiales de investigación y docencia en los términos establecidos en el art. 32 del Texto Refundido de la Ley de Propiedad Intelectual (RDL 1/1996). Para otros usos se requiere la autorización previa y expresa de la persona autora. En cualquier caso, en la utilización de sus contenidos se deberá indicar de forma clara el nombre y apellidos de la persona autora y el título de la tesis doctoral. No se autoriza su reproducción u otras formas de explotación efectuadas con fines lucrativos ni su comunicación pública desde un sitio ajeno al servicio TDR. Tampoco se autoriza la presentación de su contenido en una ventana o marco ajeno a TDR (framing). Esta reserva de derechos afecta tanto al contenido de la tesis como a sus resúmenes e índices.

WARNING. Access to the contents of this doctoral thesis and its use must respect the rights of the author. It can be used for reference or private study, as well as research and learning activities or materials in the terms established by the 32nd article of the Spanish Consolidated Copyright Act (RDL 1/1996). Express and previous authorization of the author is required for any other uses. In any case, when using its content, full name of the author and title of the thesis must be clearly indicated. Reproduction or other forms of for profit use or public communication from outside TDX service is not allowed. Presentation of its content in a window or frame external to TDX (framing) is not authorized either. These rights affect both the content of the thesis and its abstracts and indexes. 


\section{DROUGHT VARIABILITY AND CHANGE ACROSS THE IBERIAN PENINSULA}

by

Joan Ramon Coll Benages

Thesis

Doctor of Philosophy

\section{Universitat Rovira i Virgili \\ Geography Department}

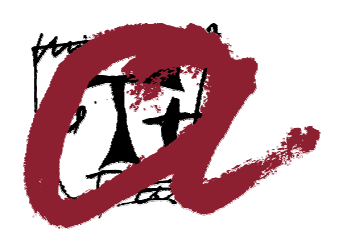

UNIVERSITAT ROVIRA I VIRGILI 
IVERSITAT ROVIRA I VIRGILI

DROUGHT VARIABILITY AND CHANGE ACROSS THE IBERIAN PENINSULA Joan Ramon Coll Benages

DL: T 955-2014 


\title{
Joan Ramon Coll Benages
}

\section{DROUGHT VARIABILITY AND CHANGE ACROSS THE IBERIAN PENINSULA}

\author{
Thesis \\ Doctor of Philosophy
}

Director: Dr. Enric Aguilar Anfrons

Geography Department

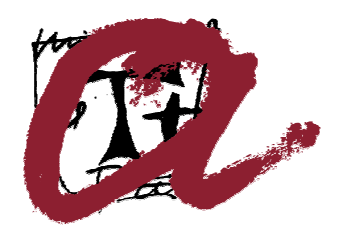

UNIVERSITAT ROVIRA I VIRGILI

Tortosa

2013 


\section{Acknowledgements}

This work would not have been possible without the collaboration and support of some people. First of all, I would like to thank my supervisor Enric Aguilar, who has been supporting and encouraging me during the four years of my $\mathrm{PhD}$. I appreciate his comments, suggestions, advice and corrections, highlighting his fulltime availability and support. I acknowledge all the chances that he gave me across time and I especially appreciate the huge confidence in me.

I thank Manola Brunet, who kindly helped me to get the required data to start the work and for all the given opportunities that allowed me to grow up as a climatologist. I especially appreciate her support before my stage at CRU.

I would like to mention all C3 staff to provide me all the facilities for developing my work successfully in terms of scientific training, computer skills as well as administrative support. I would like to thank Universitat Rovira i Virgili (URV) and C3 for financially supporting me as a PhD student.

I am very grateful to Phil Jones and CRU staff, whom kindly welcomed at Climatic Research Unit (CRU) for almost 4 months. I appreciate the guidance received by Phil during all my stage, which strongly contributed to improve my skills and capabilities in climate research. It was a great experience to meet important climate experts and good people in a friendly environment.

I also acknowledge the contribution of $\mathrm{M}^{\mathrm{a}}$ Antonia Valente and Ricardo Trigo from the Climatology and Climate Change Research Group of the Instituto Dom Luiz, Lisbon University, to provide me climatic daily data of Portugal (Porto and Lisboa time-series). I would like to thank the comments, corrections and suggestions provided by Sergio Vicente-Serrano as a reviewer of my first paper submitted to the International Journal of Climatology (IJOC).

I appreciate the grant provided by AGAUR (Generalitat de Catalunya) to fund my stage at CRU. In this way, I acknowledge the funds provided by the COST Action ESO601 for attending to the STSM in the Czech Hydrometeorological Institute and to the R course held in Portugal.

And, finally but probably the most important people, great thanks to Montsant, family and friends from Falset to be here; really close to me. 
UNIVERSITAT ROVIRA I VIRGILI
DROUGHT VARIABILITY AND CHANG

DROUGHT VARIABILITY AND CHANGE ACROSS THE IBERIAN PENINSULA

Joan Ramon Coll Benages

DL: T 955-2014

\begin{abstract}
DL: T 955-2014
\end{abstract}




\begin{abstract}
Drought variability and change is assessed in this study across the Iberian Peninsula along the $20^{\text {th }}$ century and the first decade of the $21^{\text {st }}$ century using state of the art drought indices: the Sc-PDSI, the SPI and the SPEI. Daily temperature and precipitation data from 24 time-series regularly spread over Iberian Peninsula is quality controlled and also homogenized in a monthly scale to create the Monthly Iberian Temperature and Precipitation Series (MITPS) for the period 1906-2010. The Sc-PDSI, 12-month SPI and 12-month SPEI are computed on a monthly basis using the newly MITPS dataset to quantify hydrological droughts and wet events across time. Precipitation data is only required to compute SPI, but potential evapotranspiration (PET) is also needed to perform the Sc-PDSI and SPEI, which is estimated using the Thornthwaite's method. A Principal Component Analysis is carried out to identify spatial-temporal patterns of droughts and the characteristics and trends of severity, magnitude and duration of droughts and wet events are also described.

The analysis conducted in this study confirms that drought conditions are worsening for most of the Iberian Peninsula across time except in the western and in the north-western area, where a wetting trend is identified. Furthermore, the severity and duration of droughts show a remarkable increase in the south-western area, while drought magnitude is increasing significantly in the Mediterranean region strongly induced by global warming especially during the last decades. Severity, duration and magnitude of wet events do not experience significantly variations.

Our results indicate a clear drying trend in most of the Iberian Peninsula and are in agreement with other studies which project this evolution to the whole $21^{\text {st }}$ century. For this reason, and as a link of our study to societal needs, the application of effective water management strategies will be crucial to minimize the impact of the hydrological droughts over the Iberian Peninsula into the near future.
\end{abstract}


UNIVERSITAT ROVIRA I VIRGILI
DROUGHT VARIABILITY AND CHANG

DROUGHT VARIABILITY AND CHANGE ACROSS THE IBERIAN PENINSULA

Joan Ramon Coll Benages

DL: T 955-2014

\begin{abstract}
DL: T 955-2014
\end{abstract}




\section{Contents}

Acknowledgements ..................................................... iv

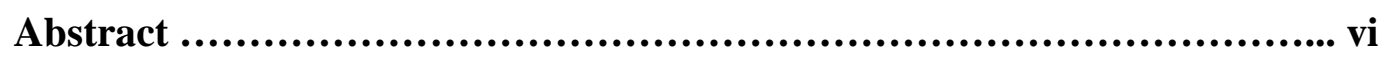

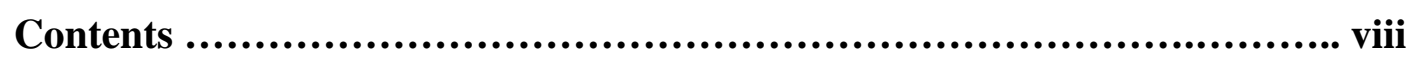

List of abbreviations ........................................................ xii

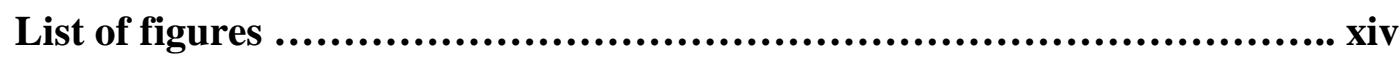

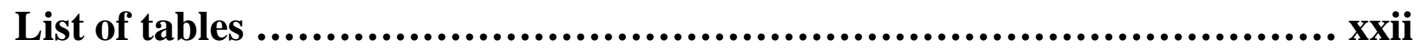

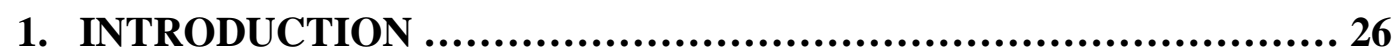

1.1. Background ............................................. 26

1.2. Aims and objectives .................................... 35

1.3. Thesis outline .............................................. 37

2. THEORETICAL APPROACH TO DROUGHT ANALYSIS ........... 40

2.1. Drought concept ........................................... 40

2.2. Drought characteristics .................................. 42

2.3. Drought classification ....................................... 47

2.3.1. Meteorological drought $\ldots \ldots \ldots \ldots \ldots \ldots \ldots \ldots \ldots \ldots \ldots \ldots . \ldots \ldots$

2.3.2. Agricultural drought $\ldots \ldots \ldots \ldots \ldots \ldots \ldots \ldots \ldots \ldots \ldots \ldots \ldots \ldots, 48$

2.3.3. Hydrological drought $\ldots \ldots \ldots \ldots \ldots \ldots \ldots \ldots \ldots \ldots \ldots \ldots \ldots . \ldots . \ldots . \ldots$

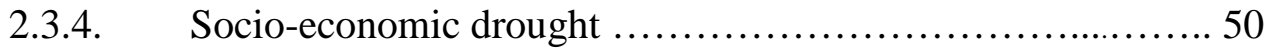

2.4. Evaluation methods: Drought indices .......................... 52

2.4.1. Percent of normal ......................................... 54

2.4.2. Quantiles Method ....................................... 56

2.4.3. The Palmer's Drought Severity Index (PDSI) ............... 58

2.4.4. The Standardized Precipitation Index (SPI) .................. 60

2.4.5. The Standardized Precipitation-Evapotranspiration Index

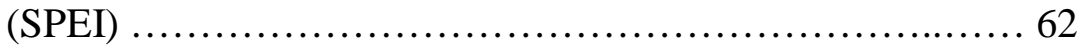

2.4.6. The Drought Monitor ................................ 64 


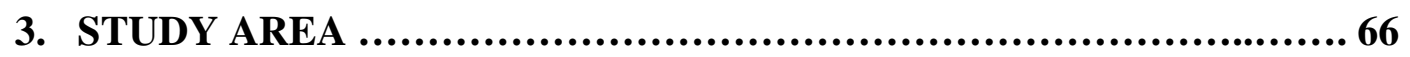

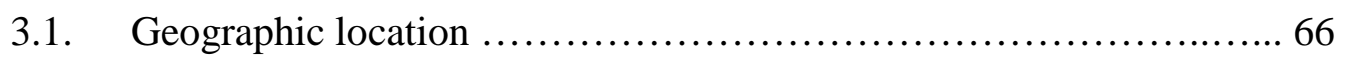

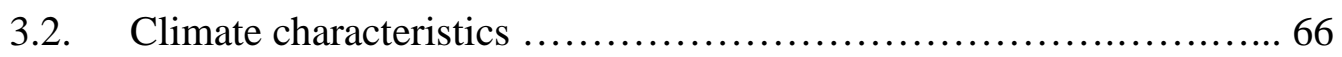

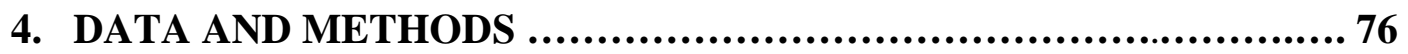

4.1. Monthly Iberian Temperature and Precipitation Series

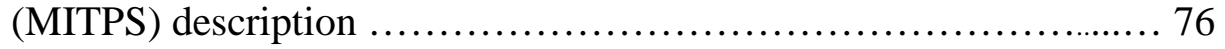

4.1.1. Additional data quality control and homogenization ........... 81

4.1.2. Missing values interpolation in MITPS ....................... 91

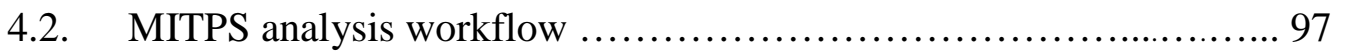

4.3. Drought indices computation ................................. 99

4.3.1. The PDSI computation and drought severity classification ..... 99

4.3.2. The SPI computation and drought severity classification ...... 103

4.3.3. The SPEI computation and drought severity classification ..... 106

4.3.4. The PET estimation method ............................ 109

4.3.5. The concept of time-scale ................................ 111

4.4. Trends computation ..................................... 114

4.5. PCA's definition, computation and Principal Component Rotation ... 116

4.6. Defining droughts and wet events and their parameter estimation .... 121

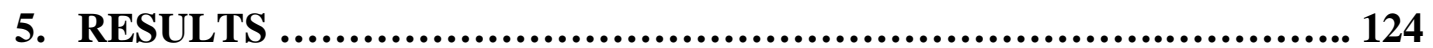

5.1. Climate fluctuations in the Iberian Peninsula ..................... 125

5.1.1. Annual and seasonal temperature variability ............... 125

5.1.2. Annual and seasonal precipitation variability ............... 129

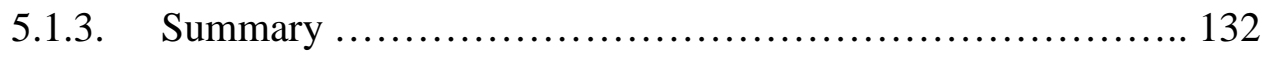

5.2. Drought variability across the Iberian Peninsula $\ldots \ldots \ldots \ldots \ldots \ldots \ldots \ldots \ldots$

5.2.1. Identification and documentary validation of dry events ..... 133

5.2.2. The frequency distribution analysis $\ldots \ldots \ldots \ldots \ldots \ldots \ldots \ldots \ldots \ldots$

5.2.3. The spatial coverage of droughts ........................ 141

5.2.4. Drought trends analysis ................................ 144

5.2.4.1. Drought evolution across the Iberian regional time-series ......................................... 144

5.2.4.2. Drought evolution across the 22 Iberian stations ....... 145 
5.2.5. The impact of global warming on drought indices and trends . 150

5.2.5.1. Analysis over the regional Iberian time-series ....... 150

5.2.5.2. Analysis over the 22 Iberian stations ................ 155

5.2.6. Discussion on the applicability on the drought indices ........ 160

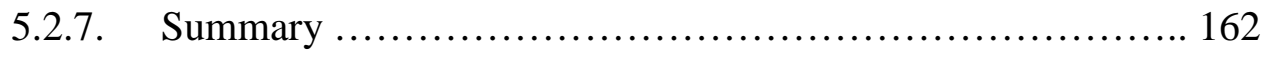

5.3. Drought fluctuations since the second half of the nineteenth century . 163

5.4. Drought regionalization of the Iberian Peninsula ................. 167

5.4.1. PCAs application and spatial-temporal patterns selection ...... 167

5.4.2. The South-western pattern .............................. 171

5.4.2.1. Annual and seasonal spatial structure .............. 171

5.4.2.2. Annual and seasonal temporal evolution ............. 172

5.4.3. The North-western pattern ........................... 175

5.4.3.1. Annual and seasonal spatial structure ............... 175

5.4.3.2. Annual and seasonal temporal evolution ............ 177

5.4.4. The Mediterranean pattern ................................. 180

5.4.4.1. Annual and seasonal spatial structure ................. 180

5.4.4.2. Annual and seasonal temporal evolution ............. 181

5.4.5. Summary .......................................... 184

5.5. Univariate analysis of droughts and wet events .................. 186

5.5.1. Characteristics and trends for the whole Iberian Peninsula .... 186

5.5.2. Characteristics and trends for the spatial-temporal patterns ... 195

5.5.2.1. The South-western pattern ......................... 195

5.5.2.2. The North-western pattern ........................ 201

5.5.2.3. The Mediterranean pattern .......................... 207

5.5.3. Changes in severity, magnitude and duration for periods ..... 212

5.5.4. Summary ........................................ 216

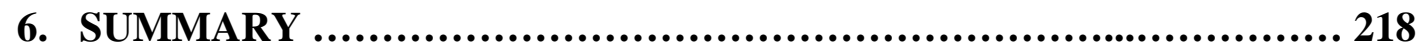

6.1. Discussion ................................................. 218

6.2. Further work .................................................. 229

6.3. Conclusions ................................................ 231

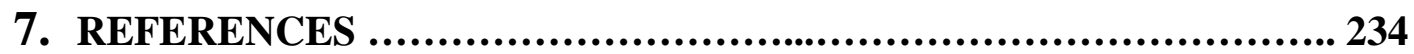


UNIVERSITAT ROVIRA I VIRGILI
DROUGHT VARIABILTT AND CHANC

DROUGHT VARIABILITY AND CHANGE ACROSS THE IBERIAN PENINSULA

Joan Ramon Coll Benages

DL: T 955-2014

DL: T 955-2014 


\section{List of abbreviations}

AEMET: Agencia Estatal de Meteorología

AWC: $\quad$ Available Water Content of the soil

BMDI: $\quad$ Bhalme \& Mooley Drought Index

CAFEC: Climatologically Appropriate for Existing Conditions

CIIFEN: Centro Internacional para la Investigación del Fenómeno de El Niño

CLIVAR: Climate Variability and Predictability Organisation

CO2: $\quad$ Carbon dioxide

CRU: $\quad$ Climate Research Unit, University of East Anglia

C3: $\quad$ Centre for Climate Change, Universitat Rovira i Virgili

DM: $\quad$ Drought Monitor

EDC: $\quad$ European Drought Centre

ENSO: $\quad$ El Niño Southern Oscillation

EOF: $\quad$ Empirical Orthogonal Function

FAO: $\quad$ Food and Agriculture Organisation

GHCN: Global Historical Climatology Network

GHG: Greenhouse Gases

HOME: COST Action ES0601, Advances in Homogenisation Methods for climate series and integrated approach.

HWSD: Harmonized World Soil Database

IP: $\quad$ Iberian Peninsula

IPCC: Intergovernmental Panel on Climate Change

MITPS: $\quad$ Monthly Iberian Temperature and Precipitation Series

NAO: $\quad$ North Atlantic Oscillation

NDMC: $\quad$ National Drought Mitigation Center

NCDC: National Climatic Data Center

PC: $\quad$ Principal Component

PCA: $\quad$ Principal Component Analysis

PET: $\quad$ Potential Evapotranspiration

PDSI: $\quad$ Palmer's Drought Severity Index

QC: $\quad$ Quality Control

RPC: $\quad$ Rotated Principal Component 
DROUGHT VARIABILITY AND CHANGE ACROSS THE IBERIAN PENINSULA

Joan Ramon Coll Benages

DL: T 955-2014

SADC: $\quad$ Southern Africa Development Community

Sc-PDSI: Self-Calibrating Palmer's Drought Severity Index

SDAPS: $\quad$ Spanish Daily Adjusted Precipitation Series

SDATS: $\quad$ Spanish Daily Adjusted Temperature Series

SNHT: Standard Normal Homogeneity Test

SPEI: $\quad$ Standardized Precipitation-Evapotranspiration Index

SPI: $\quad$ Standardized Precipitation Index

WMO: $\quad$ World Meteorological Organization 


\section{List of figures}

\section{Chapter 1}

Figure 1-1: Linear trend of annual temperatures (upper panel; in ${ }^{\circ} \mathrm{C}$ per century) and annual land precipitation amounts (lower panel; in \% per century) for 1901 to 2005 using the GHCN dataset from NCDC (Smith and Reynolds, 2005). Areas in grey have insufficient data to produce reliable trends. The percentage in precipitation (lower panel) is based on the means for the period 19611990. Trends significant at the 5\% level are indicated by white (upper panel) and black (lower panel) + marks.

Figure 1-2: Palmer Drought Severity Index. Upper Panel: PDSI time series, Lower Panel: map of annual trends from 1950-2008 in PDSI (Dai, 2011). When the values shown in the lower plot are positive the red and orange areas in the upper map are drier and the blue and green areas are wetter than average. The smooth black curve shows decadal variations. The time series approximately corresponds to a trend, and this pattern and its variations account for $67 \%$ of the linear trend of PDSI from 1900 to 2002 over the global land area. (after Dai et al., 2004b).

Figure 1-3 Change in indicators of water resources due to drought events across Europe by the 2070s. Upper Panel: projected changes in the return period of the 1961-1990 100-year drought deficit volume for the 2070s, with change in river flows and withdrawals for two climate models; ECHAM4 (left) and HadCM3 (right); Lower Panel: projected changes in the intensity (deficit volume) of 100-year droughts with changing withdrawals for the 2070s, with climate change (left, with HadCM3 climate projections) and without climate change (right). Source: Lehner et al., 2006.

Figure 1-4: Spatial distribution of the magnitude of annual trends with respect to the average annual discharge series for the analyzed period (1945-2005) (Lorenzo-Lacruz et al., 2012).

\section{Chapter 2}

Figure 2-1: Teleconnections between ENSO warm episode and droughts around the world. (www.ciifenint.org) Last visit: 08-05-2013.

Figure 2-2: World natural disasters for the period 1900-2004 obtained from Sheffield and Wood 2011.44

Figure 2-3: The propagation of a perturbation in precipitation amount through the land branch of the hydrologic cycle (Entekhabi et al., 1992).

Figure 2-4: Sequence of drought impacts (NDMC, 1995, website: http://www.drought.unl.edu/DroughtBasics/TypesofDrought.aspx. Last visit: 14-05-2013. ...

Figure 2-5: Example of Percent of Normal map for Europe from January to March 2012 available at: http://www.cpc.ncep.noaa.gov/products/Drought. Last visit: 14-05-2013.

Figure 2-6: Example of rainfall deciles over Australia from January to December 2010 available at: http://www.bom.gov.au/water. Last visit: 14-05-2013.

Figure 2-7: Global Palmer's Drought Severity Index (PDSI) for January 2002 using gridded data. Red and purple tonalities are referred to dry conditions while wet conditions are represented in blue (Dai et al., 2004). 
Figure 2-8: Interpolated global map using a 6-month SPI from April to September 2010. Regions in brown are referred to dry conditions while regions in green mean wet conditions (Sivakumar et al., 2010).

Figure 2-9: Example of global (left) 3-month and (right) 12-month SPEI, June 1995. Dry conditions are represented in red while wet conditions are in blue. Regions in white have not been studied due to the lack of sufficient data to represent drought conditions (Vicente-Serrano et al., 2010b).

Figure 2-10: Example of weekly Drought Monitor map for U.S.A. available at: http://droughtmonitor.unl.edu/ Last visit: 25-05-2013

\section{Chapter 3}

Figure 3-1: Satellite image of the Iberian Peninsula and influence areas (source: Google Earth)..... 66

Figure 3-2: Physical map of the Iberian Peninsula. Source: Instituto Geográfico Nacional available at: http://www.ign.es/ign/main/index.do. Last visit: 15-05-2013.

Figure 3-3: Annual averaged air temperature for the Iberian Peninsula (1971-2000); (Iberian Climate Atlas, 2011)

Figure 3-4: Annual averaged precipitation for the Iberian Peninsula (1971-2000); (Iberian Climate Atlas, 2011) 70

Figure 3-5: Köppen-Geiger Climate Classification for the Iberian Peninsula; (Iberian Climate Atlas, 2011)

\section{Chapter 4}

Figure 4-1: Map showing the locations of measurement stations and the elevations spread over the Iberian Peninsula......

Figure 4-2: Available Water Content of the soil (AWC in $\mathrm{mm} / \mathrm{m}^{3}$.) over the Iberian Peninsula obtained from the Harmonized World Soil Database (HWSD).

Figure 4-3: Monthly boxplots of temperature (for maximum (TX), minimum (TN), diurnal temperature range (DTR)) and precipitation (NON ZERO PREC) data for Porto (1901-2010).

Figure 4-4: Monthly boxplots of temperature (for maximum (TX), minimum (TN), diurnal temperature range (DTR)) and precipitation (NON ZERO PREC) data for Lisboa (1856-2010).

Figure 4-5: Annual boxplots of temperature (for maximum (TX), minimum (TN), diurnal temperature range (DTR)) and precipitation (NON ZERO PREC) data for Porto (1901-2010).

Figure 4-6: Annual boxplots of temperature (for maximum (TX), minimum (TN), diurnal temperature range (DTR)) and precipitation (NON ZERO PREC) data for Lisboa (1856-2010).

Figure 4-7: Frequency of rounding values after the decimal point in temperature (for maximum (TX) and minimum (TN) and precipitation (NON ZERO PREC) data for Porto (1901-2010). 
Figure 4-8: Frequency of rounding values after the decimal point in temperature (for maximum (TX) and minimum (TN) and precipitation (NON ZERO PREC) data for Lisboa (1856-2010).

Figure 4-9: Annual precipitation evolution of raw data for Porto (1901-2010) and Lisboa (1864-2010). 89

Figure 4-10: Annual mean temperature evolution of raw data and adjusted data for Porto (1901-2010) and Lisboa (1956-2010).

Figure 4-11: Potential vs. available monthly simultaneous temperature and precipitation (left axis) and the number of available stations (right axis) in the Iberian Peninsula (1850-2010).

Figure 4-12: Percentages of missing data for each time-series in terms of monthly mean temperature and monthly accumulated precipitation from 1906 to 2010 .

Figure 4-13: Mean standard errors computed for each time-series after applying multiple linear regression for temperature (upper panel) and precipitation (lower panel) for the period 1906-2010. Time-series without monthly missing data are not represented.

Figure 4-14: Impact of filled data on annual averaged temperature (upper panel) and precipitation (lower panel) for each time-series from 1906 to 2010. Grey bars represent the difference between annual averaged temperature and precipitation from the original dataset (for the whole period 1906-2010) and after filling the gaps.

Figure 4-15: Procedure diagram of the methodology applied. 98

Figure 4-16: Definition sketch of drought events. Detected droughts and wet events are shown over Iberian Peninsula for the period 1941-1960 as an example.

\section{Chapter 5}

Figure 5-1: Annual temperature anomalies (base-period 1961-1990) in the Iberian Peninsula for the period 1906-2010. Red line represents a 10-year Gaussian filter applied over the annual series. .. 126

Figure 5-2: Seasonal temperature anomalies ordered as winter (DJF, upper panel), spring (MAM), summer (JJA) and autumn (SON, lower pannel) (base-period 1961-1990) in the Iberian Peninsula for the period 1906-2010. Red line represents a 10-year Gaussian filter applied over the annual series.

Figure 5-3: Annual precipitation anomalies (base-period 1961-1990) in the Iberian Peninsula for the period 1906-2010. Red line represents a 10-year Gaussian filter applied over the annual series. 129

Figure 5-4: Seasonal precipitation anomalies ordered as winter (DJF, upper pannel), spring (MAM), summer (JJA), and autumn (SON, lower pannel) (base-period 1961-1990) in the Iberian Peninsula for the period 1906-2010. Red line represents a 10-year Gaussian filter applied over the annual series.

Figure 5-5: Variability of wet and dry conditions over the Iberian Peninsula (1906-2010) using Sc-PDSI. Red line represents a 10-year Gaussian filter applied over the annual series.

Figure 5-6: Variability of wet and dry conditions over the Iberian Peninsula (1906-2010) using 12-month SPI. Red line represents a 10-year Gaussian filter applied over the annual series. 
Figure 5-7: Variability of wet and dry conditions over the Iberian Peninsula (1906-2010) using 12-month SPEI. Red line represents a 10-year Gaussian filter applied over the annual series.

Figure 5-8: Frequency distribution (in \%) of monthly Sc-PDSI values over the major PDSI categories computed from the 22 Iberian stations (1906-2010).

Figure 5-9: Frequency distribution (in \%) of 12-month SPI values over the major SPI categories computed from 22 Iberian stations (1906-2010).

Figure 5-10: Frequency distribution (in \%) of 12-month SPEI values over the major SPEI categories computed from 22 Iberian stations (1906-2010). .140

Figure 5-11: Percentages of stations affected by various categories of drought in Sc-PDSI individual stations in the Iberian Peninsula from 1906 to 2010

Figure 5-12: Percentages of stations affected by various categories of drought in 12-month SPI individual stations in the Iberian Peninsula from 1906 to 2010.

Figure 5-13: Percentages of stations affected by various categories of drought in 12-month SPEI individual stations in the Iberian Peninsula from 1906 to 2010.

Figure 5-13: Percentages of stations affected by various categories of drought in 12-month SPEI individual stations in the Iberian Peninsula from 1906 to 2010.

Figure 5-14: Maps of annual trends (in drought index value/decade) computed for the 22 locations (19062010) using Sc-PDSI (a); 12-month SPI (b); and 12-month SPEI (c). Negative (or positive) trends represent drier (or wetter) conditions. * (or + ) symbol are referred to statistical significance at the $99 \%$ level (or 95\%). Spatial interpolation is applied using the Kriging method. 146

Figure 5-15: Variability of wet and dry conditions over the Iberian Peninsula (1906-2010) using ScPDSI-all forcing (upper panel), Sc-PDSI-without temperature changes (applying the monthly temperature climatology computed using the period 1906-2010) (in the middle panel), and the difference between the two indices (lower panel).

Figure 5-16: Variability of wet and dry conditions over the Iberian Peninsula (1906-2010) using 12month SPEI-all forcing (upper panel), 12-month SPEI-without temperature changes (applying the monthly temperature climatology computed using the period 1906-2010) (in the middle panel), and the difference between the two indices (lower panel).

Figure 5-17: Variability of wet and dry conditions over the Iberian Peninsula (1906-2010) using 12month SPEI (upper panel), 12-month SPI (in the middle panel), and the difference between the two indices (lower panel). 154

Figure 5-18: Maps of annual trends (in drought index value/decade) computed for the 22 locations (19062010) using Sc-PDSI-all forcing (a)-left), Sc-PDSI-without temperature changes (b)-left), 12month SPEI-all forcing (a)-right) and 12-month SPEI-without temperature changes (b)-right). The trend differences between Sc-PDSI-all forcing minus Sc-PDSI-without temperature changes (c)left), and between 12-month SPEI-all forcing minus 12-month SPEI-without temperature changes (c)-right) are also shown. Negative (or positive) trends represent drier (or wetter) conditions while * (or +) symbol are referred to statistical significance at the 99\% level (or 95\%) in figures a)-left and right, and b)-left and right. Spatial interpolation is applied using the kriging method..... 156 
Figure 5-19: Maps of annual trends (in drought index value/decade) computed for the 22 locations (19062010) using 12-month SPI (a)-left), 12-month SPEI-all forcing (a)-right) and 12-month SPEIwithout temperature changes (b)-right). The trend differences between 12-month SPEI-all forcing minus 12-month SPI (b)-left), between 12-month SPEI-all forcing minus 12-month SPEI-without temperature changes (c)-right), and between 12-month SPEI-without temperature changes minus 12-month SPI (c)-left) are also shown. Negative (or positive) trends represent drier (or wetter) conditions while * (or + ) symbol are referred to statistical significance at the 99\% level (or 95\%) only in figures a)-left and right, and b)-right. Spatial interpolation is applied using the kriging method.

Figure 5-20: 12-month SPEI time series for Cadiz (1854-2010), Madrid (1855-2010), Huesca (18632010), Murcia (1864-2010) and Lisboa (1865-2010). In red, 10-year gaussian filter....

Figure 5-21: Scree graph showing the eigenvalue spectrum related with different components found in rotated principal components at annual and seasonal time-scales.

Figure 5-22: Spatial distribution of the maximum weights referred to the South-western pattern (SWP) computed over the 22 12-month SPEI series at annual time-scale over the Iberian Peninsula. This component explains the $49.3 \%$ of total variance. Spatial interpolation is applied using the kriging method. 171

Figure 5-23: Spatial distribution of the maximum weights related to the South-western pattern identified over the Iberian Peninsula at seasonal time-scale. This pattern explains the $14.1 \%$ of total variance in winter (DJF), the $14.7 \%$ in spring (MAM), the $50.2 \%$ in summer (JJA) and the $51.6 \%$ of total explained variance in autumn (SON). Spatial interpolation is applied using the kriging method. .172

Figure 5-24: Fluctuations of 12-month SPEI time series associated to the South-western pattern found at annual time-scale over Iberian Peninsula for the period 1906-2010. Red line; 10-year Gaussian filter.

Figure 5-25: Fluctuations of averaged 12-month SPEI time series associated to the South-western pattern found over Iberian Peninsula at seasonal time scale for the period 1906-2010 (with smoothed by Gauss filter over 10 years). 174

Figure 5-26: Spatial distribution of the maximum weights referred to the North-western pattern (NWP) computed over the 22 12-month SPEI series at annual time-scale over the Iberian Peninsula. This component explains the $14.9 \%$ of total variance. Spatial interpolation is applied using the kriging method.

Figure 5-27: Spatial distribution of the maximum weights related to the North-western pattern identified over the Iberian Peninsula at seasonal time-scales. Note that two sub-patterns were found in winter (DJF) related to the North-western pattern. The North-western pattern explains the $48.7 \%$ of total variance in spring (MAM), the $16.2 \%$ in summer (JJA) and the $15.1 \%$ of total explained variance in autumn (SON). The sub-patterns 1 and 2 found in winter (DJF) represents the $47.4 \%$ and $4.6 \%$ of total variance respectively. Spatial interpolation is applied using the kriging method.

Figure 5-28: Fluctuations of 12-month SPEI time series associated to the North-western pattern found at annual time-scale over Iberian Peninsula for the period 1906-2010. Red line; 10-year Gaussian filter.

Figure 5-29: Fluctuations of averaged 12-month SPEI time series associated to the North-western pattern found over Iberian Peninsula at seasonal time scale for the period 1906-2010 (with smoothed by Gauss filter over 10 years). 
Figure 5-30: Spatial distribution of the maximum weights referred to the Mediterranean pattern (MedP) computed over the 22 12-month SPEI series at annual time-scale over the Iberian Peninsula. This component explains the $6.5 \%$ of total variance. Spatial interpolation is applied using the kriging method. 180

Figure 5-31: Spatial distribution of the maximum weights related to the Mediterranean pattern identified over the Iberian Peninsula at seasonal time-scales. This pattern explains the $6.8 \%$ of total variance in winter (DJF), the $6.8 \%$ in spring (MAM), the $6.4 \%$ in summer (JJA) and the $6.3 \%$ of total explained variance in autumn (SON). Spatial interpolation is applied using the kriging method. .181

Figure 5-32: Fluctuations of 12-month SPEI time series associated to the Mediterranean pattern found at annual time-scale over Iberian Peninsula for the period 1906-2010. Red line; 10-year Gaussian filter.

Figure 5-33: Fluctuations of averaged 12-month SPEI time series associated to the Mediterranean pattern found over the Iberian Peninsula at seasonal time scale for the period 1906-2010 (with smoothed by Gauss filter over 10 years).

Figure 5-34; Dry and wet events detected in the Iberian Peninsula (1906-2010) using 12-month SPEI. Black bars refer to the maximum monthly index value (maximum severity) recorded for each event, while grey bars indicate the average index value for each event. The duration in months for each event is represented in the $\mathrm{x}$ axis: bars' widths are proportional to duration.

Figure 5-35: Magnitude of wet and dry events identified over Iberian Peninsula (1906-2010) using 12month SPEI. Red bars refer to the accumulated SPEI severity (magnitude) recorded for each event related to the duration in months represented in the $\mathrm{x}$ axis: bars' widths are proportional to duration. 188

Figure 5-36; Behavior of identified dry and wet events according to the average index value for each event (upper panel) and the maximum monthly index value (maximum severity) recorded for each event (lower panel) related with the duration of each event. Most remarkable wet and dry events detected previously are also shown and black lines draw logarithmic trends. 191

Figure 5-37: Behaviour of identified wet and dry events according to the magnitude reached for each event related with the duration in months. Most remarkable wet and dry events are also shown...192

Figure 5-38: Seasonal distribution of the percentages referred to the onset, offset and maximum severity reached by wet events in the Iberian Peninsula. Seasons are shown in the y axis; where DJF is referred to winter, MAM to spring, JJA to summer and SON to autumn. Seasonal percentages for each parameter are also included inside the bars. 193

Figure 5-39: Seasonal distribution of the percentages referred to the onset, offset and maximum severity reached by droughts in the Iberian Peninsula. Seasons are shown in the y axis; where DJF is referred to winter, MAM to spring, JJA to summer and SON to autumn. Seasonal percentages for each parameter are also included inside the bars.

Figure 5-40; Dry and wet events detected in the time-series associated to the South-western pattern (1906-2010) using 12-month SPEI. Black bars refer to the maximum monthly index value (maximum severity) recorded for each event, while grey bars indicate the average index value for each event. The duration in months for each event is represented in the $\mathrm{x}$ axis: bars' widths are proportional to duration. 196

Figure 5-41: Magnitude of wet and dry events identified in the time-series associated to the Southwestern pattern (1906-2010) using 12-month SPEI. Red bars refer to the accumulated SPEI severity 
(magnitude) recorded for each event related to the duration in months represented in the $\mathrm{x}$ axis: bars' widths are proportional to duration.

Figure 5-42: Seasonal distribution of the percentages referred to the onset, offset and maximum severity reached by wet events in the time-series associated to the South-western pattern. Seasons are shown in the y axis; where DJF is referred to winter, MAM to spring, JJA to summer and SON to autumn. Seasonal percentages for each parameter are also included inside the bars. . 199

Figure 5-43: Seasonal distribution of the percentages referred to the onset, offset and maximum severity reached by droughts in the time-series associated to the South-western pattern. Seasons are shown in the y axis; where DJF is referred to winter, MAM to spring, JJA to summer and SON to autumn. Seasonal percentages for each parameter are also included inside the bars.

Figure 5-44; Dry and wet events detected in the time-series associated to the North-western pattern (1906-2010) using 12-month SPEI. Black bars refer to the maximum monthly index value (maximum severity) recorded for each event, while grey bars indicate the average index value for each event. The duration in months for each event is represented in the $\mathrm{x}$ axis: bars' widths are proportional to duration. .202

Figure 5-45: Magnitude of wet and dry events identified in the time-series associated to the Northwestern pattern (1906-2010) using 12-month SPEI. Red bars refer to the accumulated SPEI severity (magnitude) recorded for each event related to the duration in months represented in the $\mathrm{x}$ axis: bars' widths are proportional to duration...... 202

Figure 5-46: Seasonal distribution of the percentages referred to the onset, offset and maximum severity reached by wet events in the time-series associated to the North-western pattern. Seasons are shown in the y axis; where DJF is referred to winter, MAM to spring, JJA to summer and SON to autumn. Seasonal percentages for each parameter are also included inside the bars. 204

Figure 5-47: Seasonal distribution of the percentages referred to the onset, offset and maximum severity reached by droughts in the time-series associated to the North-western pattern. Seasons are shown in the y axis; where DJF is referred to winter, MAM to spring, JJA to summer and SON to autumn. Seasonal percentages for each parameter are also included inside the bars 205

Figure 5-48; Dry and wet events detected in the time-series associated to the Mediterranean pattern (1906-2010) using 12-month SPEI. Black bars refer to the maximum monthly index value (maximum severity) recorded for each event, while grey bars indicate the average index value for each event. The duration in months for each event is represented in the $\mathrm{x}$ axis: bars' widths are proportional to duration. 208

Figure 5-49: Magnitude of wet and dry events identified in the time-series associated to the Mediterranean pattern (1906-2010) using 12-month SPEI. Red bars refer to the accumulated SPEI severity (magnitude) recorded for each event related to the duration in months represented in the $\mathrm{x}$ axis: bars' widths are proportional to duration. 208

Figure 5-50: Seasonal distribution of the percentages referred to the onset, offset and maximum severity reached by wet events in the time-series associated to the Mediterranean pattern. Seasons are shown in the y axis; where DJF is referred to winter, MAM to spring, JJA to summer and SON to autumn. Seasonal percentages for each parameter are also included inside the bars.

Figure 5-51: Seasonal distribution of the percentages referred to the onset, offset and maximum severity reached by droughts in the time-series associated to the Mediterranean pattern. Seasons are shown in the y axis; where DJF is referred to winter, MAM to spring, JJA to summer and SON to autumn. Seasonal percentages for each parameter are also included inside the bars...... 211 
Figure 5-52: Averaged drought severity (in SPEI values) for the whole Iberian Peninsula (IP), for the South-western pattern (SWP), for the North-western pattern (NWP) and for the Mediterranean pattern (MedP) using the periods 1921-1950, 1951-1980 and 1981-2010.

Figure 5-53: Averaged drought magnitude ( accumulated severity in SPEI values) for the whole Iberian Peninsula (IP), for the South-western pattern (SWP), for the North-western pattern (NWP) and for the Mediterranean pattern (MedP) using the periods 1921-1950, 1951-1980 and 1981-2010.......214

Figure 5-54: Averaged drought duration (in months) for the whole Iberian Peninsula (IP), for the Southwestern pattern (SWP), for the North-western pattern (NWP) and for the Mediterranean pattern (MedP) using the periods 1921-1950, 1951-1980 and 1981-2010. 


\section{List of tables}

\section{Chapter 2}

Table 2-1: The Drought Monitor categories (adapted from Svoboda, 2000).

\section{Chapter 4}

Table 4-1: Iberian stations network. Name of station, current geographical location (latitude, longitude and altitude), length of record (temperature and precipitation) and AWC of the soil is also shown.

Table 4-2: Summary of QC results (in absolute values and also in percentages) from raw daily data for Porto, Lisboa and for the updated period of SDATS/SDAPS. The controlled time-period and the total data amount tested are also shown.

Table 4-3: Classification of PDSI categories defined by Palmer (1965)

Table 4-4: Classification of SPI categories defined by McKee et al., (1993).

Table 4-5: Classification of SPEI categories based on McKee et al., (1993). 106

\section{Chapter 5}

Table 5-1: Summary of linear trends (in ${ }^{\circ} \mathrm{C} /$ decade) computed for annual and seasonal temperature in the Iberian Peninsula (1906-2010). The associated 95\% confidence intervals and p-values are also shown. Bold (or Italic) values are referred to statistical significance at the $99 \%$ level (or 95\%). 125

Table 5-2: Summary of linear trends (in mm/decade) computed for annual and seasonal precipitation in the Iberian Peninsula (1906-2010). The associated 95\% confidence intervals and p-values are also shown. Bold (or Italic) values are referred to statistical significance at the 99\% level (or 95\%). 130

Table 5-3: Summary of annual trends (in drought index value/decade) computed for the whole Iberian Peninsula (1906-2010) using all drought indices. The associated 95\% confidence intervals and p-values are also shown. Bold (or Italic) values are referred to statistical significance at 99\% level (or 95\%)..... 144

Table 5-4: Summary of annual trends (in PDSI value/decade) computed for the 22 locations (1906-2010) using Sc-PDSI. The associated $95 \%$ confidence intervals and p-values are also shown. Negative (or positive) trends represent drier (or wetter) conditions. Bold (or Italic) values are referred to statistical significance at the $99 \%$ level (or $95 \%$ ).

Table 5-5: Summary of annual trends (in SPI value/decade) computed for the 22 locations (1906-2010) using 12-month SPI. The associated 95\% confidence intervals and p-values are also shown. Negative (or positive) trends represent drier (or wetter) conditions. Bold (or Italic) values are referred to statistical significance at the $99 \%$ level (or $95 \%$ ). 148

Table 5-6: Summary of annual trends (in SPEI value/decade) computed for the 22 locations (1906-2010) using 12-month SPEI. The associated $95 \%$ confidence intervals and p-values are also shown. Negative (or positive) trends represent drier (or wetter) conditions. Bold (or Italic) values are referred to statistical significance at the $99 \%$ level (or $95 \%$ )......

Table 5-7: Summary of annual trends (in drought index value/decade) computed for the whole Iberian Peninsula (1906-2010) using all drought indices. Linear trends from Sc-PDSI and 12-month SPEI using all forcing without temperature changes (applying the monthly temperature climatology using the period 1906-2010) are also computed. The associated 95\% confidence intervals and p-values are also shown. Bold (or Italic) values are referred to statistical significance at 99\% level (or 95\%). 155 
Table 5-8: Summary of annual trends (in PDSI value/decade) computed for the 22 locations for the common period 1906-2010 using Sc-PDSI-without temperature changes. The associated 95\% confidence intervals and p-values are also shown. Negative (or positive) trends represent drier (or wetter) conditions. Bold (or Italic) values are referred to statistical significance at the $99 \%$ level (or 95\%). 157

Table 5-9: Summary of annual trends (in SPEI value/decade) computed for the 22 locations for the common period 1906-2010 using 12-month SPEI-without temperature changes. The associated $95 \%$ confidence intervals and p-values are also shown. Negative (or positive) trends represent drier (or wetter) conditions. Bold (or Italic) values are referred to statistical significance at the $99 \%$ level (or 95\%).......159

Table 5-10: Number of extracted components and percentages of variance explained by the rotated principal components using $\mathrm{T}>0.7$ and $\mathrm{T}>1$ thresholds at annual and seasonal time-scales using 12month SPEI time series.

Table 5-11: Summary of annual trends (in SPEI value/decade) computed for the spatial patterns found at annual time scales in the Iberian Peninsula (1906-2010). The associated 95\% confidence intervals are also shown. Bold (or Italic) values are referred to statistical significance at the $99 \%$ level (or 95\%). 185

Table 5-12; Summary statisitics of the most remarkable wet and dry events in terms of maximum severity reached for each event, averaged severity and magnitude in absolute values. Duration in months is also shown.

Table 5-13: Summary statistics of all dry and wet events detected over Iberian Peninsula from 1906 to 2010. Maximum severity reached for each event, averaged severity, magnitude and duration in months are the parameters analyzed and the mean, maximum value, standard deviation, linear trend and its statistical significance (linear trend calculated for each 10 events) are the statistics in absolute values. Bold (Italic) values are referred to statistical significant trends at $99 \%$ level (95\%).....

Table 5-14; The most remarkable wet and dry events detected in terms of maximum severity reached for each event, averaged severity and magnitude in absolute values. Duration in months is also shown......197

Table 5-15: Summary statistics of all dry and wet events detected in the time-series associated to the South-western pattern from 1906 to 2010. Maximum severity reached for each event, averaged severity, magnitude and duration in months are the parameters analyzed and the mean, maximum value, standard deviation, linear trend and its statistical significance (linear trend calculated for each 10 events) are the statistics in absolute values. Bold (Italic) values are referred to statistical significant trends at $99 \%$ level $(95 \%)$. .198

Table 5-16; The most remarkable wet and dry events detected in terms of maximum severity reached for each event, averaged severity and magnitude in absolute values. Duration in months is also shown......203

Table 5-17: Summary statistics of all dry and wet events detected in the time-series associated to the North-western pattern from 1906 to 2010. Maximum severity reached for each event, averaged severity, magnitude and duration in months are the parameters analyzed and the mean, maximum value, standard deviation, linear trend and its statistical significance (linear trend calculated for each 10 events) are the statistics in absolute values. Bold (Italic) values are referred to statistical significant trends at $99 \%$ level $(95 \%)$. 204

Table 5-18: The most remarkable wet and dry events detected in terms of maximum severity reached for each event, averaged severity and magnitude in absolute values. Duration in months is also shown......209

Table 5-19: Summary statistics of all dry and wet events detected in the time-series associated to the Mediterranean pattern from 1906 to 2010. Maximum severity reached for each event, averaged severity, magnitude and duration in months are the parameters analyzed and the mean, maximum value, standard deviation, linear trend and its statistical significance (linear trend calculated for each 10 events) are the statistics in absolute values. Bold (Italic) values are referred to statistical significant trends at the $99 \%$ level $(95 \%)$ 
Table 5-20: Averaged severity (in SPEI values) of droughts and wet events for the whole Iberian Peninsula (IP), for the South-western pattern (SWP), for the North-western pattern (NWP) and for the Mediterranean pattern (MedP) using the periods 1921-1950, 1951-1980 and 1981-2010.

Table 5-21: Averaged magnitude (accumulated severity in SPEI values) of droughts and wet events for the whole Iberian Peninsula (IP), for the South-western pattern (SWP), for the North-western pattern (NWP) and for the Mediterranean pattern (MedP) using the periods 1921-1950, 1951-1980 and 19812010 . 213

Table 5-22: Averaged duration (in months) of droughts and wet events for the whole Iberian Peninsula (IP), for the South-western pattern (SWP), for the North-western pattern (NWP) and for the Mediterranean pattern (MedP) using the periods 1921-1950, 1951-1980 and 1981-2010. 
UNIVERSITAT ROVIRA I VIRGILI
DROUGHT VARIABILITY AND CHANG

DROUGHT VARIABILITY AND CHANGE ACROSS THE IBERIAN PENINSULA

Joan Ramon Coll Benages

DL: T 955-2014

\begin{abstract}
DL: T 955-2014
\end{abstract}




\section{Chapter 1}

\section{INTRODUCTION}

\subsection{Background}

Climate analyses produced during the last decades confirmed the fact that the modifications in the atmospheric system are more than a cyclic fluctuation only due to climate variability. A global climate change is defined by the Intergovermental Panel on Climate Change (IPCC) as a change in the state of the climate that can be identified using statistical tests, as changes in the mean and/or the variability of its properties and that persists for an extended period, typically decades or longer (Salomon et al., 2007). This is happening basically due to an increase of greenhouse gases (GHG), such as $\mathrm{CO}_{2}, \mathrm{C}_{\mathrm{H} 4}$, $\mathrm{N}_{20}$, and others in the atmosphere by fossil fuel combustion.

The IPCC $4^{\text {th }}$ Assessment Report (IPCC AR4, 2007) provides a summary of observed changes in climate variables. The Working Group I report indicates that global surface temperature increases $+0.74^{\circ} \mathrm{C}$ from 1906 to 2005 , although this increase is not uniform and some world regions are affected by a higher temperature increases (Fig. 1-1; top). For the century long-period, warming is statistically significant over most of the world's surface (at the 0.05 significance level) with the exception of an area south of Greenland and three smaller regions over the south-eastern USA and parts of Bolivia and the Congo basin (taking into account the low data availability in the region). Warming is strongest over the continental interiors of Asia and north-western North America and over some mid-latitude ocean regions of the southern hemisphere as well as in southeastern Brazil. This increased temperature causes an intensification of the hydrological cycle and a larger atmospheric water capacity. In opposition, land precipitation shows a light increase during the last century, although it is not uniform, neither spatially, or temporarily (IPCC AR4, Solomon et al., 2007). For most of North America, and especially over high-latitude regions in Canada, annual precipitation increases during the 105-year period (Fig. 1-1; bottom). 

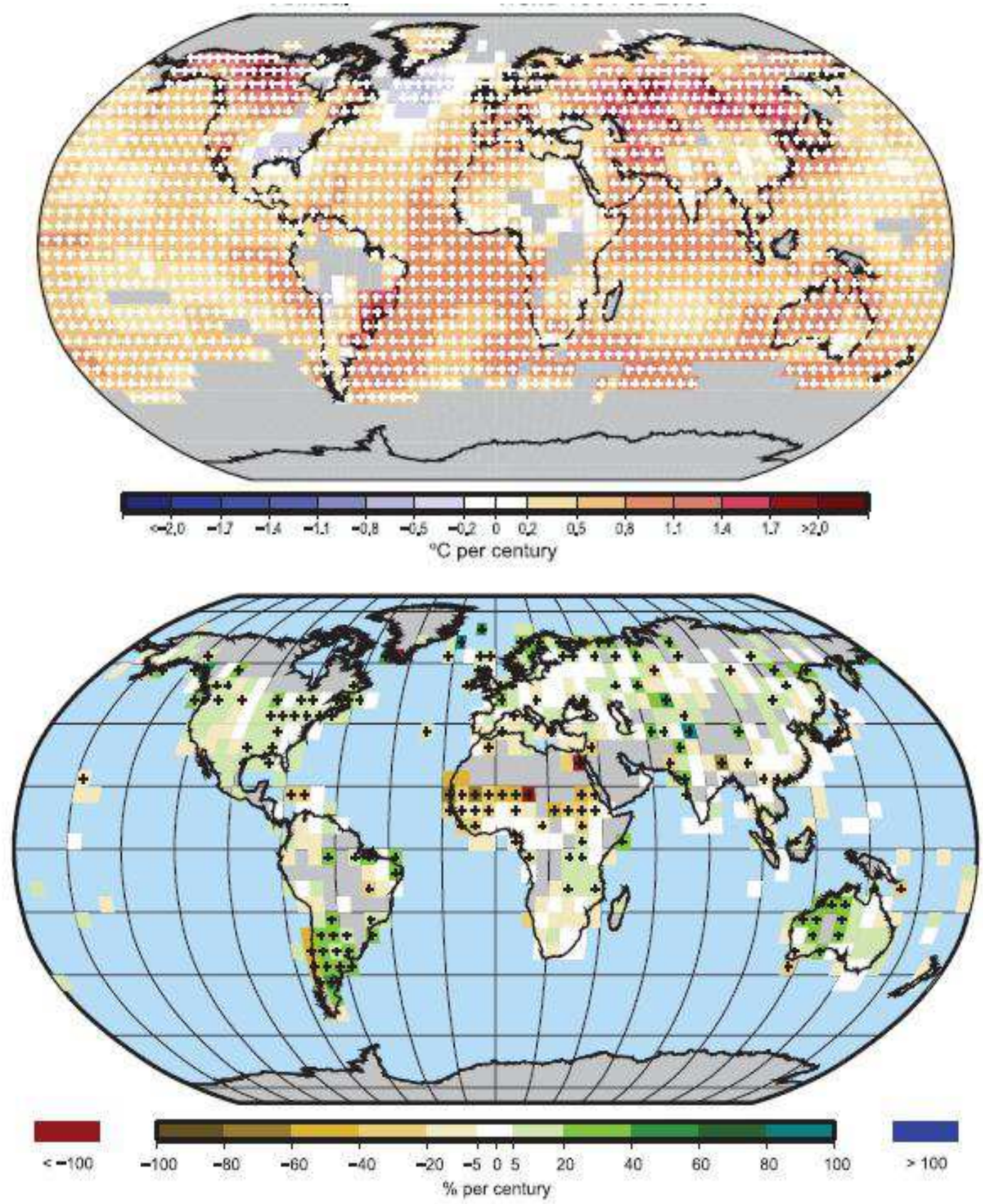

Figure 1-1: Linear trend of annual temperatures (upper panel; in ${ }^{\circ} \mathrm{C}$ per century) and annual land precipitation amounts (lower panel; in \% per century) for 1901 to 2005 using the GHCN dataset from NCDC (Smith and Reynolds, 2005). Areas in grey have insufficient data to produce reliable trends. The percentage in precipitation (lower panel) is based on the means for the period 1961-1990. Trends significant at the 5\% level are indicated by white (upper panel) and black (lower panel) + marks.

The main exception is found over the south-west USA, north-west Mexico and the Baja peninsula, where the trend in annual precipitation is negative. Across South America, increasingly wet conditions are observed over the Amazon Basin and south-eastern South America, including Patagonia, while negative trends in annual precipitation are found over Chile and parts of western coast of the continent. The largest negative trends 
are observed over western Africa and the Sahel. North-western Australia shows areas with moderate to strong increases in annual precipitation, while over most of Eurasia, and for 1901-2005, areas with increased precipitation are larger than those characterized by negative trends.

Although the reduction in the precipitation amounts is very often the main cause of drought, increased potential evapotranspiration related to changes in radiation, wind speed, or vapour pressure deficit (itself linked to temperature and relative humidity), can contribute to variations in soil moisture and consequently in the advent of hydrological droughts. Thereafter, the combination of global increasing temperatures and reduction in precipitation in some areas must be linked an intensification of evapotranspiration rate and increased water demand. Most of the observed increases in global average temperatures since the early- $20^{\text {th }}$ century is very likely ( $>90 \%$ probability of occurrence, (IPCC AR4, 2007)) due to the observed increase in anthropogenic GHG concentrations. The reasoning in the previous links, anticipates a connection between human-induced warming and intesified droughts.

The IPCC Special Report on Managing the Risks of Extreme Events and Disasters to Advance Climate Change Adaptation, SREX, (Fleig et al., 2012) focused on the inspection of changes in trends and impacts derived from extreme events, indicated that there are still large uncertainties regarding the observed global-scale trends in droughts. However, droughts became more common, especially in the tropics and sub-tropics, and the area affected by droughts around the world increased likely ( $>66 \%$ probability of occurrence) since the 1970s. It is more likely than not that there is a human contribution to this trend. Decreased land precipitation in many regions and global increased temperatures, which enhance evapotranspiration and reduce soil moisture, are important factors that contributed to more regions experiencing droughts (Dai et al., 2004b). Many regional or large-scale studies show recent trends towards drier conditions (Dai et al., 2004, 2011 and 2012; Heim, 2002; van der Schrier et al., 2006, 2007 and 2011; Vicente-Serrano et al., 2006, 2010 and 2012; Dubrovsky et al., 2007b, 2008; Brázdil et al., 2009; Kingtse et al., 2008, 2009; Sheffield et al., 2009 and 2012; Briffa et al., 2009).

Using the Palmer's Drought Severity Index (PDSI), Dai et al., (2004b) found a large drying trend over Northern Hemisphere land since the mid-1950s (Fig. 1-2; upper panel). Dai (2011 and 2012) updates his previous work and finds that global drought areas increased substantially since the middle of the $20^{\text {th }}$ century, mainly due to widespread 
drying since the 1970s over most of Africa, southern Europe, East and South-east Asia, eastern Australia, and many parts of the northern mid-high latitudes while increased wetness are identified over the Central US, Argentina and northern high-latitude areas (Fig. 1-2; lower panel). These trends in the PDSI index are found to be largely affected by changes in temperature and also in precipitation. Controversially, the study carried out by Sheffield et al., (2012) indicates that previous calculations of the increase in global drought were overestimated in terms of drying trends and in the proportion of area affected by drought. This is mainly attributed to inconsistencies in the forcing data sets and simulation configuration.
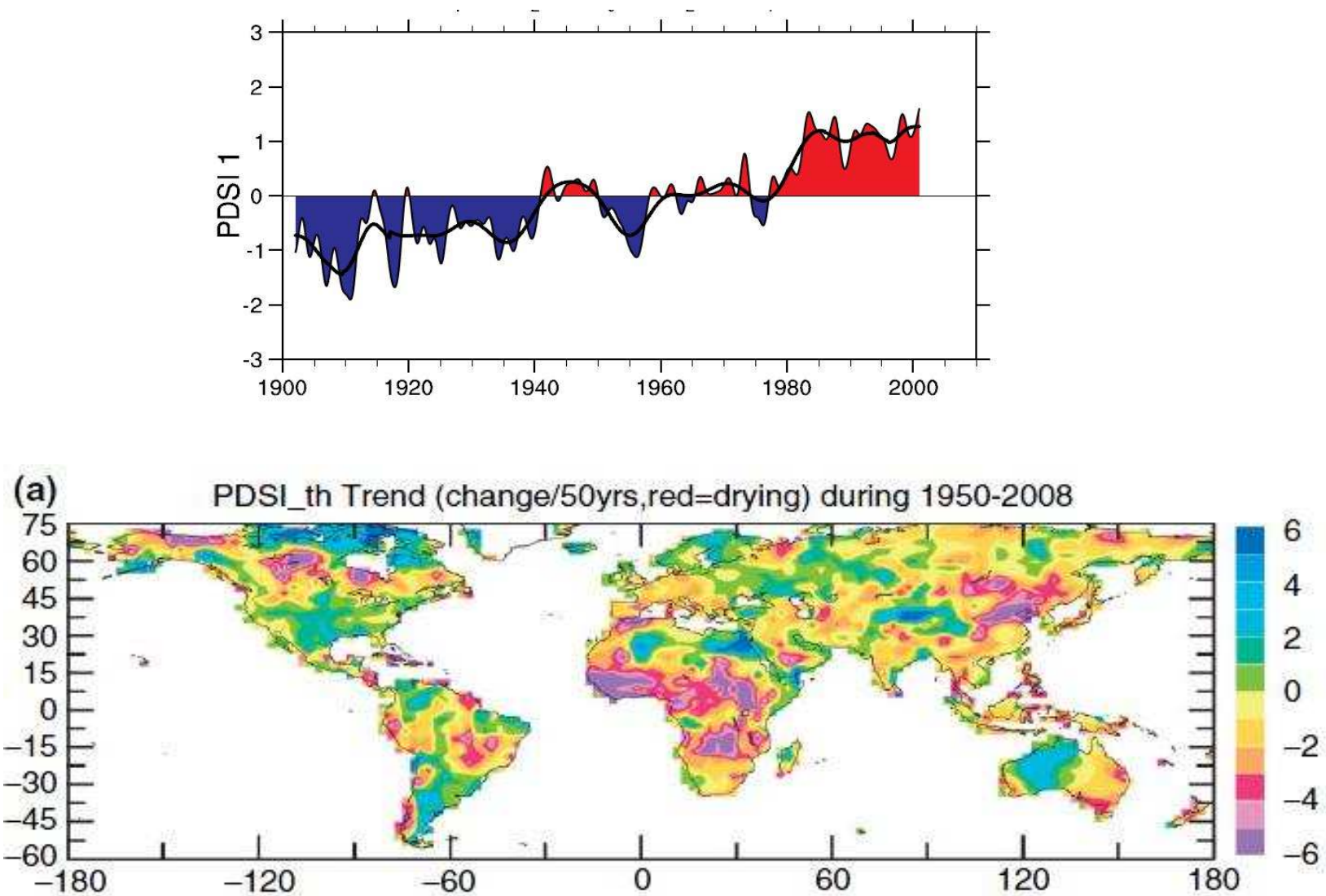

Figure 1-2: Palmer Drought Severity Index. Upper Panel: PDSI time series, Lower Panel: map of annual trends from 1950-2008 in PDSI (Dai, 2011). When the values shown in the lower plot are positive the red and orange areas in the upper map are drier and the blue and green areas are wetter than average. The smooth black curve shows decadal variations. The time series approximately corresponds to a trend, and this pattern and its variations account for $67 \%$ of the linear trend of PDSI from 1900 to 2002 over the global land area. (after Dai et al., 2004b).

Coupled climate models used for the IPCC AR4 project increased aridity during the $21^{\text {st }}$ century over the above mentioned areas. At the same time, indicate an increase in droughts, in particular in subtropical and mid-latitude areas (Christensen et al., 2007). An increase in dry spell length and frequency is considered very likely (>90\% probability of 
occurrence, (IPCC AR4, 2007)) over the Mediterranean region, southern areas of Australia and New Zealand, and likely over most subtropical regions, with little change over northern Europe. Moreover, available global and regional drought studies (Hirabayashi et al., 2008b; Feyen and Dankers, 2009) project a higher likelihood of hydrological drought by the end of this century for eastern Europe, central Eurasia, inland China and northern North America (IPCC Special Report, Fleig et al., 2012). It is projected that about 5.500 millions people will live in water-stressed areas around the world by 2025 (UNESCOWWAP, 2010).

In southern Europe, there is a medium confidence (medium evidence and medium agreement) (Mastrandrea et al., 2010) regarding the increase in dryness, meanwhile there are large inconsistencies between different drought indices in this region, and inconsistent or statistically non-significant trends in the rest of the continent. For example, Dai et al., (2004); Dai, (2011) and (2012) find increased dryness over most of the European continent based on Sc-PDSI, but Lloyd-Hughes and Saunders (2002); Van der Schrier et al., (2006b) and Sheffield et al., (2012) only find statistically nonsignificant changes in drought conditions over Europe with the exception of the Mediterranean region. Other studies of the evolution of precipitation, drought conditions and moisture availability in the Mediterranean during the $20^{\text {th }}$ century confirm a clear decrease in rainfall (Xoplaki et al., 2004; Trigo et al., 2006; López-Moreno et al., 2009) and an increase of severe drought episodes over most of the Mediterranean basin (Sousa et al., 2011), in the Balkans (Xoplaki et al., 2004), in the central-western Mediterranean (Altava-Ortiz et al., 2010) and in the Iberian Peninsula (Garcia-Herrera et al., 2007). Focusing on stream flows, Stahl et al., (2010) research over Europe finds negative trends (lower stream-flow) in southern and eastern regions, and generally positive trends (higher stream-flow) elsewhere (especially in northern Europe). Low flow decreases in most regions where the lowest mean monthly flow occurs in summer. Connected to this, the larger summer temperature variability projected by Schar et al., (2004) and Seneviratne et al., (2006) for 2070 and 2099 will likely lead more droughts in many European regions.

There have been several continental or global-scale assessments of potential change in hydro-meteorological drought indicators, but relatively few on measures of water resources drought or drought impacts. This is because these impacts are very dependent on the socioeconomic context (IPCC Special Report, 2012). Lehner et al., (2006) uses a 
generalized drought deficit volume indicator, calculated by comparing simulated river flows with estimated withdrawals for municipal, industrial, and agricultural uses. The indicator is computed across Europe, using climate change projections from two climate models (ECHAM4 and HadCM3) and assuming changes in withdrawals over time.
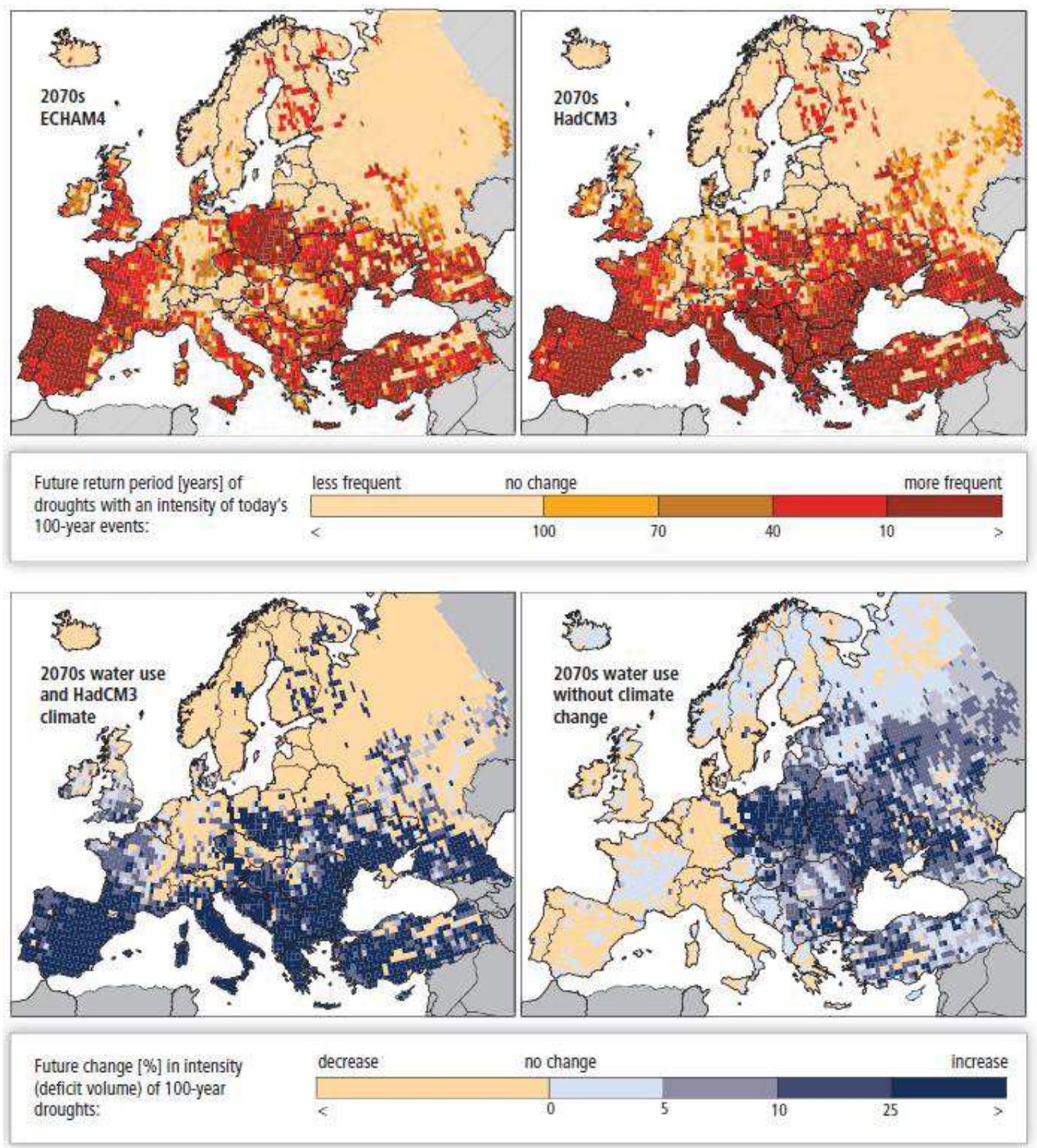

Figure 1-3 Change in indicators of water resources due to drought events across Europe by the 2070s. Upper Panel: projected changes in the return period of the 1961-1990 100-year drought deficit volume for the 2070s, with change in river flows and withdrawals for two climate models; ECHAM4 (left) and HadCM3 (right); Lower Panel: projected changes in the intensity (deficit volume) of 100-year droughts with changing withdrawals for the 2070s, with climate change (left, with HadCM3 climate projections) and without climate change (right). Source: Lehner et al., 2006. 
They show substantial changes in the return period of drought deficit volumes, comparing the 100-year return period for the 1961-1990 period with projections for the 2070s (Fig. 1-3). Lehner et al., 2006 also demonstrate that, in southern and western Europe, changes in withdrawals alone are projected to increase deficit volumes by less than $5 \%$, whereas the combined effect of changing withdrawals and climate change effects (including temperature, precipitation and other climate elements dynamics) is projected to increase deficit volumes by at least $10 \%$, and frequently by more than $25 \%$. In Eastern Europe, increasing withdrawals are projected to intensify drought deficit volumes by over $5 \%$, and more than $10 \%$ across large areas, but this is offset under both climate scenarios by increasing runoff.

Regions located in the transition zone between major climate zones, (e.g. from mesothermic to dry climates) are particularly susceptible to drought and thus to potential changes in climate. A shift in climate may create a new transitional zone with unknown feedback mechanisms. This is the case of the Iberian Peninsula, where temperatures clearly increased during $20^{\text {th }}$ century (Brunet et al., 2006, 2007) in phase with the antropogenic forcing described elsewhere. Precipitation patterns show a high interannual variability, but appreciable changes in annual precipitation were not detected in a secular perspective (Barrera-Escoda, 2008) maybe with the exception of the spring season (Saladié, 2004). A statistically significant increase of droughts is found in the north and east of the Iberian Peninsula (Vicente-Serrano and Cuadrat-Prats, 2007), using Markov chains in Catalonia (Serra et al., 2006), in some areas of Valencia region (Vicente-Serrano et al., 2004) and in the Tagus basin (Lorenzo-Lacruz et al., 2010). Sousa et al., (2011) and VicenteSerrano et al., (2011) show that the north-west of the Iberian Peninsula is an exception to the predominant trend in the $20^{\text {th }}$ century towards drier conditions, which are identified for most of the western Mediterranean. Furthermore, more frequent cycles of dry events are identified in south-western Iberian Peninsula in comparison with the north-western region (Santos et al., 2010).

Finally, annual and seasonal trend analysis on Iberian stream-flows reveal a generalized and significant decreasing trend (1-3\% per year; Fig. 1-4) in stream-flow in most parts of the Iberian Peninsula during the second half of the $20^{\text {th }}$ century, especially in winter and spring (Lorenzo-Lacruz et al., 2012). Lorenzo-Lacruz concludes that these trends are probably related to a downward trend in precipitation (during the second half of $20^{\text {th }}$ century), influenced by the persistent positive NAO phase (North Atlantic Oscillation), 
in combination with an increase in water demand resulting from population growth and irrigation demands. Moreover, the drought duration and magnitude is becoming worse over most of the hydrological regions of the the Iberian Peninsula and the area affected by droughts is also increasing (Lorenzo-Lacruz et al., 2013).

Being consistent with the observed trends, climate models project a large increase in temperatures and a decrease in precipitation of roughly $20 \%$ in southern Europe by the end of $21^{\text {st }}$ century (IPCC AR4, 2007), including the whole Iberian Peninsula (Sanchez, 2009; Gómez-Navarro et al., 2010; Rodríguez-Puebla et al., 2010; Alvarez et al., 2011; Vicente-Serrano et al., 2011; Jerez et al., 2012a and 2012c) in spite of large uncertainties that are still affecting model outputs (Blenkinsop et al., 2007; Sheffield and Wood 2008b; Rammukainen, 2010; Mishra, 2011). In consequence, an increase of drought conditions can be expected in the Mediterranean basin (Blekinsop et al., 2007; Planton et al., 2008; Mariotti et al., 2008; Mata, 2008; Dai, 2011; IPCC Special Report 2012) and also over the Iberian Peninsula under climate change conditions (Beniston et al., 2007; Rodríguez-Puebla et al., 2010; Alvarez et al., 2011; Sanchez et al., 2012). Most of the future projections show that droughts will become more common in the Iberian Peninsula with negative effects in water availability and undesirable environmental and socio-economic impacts.
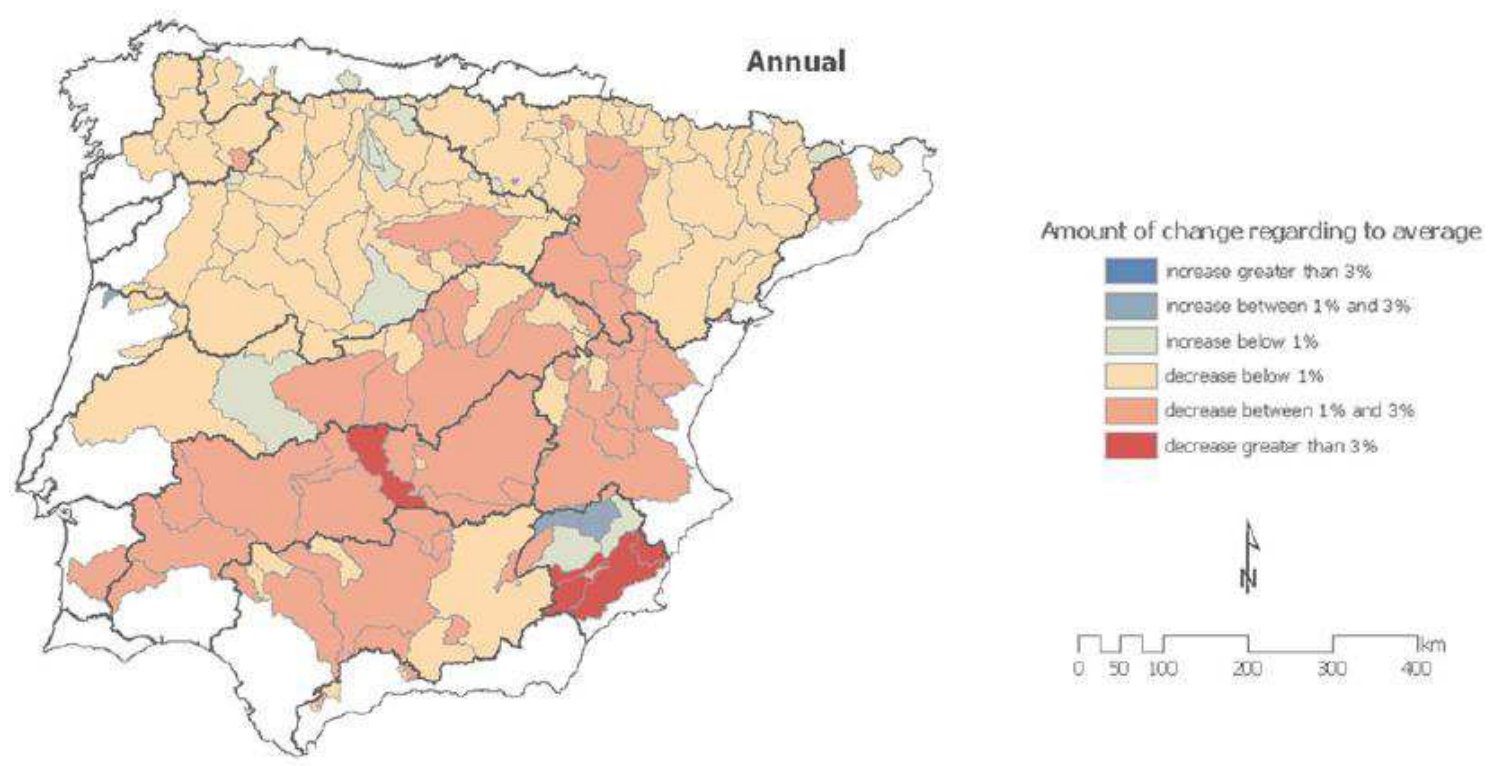

Figure 1-4: Spatial distribution of the magnitude of annual trends with respect to the average annual discharge series for the analyzed period (1945-2005) (Lorenzo-Lacruz et al., 2012).

The most severe human consequences of droughts are often found in semiarid regions (this is the case of the Iberian Peninsula), where semi-arid conditions prevail in normal conditions and water demand is close to, or exceeds, natural availability and/or society 
lacks the capacity to mitigate or adapt to drought (Iglesias et al., 2009). For this reason, water management strategies will become crucial in the Iberian Peninsula to ensure water supply when water demand is increasing progressively trying to avoid economic damages as occurred in Spain in the 1990s, when an extreme drought affected six million people and caused material losses of US\$ 4.5 billion (CRED, 2010).

As described above, climate change is only one of the different factors that influence future water stress; others - related to other global change aspects - are demographic, socio-economic and technological changes. They will also play determinant roles at most time horizons and in most regions. Changes in climate patterns and an increasing probability of drought occurrence may worsen the conditions of available freshwater resources for consumption, crops irrigation or tourism and leisure in the Iberian Peninsula causing unknown environmental and socio-economic impacts. 


\subsection{Aims and objectives}

The Mediterranean basin, including the whole Iberian Peninsula, is an area of special interest for climatologists due to its high climate vulnerability caused by its location in the transitional area between temperate and subtropical climates. General Circulation patterns (together with other factors) determine a climate simultaneously influenced by the West Jet Stream located at higher latitudes and the Subtropical stability located at lower latitudes.

Under climate change conditions, this sensitive climate is altered and experts have just observed and predicted an increase of temperature and a decrease of precipitation that will enhance the evapotranspiration rate. As a consequence, drought conditions are expected to worsen over the Iberian Peninsula (Salomon et al., 2007; Fleig et al., 2012).

This general hypothesis, formulated in the successive IPCC assesement reports, refers to a future perspective which builds over already observed events. The evaluation of these observed events is carried out in this work to question whether drought conditions have worsened over Iberian Peninsula during the $20^{\text {th }}$ century and the first decade of the $21^{\text {st }}$ century.

The main objective of this thesis is to identify and analyze the spatial and temporal variability of hydrological droughts across Iberian Peninsula along the $20^{\text {th }}$ century and the first decade of the $21^{\text {st }}$ century in order to detect a drying or a wetting trend in a multi-decadal perspective (long-term periods).

For this purpose, it is necessary to investigate how the variability of droughts has changed across time and how this affects the whole Iberian Peninsula, fulfilling the following specific objectives:

1. The creation of a regional time series for the whole Iberian Peninsula in order to know the temporal evolution of temperature and precipitation along the $20^{\text {th }}$ century and the first decade of the $21^{\text {st }}$ century. This will provide valuable information about climate variability and change in the region of interest.

2. The computation of the most widely used drought indices (Sc-PDSI, 12-month SPI and 12-month SPEI) for detecting hydrological dry events (droughts) and wet events using comprehensive drought classifications. This will help to 
quantify the severity of these extreme events across time. The obtained results will provide decisive information about how the variables involved and the methodology applied to compute each drought index can affect drought variability and change across Iberian Peninsula.

3. The validation of the detected dry events through documentary sources that will provide reliability and consistency to the obtained results. The impacts of the most important identified drought events will be searched in specific publications provided from official meteorological services to verify their magnitude in order to corroborate the consistency of applied methodology.

4. The analysis of drought trends and drought spatial distribution will help to describe the impact of climate change on droughts over the Inerian Peninsula along the $20^{\text {th }}$ century.

5. The regionalization of drought conditions will provide crucial information about different behaviours of this extreme event from the spatial-temporal patterns found at annual and seasonal time-scale.

6. The analysis of the characteristics and trends of severity, magnitude and duration of droughts and wet events will be useful to find out wether the behaviour of these parameters has changed in the Iberian Peninsula and/or in the different spatial-temporal patterns during last decades. 


\subsection{Thesis outline}

This PhD Thesis is structured in 8 chapters, including this Chapter 1, which covers the introductory section including a background to drought studies as well as the formulation of the aims and objectives of this work. Chapter 2 is a review about the state-of-the-art knowledge about droughts around the world including topics ranging from different definitions of the concept to the evaluation methods for detecting dry events. First of all a general introduction to the concept of drought is made, together with the description of the terminology used in the descrition of climatological droughts. After this, different meanings of "drought", according to different scientific disciplines, such as climatology, hidrology or agriculture are specified. Finally, the most widely employed evaluation methods of drought based on drought indices are explained taking into account the involved variables, introducing the results obtained by different authors, pros and cons of each drought index, and their use in drought analyisis and monitoring. .

Chapter 3 describes the area of study, the Iberian Peninsula, including its geographical situation and its main climate characteristics in terms of temperature and precipitation and the widely used Köppen Climate Classification. Chapter 4 describes the dataset used in this study and the procedures applied to the data in order to obtain the results. In this way, the techniques used to data treatment, drought indices, trend computation, Principal Component Analysis and drought parameter estimation are thoroughly explained in this section. The methodology to create the Monthly Iberian Temperature and Precipitation Series (MITPS) is introduced in terms of data quality control and homogenisation, monthly missing values infilling and the regional time-series computation from the individual time series is also discussed. Therefore, the definition and application of the drought indices tested in this study (Sc-PDSI, SPI and SPEI) is also exposed taking into account the main parameters used to compute the algorithms, the method used to estimate the Potential Evapotranspiration (PET) and the time-scale selected to identify hidrological droughts. Moreover, the followed procedure to compute temporal trends and the regionalization of droughts using Principal Component Analysis (PCA) are also described. Finally, the definition and computation of drought parameters are widely explained at the end of this section. 
Chapter 5 describes the application of the methodology introduced in Chapter 4 over the new MITPS dataset previously created. First of all, the climate fluctuations are analyzed over the Iberian Peninsula in terms of temperature and precipitation at annual and seasonal time-scales. Moreover, the linear trends and their statistical significance are also computed. This analysis provides crucial information related to the behaviour of the main climate variables in the Iberian Peninsula under climate change conditions. After the previous description, the most widely used drought indices in different timescales (Sc-PDSI, the 12-month SPEI and the 12-month SPI) are computed to identify wet and dry periods across Iberian Peninsula along the $20^{\text {th }}$ century. The most relevant droughts are found and also validated using documental sources while the calibration of drought indices is checked to ensure the reliability of the results. Thus, a trend analysis is carried out for the whole region under study as well as for each location individually in order to find out significant fluctuations in drought conditions. Furthermore, the role of temperature in drought indices is also assessed to quantify the effect of global warming on drought trends. Moreover, the evolution of the drought spatial coverage is performed across time.

Next, Principal Component Analysis (PCA) is applied at annual and seasonal timescales at 12-month SPEI time-series for the common period 1906-2010 in order to detect spatial-temporal variations of droughts.

Finally, the characteristics and trends of the main parameters related to dry and wet events are analysed for the whole Iberian Peninsula and for the spatio-temporal patterns found at annual time-scale. The severity, duration, magnitude and other interesting parameters such as the seasonal distribution of the onset, offset and the period of the maximum severity reached by dry or wet events are also studied. This section also shows the changes identified in terms of severity, magnitude and duration of droughts and wet events for the whole Iberian Peninsula and also for the spatial-temporal patterns found at annual time-scale using the common periods 1921-1950, 1951-1980 and 19812010.

Chapter 6 covers the discussion and conclusions from the obtained results, as well as further work to be done in the near future and finally, Chapter 7 is dedicated to the references used for this study. 
UNIVERSITAT ROVIRA I VIRGILI
DROUGHT VARIABILITY AND CHANG

DROUGHT VARIABILITY AND CHANGE ACROSS THE IBERIAN PENINSULA

Joan Ramon Coll Benages

DL: T 955-2014

\begin{abstract}
DL: T 955-2014
\end{abstract}




\section{Chapter 2}

\section{THEORETICAL APPROACH TO DROUGHT ANALYSIS}

This chapter introduces the conceopt of drought and its different formulation, according to different scientific disciplines and the review of the state-of-the-art knowledge about droughts around the world, including topics ranging from different definitions of the concept to the evaluation methods and concepts used for detecting, describing and evaluating dry events.

\subsection{Drought concept}

Although the concept of drought is intuitively known by most people, its scientific definition is not trivial at all. Drought is a complex natural hazard that can be interpreted from different points of view, according to different interests. For example, urban inhabitants would identify a drought event when the regional or national government applies some water restrictions in the city. But, a farmer will surely talk about drought when his crops experiment a water shortage affecting their growth. No matter what's point of view we use, drought affects our interests. An adequate, objective and scientific definition of drought is therefore difficult. So, it is not surprising that two of the main questions which scientists have been trying to answer over time are how to define drought and how to evaluate its temporal and spatial evolution.

The Great Britain Meteorological Office proposed, in 1951, a general definition of drought based on precipitation amounts and duration: "Drought is a period of more than some particular number of days with precipitation less than some specified small amount" (Great Britain Meteorological Office, 1951). This and other definitions agree in the fact that a drought is a period with little precipitation, but discrepancies arise in the definition of its duration period and the size of the precipitation deficit causing the event. Palmer discussed more in depth the time scale of droughts, defining a drought period as an interval in the range of months or years, where the actual moisture supply at a given place rather consistently falls short of the climatically expected or climatically appropriate moisture supply (Palmer, 1965). 
The World Meteorological Organization (WMO) in 1966 defined drought as a prolonged absence or significant deficit of rainfall. But, in 1992 WMO changed its drought definition and simplified the drought event as a period time with abnormally dry weather conditions which produces a serious hydrological imbalance due to a long enough lack of rainfall.

Conceptual definitions try to help people and policymakers to understand the concept of drought. This family of definitions was formulated in general terms, without considering climate variability and time period and intends to offer a general vision of the phenomenon. For example, the definition offered by the Intergovernmental Panel on Climate Change (IPCC, 2007) of drought for policymakers is: "Drought is a prolonged absence or marked deficiency of precipitation", or "a deficiency of precipitation that results in water shortage for some activity or for some group" or "a period of abnormally dry weather sufficiently prolonged for the lack of precipitation to cause a serious hydrological imbalance" (IPCC AR4., 2007). This definition has three different parts talking about intensity, duration and impact of the drought.

On the other hand, drought and aridity cannot be confused. The National Climatic Data Center (NCDC) clearly explains the difference between both concepts (see http://www.ncdc.noaa.gov/oa/ncdc.html, last visit: 09-05-2013). Aridity is measured by comparing long-term average water supply (precipitation) to long-term water demand (evapotranspiration). If climatological water demand is greater than climatological water supply, then the climate is arid or semi-arid. Drought refers to a moisture imbalance that occurs on scales of months or a few years and results in a departure from climatological normals. Aridity is permanent, but drought is temporary and can be associated to arid and non-arid climates (Dai, 2011). To make thinks even more complex, some climates are characterized for more frequent droughts than others. The frequency and intensity of droughts can also be monitored from a climatic point of view by studying them not as single events, but according their frequency, duration and intensity across time. 


\subsection{Drought characteristics}

It is known that drought is the consequence of atmospheric phenomena of gradual development, often characterized by an undefined beginning and end of the event according to the National Drought Mitigation Center (NDMC) (Wilhite and Glantz 1985 and http://www.drought.unl.edu/DroughtBasics/WhatisDrought.aspx, Last visit: 05-05-2013). In the most general sense, drought originates from a deficiency of precipitation over an extended period of time resulting in a water shortage for some activity, group or environmental sector. However droughts depend not only on precipitation, but temperature (related to evapotranspiration), relative humidity, dry winds, solar radiation, or cloudiness, among others can play an important role to cause drought or worsening its effects. For example, the role of temperature was evident in the devastating central European drought during the summer of 2003. Although previous precipitation was lower than normal, the extremely high temperatures over most of Europe during June and July (more than $4^{\circ} \mathrm{C}$ above climatological normals) caused the greatest damage to cultivated and natural systems, and dramatically increased evapotranspiration rates and water stress (Rebetez et al., 2006). Moreover, a higher persistence of dry winds or intense solar radiation in a particular region can produce a decrease of relative humidity causing an intensification of evapotranspiration rate. This prolonged meteorological situation can initiate a drought or worsening its effects depending on the region.

Drought is considered as a regional phenomenon because the main causes that can produce it are linked to the regional scale. Empirical studies showed that drought is never the result of a single cause. It is the result of many causes, often synergistic in nature (Magaña et al. 1997, Estrada, 2001 and Contreras, 2003). For example, during an ENSO event (El Niño-Southern Oscillation), drought can occur virtually anywhere in the world, though researchers have found the strongest connections between ENSO and intense drought in Australia, India, Indonesia, the Philippines, Brazil, parts of east and south Africa, the western Pacific basin islands (including Hawaii), Central America, and various parts of United States (Fig. 2-1). Drought occurs in each of the above regions at different times (seasons) during an event and in varying degrees of magnitude. 


\section{WARM EPISODE RELATIONSHIPS DECEMBER - FEBRUARY}

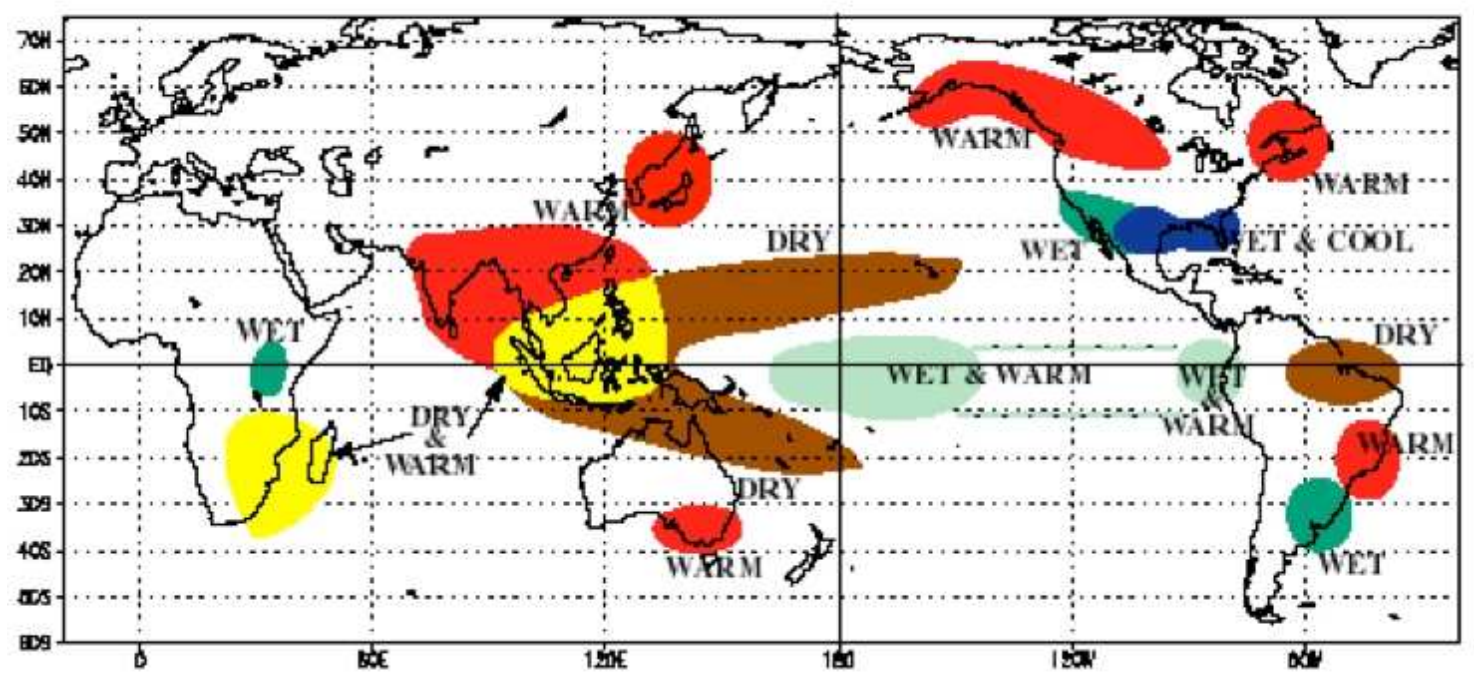

Figure 2-1: Teleconnections between ENSO warm episode and droughts around the world. (www.ciifenint.org) Last visit: 08-05-2013.

On the other hand, the immediate cause of drought is the predominant sinking motion of air (subsidence) that results in compressional warming or high pressure, which inhibits cloud formation and results in lower relative humidity and less precipitation (NDMC; available at: $\underline{w w w . d r o u g h t . u n l . e d u / D r o u g h t B a s i c s / P r e d i c t i n g D r o u g h t . a s p x}$ Last visit: 1405-2013. Most climatic regions experience seasonal changes in the influence of high pressure. Prolonged droughts occur when large-scale anomalies in atmospheric circulation patterns persist for months, seasons or longer, extending the persistence of high pressure beyond their climatological normals. Thus, many droughts around the world can be explained due to the high pressure belt oscillations and they prolonged abnormally conditions (Jáuregui, 1979).

The synergistic nature of drought and the complexity of the phenomenon worsen the drought prediction quality. Predicting drought depends on the ability to forecast, at least, two fundamental surface parameters; precipitation and temperature. From the historical record we know what climate is inherently variable. We also know that anomalies of precipitation and temperature may last from several months to several decades. The potential for improved drought predictions in the near future differs by region, season and climatic regime.

According to the National Drought Mitigation Center of USA (NDMC) and the European Drought Centre (EDC), drought produces a complex variety of impacts which may be more catastrophic than other extreme events. (Fig. 2-2) 


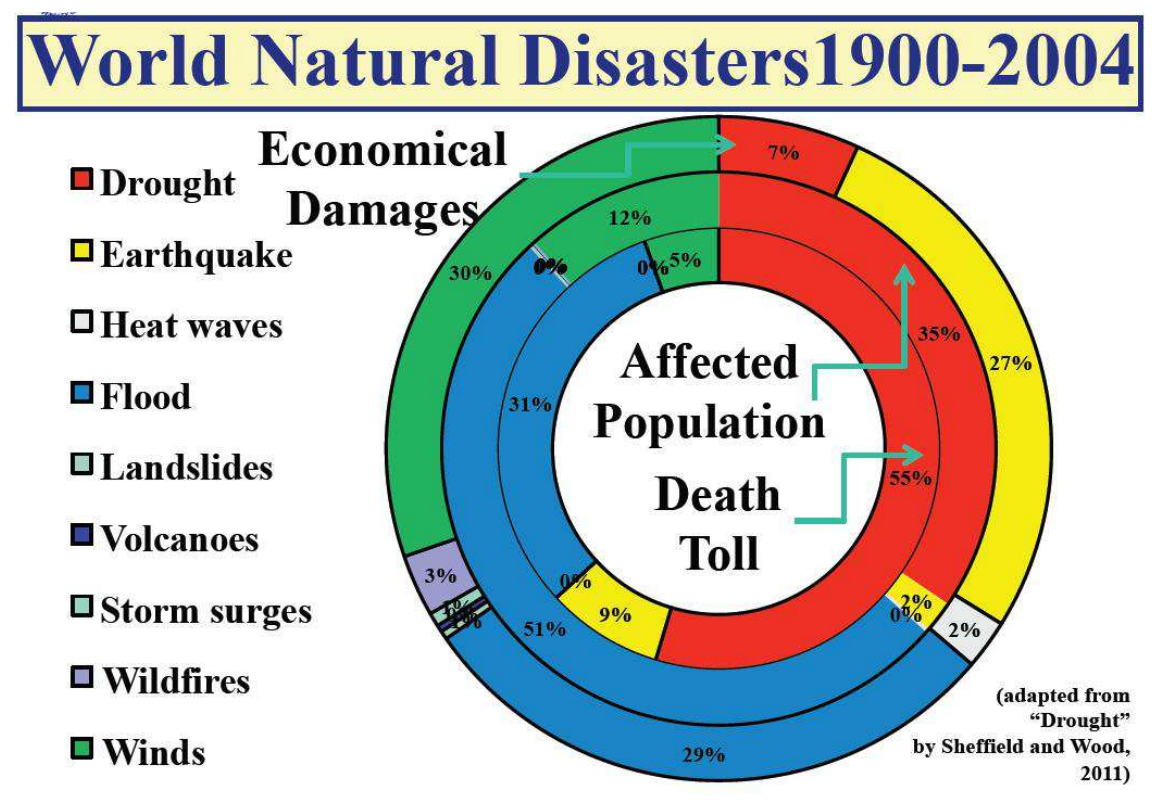

Figure 2-2: World natural disasters for the period 1900-2004 obtained from Sheffield and Wood 2011

This complexity exists because water is integral to our ability to produce goods and provide services. Impacts are commonly referred to as direct or indirect. Reduced crop, rangeland, and forest productivity, increased fire hazard, reduced water levels and wildlife mortality rates are a few examples of direct impacts. The consequences of these impacts lead to indirect impacts. For example, a reduction in crop, rangeland and forest productivity may result in reduced income for farmers and agribusiness, increased prices for food and timber, unemployment, reduced tax revenues because of reduced expenditures, increased crime, foreclosures on bank loans to farmers and businesses, migration, and disaster relief programs.

The impact of drought can be categorized as economic, environmental or social.

Many economic impacts occur in agriculture and related sectors, including forestry and fisheries, because of the reliance of these sectors on surface and subsurface water supplies. In addition to obvious losses in yields in crop and livestock production, drought can be associated with increases in insect infestations, plant disease, wind erosion and reduce growth. The incidence of forest and range fires increases substantially during extended droughts, which in turn places both human and wildlife populations at higher levels of risk. Water shortages can also affect negatively recreation and tourism industries, hydropower production and can food, energy, and other products prices. For example, the European Drought Observatory, sponsored by the European Commission and Member States, routinely performs estimates about the 
costs of droughts in Europe over the last 30 years, evaluated in at least 100 billion Euro (European Commission, 2007). The drought of 2003 in Central and Western Europe has been responsible for an estimated economic damage or more than 12 billion Euros alone (Munich Re, 2004). And the drought situation that developed from November 2004 in southern Portugal and Spain posed a severe challenge to agriculture and affected water supply to households and industry (European Parliament, 2005).

Environmental losses are the result of damages to plant and animal species, wildlife habitat, and air and water quality; forest and range fires, degradation of landscape quality, loss of biodiversity and soil erosion. Some of the effects are short-term and conditions quickly return to normal following the end of the drought. Other environmental effects linger for some time or may even become permanent. Wildlife habitat, for example, may be degraded through the loss of wetlands, lakes and vegetation. Despite, environmental losses are difficult to quantify due to the complexity of dynamic biological system.

Finally, social impacts mainly involve public safety, health, conflicts between water users and reduced quality of life. Many of the impacts specified as economic or environmental have social components as well. Population emigration is a significant problem in many countries, often stimulated by greater availability of food and water elsewhere. Migration usually takes place from rural to urban areas near the stressed area or to regions outside the drought areas. For example, the drought-prone northeast region of Brazil had a net loss of nearly 5.5 million people between 1950 and 1980. Although not all of this population shift was directly attributable to drought, it was a primary factor for many in their decision to relocate. However, drought represents one of the most important natural triggers for malnutrition and famine, a significant widespread problem in many parts of Africa. In this case, the Southern Africa Development Community (SADC), for example, monitors the crop and food situation in the region and issues alerts during periods of impending crisis.

Knowing the serious impacts of drought in population and their activities, some actions and plans to adapt or mitigate its negative effects have been created. United States is pioneer in the development of plans of drought for policymakers and people in general. In 2003 National Drought mitigation Center (NDMC) had been created and since, helps people and institutions develop and implement measures to reduce societal vulnerability and risk management to drought. In Europe, European Drought Centre funded Xerochore project recently which its objective is to synthesize knowledge on past and 
future droughts and to compile a roadmap on research needs and policy choices in European areas of drought. However, African Drought Risk and Development Network, developed by the United Nations is designed as a resource for drought reduction in Africa and includes discussion, lessons and resources for planners, journalists, students and others interested in drought and dry land issues. The Centro Internacional para la Investigación del Fenómeno de El Niño (CIIFEN) provides predictions about the probability of drought and its impacts for South and Central America depending on evolution of ENSO event. Finally, Australian Drought Watch Service has as a one of their objectives to inform the national government and population possible impacts when drought appears. 


\subsection{Drought classification}

Droughts can be classified basically in three categories depending on our scientific focus (Heim, 2002). Moreover, it is commonly accepted that drought is a multi-scalar phenomenon. This means that droughts can be monitored and analysed at different time scales (daily, weekly, monthly, seasonal or longer) depending on the focus of interest. McKee et al., (1993) clearly illustrated this essential characteristic of droughts through the consideration of usable water resources including soil moisture, ground water, river discharges and reservoir storages. The time period from the arrival of water inputs to the availability of a given usable resource differs considerably. Thus, the time-scale over which water deficits accumulate becomes extremely important, and functionally distinguishes among three categories: meteorological drought, agricultural drought and hydrological drought.

\subsubsection{Meteorological drought}

Based on climatic data, and by comparison with the climatic normal, drought is defined on the basis of the degree of dryness and the duration of the dry period. Definitions of meteorological drought must be considered as region specific since the atmospheric conditions that result in deficiencies of precipitation are highly variable from region to region. Some definitions of meteorological drought identify periods of drought on the basis of number of days with precipitation less than some specified threshold. For example, in Bali (Indonesia) in the 1960s, it was defined as a meteorological drought a six days period without rain (Hudson and Hazen, 1964). This measure is only appropriate for regions characterized by a year-round precipitation regime such as the Köppen Af climate (Wet Tropical) in precipitation favoured regions, such as islands and/or areas sumitted to orographic intensification. Other definitions may relate actual precipitation departures to normal amounts characteristic for the monthly, seasonal or annual time scales. Monthly precipitation less than $100 \mathrm{~mm}$ during the rainy season is labelled as a meteorological drought in north-eastern Brazil. In Spain, a particular year is considered to be dry when precipitation is less than annual average in different watersheds; $15-25 \%$ in the Cantábrico, Duero and Ebro, 20-25\% in Guadalquivir, 30\% in Guadiana/Tajo, and $40-50 \%$ in south-eastern zone (Olcina, 1994). 
Different definitions of meteorological drought provide specific information about each characteristics of regional climate and it is impossible to extrapolate a definition of one region to another (Marcos, 2001).

\subsubsection{Agricultural drought}

Agriculture is usually the first economic sector affected by the shortage of precipitation or - in a more extensive senes - to water availability deficits, so this sector shows a special interest in drought research. Agricultural drought occurs when there is not enough soil moisture to allow the development of a particular crop in any stage of growth. Plant water demand depends on prevailing weather conditions, biological characteristics of the specific plant, its stage of growth, the physical and biological properties of the soil and cropping techniques. Considering this, it is impossible to establish valid global, even regional agricultural drought thresholds. Despite that, Kulik (1962) defined agricultural drought as the "period in which there are only $19 \mathrm{~mm}$ of water available in the first $20 \mathrm{~cm}$ of soil". This implies that if the moisture level in subsoil is sufficient to provide water to a particular crop during the meteorological drought period, there is no agricultural drought at this moment, even if there is meteorological drought. Meteorological drought appears often before agricultural drought. If the meteorological drought continues, agricultural drought will appear. Obviously, this is true in the absence of irrigation.

\subsubsection{Hydrological drought}

After meteorological drought appears, the crops may suffer water stress and, if the precipitation deficiency worsens, hydrological drought will manifest. Hydrological drought can be described as a deficiency in the flow or volume of surface water or groundwater (rivers, lake levels, reservoirs, ground water, etc.) caused by climate variability (e.g. less precipitation than normal) or water management (e.g. irrigation during dry season). Hydrological measurements cannot be an indicator of the beginning of the drought, because there is a time lag between rainfall shortage and rivers flow depletion (Fig. 1). But, for this reason, this kind of drought is a great indicator of the severity of a dry event (Marcos, 2001). The frequency and severity of hydrological 
drought is often defined on a watershed scale. Agricultural drought appears shortly after meteorological drought, but hydrological drought can be delayed for months since the onset of the rainfall shortage. In the event of a meteorological drought followed by a short-lived agricultural drought, hydrological drought may not appear. For example, a precipitation deficiency may result in a rapid depletion of soil moisture that is almost immediately discernible to farmers but the impact of this deficiency on the reservoir levels may not affect hydroelectric power production, potable water supply, or recreational uses for many months. The contrary pattern also commonly occurs. For example, four years of low precipitation will probably produce a severe hydrological drought in terms of river discharge and reservoir storages, but during the drought period high precipitation events may produce high levels of soil moisture (Vicente-Serrano et al., 2011). From the discussion above, it is easy to conclude that the temporal sequence is: meteorological drought, agricultural drought and then hydrological drought. (Fig. 2-3)

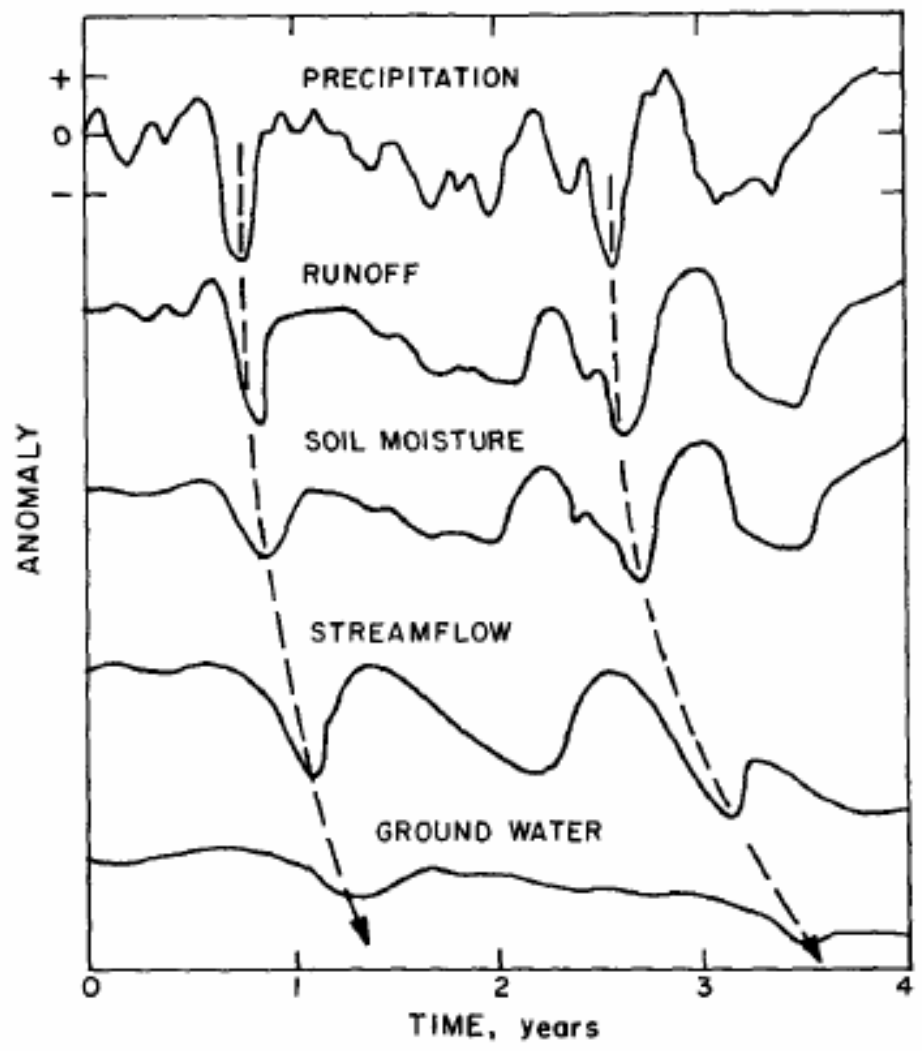

Figure 2-3: The propagation of a perturbation in precipitation amount through the land branch of the hydrologic cycle (Entekhabi et al., 1992).

Although climate is a primary contributor to hydrological drought, other factors such as changes in land use, land degradation, and the construction of dams dramatically affect the hydrological characteristics of the basin. Thus, hydrological drought does not only 
depend on the existing water volume in the reservoirs or rivers, but also it is important how this water is used. The close relationship between the temporal evolution of precipitation and streamflow has become evident at all temporal scales but, together with climate variability, water consumption by humans is also responsible for changes in hydrological systems (Lorenzo-Lacruz et al., 2012).

\subsubsection{Socio-economic drought}

In general terms, socio-economic drought occurs after agricultural drought and it corresponds to water availability reduction that produces economic or personal damages. Socio-economic drought may be defined as "Extensive and significant negative deviation of the precipitation compared with normal regime around which a society has been established" (Rasmussen, 1987). Is not necessary the restriction of water supply to produce socio-economic drought, but it also appears when some economic sector is affected by precipitation deficiency. In other words, socio-economic drought occurs when the demand for an economic good exceeds supply as a result of a weatherrelated shortfall in water supply. In most instances, the demand for economic goods is increasing as a result of increasing population and per capita consumption. This increased water consumption causes more socio-economic drought even in a mild meteorological drought. In many developing countries, agricultural drought is the beginning of socio-economic drought, because in this kind of countries the agricultural sector is the most important sector in their economies. So, socio-economic drought may also be defined as "Unusual water deficit generates adverse impacts on society suffers, altering the normal development of their collective life" (Pita López, 1995).

In this case, drought components as severity and duration of dry event are equally crucial that how the economy and society develop its activities. Particular actions may increase the vulnerability in front of rainfall shortage. Drought effects on the economy and society, measured in material losses, population affected or victims, will be more or less important depending on vulnerability. So some droughts may be considered catastrophes in terms of vulnerability.

These four types of drought described show a drought evolution process determined by natural climate variability, event duration and the interaction between climate and society (see Fig. 2-4). 


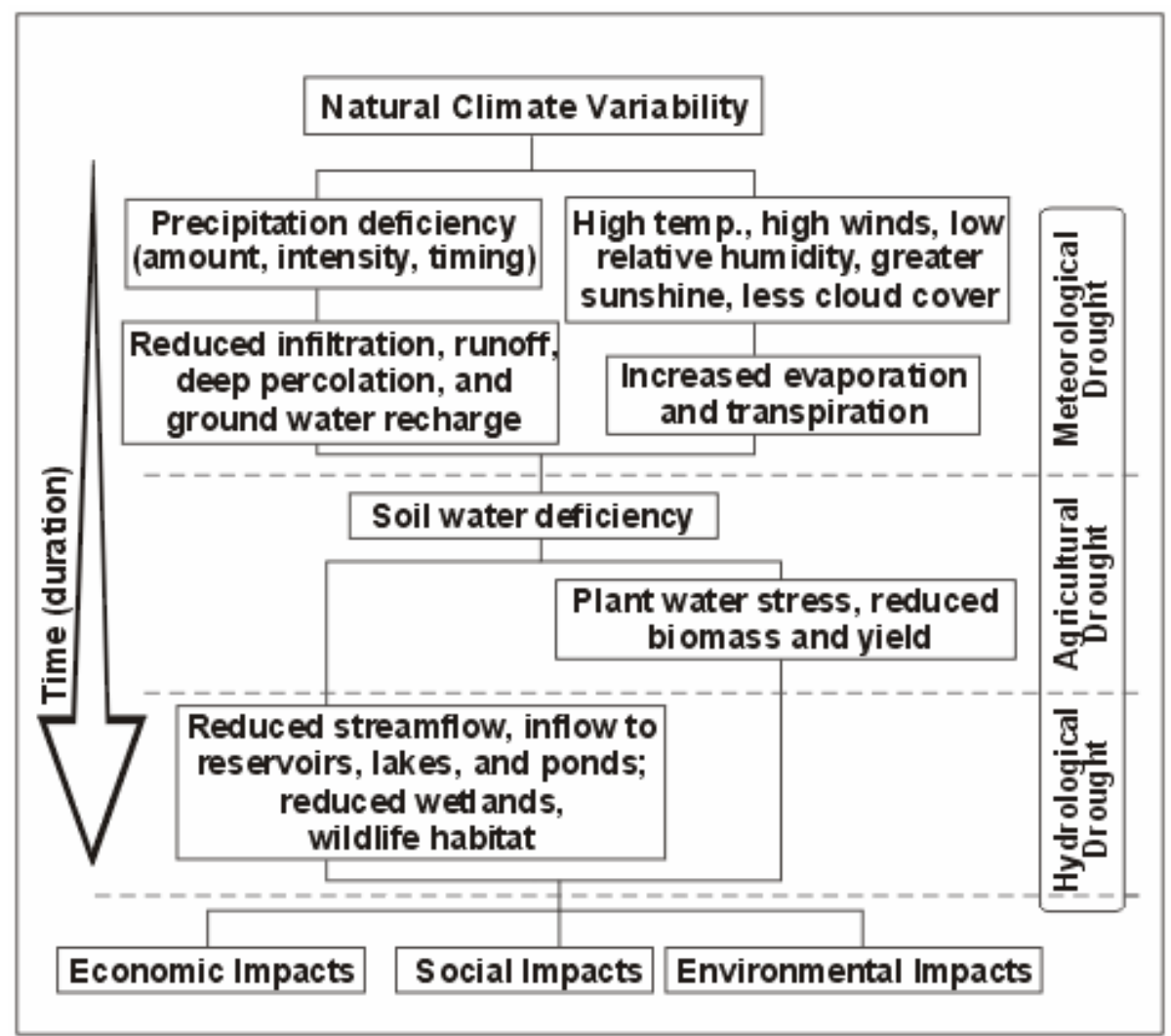

Figure 2-4: Sequence of drought impacts (NDMC, 1995, website: http://www.drought.unl.edu/DroughtBasics/TypesofDrought.aspx. Last visit: 14-05-2013. 


\subsection{Evaluation methods: Drought indices}

Theoretical definitions of different forms of drought need to be transferred into a numerical format to concrete characteristics of dry events (Marcos, 2001). Then, a question appears: which components allow us to define and identify a drought? Burton et al. (1978) listed seven parameters to characterize it. A first one refers to the magnitude of the drought, other four describe its temporal component (duration, frequency, implantation rate and temporal spacing), and the last two are related to spatial characteristics of the phenomenon (extension and spatial dispersion). To quantify these parameters is not enough to measure the number of wet days or evaluate perceptions about rainfall shortage, but it is necessary to apply mathematical formulas to establish the duration and magnitude of a dry event. The most important parameters to detect and analyze droughts, according to Burton, are described below.

- Magnitude is the average rainfall or flow deficit for the duration period of the dry event. Its meassured as an anomaly to the long term average of precipitation or flow over a chosen period, expressed either in percentage or difference (absolute value). Dracup et al. (1980) indicate that, besides magnitude, drought severity can be measured as well.

- Severity can be defined as an accumulated deficit of precipitation or flow for the duration of dry period.

- Duration is the time (number of consecutive time steps, either days, months or years) for which the precipitation or flow recorded are less than a prescribed threshold for the same period.

- Frequency is the number of known cases of drought occurred for a particular period. It can also measured through the empirical probability that the precipitation or flow is less than average, or less than return period of dry event (average time interval of which can expected a drought of a particular magnitude).

- Implantation rate refers to the elapsed time between the beginning of the precipitation or flow deficit, and the moment when this deficit reaches its maximum value. 
- Temporal spacing is the elapsed time between various dry events. It provides a measure of regularity or randomness of the drought. Through this parameter we can obtain a first approximation to drought predictability.

- Extension is the total surface that suffers water shortage.

- Spatial dispersion measures the diffusion or concentration degree of precipitation or flow anomaly.

Knowing these parameters, Burton et al. (1978) defined drought as a pervasive risk due to its intermediate frequency, length duration, slow implantation rate, relatively random temporal spacing, expanse of territory affected and high spatial diffusion.

In this way, some numerical standard is needed for comparing measures of drought from region to region, as well as, for comparing past drought events (Heim, 2002). However, the considerable disagreement that exists about the definition of drought makes it impossible to devise a universal drought index. Furthermore, drought's characteristics and the wide range of economic sectors on which it has an impact make its effects difficult to quantify. Because of the complexity of drought, no single index has been able to adequately capture the intensity and severity of drought and its potential impacts on such a diverse group of users.

The World Meteorological Organisation defined a drought index as "an index which is related to some of the cumulative effects of a prolonged and abnormal moisture deficiency" (WMO, 1992).

The American Meteorological Society (1997) suggested that the time and space processes of supply and demand are the two basic processes that should be included in an objective definition of drought and, thus, in the derivation of a drought index.

A wide variety of drought indices exist to characterize dry conditions basically in its two most relevant parameters; magnitude (or severity) and duration. Multiple articles were published discussing pros and cons about various drought quantification methods (Alley, 1984; Karl, 1986; Heim, 2002; Dubrovsky et al., 2008; Vicente-Serrano et al., 2010 and 2011, Dai, 2011 and 2012; Shefield et al., 2012).

A long list of drought indices were described for detecting and analysing drought conditions: the Palmer's Drought Severity Index (Palmer, 1965); Deciles Method (Gibbs and Maher, 1967); Keetch-Byram Drought Index (Keetch and Byram, 1968); Surface Water Supply Index (Shafer and Daezman, 1982); The Standard Precipitation Index (SPI) (McKee et al., 1993), the Standardized Precipitation-Evapotranspiration Index (SPEI) (Vicente-Serrano 
et al., 2010), the Standardized Streamflow Index (SSI) and The Drought Monitor (Svoboda, 2000) among others. In this section, the most widely drought indices list were described.

\subsubsection{Percent of Normal}

The percent of normal precipitation is one of the simplest measures of rainfall deficit for a particular location. Analyses using the percent of normal are very effective when used for a single region or a single season (Hayes, 1997). Percent of normal is also easily misunderstood and gives different indications of conditions, depending on the location and season. It is calculated by dividing actual precipitation by normal precipitation (typically considered to be a 30-year mean or, if it is possible, more than 50-year mean) and multiplying by $100 \%$. This can be calculated for a variety of time scales. Usually these time scales range from a single month to a group of months representing a particular season, to a natural or hydrological year. Normal precipitation for a specific location is considered to be $100 \%$. One of the disadvantages of using the percent of normal precipitation is that the mean, or average, precipitation is often not the same as the median precipitation, which is the value exceeded by $50 \%$ of the precipitation occurrence in a long-term climate record. The reason for this is that precipitation on monthly or seasonal scales does not have a normal distribution. Use of the percent of normal comparison implies a normal distribution where the mean and median are considered the same. Other drawbacks of this approach are the difficulty to identify the beginning and end of drought period, and its severity as well, because the chosen percentage for a region is not applicable in another (Marcos, 2001). In other words, percent of normal cannot be comparable between different climatic regions or for various time periods because normal precipitation will probably change among regions and across time.

Despite this, it is the most used drought index, because it is very simply and does not need complex climatic information. It is ideal for some regions with a few available climate records. Bhalme and Mooley renamed this method using the acronym BMDI (Bhalme \& Mooley Drought Index), in spite it was not a novelty at all.

As an example, figure 2-5 shows dry and wet conditions for Europe from January to March 2012 using percent of normal method. Near normal conditions are expressed in yellow and light green; green and blue colors depict wet conditions; brown or red are 
associated to dry conditions. As described above, this method uses percentages to know the degree of dryness or wetness, but these percentages do not represent the same amount of precipitation among different regions because the normal precipitation is not the same. For example, the $25 \%$ of precipitation (red colour in fig. 2-5) was recorded in some areas of the Iberian Peninsula, but also in some parts of the Scandinavian Peninsula among others. This means that just the $25 \%$ of precipitation was recorded in these regions, but the total amount of recorded precipitation will be different because the normal precipitation is different in the Iberian Peninsula, the British Isles or in Scandinavia during this period although both regions recorded the same percentage of precipitation. For this reason, the degree of dryness (in this case) cannot be comparable between these three regions, although the percent of normal index inform us that both regions suffered extremely dry conditions from January to March 2012.

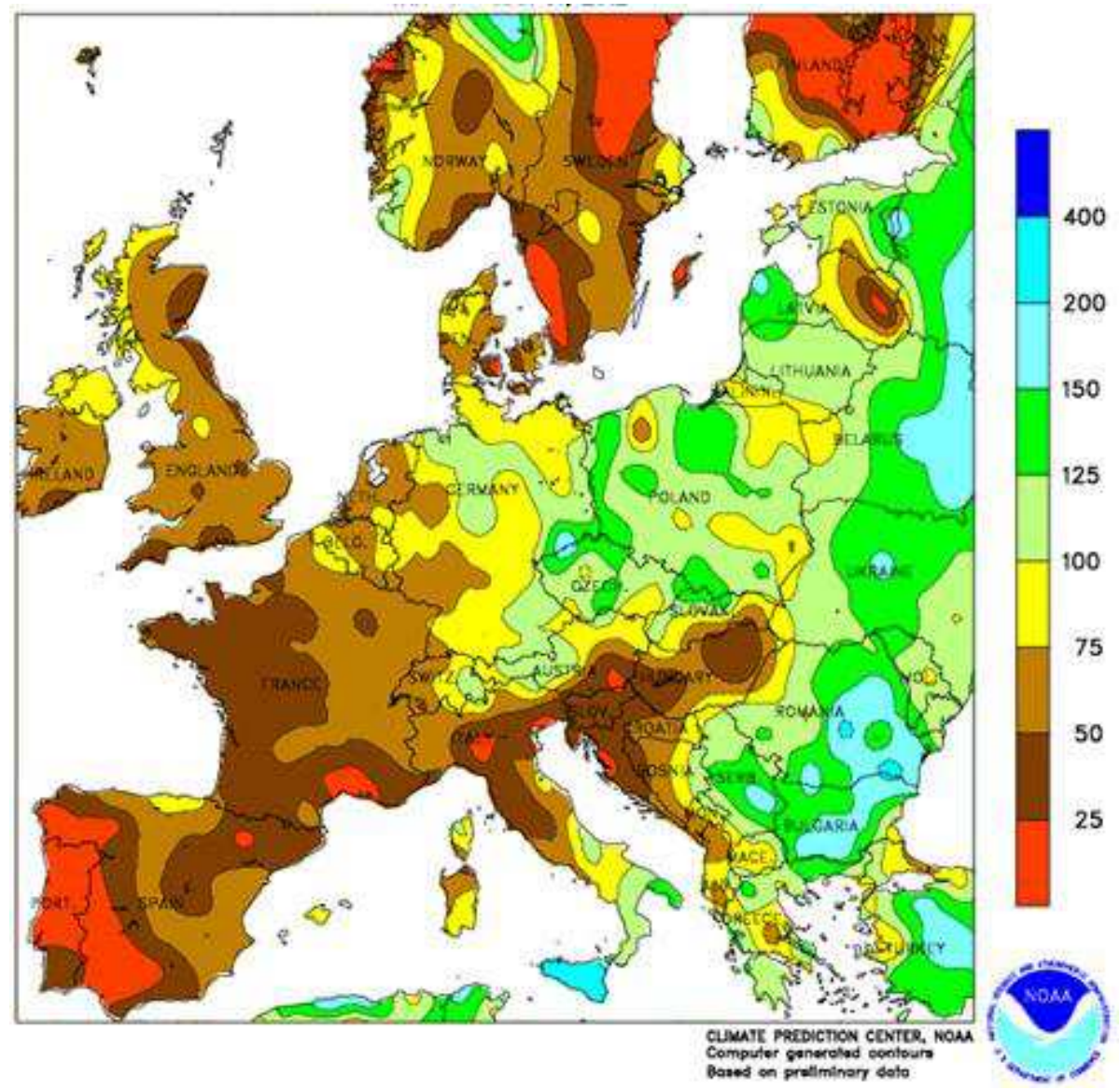

Figure 2-5: Example of Percent of Normal map for Europe from January to March 2012 available at: http://www.cpc.ncep.noaa.gov/products/Drought. Last visit: 14-05-2013. 


\subsubsection{Quantiles Method}

Percent of normal method has some limitations (see section above). To avoid them, dryness thresholds can be defined by the calculation of different quantiles. This technique consists to divide the distribution of rainfall occurrence during using intervals for each $20 \%$ (quintiles), $10 \%$ (deciles) or 1\% (percentiles) of the distribution (Marcos, 2001). These thresholds are a better representation of the statistical distribution of the climate reality in the studied area because they are values referenced to the statistical distribution of precipitation series and not linked to absolut values. Thereafter, they can be compared among different regions. It is necessary to have long series (30-year minimum and, if it possible, more than 50-year), to achieve reliable and statistically robust results. The most widely used theresholds are pearhaps the quintiles. In this way, it is considered that a period is very dry when the precipitation value is less than $20 \%$ of the distribution ( $1^{\text {st }}$ quintile); dry period when it is between $20-40 \%$ ( $2^{\text {nd }}$ quintile), normal period when it is between $40-60 \%\left(3^{\text {rd }}\right.$ quintile, centered over the median or central value), wet period between $60-80 \%\left(4^{\text {th }}\right.$ quintile) and very wet period when the precipitation value is higher than $80 \%$ of the distribution values $\left(5^{\text {th }}\right.$ quintile).

When it is necessary to apply more precision in these thresholds, it is possible to increase the number of intervals using deciles (establishing 10 intervals in series, each one representing $10 \%$ of values) or percentiles (establishing 100 intervals, each one representing $1 \%$ of values into distribution).

The technique developed by Gibbs and Maher (1967) divided the distribution of occurrences over a long-term precipitation record into ten categories. By definition the fifth decile is the median, and it is the precipitation amount is not exceeded by $50 \%$ of the occurrences over the period of reference. The deciles method was selected as the meteorological measurement of drought within the National Climate Centre from Australia (among others) because it is relatively simple to calculate, and requires less data and fewer assumptions (Smith et al., 1993). In Australia, farmers and ranchers can only request government assistance if the drought is shown to be an event that occurs only once in 20-25 years (deciles 1 and 2 over a 100-year record) and has lasted longer than 12 months (White and O'Meagher, 1995). This uniformity in drought classifications has 
assisted Australian authorities in determining appropriate drought responses. One disadvantage of the deciles system is that a long climatological record is needed to calculate the deciles accurately (Hayes, 1997).

The Bureau of Meteorology supported by the Australian Government issues regular regional rainfall deciles maps to monitor drier or wetter conditions during a particular period. Figure 2-6 shows the rainfall deciles over Australia from January to December 2010 using rainfall deciles ranges (blue ranges are referred to wetter conditions above normal $\left(>7^{\text {th }}\right.$ decile $)$ meanwhile red ranges are drier conditions below normal $\left(<4^{\text {th }}\right.$ decile)). Although some regions have different climatic conditions, this method allows that the results are comparable among different climatic regions because it's based on rainfall distribution occurrence and the ranges are the same for the whole region.

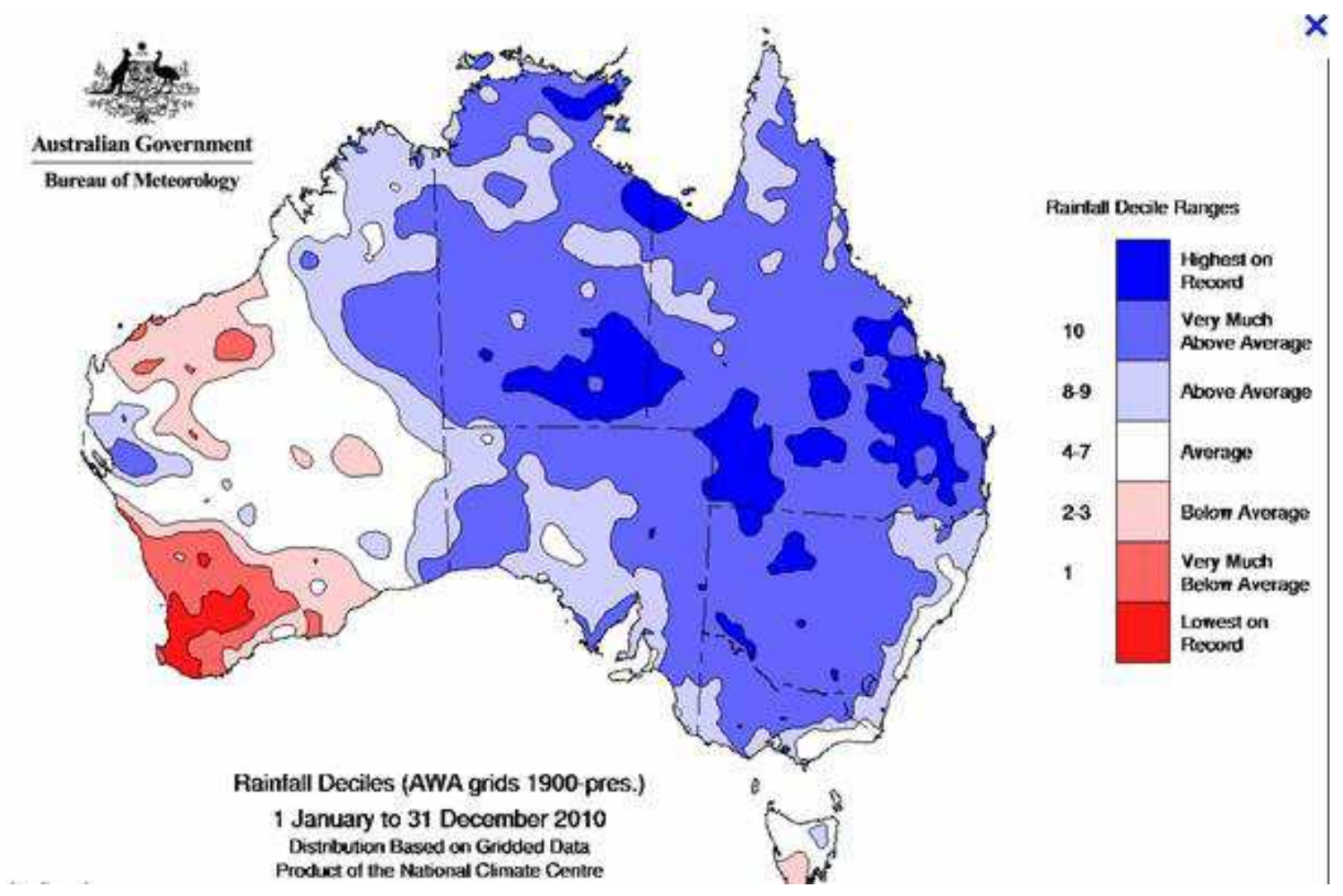

Figure 2-6: Example of rainfall deciles over Australia from January to December 2010 available at: http://www.bom.gov.au/water. Last visit: 14-05-2013. 


\subsubsection{The Palmer's Drought Severity Index (PDSI)}

The Palmer's Drought Severity Index (PDSI) (Palmer, 1965) is based on the supply-anddemand concept of the water balance equation taking into account more than just the precipitation deficit at specific locations (Hayes, 1997). The PDSI is based on precipitation and temperature data, as well as the local Available Water Content (AWC) of the soil. Palmer's Index includes in its computation two important parameters related to drought development: soil moisture and evapotranspiration. Soil moisture generally refers to the amount of water stored in the unsaturated soil zone and it is a source of water for the atmosphere through processes leading to evapotranspiration from land, which include mainly plant transpiration and bare soil evaporation (Seneviratne et al., 2010). Thus, it incorporates antecedent and current moisture supply (precipitation) and demand (PET) into a hydrological accounting system.

This drought index became widely used in the United States (i.e. the U.S. Drought Monitor (NCDC and NDMC)) and for the Intergovernmental Panel on Climate Change (IPCC) in its $4^{\text {th }}$ assessment (2007) (Dai et al., 2004b). However, Van der Schrier et al. (2006) derived the time series (1901-2002) and maps of Sc-PDSI for Europe and North America compiled by the Climatic Research Unit (CRU).

Palmer applied what he called Climatologically Appropriate for Existing Conditions (CAFEC) quantities to normalize his computations so he could compare the dimensionless index across space and time. These quantities are related to evapotranspiration values, recharge, runoff, loss, potential evapotranspiration (PET), potential recharge, potential runoff, and potential loss. The calculation of these parameters depends heavily on the available water holding capacity (AWC).

According to Heim (2002) CAFEC procedure enables the index to measure abnormal wetness (positive values) as well as dryness (negative values), with persistently normal precipitation and temperature theoretically resulting in an index of zero in all seasons in all climates. When PDSI value remains positive (or negative) during a few consecutive months it means wet event (or dry) has produced. When PDSI changes the sign, although it only occurs in a month, the last wet or dry event has finished and starts another one. 
But PDSI is problematic when it is used in other regions out of United States, mainly due to different climatic and land cover properties (Sousa et al., 2011). It has been shown that the application of the PDSI tends to result in an exaggerated frequency of extreme dry and wet events (van der Schrier et al., 2006). Moreover, PDSI has been criticized for a variety of reasons of which most significant is perhaps that is not comparable between diverse climatological regions (Alley, 1984 and Karl, 1986). This problem has been solved by Wells et al. (2004) creating Self-Calibrated PDSI (Sc-PDSI) which improves the "original" PDSI. A detailed description of the modifications to this algorithm to obtain the Sc-PDSI is given by Wells et al., 2004 and van der Schrier et al. (2006a).

Figure 2-7 shows the global Palmer's Drought Severity Index (PDSI) for January 2002 as example distinguishing dry conditions in orange or red and violet, meanwhile wet conditions are represented in green or blue. In this case, it's not possible to detect various types of droughts due to the fixed time-scale of PDSI, but extreme conditions were identified to different parts of the world (e.g. drier conditions were detected in most of North America, Central America and the northern South America, the Mediterranean basin, Saharan and Sub-Saharan region, Arab world and some areas in the north of Russia, eastern Asia and most of Australia). This map was computed using the "original" PDSI including the limitations and deficiencies reported above by other authors.

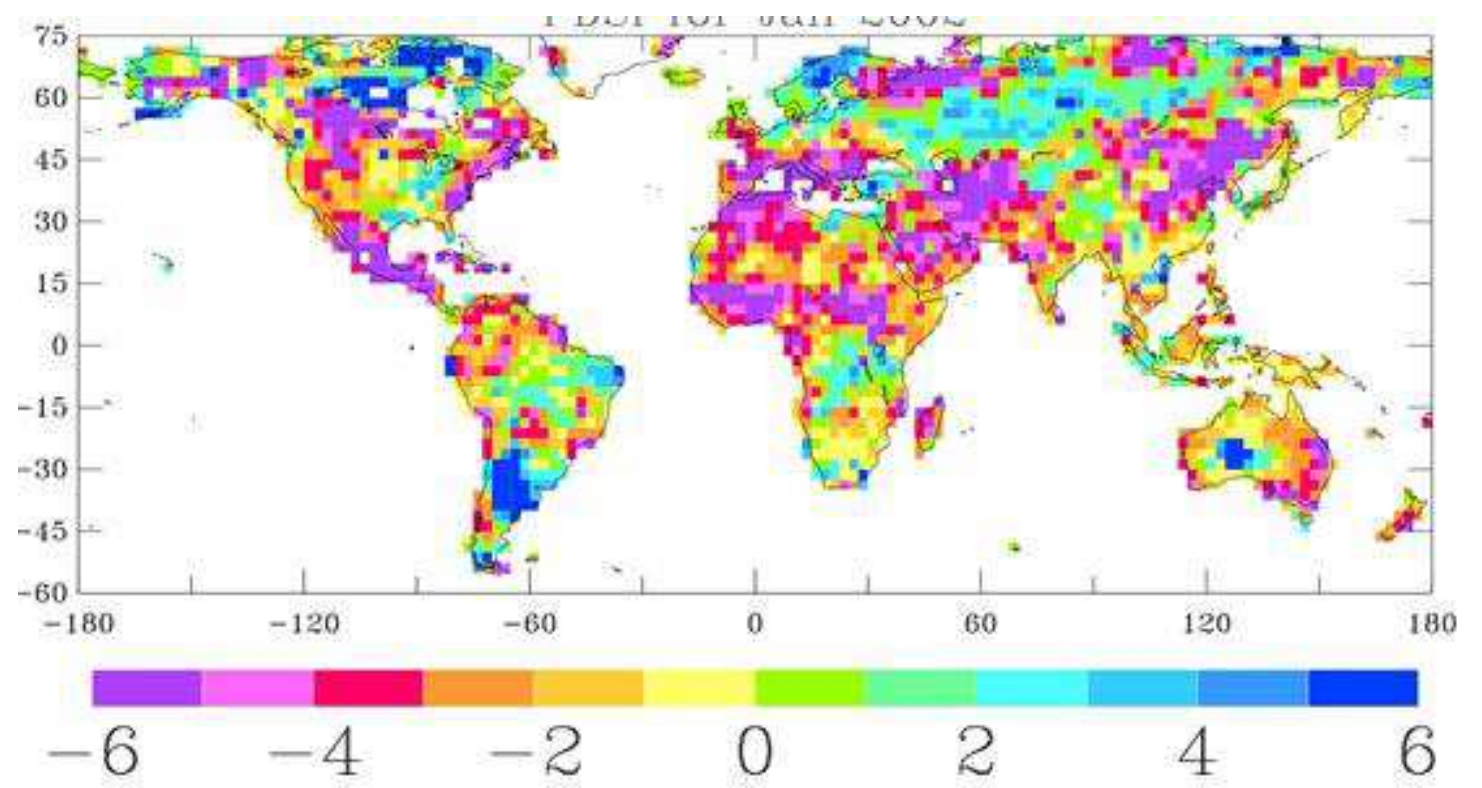

Figure 2-7: Global Palmer's Drought Severity Index (PDSI) for January 2002 using gridded data. Red and purple tonalities are referred to dry conditions while wet conditions are represented in blue (Dai et al., 2004). 


\subsubsection{The Standardized Precipitation Index (SPI)}

The SPI was designed to quantify the precipitation deficit for multiple time scales. These time scales reflect the impact of drought on the availability of the different water resources. Soil moisture conditions respond to precipitation anomalies on a relatively short scale, while ground water, stream flow, and reservoir storage reflect the longerterm precipitation anomalies (Hayes, 1997). For these reasons, McKee et al. (1993) originally calculated the SPI for 3, 6, 12, 24 and 48 month time scales. This drought index is based on the premise that precipitation is the most important parameter to define droughts, although temperature or evapotranspiration can influence the behaviour of drought severity (Guttman, 1998; Keyantash and Dracup, 2002).

The index has the advantages of being easily calculated, having modest data requirements (only precipitation), and being independent of the magnitude of mean rainfall and hence comparable over a range of climatic zones. It does, however, assume the data are normally distributed, and this can introduce complications for short time periods (Agnew, 2000). The SPI has been accepted by the World Meteorological Organization (WMO) as the reference drought index and it should be used by national meteorological and hydrological services worldwide to characterize meteorological droughts (Hayes et al., 2011).

McKee et al. (1993) used the classification system to define drought intensities resulting from the SPI. McKee et al. (1993) also defined the criteria for a "drought event" for any of the time scales. A drought event occurs any time the SPI is continuously negative and the event ends when the SPI becomes positive. Each drought event, therefore, has a duration defined by its beginning and end, and intensity for each month that the events continue. The accumulated magnitude of drought can also be drought magnitude, and it is the positive sum of the SPI for all the months within a drought event.

The SPI allows the determination of duration, magnitude and intensity of droughts (Hayes et al., 1999). Its main advantage is that it can be calculated for several time scales (McKee et al., 1995; Komuscu, 1999) and identifies various types of drought; meteorological; from 1 to 6 months time-scale, agricultural; from 3 to 9 months time-scale, or hydrological; greater or equal than 12 months time-scale (Vicente-Serrano et al., 2006). The SPI has been extensively used for drought analysis in many studies (e.g., Hayes et al., 1999; Lana et al., 2001; Vicente-Serrano et al. 2004, 2006, 2008, 2010 and 2011; Mavromatis, 2007; Kingtse et al. 2008, 2009; Dubrovsky et al. 2007b, 2008; Wu et al. 2009; Subash et al. 2010), and has become 
an important component in many drought monitoring efforts (i.e., the U.S. Drought Monitor (NCDC and NDMC), North American Drought Monitor (NOAA) and European Drought Observatory (EDC).

Lloyd-Hughes and Saunders (2002) developed a high spatial resolution, multi-temporal SPI-based climatology of Europe and SPI maps are operationally available for the U.S.A. as well.

As an example, figure 2-8 shows the global distribution of meteorological dryness and wetness at the end of September 2010 using a 6-month SPI. Regions in white are referred to normal conditions meanwhile regions in red (drier conditions) and green (wetter conditions) represent extreme conditions in SPI. Regions in grey (out of oceans) are referred to missing data (Sahara and some parts of central Asia). Meteorological dryness was detected in Greenland, western Alaska, in some areas of central and southern South-America, central Russia and some areas spread over central and southern Africa among others. Otherwise, wetter conditions were identified in central and northern North-America, in western Africa, in east of Europe, in northern Russia, in some areas in southern Asia, Indonesia and in central Australia.

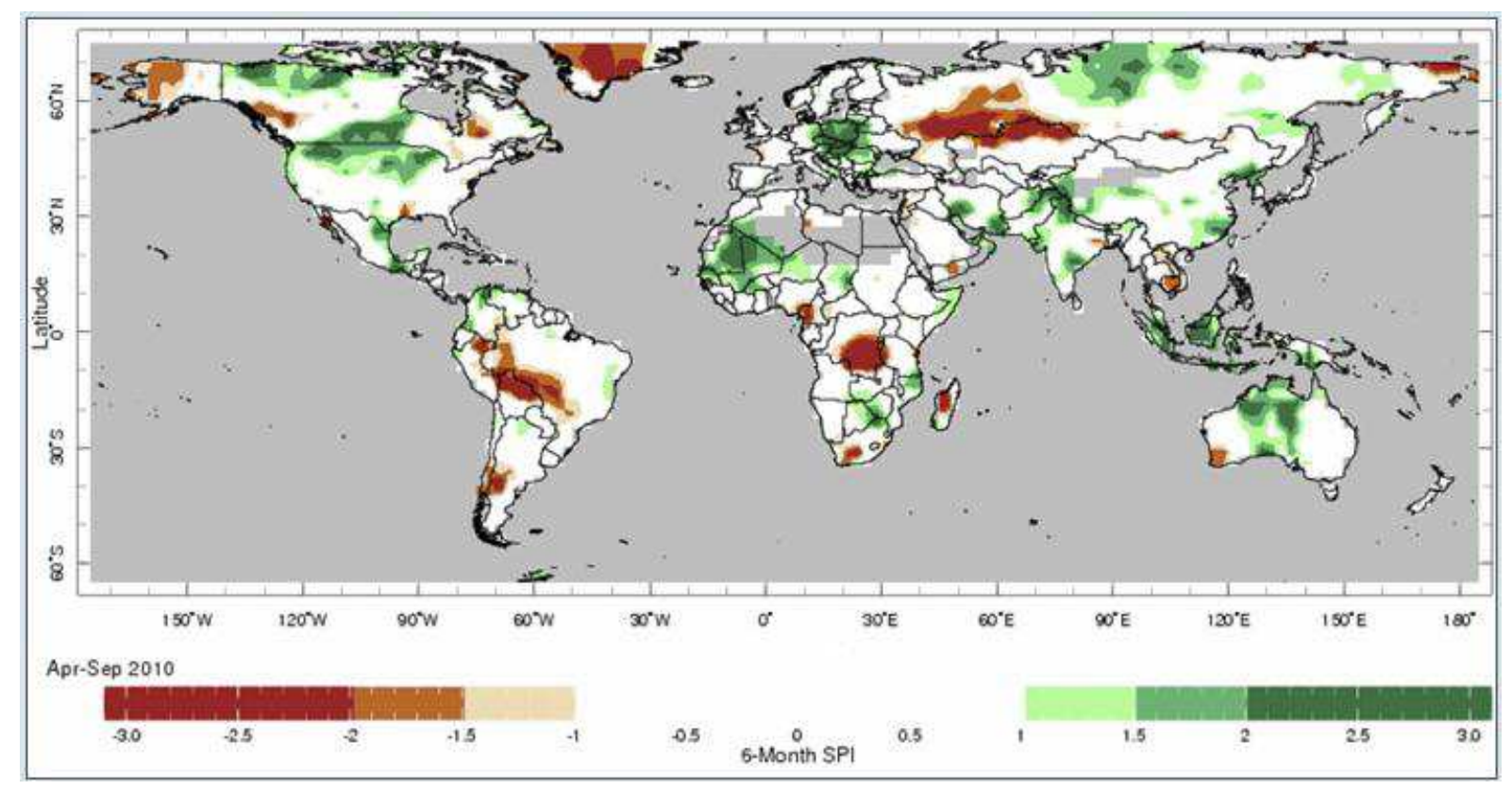

Figure 2-8: Interpolated global map using a 6-month SPI from April to September 2010. Regions in brown are referred to dry conditions while regions in green mean wet conditions (Sivakumar et al., 2010). 


\subsubsection{Standardized Precipitation-Evapotranspiration Index (SPEI)}

On the other hand, the newly Standardized Precipitation Evapotranspiration Index (SPEI) is based on the original SPI calculation procedure. The novelty of SPEI is that includes potential evapotranspiration (PET) in its algorithm and represents a simple climatic water balance which is calculated at different time scales (Vicente-Serrano et al., 2010). The SPEI combines the sensitivity of Palmer's Drought Severity Index (see section 2.4.3) to changes in evaporation demand (caused by temperature fluctuations and trends) with the simplicity of calculation and the multi-temporal nature of the SPI. Thus, SPEI solved the main criticism of SPI, namely that it is based only on precipitation variability (Vicente-Serrano et al., 2011). The new index is particularly suited to detecting, monitoring and exploring the consequences of global warming on drought conditions. SPI and SPEI are purely statistical, and are not intended to reproduce the water balance of any particular system. The advantages of such indices are that:

a) Their calculation only requires climatological information, which is often available and of reasonable quality.

b) They do not require any assumptions about the system being modelled.

c) They compute the climatological anomalies for periods of exact length (termed the "time scale" of the index.

The ability to calculate these indices at various time scales allows choice of the scale most appropriate to the system under study, and can be achieved using simple statistics such as correlation analysis (Vicente-Serrano et al., 2011).

Both SPI and SPEI maintain units with a robust statistical meaning, and the series of the various time-scales are comparable between them. These indices have the advantage of determining exactly the period (time-scale) in which the antecedent conditions are affecting the value of the index.

Vicente-Serrano et al., (2010b) created a new global 0.5 gridded dataset (1901-2006) of a multi-scalar drought index (SPEI), which considers the joint effects of temperature and precipitation on droughts. The main advantage of the new dataset lies in its multiscalar character, which allows discrimination between different types of drought.

Some studies tested the reliability and consistency of SPEI compared with other drought indices obtaining better results as a global gridded map (Vicente-Serrano et al., 2010b) as a few locations around the world (Vicente-Serrano et al., 2010). Therefore, drier conditions 
were detected using SPEI in Czech Republic (Potop et al., 2011) and for detecting agricultural droughts in Republic of Moldova (Potop, 2011).

Figure 2-9 shows, as example, the global SPEI computed for June 1995 at different time-scales (3-month and 12-month) in order to detect different types of drought. The time-scale of 3-month is widely used to identify meteorological drought (and agricultural drought in some particular crops) and 12-month time-scale is suitable to detect hydrological droughts (Vicente-Serrano, 2006). Drier conditions are represented with red colour meanwhile wetter conditions are referred to blue colour in fig. 2-9. Both maps show similar results, although meteorological drought became extreme in western Russia (left map) meanwhile hydrological drought was moderate at the same region (right map). Moreover, wetter conditions were identified in south-eastern Australia (left map), but drier conditions were detected at 12-month time-scale (right map). This means that short rainfall periods were enough to eliminate meteorological drought but not sufficient to stop hydrological drought. These differences represent the capacity of SPEI to detect various types of droughts around the world in a particular time-period.

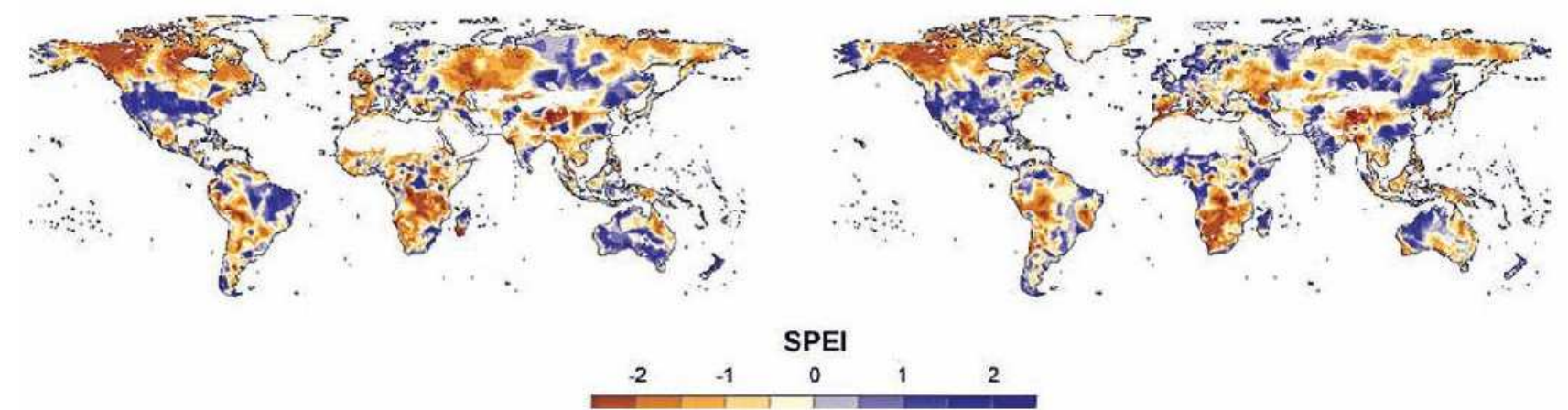

Figure 2-9: Example of global (left) 3-month and (right) 12-month SPEI, June 1995. Dry conditions are represented in red while wet conditions are in blue. Regions in white have not been studied due to the lack of sufficient data to represent drought conditions (Vicente-Serrano et al., 2010b). 


\subsubsection{The Drought Monitor}

Agencies within NOAA and the U.S. Department of Agricultural (USDA) together with the National Drought Mitigation Center (NDMC) produce a weekly Drought Monitor (DM) product that incorporates climatic data and professional input from all levels (Svoboda, 2000). In a review, Heim (2002) discussed the implementation of several key indices and ancillary indicators from different agencies to create the final map. The key parameters include the Palmer's Drought Index (PDI), Crop Moisture Index (CMI), soil moisture model percentiles, daily stream flow percentiles, percent of normal precipitation, topsoil moisture and a satellite-based Vegetation Health Index (VHI). The ancillary indicators include such indices as the Surface Water Supply Index (SWSI), SPI, snow pack conditions, reservoir levels, groundwater levels determined from wells, crop status, and direct in situ soil moisture measurements.

The key parameters are objectively scaled to five DM categories. The classification scheme includes the categories D0 (abnormally dry area) to D4 (exceptional drought event) and labels indicating the time-scale of the drought and which sectors are being impacted by drought ( $\mathrm{S}$; for short time-scales (typically $<6$ months) generating impacts on agriculture and grasslands, W; for long time-scales (typically $>6$ months) generating hydrological and ecological impacts (see table 2-1 and Fig. 2-10). Final maps are adjusted manually to reflect real-world conditions. Consequently, the DM is a consensus product reflecting the collective best judgement of many experts based on several indicators.

\begin{tabular}{|c|c|c|}
\hline $\begin{array}{c}\text { Drought Monitor } \\
\text { category }\end{array}$ & Description & Impacts \\
\hline D0 & Abnormally dry & Minor impacts \\
\hline D1 & Moderate drought & $\begin{array}{c}\text { Some crop damage, high wildfire risk, water } \\
\text { shortage }\end{array}$ \\
\hline D2 & Severe drought & $\begin{array}{c}\text { Moderate crop damage, very high wildfire risk, } \\
\text { water restrictions }\end{array}$ \\
\hline D3 & Extreme drought & $\begin{array}{c}\text { Serious crop losses, extreme wildfire risk, extensive } \\
\text { water restrictions }\end{array}$ \\
\hline D4 & Exceptional & $\begin{array}{c}\text { Exceptional and extensive crop losses, extreme } \\
\text { wildfire risk, extensive water restrictions }\end{array}$ \\
\hline
\end{tabular}

Table 2-1: The Drought Monitor categories (adapted from Svoboda, 2000) 
A limitation of DM lies in its attempt to show drought at several time scales (from short-term drought to long-term drought) on one map product. The intent of the DM is not to replace any local or state information or subsequently declared drought emergencies or warnings, but rather to provide a general assessment of the current state of drought around the United States, Pacific possessions and Puerto Rico (Svoboda, 2000). The Drought Monitor may be found by internet at http://droughtmonitor.unl.edu/. Last visit: 25-05-2012.

Figure 2-10 shows an example of weekly Drought Monitor for USA in March 2012. Distinct drought categories are represented in brown, red, orange or yellow to indicate the intensity of drought, meanwhile no dry conditions remain in white. Moreover, solid and bold lines delineate the region of dominant impacts distinguishing between impacts derived from short-term droughts, long-term droughts or a combination of both.

\section{U.S. Drought Monitor \\ March 6, 2012 \\ Valid 7 a.m. EST}

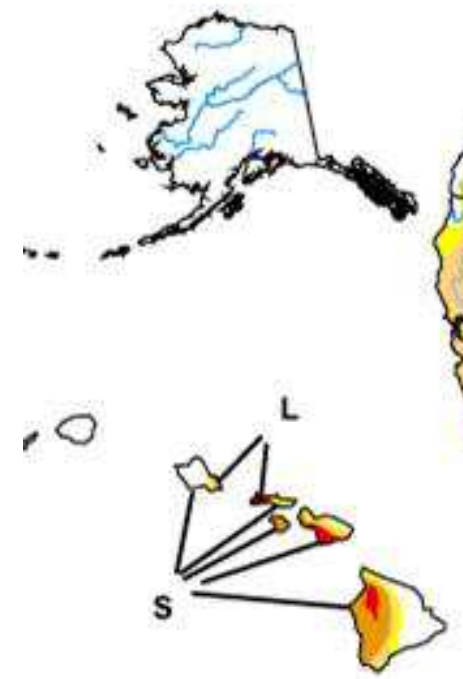

Intensity

DO Abnormally Dry

D1 Drought - Moderate

D2 Drought - Severe

D3 Drought - Extreme

D4 Drought - Exceptional

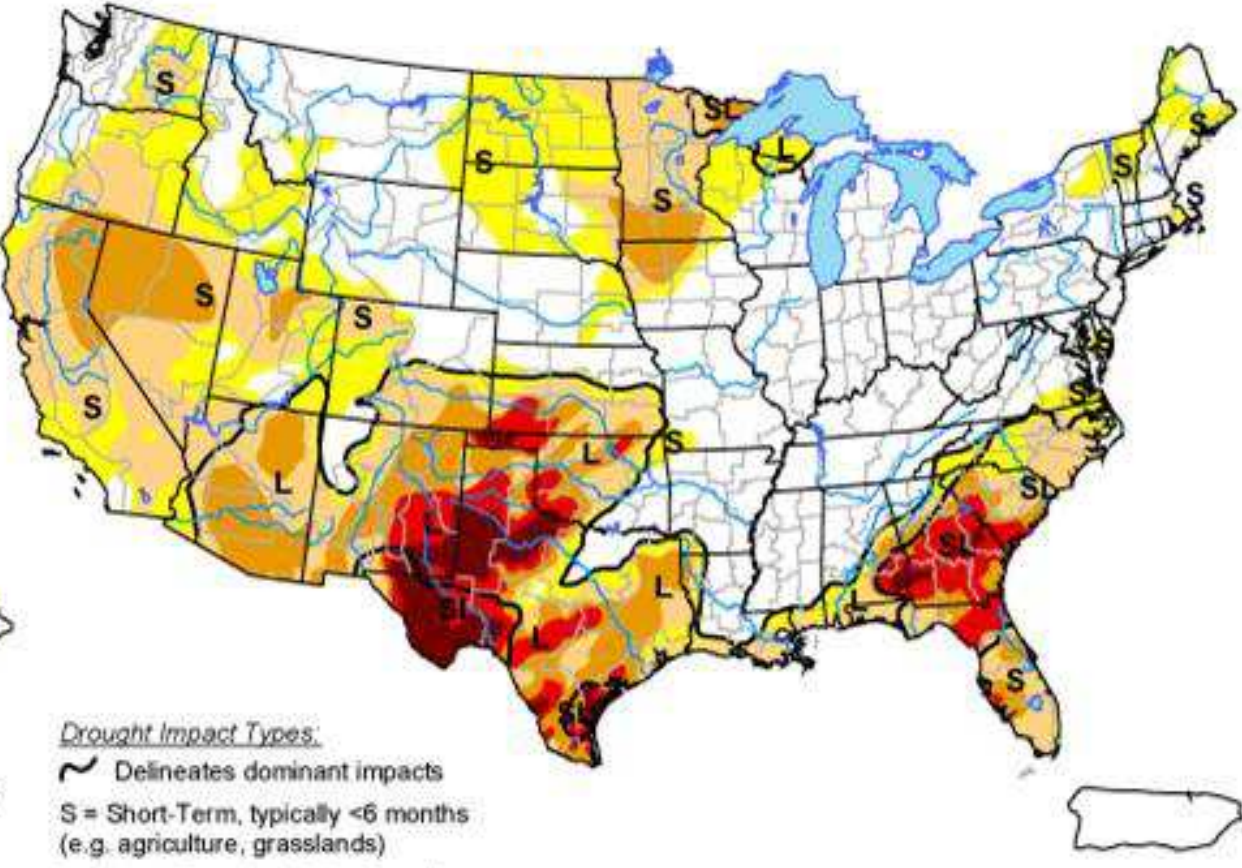

griculture, grasslands)

$L=$ Long-Term, typicality $>6$ months

(e.g. hydrology, ecology)

The Drought Monitor focuses on broad-scale conditions. Local conditions may vary. See accompanying text summary for forecast statements.

http://droughtmonitor.unl.edu/

Author: Michael Brewer/L. Love-Brotak, NOAA/NESDIS/NCDC

Figure 2-10: Example of weekly Drought Monitor map for U.S.A. available at: http://droughtmonitor.unl.edu/ Last visit: 25-05-2013 


\section{Chapter 3}

\section{STUDY AREA}

\subsection{Geographic location}

The Iberian Peninsula, with an extension of $538.254 \mathrm{Km} 2$, is located at the southwest of the European continent between $36^{\circ}$ and $44^{\circ}$ latitude $\mathrm{N}$ and between longitude $-10 \mathrm{~W}^{\circ}$ and $5^{\circ}$ E. It is surrounded by the Mediterranean Sea to the east and southeast and by the Atlantic Ocean to the north, west and southwest. This peninsula is attached to the European continent by the Pyrinees at the northeast of the peninsula. Iberia's southernmost tip is only fourteen kilometers far from Africa (Fig. 3-1).

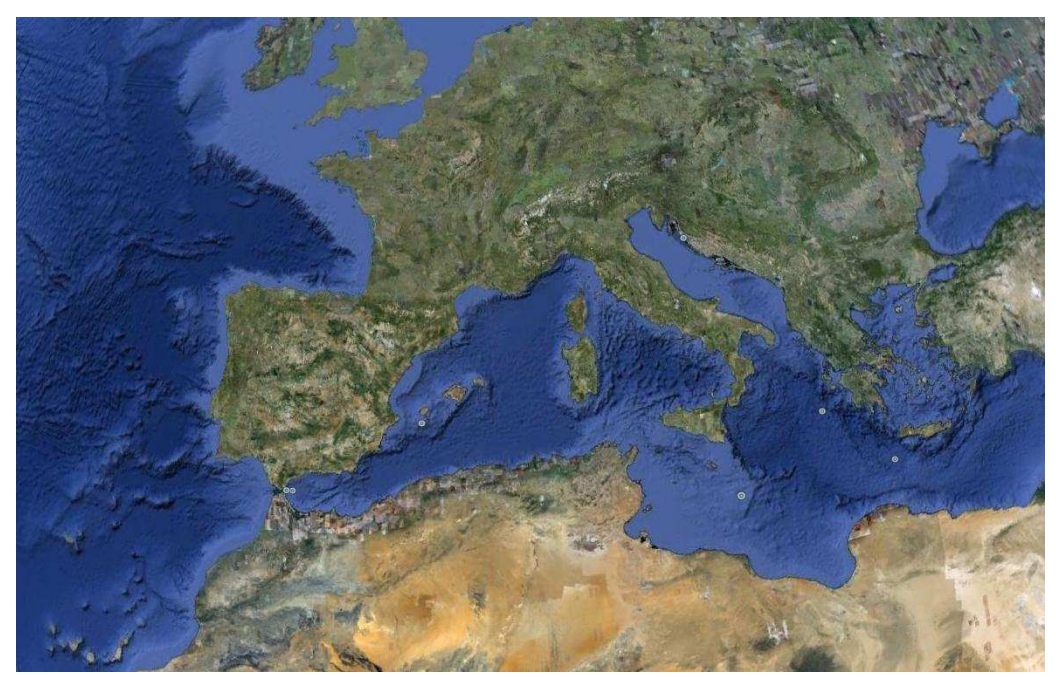

Figure 3-1: Satellite image of the Iberian Peninsula and influence areas (source: Google Earth)

\subsection{Climate characteristics}

The Iberian Peninsula is located in a transitional area between temperate and subtropical climates. Basically, its latitude, topography, maritime influence and General Circulation patterns (together with other factors) determine the climate influenced simultaneously by the Polar Jet Stream associated with the Westerlies located at higher latitudes and the Subtropical High Pressure Belt located at lower latitudes, both climate factors configure the Ferrel Cell. 
General circulation patterns divide the Iberian Peninsula into two markedly different climatic areas. A northern area comprising Galicia, Cantabria and Pyrenees is most of the time beyond the influence of the subtropical high pressure over the year due to its higher latitude. The rest of the Iberian Peninsula is influenced by subtropical high pressure especially in summer (Capel Molina, 2000).

In consequence, the northern area is influenced over the year by the West Jet Stream and low pressure originated along Polar Front giving particular climate characteristics similar to Western Europe (mild winters, cool summers, high humidity, abundant cloudiness and frequent rains in all seasons). On the other hand, the rest of the peninsula belongs to a Mediterranean climate (Köppen Cs type) due to markedly differences in general circulation patterns between summer and winter (mild winters in coast and severe in interior, dry and hot summers, sun many times and very irregular rains in fall, winter and spring). Some continental and souteastern locations, isolated from the oceanic flow, fall into de the semi-arid Köppen types (BS).

The subtropical high pressure, the Siberian winter anticyclone and the Saharan low pressure are the most important atmospheric elements that they have more influence in the Iberian Peninsula. The subtropical high pressure is defined by a strong anticyclone located over the Atlantic sea (known as an Azores anticyclone). The Siberian anticyclone causes occasional continental cold air advections over the Iberian Peninsula when this high pressure is moved to the west. Finally, the Saharan low pressure influences in peninsula's climate related to frequency and severity of African warm air advections.

General atmospheric circulation is not the only element exerting an influence over the climate of the Iberian Peninsula. The orography plays a critical role in regional climate diversity, as the Iberian Peninsula is one of the most mountainous regions in Europe, being Spain only second to Switzerland in mean elevation above sea level, with an average altitude above $500 \mathrm{~m}$. Besides the direct effect of the orography, its particular configuration over the peninsula is a key factor in the dynamics of peninsular climate increasing the continentally effect. The mountain systems extend preferably along parallels closing hydrographic basins and modifying general circulation patterns (see Figure 3-2).

The Galaico massif, the Cantabrian range and the Pyrenees are important barriers to the penetration of maritime air masses were coming directly from the Atlantic sea but, in opposite, the hydrographic basins of Duero, Tagus, Guadiana and Guadalquivir rivers 
promote this penetration of oceanic air related with Atlantic storms. On the other hand, the Mediterranean coastal mountain systems do not allow the progress of the Mediterranean air to the interior of the Iberian Peninsula by focusing on their continental. These climatic implications are remarkable between Atlantic and Mediterranean influence regions.

The influence of the interior plateau and the great mountains transform a territory that should be warm-temperate or subtropical to a cold-temperate. In addition, areas where moisture is expected to be low become in humid regions or otherwise by the direct effect of the mountains.

The climate of the Iberian Peninsula is influenced as well by the warm waters that surround it. The air masses that penetrate in the peninsula are warmer and more humid due to maritime origin. Even so, the oceanic climatic characteristics are stronger modified by the orographic constraints previously described.

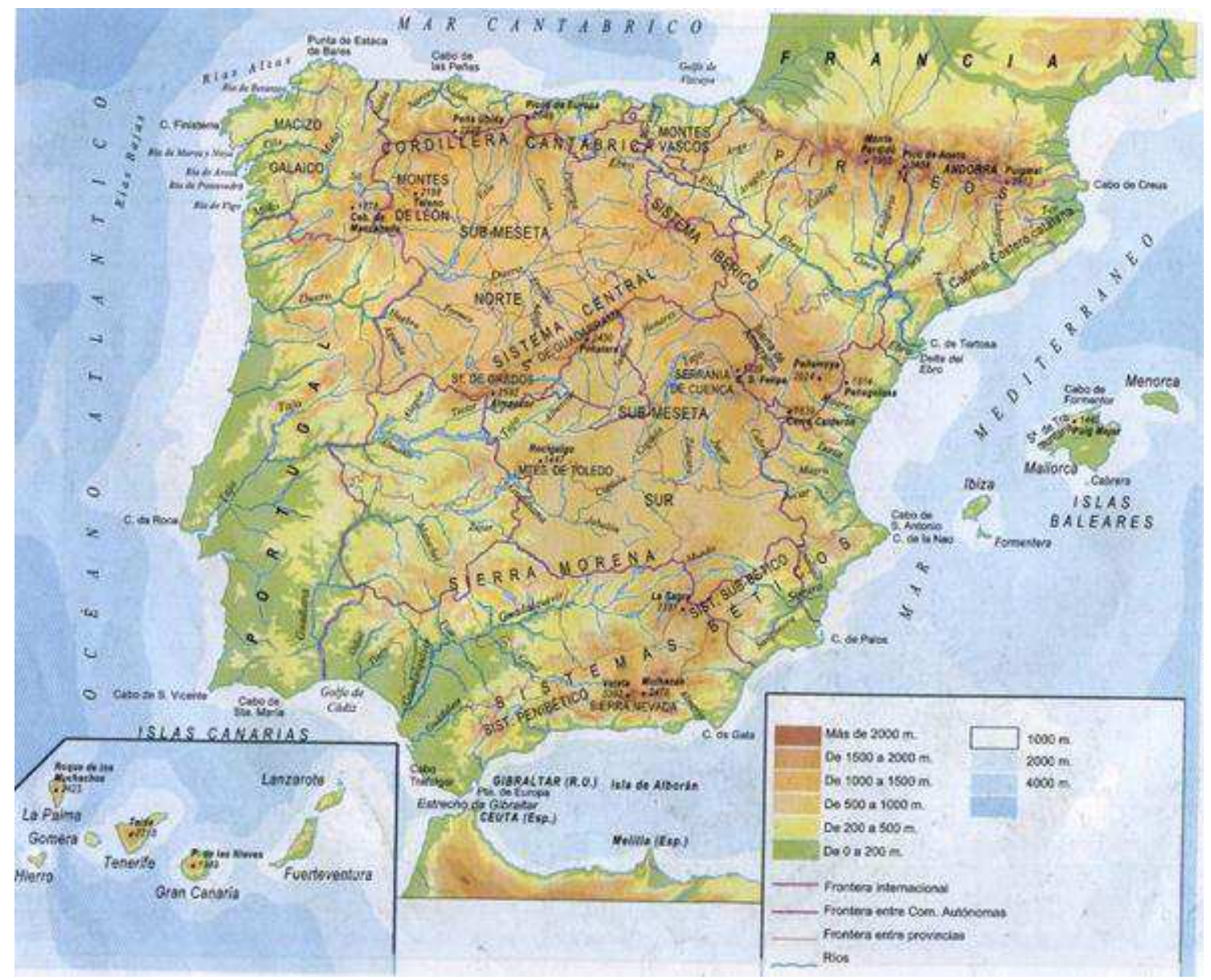

Figure 3-2: Physical map of the Iberian Peninsula. Source: Instituto Geográfico Nacional available at: http://www.ign.es/ign/main/index.do. Last visit: 15-05-2013. 
Furthermore, the Iberian Climate Atlas (2011) provides crucial climate information about annual average air temperature and precipitation for the Iberian Peninsula using the normal period 1971-2000.

The Iberian Peninsula has an irregular distribution of the annual average temperature determined by its complex topography. The latitudinal variation of temperatures is about $5^{\circ} \mathrm{C}$ between northern and southern coasts. Moreover, Mediterranean region is $2^{\circ} \mathrm{C}$ warmer than Atlantic region and the altitude plays an important role in annual variability of temperatures in mountain areas (Fig. 3-3).

Annual precipitation amounts decrease from northwest to southeast of the Iberian Peninsula being higher in the Atlantic (higher than $1000 \mathrm{~mm}$. per year) than in the Mediterranean region (about $500 \mathrm{~mm}$. per year) (Fig. 3-4). In addition, precipitation amounts increase with altitude and decrease in downwind of moist winds. The negative aspects of precipitation patterns in the Iberian Peninsula are its temporal variability and the frequency of heavy showers that appear in the interior and in the Mediterranean region (de Castro et al., 2006).

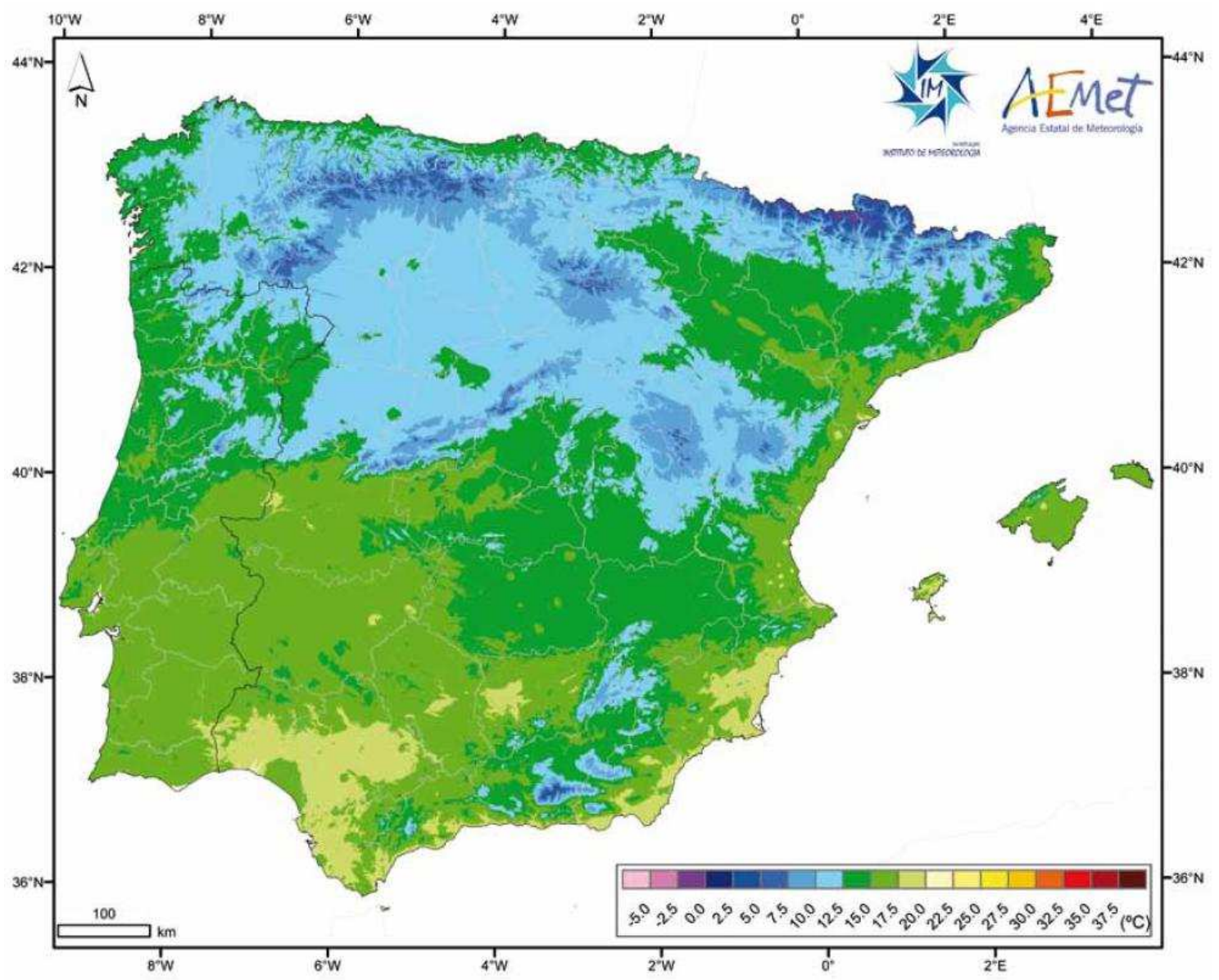

Figure 3-3: Annual averaged air temperature for the Iberian Peninsula (1971-2000); (Iberian Climate Atlas, 2011) 


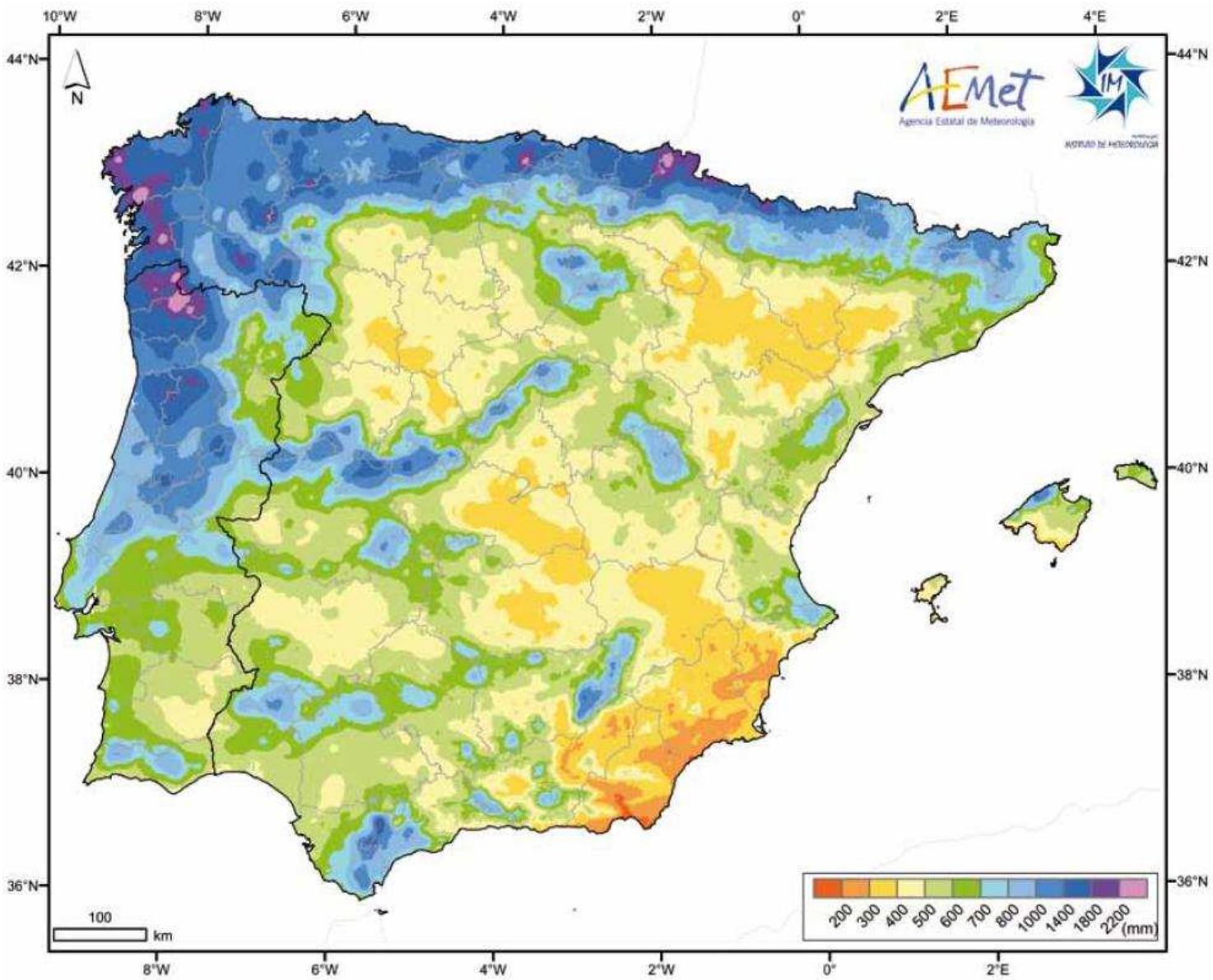

Figure 3-4: Annual averaged precipitation for the Iberian Peninsula (1971-2000); (Iberian Climate Atlas, 2011)

In order to identify the climate types within the Iberian Peninsula, the Köppen Climate Classification system was applied. This classification system, although created almost 100 years ago, continues- with some modifications - to be one of the most widely used for climate studies in the world. The Köppen Climate Classification system defines distinct types of climate using average monthly values for precipitation and air temperature. In order to identify different climates, air temperature and precipitation ranges were established, based mainly on their influence on the distribution of vegetation and human activity. 


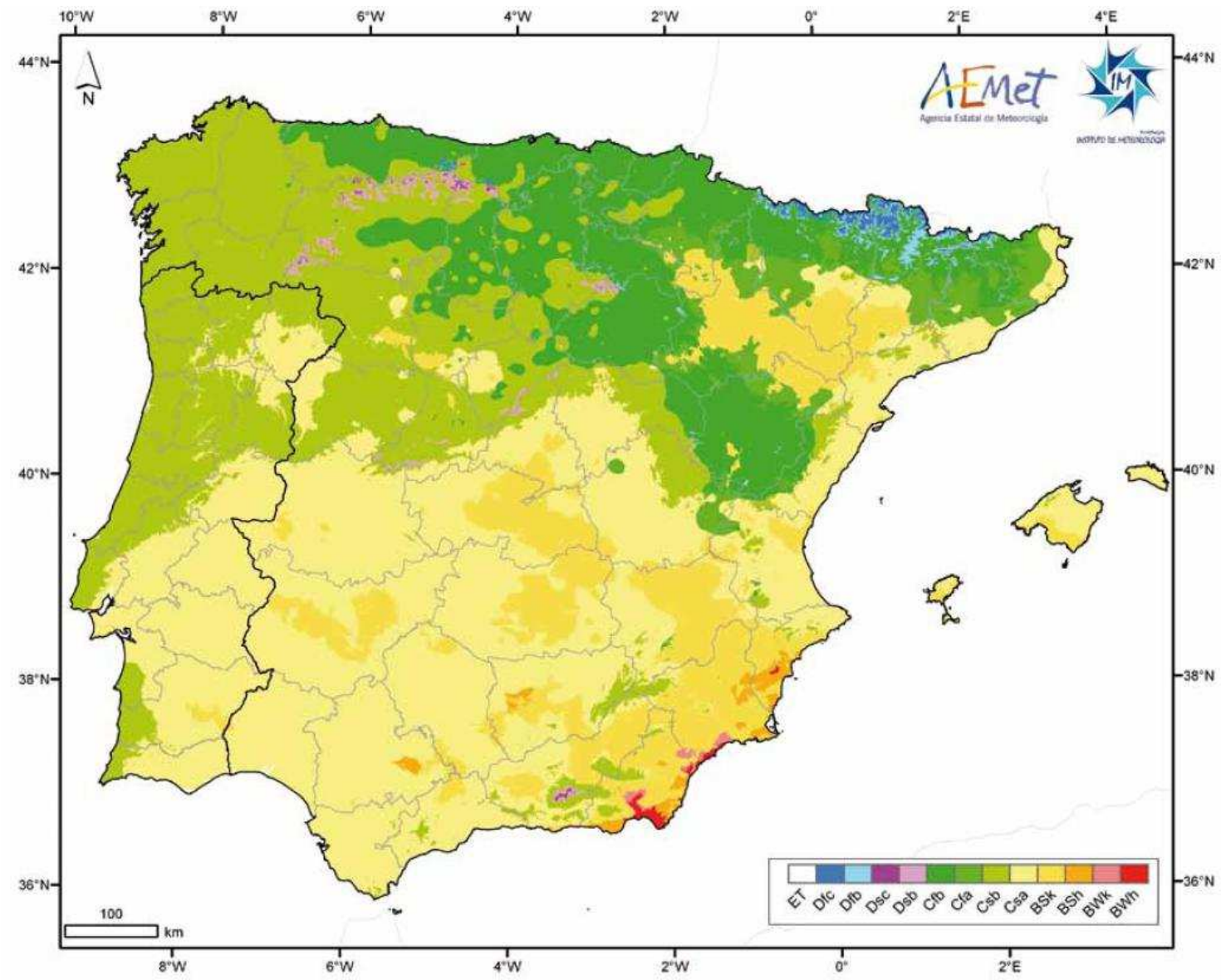

Figure 3-5: Köppen-Geiger Climate Classification for the Iberian Peninsula; (Iberian Climate Atlas, 2011)

The results of this classification show the following types of climate present in the Iberian Peninsula obtained from the Iberian Climate Atlas (2011) (Fig. 3-5).

\section{a) Dry climates- Type B}

- $\quad \boldsymbol{B} \boldsymbol{W h}$ (hot desert) and $\boldsymbol{B} \boldsymbol{W k}$ (cold desert).

There are small areas in the southeast of the Iberian Peninsula, in the Spanish provinces of Almeria, Murcia and Alicante, coinciding with minimum rainfall values for the Peninsula.

The annual variability of temperature and precipitation from Murcia (Southeastern Iberian Peninsula) is shown as an example of this type of

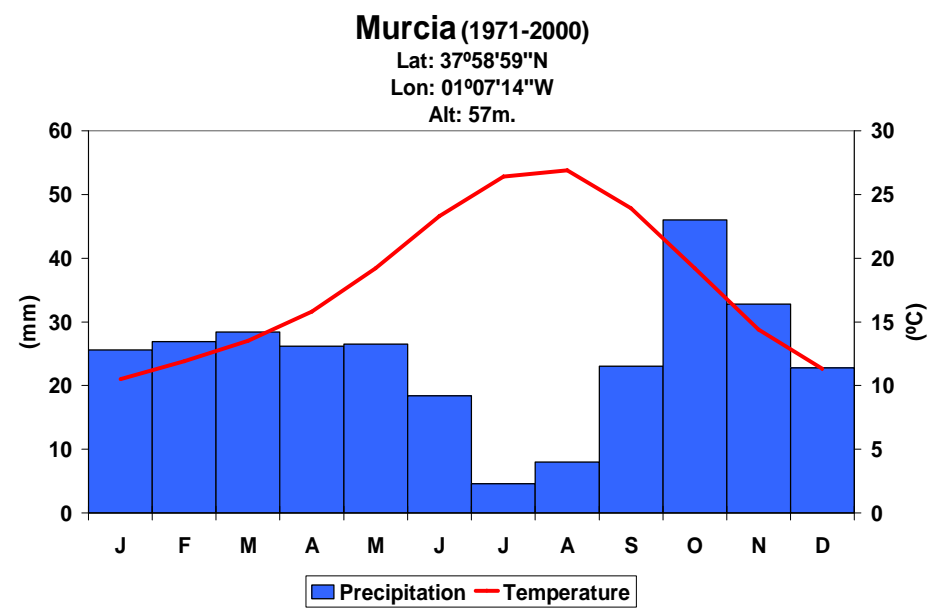


climate. Murcia belongs to Mediterranean climate and it is the driest area of the peninsula recording less than $300 \mathrm{~mm}$. per year. It is suffering water stress during six months per year coinciding the driest and hottest months in summer. The averaged temperature is around $18^{\circ} \mathrm{C}$, but it reaches more than $25^{\circ} \mathrm{C}$ in average in summer and no less than $10^{\circ} \mathrm{C}$ in winter. Most of the months the precipitation amount does not reach 30 $\mathrm{mm}$., except in October and November, when the amount is slightly greater.

\section{- $\quad \boldsymbol{B S h}$ (hot steppe) and BSk (cold steppe).}

In Spain, this is widespread in the southeast of the Peninsula and in the Ebro valley, and less in the southern of the Central plateau and Extremadura. In Portugal this covers only a small region in the district of Beja.

Zaragoza, located in the Ebro basin, is an example of this type of climate and belongs to Mediterranean climate as Murcia, but it has some differences. The precipitation amount reaches $318 \mathrm{~mm}$. per year and the averaged temperature is $15^{\circ} \mathrm{C}$. Spring and autumn are the rainy seasons and the hottest and driest months coincide in summer. The temperature in winter is less than $10^{\circ} \mathrm{C}$ in average, and almost reaches $25^{\circ} \mathrm{C}$ in summer months (continental climate), while the

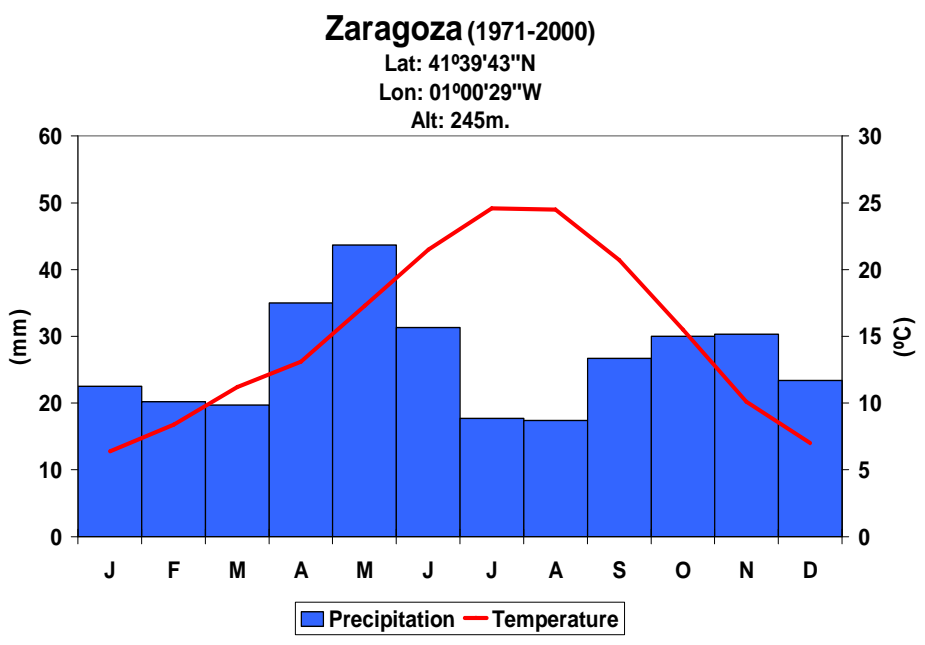
precipitation amount overcomes $30 \mathrm{~mm}$. in spring months and it is less than $20 \mathrm{~mm}$. in summer months, except in June.

\section{b) Temperate Climates - Type C}

- Csa (temperate with dry or hot summer).

This is the type of climate which covers most of the Iberian Peninsula, occupying approximately $40 \%$ of its surface. This covers the majority of the southern of the Central plateau, and the Mediterranean coastal region, with the exception of the arid zones in the southeast.

In this way, Barcelona (Mediterranean coast) and Sevilla (southwestern Iberian Peninsula) were selected to represent this type of climate. Barcelona belongs to 
Mediterranean climate while Sevilla has a clear influence from Atlantic Ocean. This is noticeable when both climate plots are compared. Autumn and spring are the rainy seasons in Barcelona reaching 70 or $80 \mathrm{~mm}$. in some months, while winter is drier and summer is the driest and hottest season producing water deficit, especially in July. Otherwise, winter and autumn are the rainy seasons in Sevilla reaching $80 \mathrm{~mm}$. in November or December, but the driest season is summer when the water deficit begins in May and finishes in October. Despite the inter-seasonal precipitation variability, both locations have not too many differences in yearly amounts $(534 \mathrm{~mm}$. in Sevilla and 649 $\mathrm{mm}$. in Barcelona). On the other hand, Barcelona is colder in average than Sevilla $\left(14.9^{\circ} \mathrm{C}\right.$ and $18.6^{\circ} \mathrm{C}$ respectively). Monthly temperature overcomes $27^{\circ} \mathrm{C}$ in summer in Sevilla, but does not reach this threshold in Barcelona $\left(23^{\circ} \mathrm{C}\right)$. Monthly temperature overcomes $10^{\circ} \mathrm{C}$ in winter months in Sevilla and this is not the case in Barcelona (around $8-9^{\circ} \mathrm{C}$ ).
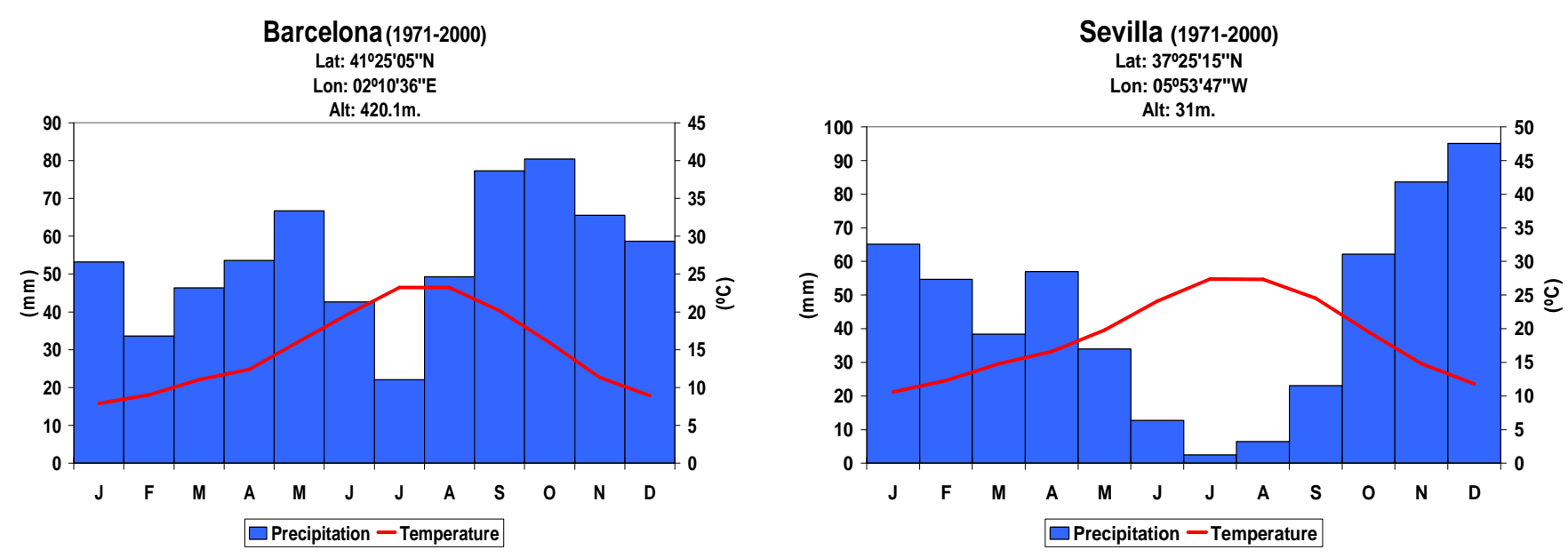

- $\quad \boldsymbol{C s} \boldsymbol{b}$ (temperate with dry or temperate summer).

This covers the majority of the northeast of the Peninsula, as well as almost all of the west coast of Mainland Portugal, and numerous mountainous regions within the Peninsula.

La Coruña represents this type of climate recording great amounts of precipitation along the year, except in summer, coinciding with the driest season. La Coruña has a clear Atlantic influence amounting around $1000 \mathrm{~mm}$. per year. Furthermore, this Atlantic influence implies a temperate climate along the year $\left(14.5^{\circ} \mathrm{C}\right.$ in average) with low temperature variability between summer (reaching $18-19^{\circ} \mathrm{C}$ ) and winter (reaching 10$\left.11^{\circ} \mathrm{C}\right)$. 
- $\quad C f a$ (temperate with a dry season and hot summer).

This is mainly seen in the northeast of the Peninsula, within an area of medium altitude which surrounds the Pyrenees and the Iberico System.

Soria, located in the Iberico System at medium altitude (around $1.100 \mathrm{~m}$.) represents this type of climate. The precipitation amount per year is about $500 \mathrm{~mm}$. reaching maximum amounts at the end of spring (April and May), in June, at the end of fall (October and November) and in December. Less precipitation is concentrated in March, July, August and September. Soria is an

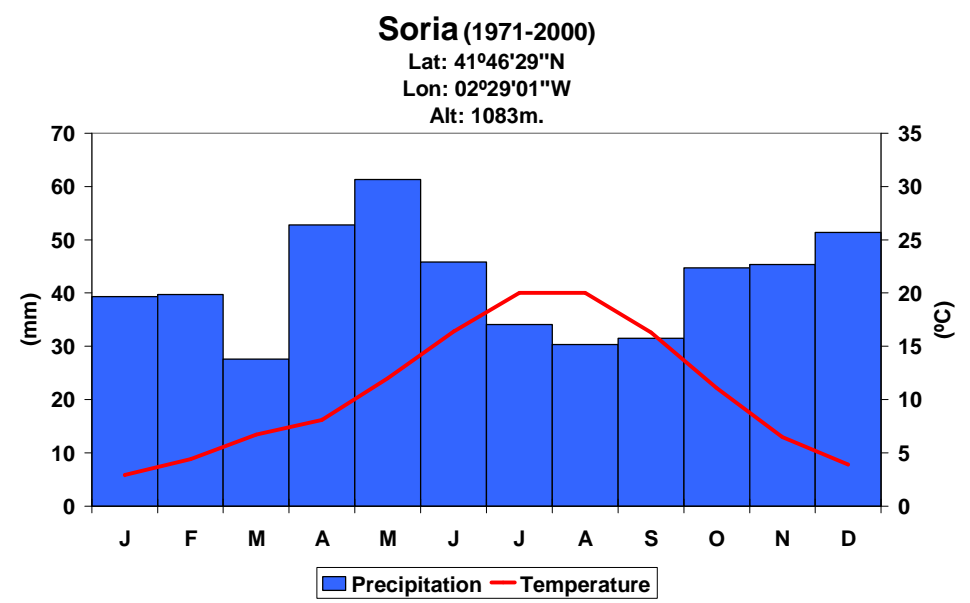
example of continental climate in a mid-altitude because it has a remarkable annual thermal oscillation. Averaged temperature reaches $20^{\circ} \mathrm{C}$ at the end of summer (July and August) coinciding with low precipitation and leading water deficit till October. Otherwise, monthly temperature is below $5^{\circ} \mathrm{C}$ during winter months.

- $\quad \boldsymbol{C f b}$ (temperate with a dry season and temperate summer).

These are located in the Cantabrian coast, in the Iberico System, as well as part of the northern of the Central plateau and a large part of the Pyrenees, with the exception of areas of high altitude.

San Sebastián, located in the Cantabrian coast, has been chosen as example of this type of climate. Precipitation and temperature variability are more regular than other locations due to oceanic

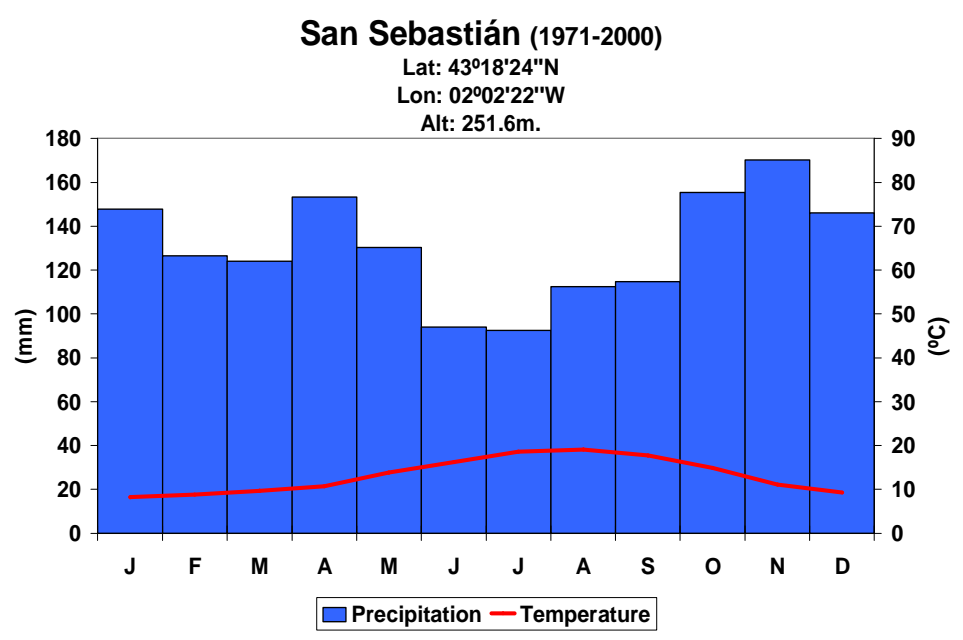
influence. Precipitation amount is remarkable along the year (around $1.500 \mathrm{~mm}$.) reaching maximum records in October, November and April. The driest season coincides in summer months but it is not enough dry to produce water deficit. Finally, 
averaged annual temperature is $13.2^{\circ} \mathrm{C}$ with non remarkable oscillations (around $8-9^{\circ} \mathrm{C}$ in winter months and $16-19^{\circ} \mathrm{C}$ in summer in average).

c) Cold Climates - Type D

- Dsb (cold with temperate and dry summer) and Dsc (cold with dry and fresh summer).

These are located in small areas of the mountainous regions at higher altitudes in the Cantabrian range, in the Iberico System, in the Central System and in the Nevada range.

- $\quad$ Dfb (cold without dry season and temperate summer) and Dfc (cold with a dry season and fresh summer).

Also seen in the highest altitude of the Pyrenees and in some small areas at high altitude in the Cantabrian range and in the Iberico System.

\section{d) Mountain Climates - Type H}

- $\quad \boldsymbol{E T}$ (Tundra).

This is seen only in small areas on the highest plains of the Central Pyrenees and in the highest elevations seen in the Cantabrian range. 


\section{Chapter 4}

\section{DATA AND METHODS}

This chapter describes the dataset employed and the methods applied in this study. The discussion includes the Monthly Iberian Temperature Dataset and Precipitation Series compilation, the techniques used for data treatment (including quality control, homogenization, missing data interpolation and regional series computation), the obtention of drought indices and trends, the application of principal components analysis and the drought parameter estimation. All of them are presented before discussing the obtained results in the next chapter.

\subsection{Monthly Iberian Temperature and Precipitation Series (MITPS) description}

The final dataset employed for this study is integrated by 22 long temperature and precipitation time series regularly spread over the Iberian Peninsula and extending from the mid-nineteenth century to the present (Fig. 4-1). Monthly means derived from the Spanish Daily Adjusted Temperature/Precipitation Series (SDATS, SDAPS Brunet et al. 2006, 2007). SDATS and SDAPS have been updated with data directly obtained through AEMET. Two of the original SDATS series (Pamplona and San Sebastian) have been removed from the dataset due to excessive missing values and two additional Portuguese time series have been obtained from the Climatology and Climate Change Research Group of the Instituto Dom Luiz (Lisbon University) to improve the coverage on the western side of the Iberian Peninsula (Fig. 4-1 and table 4-1). Monthly averages of daily maximum and minimum temperature, as well as monthly accumulated precipitation, are derived for those months with $95 \%$ or more days with available temperature/precipitation.

In order to compute the Palmer Drought Severity Index, Available Water Content of the soil for each location (AWC) is required and it was obtained from the Harmonized World Soil Database (HWSD) (Fig. 4-2) available at; 
http://www.iiasa.ac.at/Research/LUC/External-World-soil-database/HTML/ (Last visit: 20-03-2013).

Brunet et al., (2006) selected the SDATS and SDAPS networks (Table 3-1) based on temporal and spatial coverage, climatic representativeness and long-term continuity of data. These criteria are similar to those used in other regional studies (Briffa et al., 2009; Vicente-Serrano et al., 2006; Brunet et al., 2006) which prioritize quality and temporal continuity over number of stations, a criterion is widely accepted for climate analyses focused on the regional-scale.

From figure 4-1, a reasonable well-spaced distribution of the stations represents the main physiographic units of the Iberian Peninsula. In the coastal lowland sectors there are three stations over the Northern Atlantic coast (Porto, La Coruña and San Sebastián), five over the Mediterranean coast (Barcelona, Valencia, Alacant, Murcia and Málaga) and three over South-western Atlantic coast (Cadiz, Huelva and Lisboa). Moreover, there are four stations over the Northern Plateau (Burgos, Soria, Valladolid and Salamanca) and four over the Southern Plateau and influenced areas (Madrid, Albacete, Ciudad Real and Granada). Finally, the Ebro basin has three stations (Pamplona, Huesca and Zaragoza), one more in Guadalquivir basin (Sevilla) and another one in Guadiana basin (Badajoz).

This network essentially covers the entire Iberian Peninsula and the main climate types (Dry climates-Type B and Temperate climates-Type C), and sub-types (BWh, BWk, $\mathrm{BSh}, \mathrm{BSk}, \mathrm{Csa}, \mathrm{Csb}, \mathrm{Cfa}$ and $\mathrm{Cfb}$ ) are represented according to the Köppen-Geiger Climate Classification previously described.

In addition, more than two-thirds of the meteorological stations selected are located in non-urban areas from mid- $20^{\text {th }}$ century onwards, with most of them located at airfields and airports in order to avoid potentially biases related to urban heat island influences. 


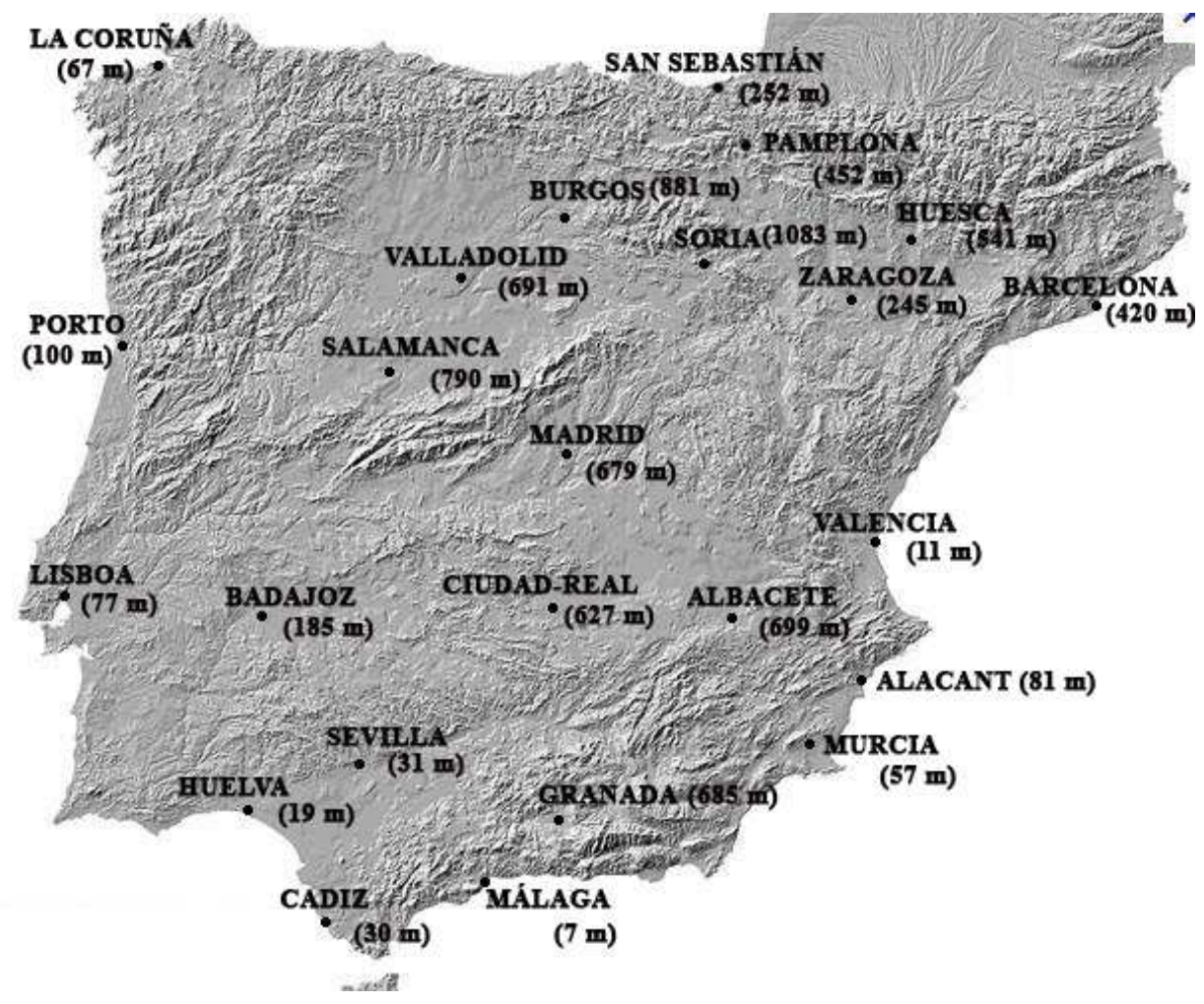

Figure 4-1: Map showing the locations of measurement stations and the elevations spread over the Iberian Peninsula.

As most long-term climatological time series are affected by a number of non-climatic factors that can make these data unrepresentative of the actual climate variation occurring over time, quality control and homogenization procedeures are necessary. These factors include changes in instruments, observing practices, station locations, the algorithms used to calculate means, and the station environment. Some changes cause sharp discontinuities while other changes, particularly changes in the environment around the station, can cause gradual biases in the data. All of these inhomogeneities can bias a time series and lead to misinterpretations of the studied climate. It is important, therefore, to remove the inhomogeneities or at least determine the possible error they may cause (Aguilar et al., 2003). In the original SDATS/SDAPS series, daily maximum and minimum temperatures and daily precipitation of mainland Spain were adjusted by the Centre for Climate Change (C3) for the period 1850-2005 (Brunet et al., 2006). The series were quality controlled and homogenized applying the Standard Normal Homogeneity Test (SNHT) (Alexandersson and Moberg, 1997) following the procedure described by Aguilar et al., (2002). Monthly factors were interpolated to the daily scale (Vincent et al., 2002). 


\begin{tabular}{|c|c|c|c|c|c|c|}
\hline Location & Latitude & Longitude & $\begin{array}{l}\text { Altitude } \\
\text { (m) }\end{array}$ & Temperature & Precipitation & $\begin{array}{l}\text { AWC } \\
(\mathrm{mm})\end{array}$ \\
\hline ALBACETE & $38^{\circ} 57^{\prime} 08^{\prime \prime} \mathrm{N}$ & $01^{\circ} 51^{\prime} 47^{\prime \prime} \mathrm{W}$ & 698.6 & 1893-2010 & $1894-2010$ & 50 \\
\hline ALICANTE & $38^{\circ} 22^{\prime} 00^{\prime \prime} \mathrm{N}$ & $00^{\circ} 29^{\prime} 40^{\prime \prime} \mathrm{W}$ & 81.5 & $1893-2010$ & $1894-2010$ & 50 \\
\hline BADAJOZ & $38^{\circ} 53^{\prime} 00^{\prime \prime} \mathrm{N}$ & $06^{\circ} 49^{\prime} 45^{\prime \prime} \mathrm{W}$ & 185 & $1864-2010$ & $1876-2010$ & 15 \\
\hline BARCELONA & $41^{\circ} 25^{\prime} 05^{\prime \prime} \mathrm{N}$ & $02^{\circ} 10^{\prime} 36^{\prime \prime} \mathrm{E}$ & 420.1 & $1885-2010$ & $1855-2010$ & 50 \\
\hline BURGOS & $42^{\circ} 21^{\prime} 22$ " N & $03^{\circ} 36^{\prime} 57^{\prime \prime} \mathrm{W}$ & 881 & $1870-2010$ & $1870-2010$ & 50 \\
\hline CADIZ & $36^{\circ} 27^{\prime} 55^{\prime \prime} \mathrm{N}$ & $06^{\circ} 12^{\prime} 37^{\prime \prime} \mathrm{W}$ & 30 & $1850-2010$ & $1853-2010$ & 150 \\
\hline CIUDAD REAL & $38^{\circ} 59^{\prime} 22 ” N$ & 035두 11" W & 627 & $1893-2010$ & $1894-2010$ & 150 \\
\hline GRANADA & $37^{\circ} 08^{\prime} 10^{\prime \prime} \mathrm{N}$ & 03 37’ 52” W & 685 & $1893-2010$ & $1894-2010$ & 50 \\
\hline HUELVA & $37^{\circ} 16^{\prime} 48^{\prime \prime} \mathrm{N}$ & $06^{\circ} 54^{\prime} 35^{\prime \prime} \mathrm{W}$ & 19 & $1903-2010$ & $1903-2010$ & 100 \\
\hline HUESCA & $42^{\circ} 05^{\prime} 00 " \mathrm{~N}$ & $00^{\circ}$ 19' 35" W & 541 & $1861-2010$ & $1861-2010$ & 100 \\
\hline LA CORUÑA & $43^{\circ} 22^{\prime} 02^{\prime \prime} \mathrm{N}$ & $08^{\circ} 25^{\prime} 10^{\prime \prime} \mathrm{W}$ & 67 & $1882-2010$ & $1882-2010$ & 15 \\
\hline MADRID & $40^{\circ} 24^{\prime} 40^{\prime \prime} \mathrm{N}$ & 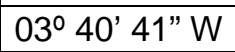 & 678.9 & $1853-2010$ & $1854-2010$ & 150 \\
\hline MALAGA & $36^{\circ} 39^{\prime} 57^{\prime \prime} \mathrm{N}$ & 04을' 57' W & 6.5 & $1893-2010$ & $1894-2010$ & 150 \\
\hline MURCIA & $37^{\circ} 58^{\prime} 59^{\prime \prime} \mathrm{N}$ & $01^{\circ} 07^{\prime} 14^{\prime \prime} \mathrm{W}$ & 57 & $1863-2010$ & $1863-2010$ & 50 \\
\hline PAMPLONA & $42^{\circ} 46^{\prime} 06^{\prime \prime} \mathrm{N}$ & $01^{\circ} 38^{\prime} 21^{\prime \prime} \mathrm{W}$ & 452 & $1880-2010$ & $1880-2010$ & 50 \\
\hline SALAMANCA & $40^{\circ} 56^{\prime} 50^{\prime \prime} \mathrm{N}$ & 05 29' 41" W & 789.8 & $1893-2010$ & $1894-2010$ & 150 \\
\hline SAN SEBASTIAN & $43^{\circ} 18^{\prime} 24$ ' N & $02^{\circ} 02^{\prime} 22^{\prime \prime} \mathrm{W}$ & 251.6 & $1893-2010$ & $1894-2010$ & 50 \\
\hline SEVILLA & $37^{\circ} 25^{\prime} 15^{\prime \prime} \mathrm{N}$ & $05^{\circ} 53^{\prime} 47^{\prime \prime} \mathrm{W}$ & 31 & $1893-2010$ & $1894-2010$ & 150 \\
\hline SORIA & 414' 29" N & $02^{\circ}$ 29'01" W & 1083 & $1893-2010$ & $1894-2010$ & 50 \\
\hline VALENCIA & $39^{\circ} 28^{\prime} 48^{\prime \prime} \mathrm{N}$ & $00^{\circ}$ 22' 52” W & 11.4 & $1864-2010$ & $1884-2010$ & 75 \\
\hline VALLADOLID & $41^{\circ} 38^{\prime} 40^{\prime \prime} \mathrm{N}$ & 04ㅇ4ㄴ 35” W & 691.4 & $1893-2010$ & $1894-2010$ & 50 \\
\hline ZARAGOZA & $41^{\circ} 39^{\prime} 43^{\prime \prime} \mathrm{N}$ & $01^{\circ} 00^{\prime} 29^{\prime \prime} \mathrm{W}$ & 245 & $1887-2010$ & $1891-2010$ & 150 \\
\hline PORTO & $41^{\circ} 08^{\prime} 00^{\prime \prime} \mathrm{N}$ & $08^{\circ} 36^{\prime} 00^{\prime \prime} \mathrm{W}$ & 100 & $1901-2010$ & $1906-2010$ & 150 \\
\hline LISBOA & 38운 $43^{\prime} 00^{\prime \prime} \mathrm{N}$ & 090ㅜ 09' 00" W & 77 & $1855-2010$ & $1863-2010$ & 15 \\
\hline
\end{tabular}

Table 4-1: Iberian stations network. Name of station, current geographical location (latitude, longitude and altitude), length of record (temperature and precipitation) and AWC of the soil is also shown.

The original raw daily maximum temperature (Tmax), daily minimum temperature (Tmin) and daily precipitation (Prec) were subjected to various quality control (QC) tests to identify and flag major errors of digitization as well as to ensure internal consistency, temporal coherence, and spatial coherence of the data. Checks of gross errors (aberrant values, problems with decimal points, calendar dates, negative precipitation,...) Tmax $<$ Tmin values, consecutive values repeating at least four times, temperature (precipitation) values greater than $\pm 4( \pm 6)$ standard deviations of the threshold for both the candidate record and its group of reference stations, and values exceeding the expected amount of change were exhaustively assessed in the raw data.

As mentioned above, The Standard Normal Homogeneity Test (SNHT) was used to homogenize monthly temperature and precipitation. This method is based on the application of iterative process using a candidate time-series together with a group of reference time-series. The SNHT does not presupose the homogeneity of any timeseries, so all of them are used as candidate and reference time-series during the process. Taking into account that the probability that all time-series are affected by a break point 
at the same time is very poor, the comparison between any candidate station and the reference time-series should detect abrupt shifts and artificial trends in the time-series. More detailed information on the applied QC and homogenisation procedure are shown and discussed in Brunet et al., (2006). For this study, SDATS and SDAPS were updated for the period 2006-2010 directly from the AEMET servers available at www.aemet.es (Last visit: 15-03-2010) to cover the current period.

Otherwise, raw daily data of temperature and precipitation from Porto and Lisboa are pending to be quality controlled and to test the homogeneity, which will be carry out in section 4.2.

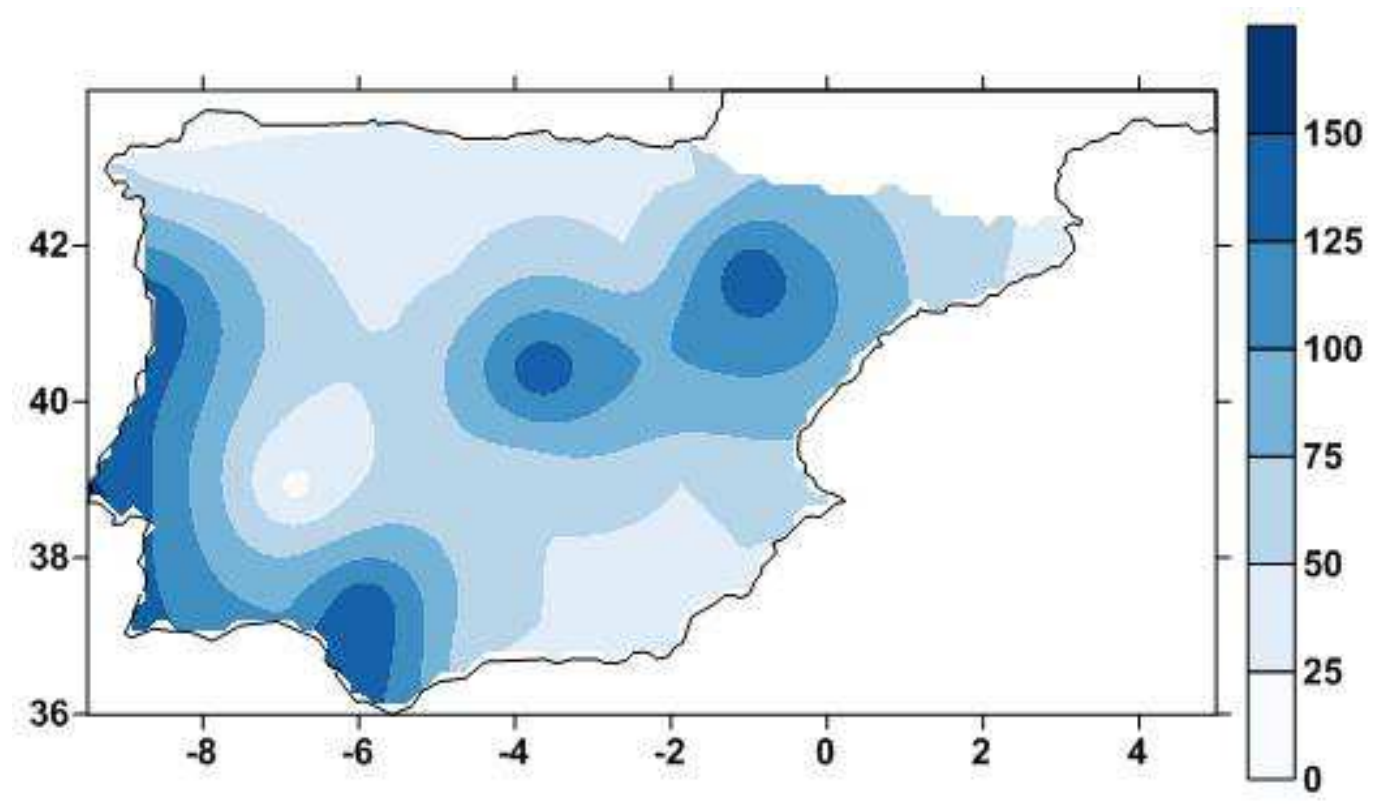

Figure 4-2: Available Water Content of the soil (AWC in $\mathrm{mm} / \mathrm{m}^{3}$.) over the Iberian Peninsula obtained from the Harmonized World Soil Database (HWSD).

The most dominant soil type was selected for each location obtaining the amount of the AWC of the soil, which is divided into nine classes; from wetlands (which are given as AWC of the soil of $1000 \mathrm{~mm} / \mathrm{m}^{3}$ ) to soils with AWC of less than $20 \mathrm{~mm} / \mathrm{m}^{3}$. 


\subsubsection{Additional data quality control and homogenisation}

As described in the previous section, two additional series plus a 5-year update to the 22 SDATS/SDAPS series are used. Therefore this new information requires a new quality control and a homogenization effort to ensure that the new data is free from nonclimatic biases. The procedures employed are described in this section.

The quality control (QC) procedure is applied in order to identify errors derived from data collection, manipulation, digitalization or transmission. The $\mathrm{QC}$ must be rigorous especially in daily data and it is the previous step before applying the homogenization tests or any climate analysis. Any individual or group of records that exceed an established threshold (standard deviation) relative to the normal distribution of the timeseries will be flagged as outliers or potential errors. After that, these outliers will be revised thoroughly to decide whether they can be validated or removed using -99.9 as a code for missing values. An efficient QC can remove data errors from the time-series that would surely affect negatively the final results. This is the key to avoid some wrong climate interpretations induced by data errors in a climate change context (Aguilar et al., 2003; Brunet et al., 2005).

The QC of daily temperature and precipitation is carried out in this study using the ExtraQC Quality Control software produced by the Centre for Climate Change (C3) and available at www.c3.urv.cat/data.html (Last visit: 25-03-2013). This software is a set of Rcoded functions for quality control integrated into the widely used ETCCDI's software R-Climdex to produce an unofficial version called R-Climdex-Extraqc. Extraqc routines include the following tests to flag various kinds of potential errors.

- Duplicate dates control.

- Rounding problems evaluation.

- Out of range values, based on fixed threshold values.

- Outliers, based on Interquartile Range exceedance.

- Interdiurnal differences based on fixed threshold values.

- Coherence between maximum and minimum temperatures.

- Consecutive equal values control.

The detection of outliers is carried out using a range with p25 -3 interquartilic ranges (lower bound) and p75 +3 interquartilic ranges (upper bound) for temperature. The same ranges, but using 5 interquartilic ranges, are used for precipitation. The advantage 
of this approach is that the detection of this percentile based oultiers is not affected by the presence of larger outliers, so one run of the process is enough.

The ExtraQC quality control is only applied to daily temperature (maximum and minimum) and daily precipitation from Porto (1901-2010) and Lisboa (1856-2010) time-series, as SDATS and SDAPS (1850-2005) were intensively quality controlled and adjusted on source (Brunet et al., 2006 and 2007) according to section 4. Nevertheless, in this study SDATS and SDAPS were updated from 2006 to 2010 directly from the AEMET servers. Therefore, the last segment (2006-2010) of SDATS and SDAPS must also be quality controlled in a daily scale. In this way, the raw data (maximum and minimum temperature and precipitation) from SDATS and SDAPS are recovered for the whole period from each time-series and the last segment of data is appended since 2003 to ensure data continuity and consistency over the entire period (e.g. Cadiz 1850$2005+2006-2010)$. Once all the raw data of daily maximum and minimum temperature, and precipitation are prepared for the whole period, the QC is applied.

Table 4-2 shows the QC results for Porto, Lisboa and for the last segment of SDATS/SDAPS. Despite the longevity of Porto and Lisboa time-series, a low percentage of flagged values are identified (the $0,08 \%$ and the $0,11 \%$ respectively relative to the total amount of data). The $0,06 \%$ of the total amount of data are validated in both time-series while the $0,02 \%$ and the $0,04 \%$ cannot be recovered in Porto and Lisboa respectively. Otherwise, the $0,21 \%$ of the total amount of data are flagged in the case of the last segment of SDATS/SDAPS (2006-2010) being validated the 0,13\% and missed the rest of $0,08 \%$ of the data. These results confirm that Porto and Lisboa timeseries have a high quality of the records thank to the low percentages of flagged data. The data have been validated searching the original values from the raw time-series in order to replace them while missing data were replaced by -99.9 .

\begin{tabular}{|c|c|c|c|c|c|c|}
\cline { 2 - 7 } \multicolumn{1}{c|}{} & \multicolumn{2}{c|}{ Porto } & \multicolumn{2}{c|}{ Lisboa } & \multicolumn{2}{c|}{ SDATS/SDAPS } \\
\hline Period & \multicolumn{2}{c|}{$1901-2010$} & \multicolumn{2}{c|}{$1856-2010$} & \multicolumn{2}{c|}{$2006-2010$} \\
\hline Data amount & \multicolumn{2}{|c|}{118642} & \multicolumn{2}{c|}{167007} & \multicolumn{2}{c|}{131400} \\
\hline Flagged values & 99 & $0,08 \%$ & 183 & $0,11 \%$ & 271 & $0,21 \%$ \\
\hline $\begin{array}{c}\text { Validated } \\
\text { values }\end{array}$ & 77 & $0,06 \%$ & 108 & $0,06 \%$ & 169 & $0,13 \%$ \\
\hline Set to missing & 22 & $0,02 \%$ & 75 & $0,04 \%$ & 102 & $0,08 \%$ \\
\hline
\end{tabular}

Table 4-2: Summary of QC results (in absolute values and also in percentages) from raw daily data for Porto, Lisboa and for the updated period of SDATS/SDAPS. The controlled time-period and the total data amount tested are also shown. 
Figure 4-3 and 4-4 show the annual climate cicle for Porto and Lisboa respectively using monthly boxplots for maximum temperature (TX), minimum temperature (TN), derived diurnal temperature range (DTR) and precipitacion (PREC). All tested variables represented very well the climate regime in Porto and Lisboa because most of the values fall inside the established thresholds but there are some supicious values or outliers (in round circles), especially in summer precipitation for Porto, and in summer/autumn precipitation and summer TN for Lisboa.

The evolution of the quality controlled variables for Porto and Lisboa across time can be seen in the inspection of figures 4-5 and 4-6 respectively. The annual plots show the normal evolution of the Porto and Lisboa time-series for the whole period in spite of some discontinuity can be deduced, at least in TN and also reflected in DTR, at the beginning of the Porto time-series. Moreover, another discontinuity can be identified in TX and also reflected in DTR for Lisboa around 1940s. These possibilities will be checked using the homogeneity test once the QC is tested. Nevertheless, these plots confirm the good results found in the QC and described in table 4-2.

Finally, the frequency of rounding values after de decimal point is shown for Porto (Fig. 4-7) and Lisboa (Fig. 4-8) using the same variables tested before. Both observatories show higher frequency of 0.1 and 0.2 in daily precipitation probably related to negligible precipitation or trace precipitation normally identified as 0.1 or 0.2 . Otherwise, the rounding values are more evident in the case of TX and TN in both time-series finding the higher rates of frequency in 0.0 and 0.5 in detriment of 0.3 and 0.9 . This is often related to the measurement practices given by the observer. 
NON ZERO PREC
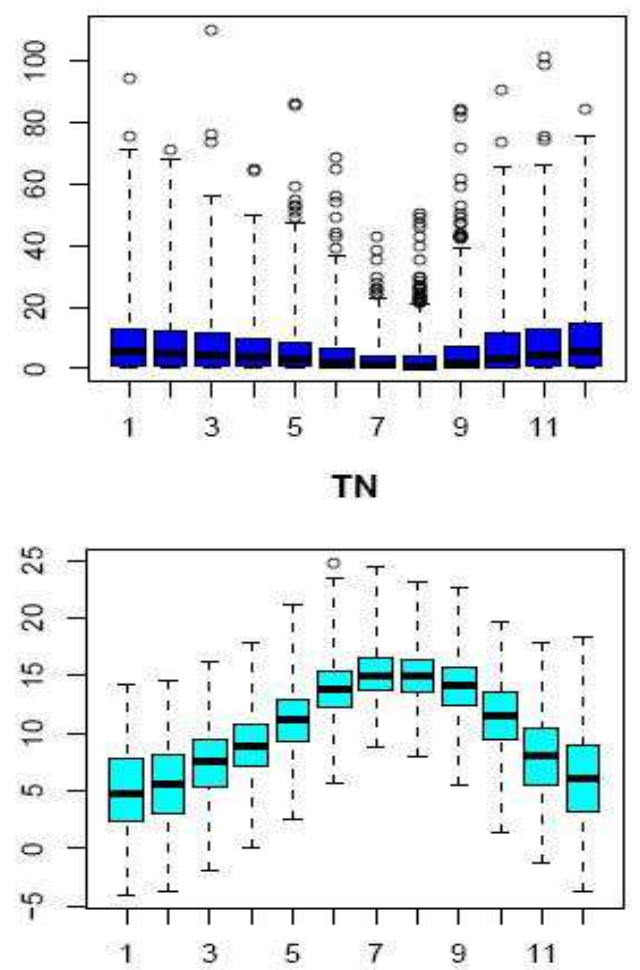

TX
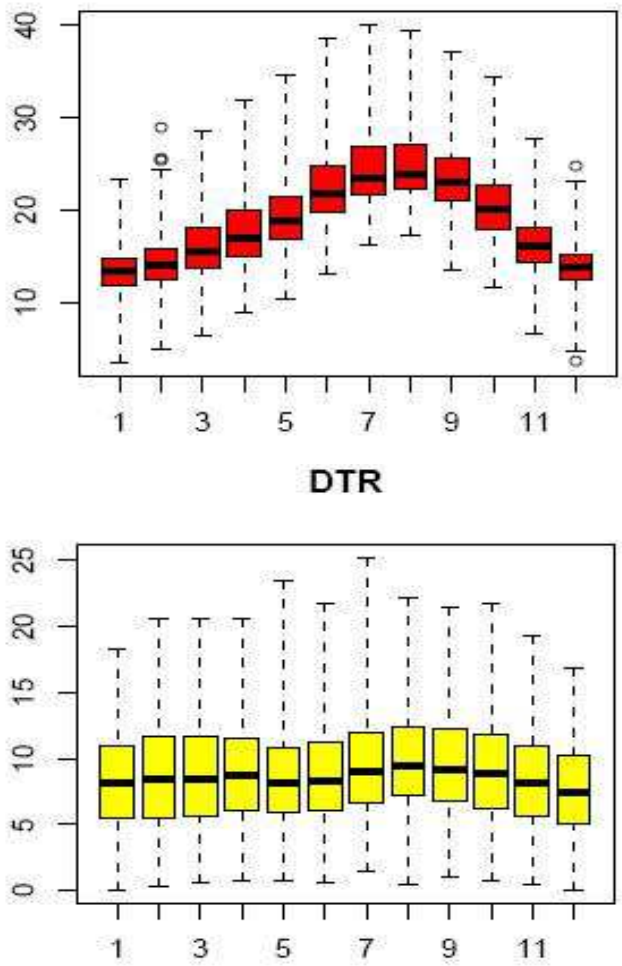

Figure 4-3: Monthly boxplots of temperature (for maximum (TX), minimum (TN), diurnal temperature range (DTR)) and precipitation (NON ZERO PREC) data for Porto (1901-2010).

NON ZERO PREC
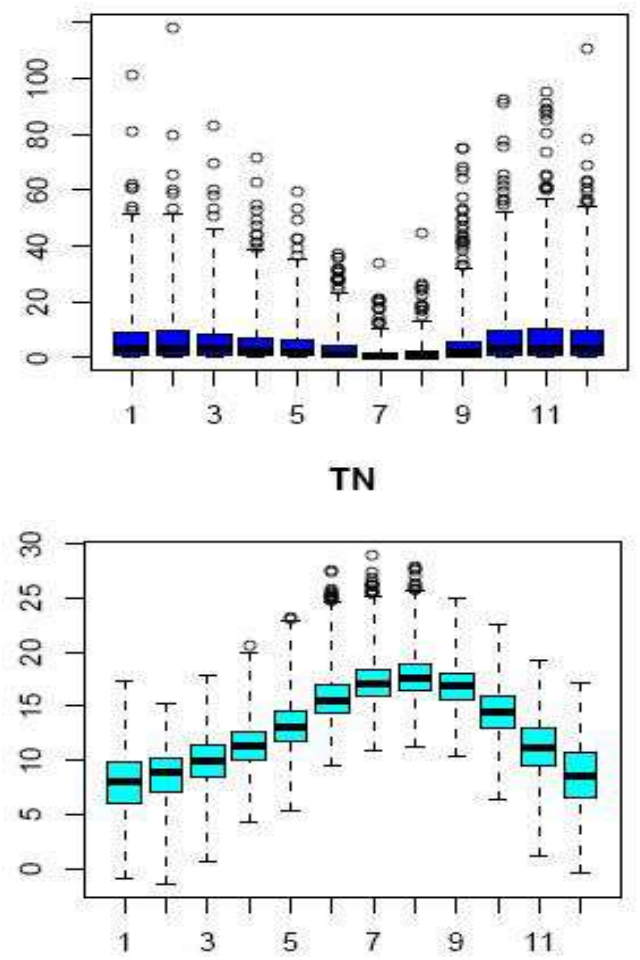

TX
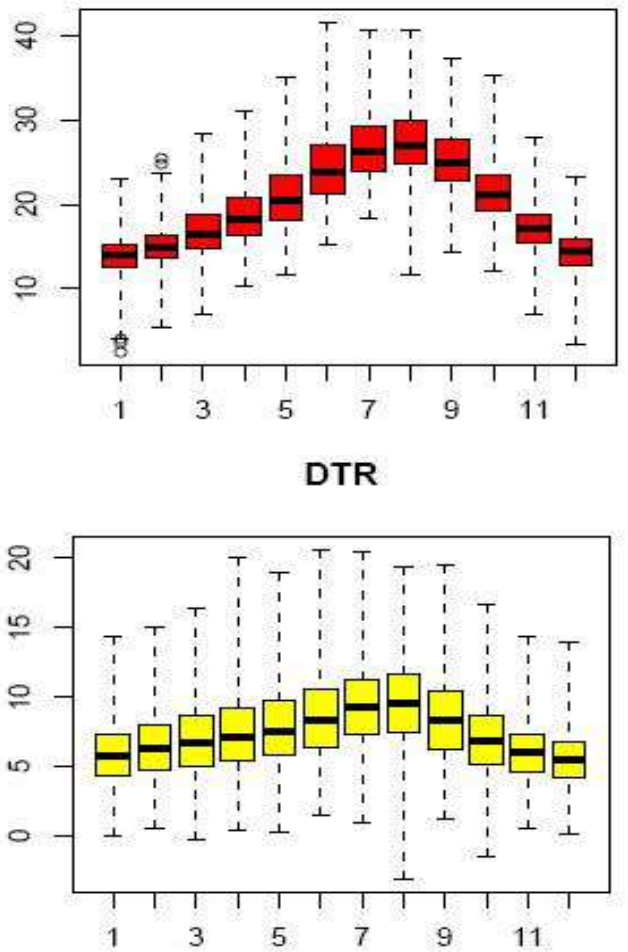

Figure 4-4: Monthly boxplots of temperature (for maximum (TX), minimum (TN), diurnal temperature range (DTR)) and precipitation (NON ZERO PREC) data for Lisboa (1856-2010). 
NON ZERO PREC

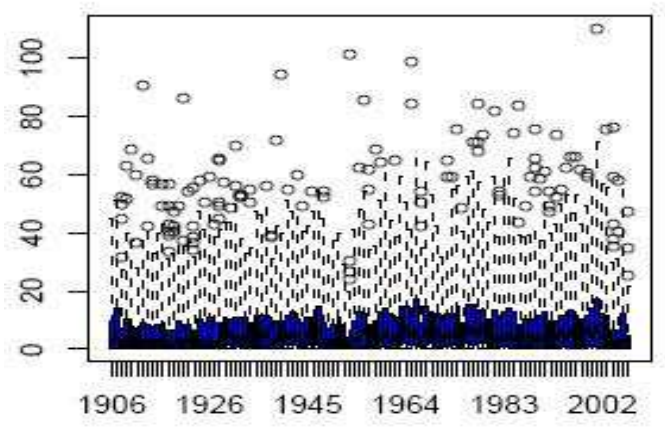

TN

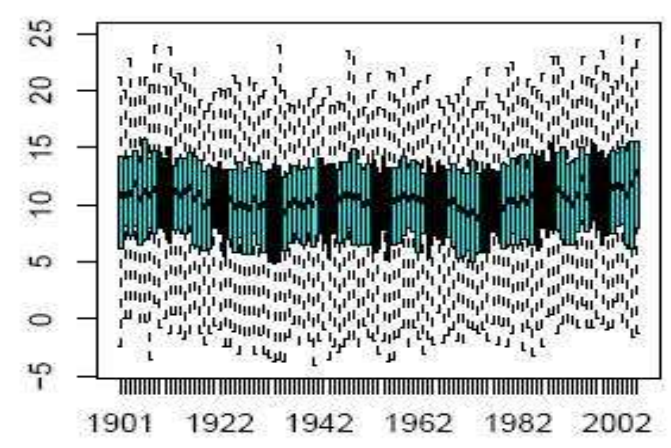

TX
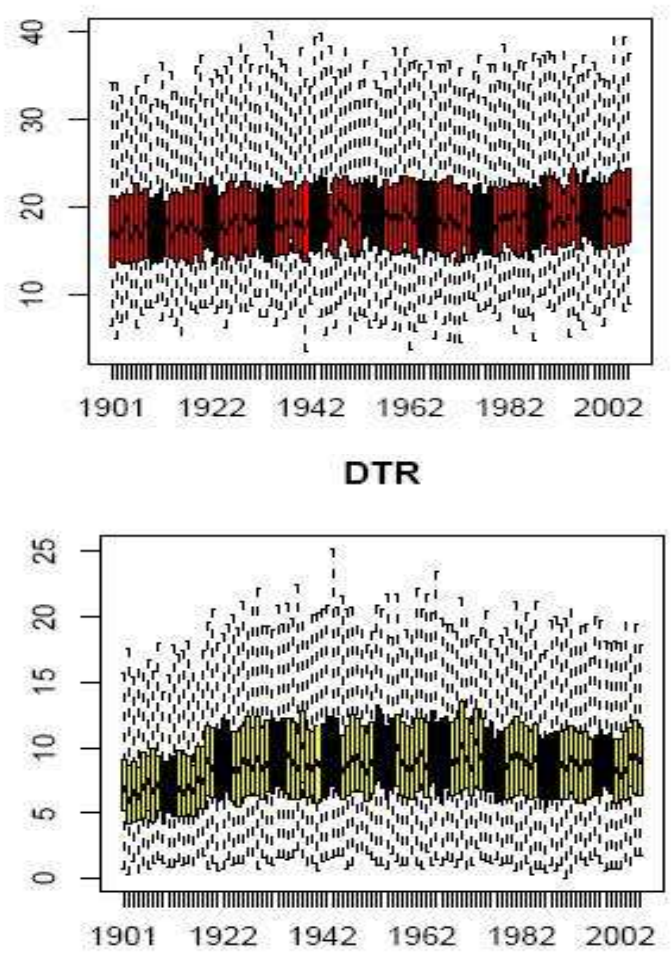

Figure 4-5: Annual boxplots of temperature (for maximum (TX), minimum (TN), diurnal temperature range (DTR)) and precipitation (NON ZERO PREC) data for Porto (1901-2010).

NON ZERO PREC

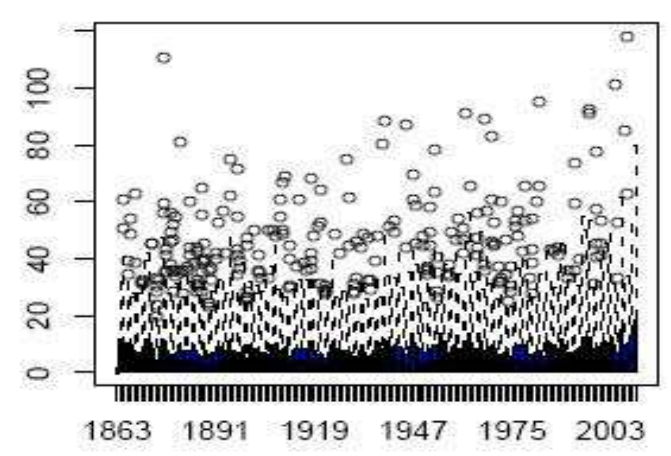

TN

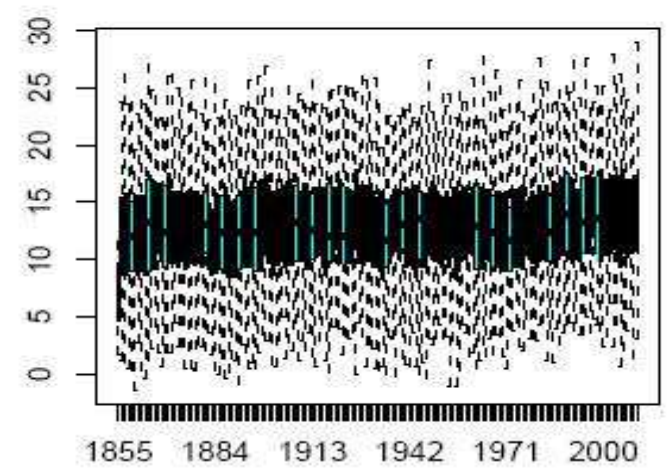

TX
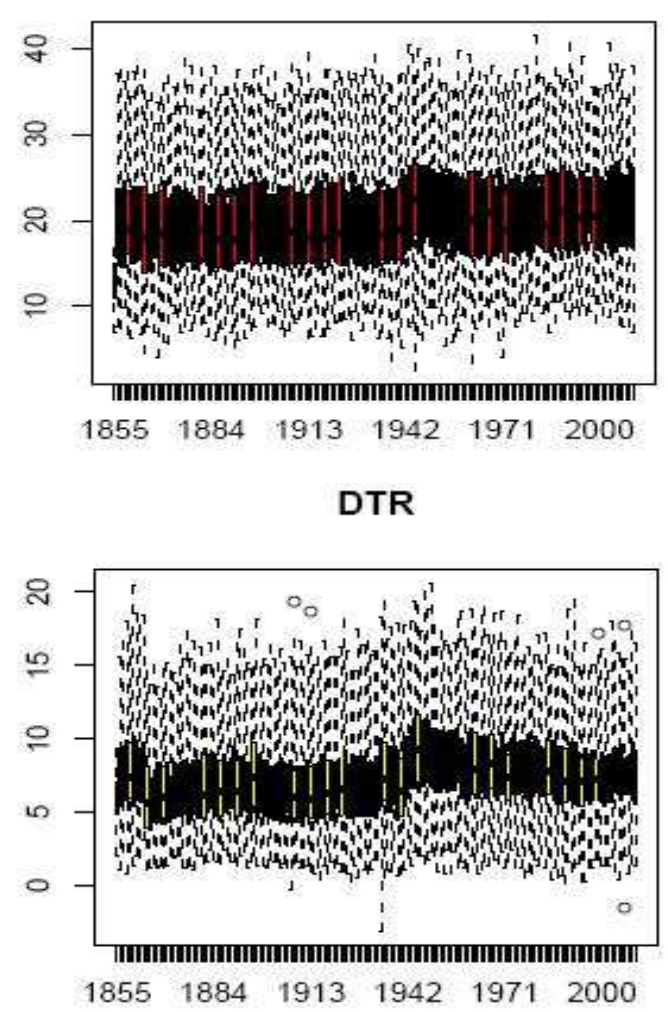

Figure 4-6: Annual boxplots of temperature (for maximum (TX), minimum (TN), diurnal temperature range (DTR)) and precipitation (NON ZERO PREC) data for Lisboa (1856-2010). 

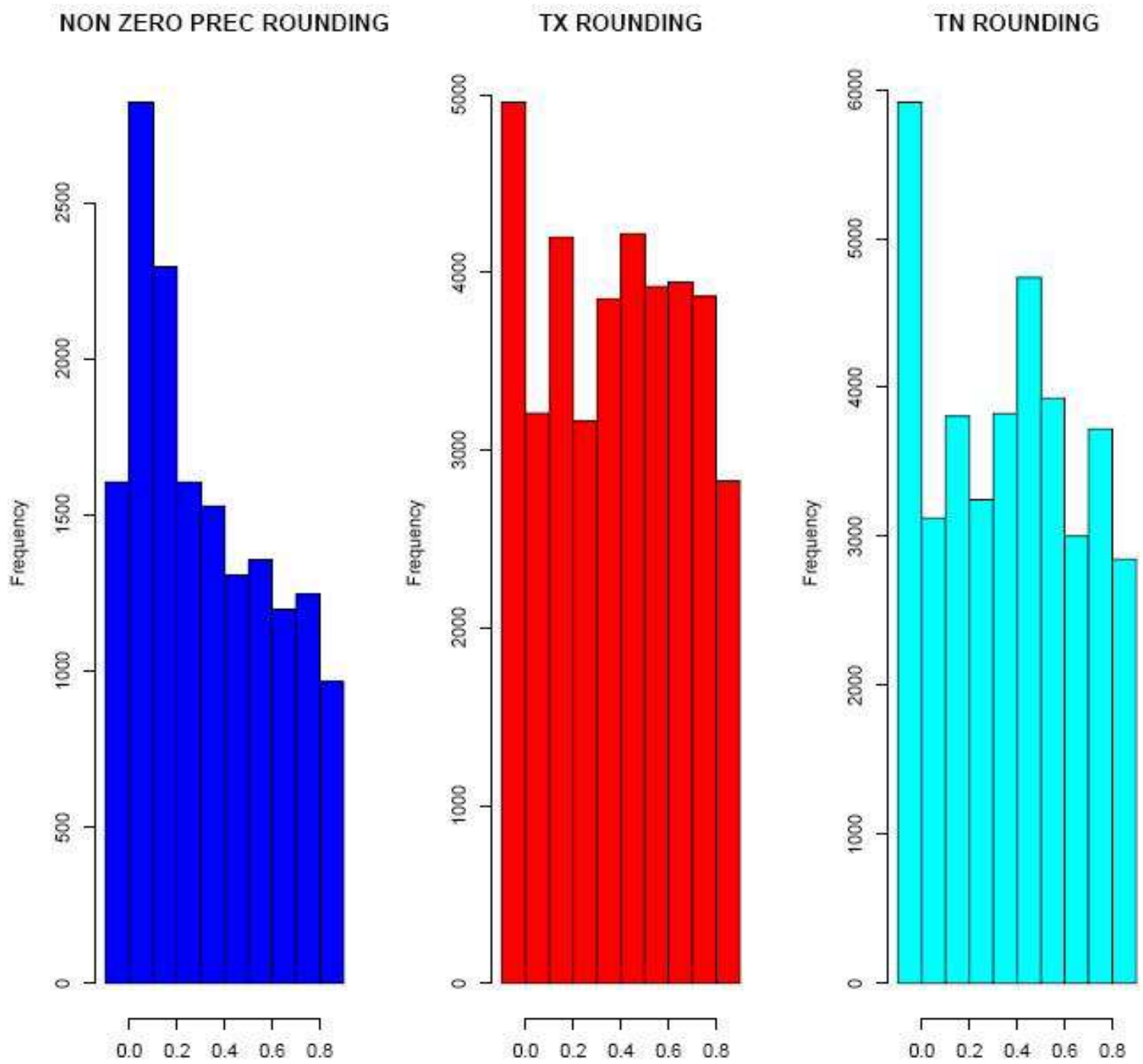

Figure 4-7: Frequency of rounding values after the decimal point in temperature (for maximum (TX) and minimum (TN) and precipitation (NON ZERO PREC) data for Porto (1901-2010). 

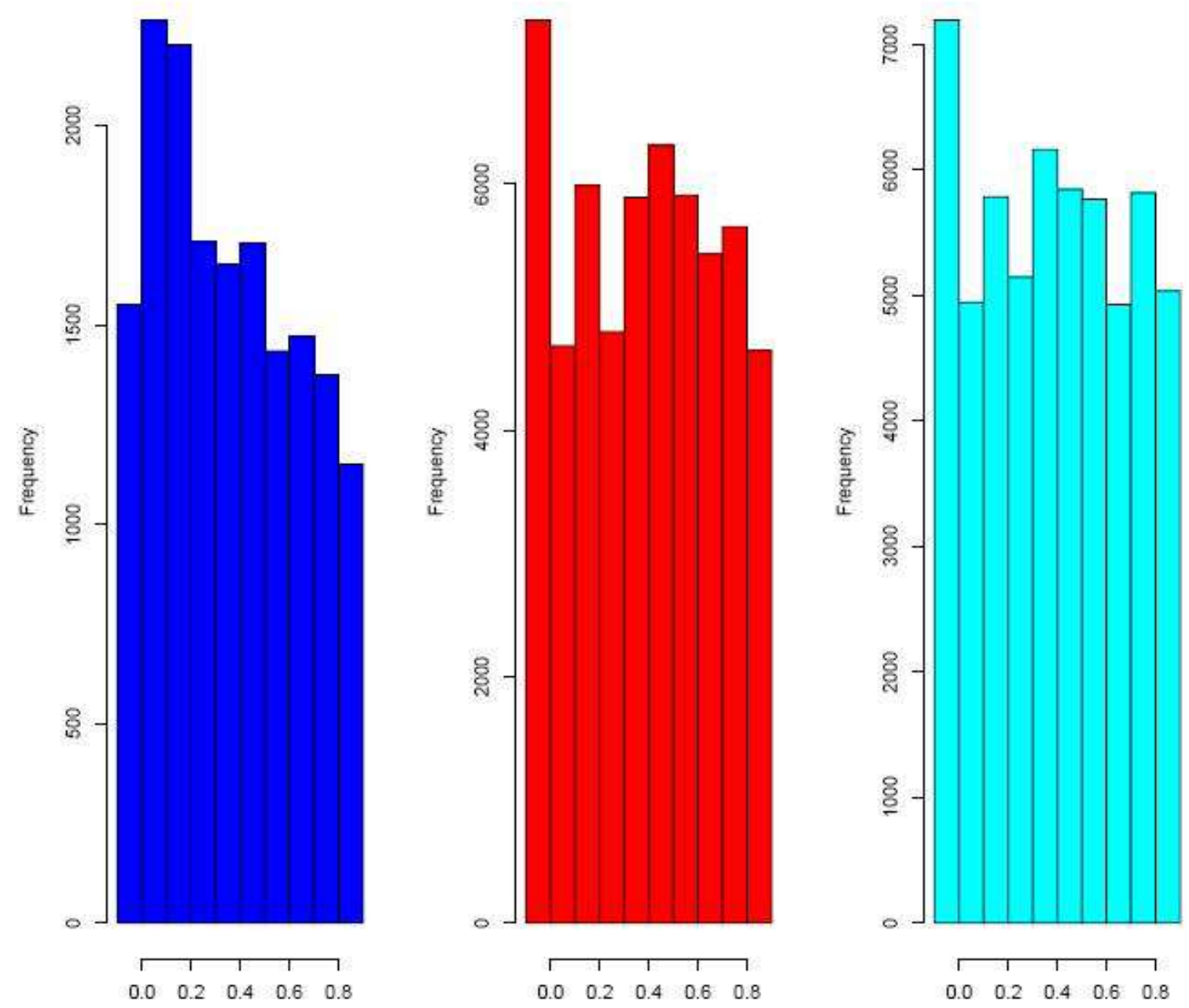

Figure 4-8: Frequency of rounding values after the decimal point in temperature (for maximum (TX) and minimum (TN) and precipitation (NON ZERO PREC) data for Lisboa (1856-2010).

As mentioned before, most of the long time-series are affected by non-climatic factors, mainly relocations of the measurement stations, changes of the instruments, different measurement techniques, among others. These factors can introduce discontinuities in the time-series in terms of a shift (e.g. a relocation of the observatory) or a gradual trend leading an artificial trend on data (e.g. the urban heat island promoted by a gradual development of the cities). Thus, it is crucial to apply the appropriate correction method to get temporal and spatial comparability of any time-series against itself or towards other time-series before developing a climate analysis (Aguilar et al., 2003).

The Standard Normal Homogeneity Test (SNHT; Alexandersson and Moberg, 1997) is selected as the correction method in this study. As described in section 4, SDATS and SDAPS were already homogenized previously (in Brunet et al., 2006 and 2007) for the 
period 1850-2005 using the SNHT correction method. Thus, it makes sense to homogenize Porto and Lisboa time-series using the same approach in spite of other newer homogenisation methods currently available which outperform SNHT (Venema et al., 2013). The SNHT is based on the application of iterative process using a candidate time-series together with a group of reference time-series. The SNHT does not presupose the homogeneity of any time-series, so all of them are used as candidate and reference time-series during the process. Taking into account that the probability that all time-series are affected by a break point at the same time is very poor, the comparison between any candidate station and the reference time-series should detect abrupt shifts and artificial trends in the time-series. More detailed information about the homogenisation procedure was described and widely discussed in Brunet et al., (2006). The RSNHT software, developed by the Centre for Climate Change (C3) and available at: www.c3.urv.cat/data.html (Last visit: 25-03-2013), is a code created using the R environment to compute the SNHT correction method at the monthly scale. In this way, the two Portuguese series (Lisboa and Porto) are tested using the RSNHT code to find breaks and correct them for the whole period in a monthly scale. Therefore, monthly precipitation and monthly mean temperature for Porto and Lisboa are required for this purpose. The last segment of SDATS/SDAPS (2006-2010) is not adjusted after a subjective graphical evaluation which did not find evidence of large inhomogeneities. As mentioned above, the SNHT requires references series to test and correct the candidate series. Therefore, raw data of monthly precipitation and mean temperature from La Coruña, Porto, Lisboa, Salamanca, Badajoz, Cadiz, Valladolid and Madrid are selected to be tested under the criterion of geographical proximity and similar climate characteristics. The six best correlated time-series (Pearson $r>0.7$ ) are chosen as a reference series for Porto (La Coruña, Valladolid, Salamanca, Madrid, Badajoz and Lisboa) and for Lisboa (La Coruña, Porto, Salamanca, Badajoz, Cadiz and Madrid).

After the accurate inspection of the outputs provided by the RSNHT, the breaks found in monthly precipitation for Porto and Lisboa were not adjusted to be not too much relevant for the time-series. In fact, Figure 4-9 shows the annual evolution of precipitation for Porto and Lisboa demonstrating similar inter-annual variability between both time-series. In this case, to keep the original monthly precipitation for Porto and Lisboa is highly preferred. 


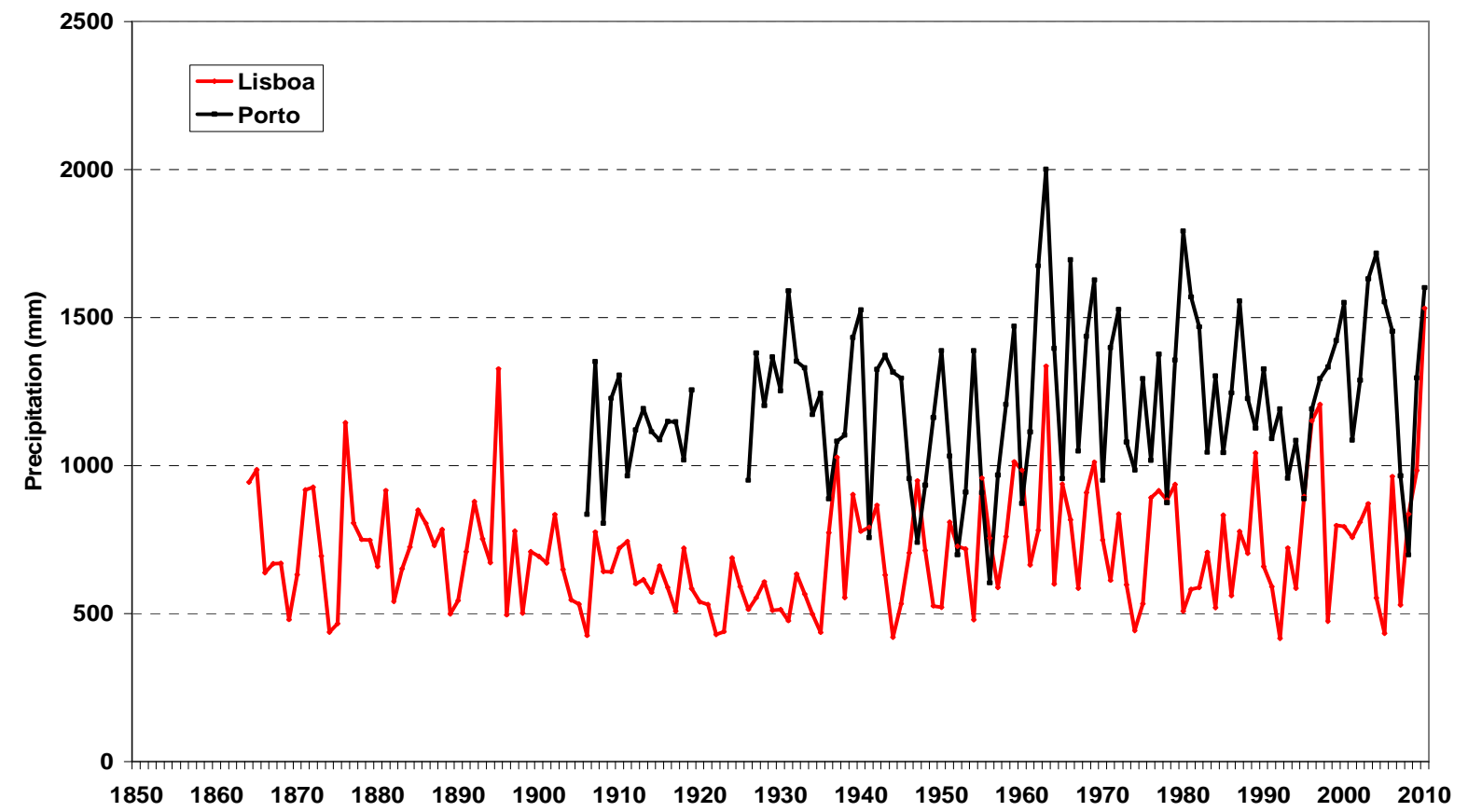

Figure 4-9: Annual precipitation evolution of raw data for Porto (1901-2010) and Lisboa (1864-2010).

On the contrary, monthly mean temperature is adjusted to correct 4 breaks in Lisboa (detected in 1871, 1892, 1942 and 1964) and 2 breaks in Porto time-series (detected in 1923 and 1976). Twelve different correction factors (one for each month) are applied to the time-series to ensure a reliable homogenisation. Figure 4-10 shows the annual evolution of raw data and adjusted mean temperature for Porto and Lisboa. Applying the correction factors to the raw data, the adjusted data are obtained for both time-series. Therefore, the Portuguese time-series can be integrated to the rest of SDATS and SDAPS to produce a new high quality dataset called as Monthly Iberian Temperature and Precipitation Series (MITPS). 


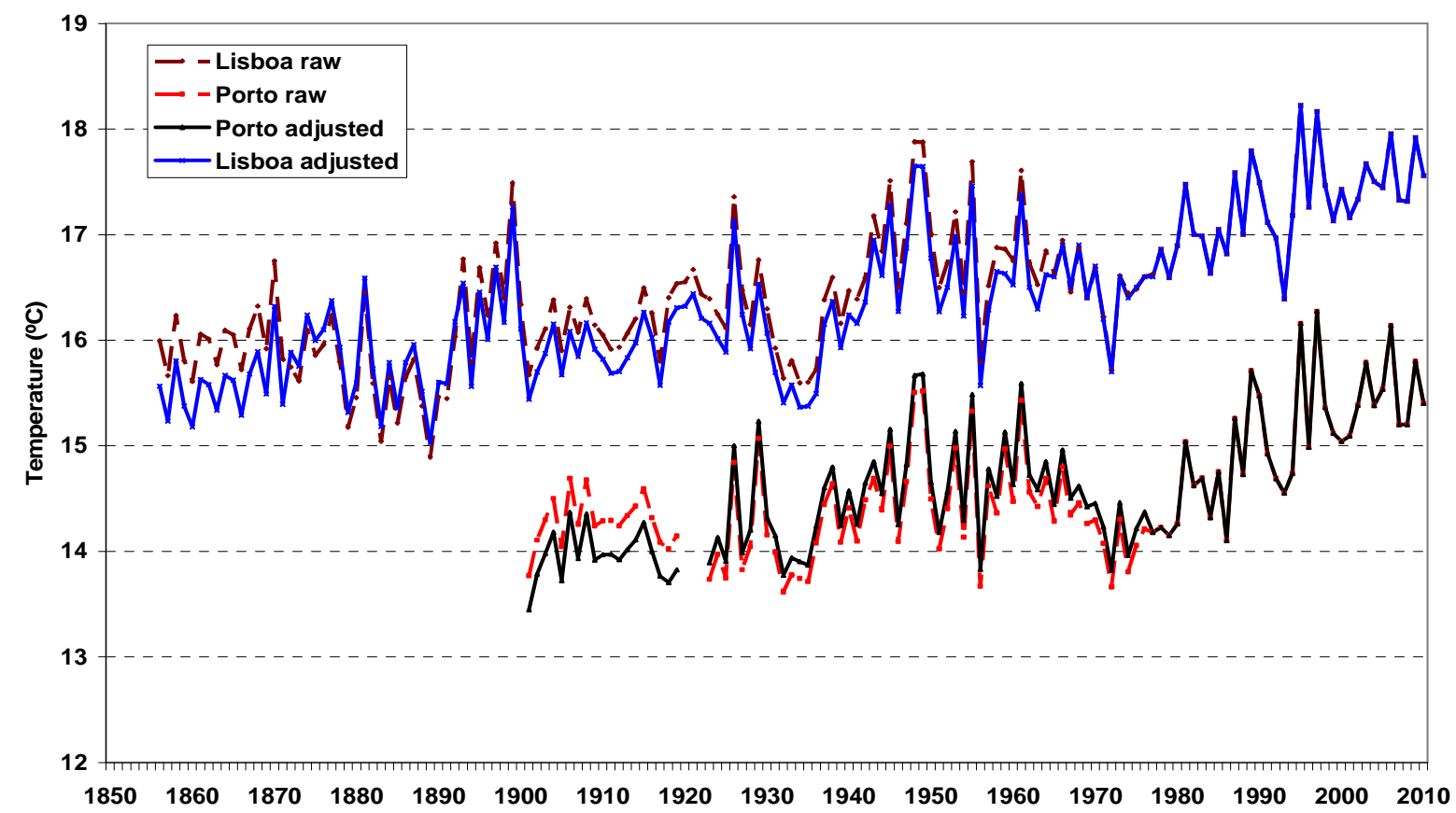

Figure 4-10: Annual mean temperature evolution of raw data and adjusted data for Porto (1901-2010) and Lisboa (1956-2010). 


\subsubsection{Missing values interpolation in MITPS}

Although the time-series selected for this study were chosen among the most complete long term records, they are affected, at some degree by the existence of missing values in monthly mean temperature and monthly accumulated precipitation. These missing data can influence negatively to the results obtained from the drought indices or even prevent us from the application of some techniques that require strict data continuity. As has been discussed in previous sections, drought indices computation takes into account monthly or weekly precipitation amount (all drought indices) and monthly or weekly mean temperature (just some indices) together with AWC of the soil (Sc-PDSI only). Therefore, the availability of drought severity values depends directly of the simultaneous availability of temperature and precipitation data. For example, if monthly temperature is available for a given month, but precipitation amount is missing, drought severity value for this month cannot be calculated. For this reason, it is very important to ensure that long term records are of high quality and have continuous records of simultaneous temperature and precipitation and monthly missing data must be filled. Data infilling has been limited to short duration gaps (no more than 3 consecutive months) to ensure the quality of the interpolation.

Figure 4-11 shows the availability of monthly temperature and precipitation (per year) across time (1850-2010) in the Iberian time series (24 time series) compared with potential data obtained from number of available time series (stations).

Three stations are available from the 1850s onwards, 7 from 1860s, 8 from 1870s, 12 from 1880s, 22 from 1890s and 24 from 1900s.

Different periods with frequent missing values across the whole dataset are evident from the inspection of figure 4-11. The fraction of missing data for the whole period (18502010) represents about $9 \%$ of the potential data. Moreover, for the two shorter subperiods of 1899-1905 and 1931-1939 missing data percentages are higher at 22\% and $17 \%$ respectively. This marked reduction in the available data in both intervals is mainly related to the political instabilities experienced by Spain between the end of the $19^{\text {th }}$ century and in the early 1940s, associated with the so-called 1898 Crisis (lost of the the overseas Spanish Colonies of Cuba and Philippines) and the convulse transition to the II Republic and its abrupt end with the Spanish Civil War from 1931 to 1939. Due to these severe political and socio-economic crises, meteorological operational services 
in Spain were dramatically disturbed during these times (Brunet et al., 2006). Finally, during 1940-2010 data availability was always above 95\%.

Availability of monthly temperature and precipitation data in the lberian time series (1850-2010)

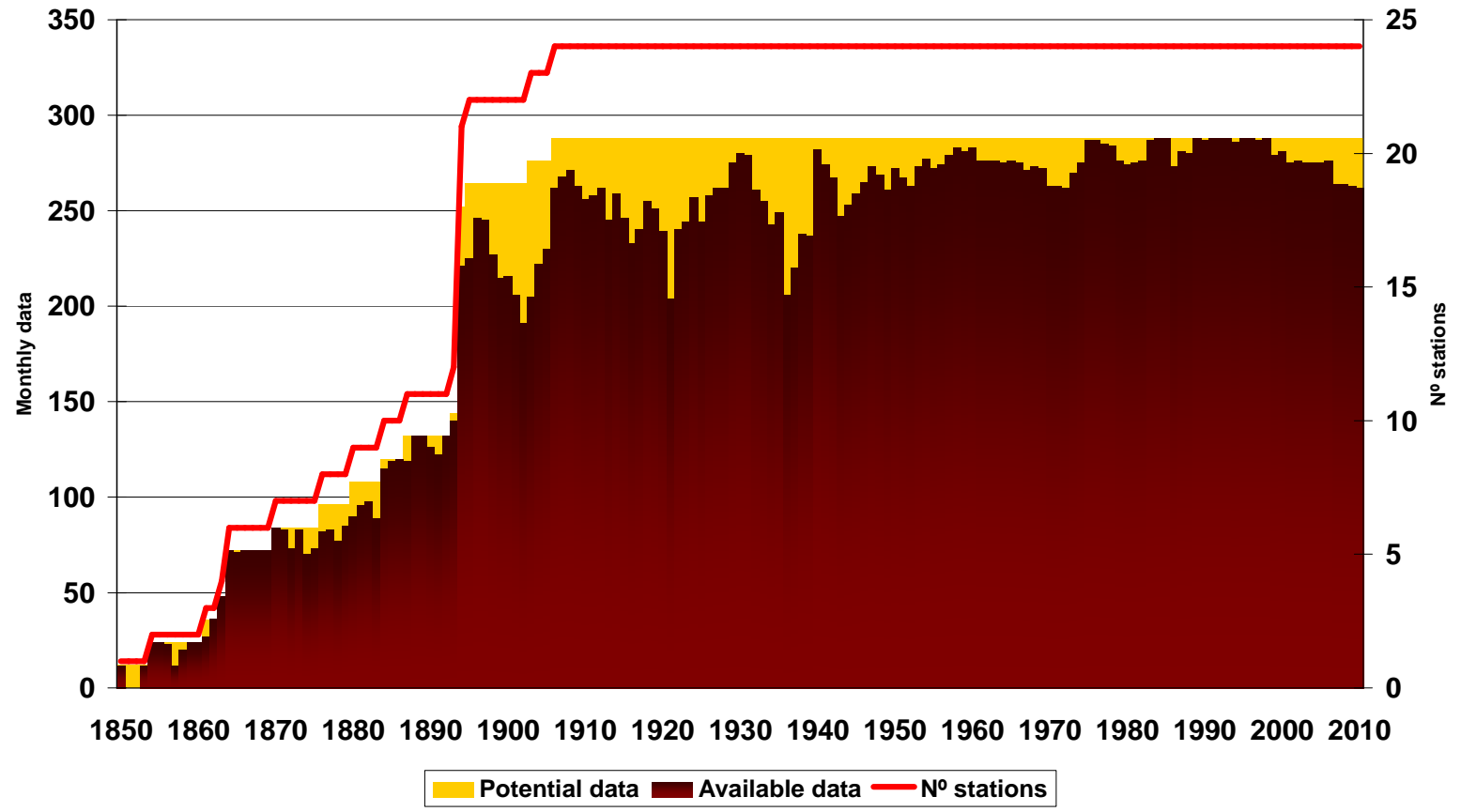

Figure 4-11: Potential vs. available monthly simultaneous temperature and precipitation (left axis) and the number of available stations (right axis) in the Iberian Peninsula (1850-2010).

Individual time series have also been inspected to detect missing remarkable missing periods for each of them. Figure 4-12 shows the percentages of missing data for each time-series in monthly mean temperature and monthly accumulated precipitation for the period 1906-2010 (when all time-series guarantee continuity in their records, as shown in fig. 4-11). The fraction of missing data is about $4 \%$ for monthly mean temperature and of 5\% is related to monthly accumulated precipitation for the period 1906-2010. Moreover, sixteen time-series are affected by less than 5\% of missing data, six stations have between 5 and $10 \%$ of missing data for at least one variable (Valencia, Soria, Porto, Madrid, Huesca and Albacete) and, finally, San Sebastián shows almost 20\%, both in temperature and precipitation, while Pamplona has almost $30 \%$ of missing data in precipitation (Fig. 4-12).

We do not attempt to fill entire periods with consecutive years with missing data, such as 1850-1905, which no data or sparse years in most stations (see fig. 4-11), but punctual gaps are reconstructed to ensure continuity and reliability on results. Due to excessive missing data, Pamplona and San Sebastián are discarded (although San Sebastián data 
series has been dramatically improved after a recent Data Rescue effort in the Center of Climate Change, $\mathrm{C} 3$, the data processing has not ended at the moment of writing these lines). Thereby, the original dataset composed by 24 time-series is reduced to 22 timeseries to guarantee high quality on results.

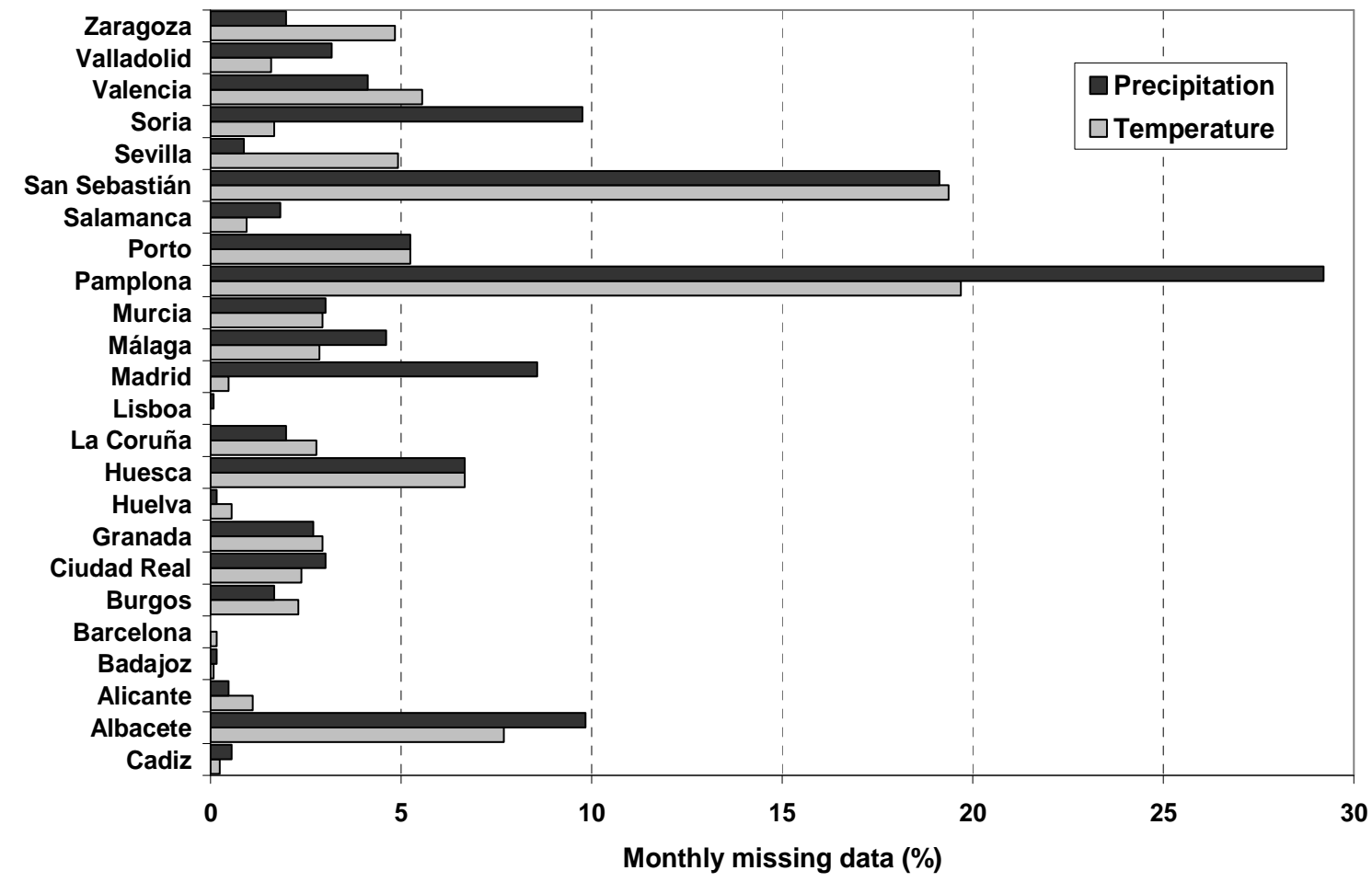

Figure 4-12: Percentages of missing data for each time-series in terms of monthly mean temperature and monthly accumulated precipitation from 1906 to 2010.

Missing values are infilled using multiple linear regression with neighboring series from 1906 to 2010. The four best correlated time series (Pearson's $r>0.7$ ) are selected to complete punctual gaps for each candidate time-series month by month. VicenteSerrano et al., (2005) and (2006) applied this method to complete missing values in 51 Iberian precipitation series from 1910 to 2000 in order to provide continuity in timeseries. They obtained reliable results in drought detection and analysis using a specific drought index (SPI) and, then the spatial-temporal patterns of droughts were computed for the whole Iberian Peninsula.

However, it is important to check the consistency of the results provided from the application of the method. Figure 4-13 shows mean standard errors computed for each time-series after reconstructing via multiple linear regression for monthly temperature and precipitation the whole 1906-2010. Lisboa temperature and precipitation series and Barcelona preciptiation series do not appear as it does not present any missing data. The 
mean standard error in monthly temperature is $0.47^{\circ} \mathrm{C}$ while in monthly precipitation is $21.2 \mathrm{~mm}$ after averaging all time-series.
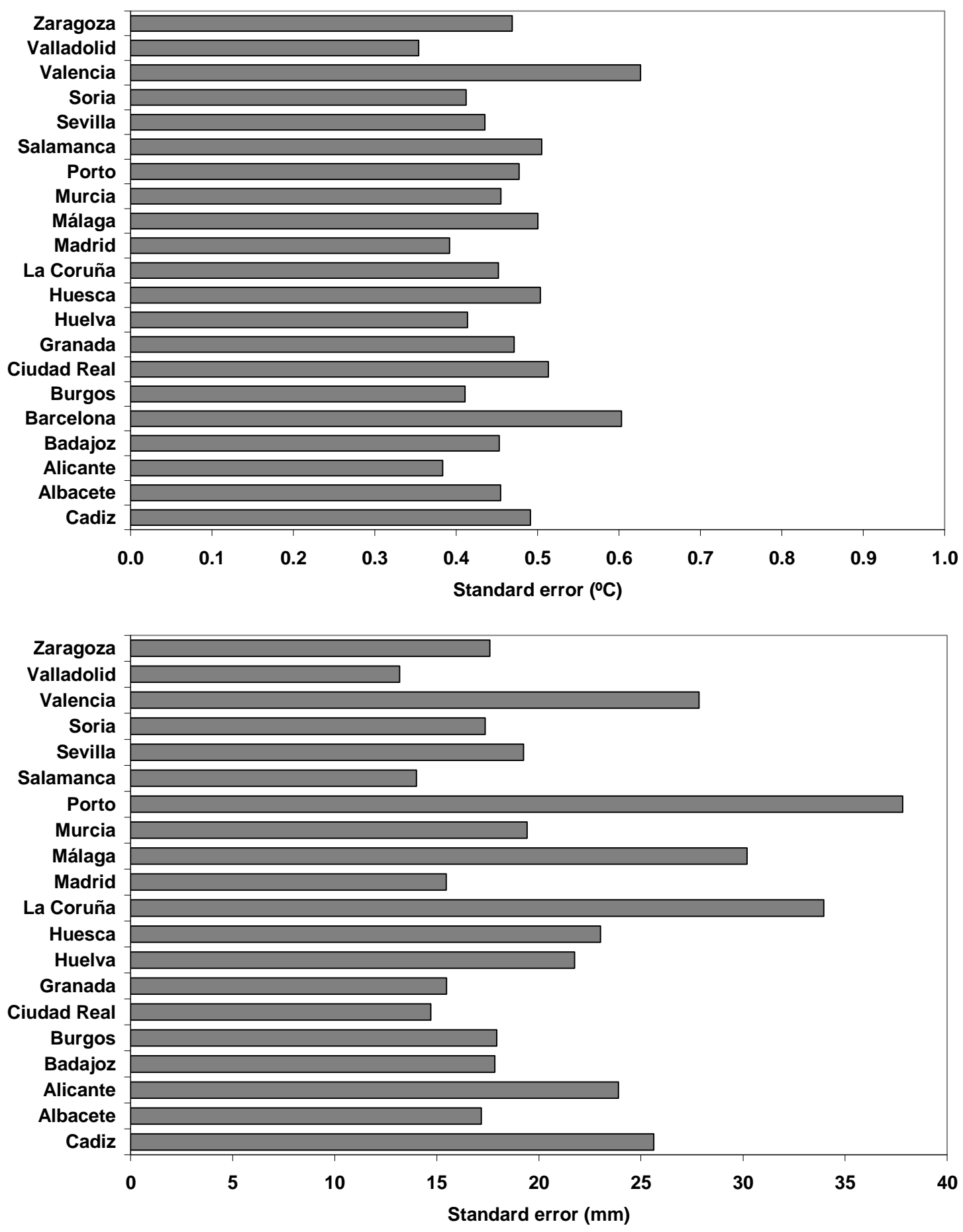

Figure 4-13: Mean standard errors computed for each time-series after applying multiple linear regression for temperature (upper panel) and precipitation (lower panel) for the period 19062010. Time-series without monthly missing data are not represented.

The final impact on the final time-series is regarded as neglectable, not only for the method applied, but also due to the low percentage of missing data found in the time- 
series under study. Figure 4-14 shows the difference between annual averaged temperature and precipitation of the original dataset (including missing data) and after filling the gaps for all time-series from 1906 to 2010. In the case of temperature, the change in annual mean values after introducing the reconstructed values falls in the range of $\pm 0.02^{\circ} \mathrm{C}$; among the five time series surpasing this threshold, Valencia shows the largest differences, with a range of $\pm 0.09^{\circ} \mathrm{C}$ in the annual averages. On the other hand, most of the time-series do not reach $\pm 2 \mathrm{~mm}$ of change in annual precipitation after filling monthly missing data. Just six time-series exceed this value and Soria and Madrid reach the highest rate of change $( \pm 6 \mathrm{~mm}$ ) in annual precipitation. Those series with larger discrepancies between non-filled and infilled time series agree, as expected, with those were more values have been interpolated. Nonetheless, the low percentage of monthly missing data on original dataset has an inappreciable impact on temperature and precipitation time-series in the Iberian Peninsula for the period 1906-2010.

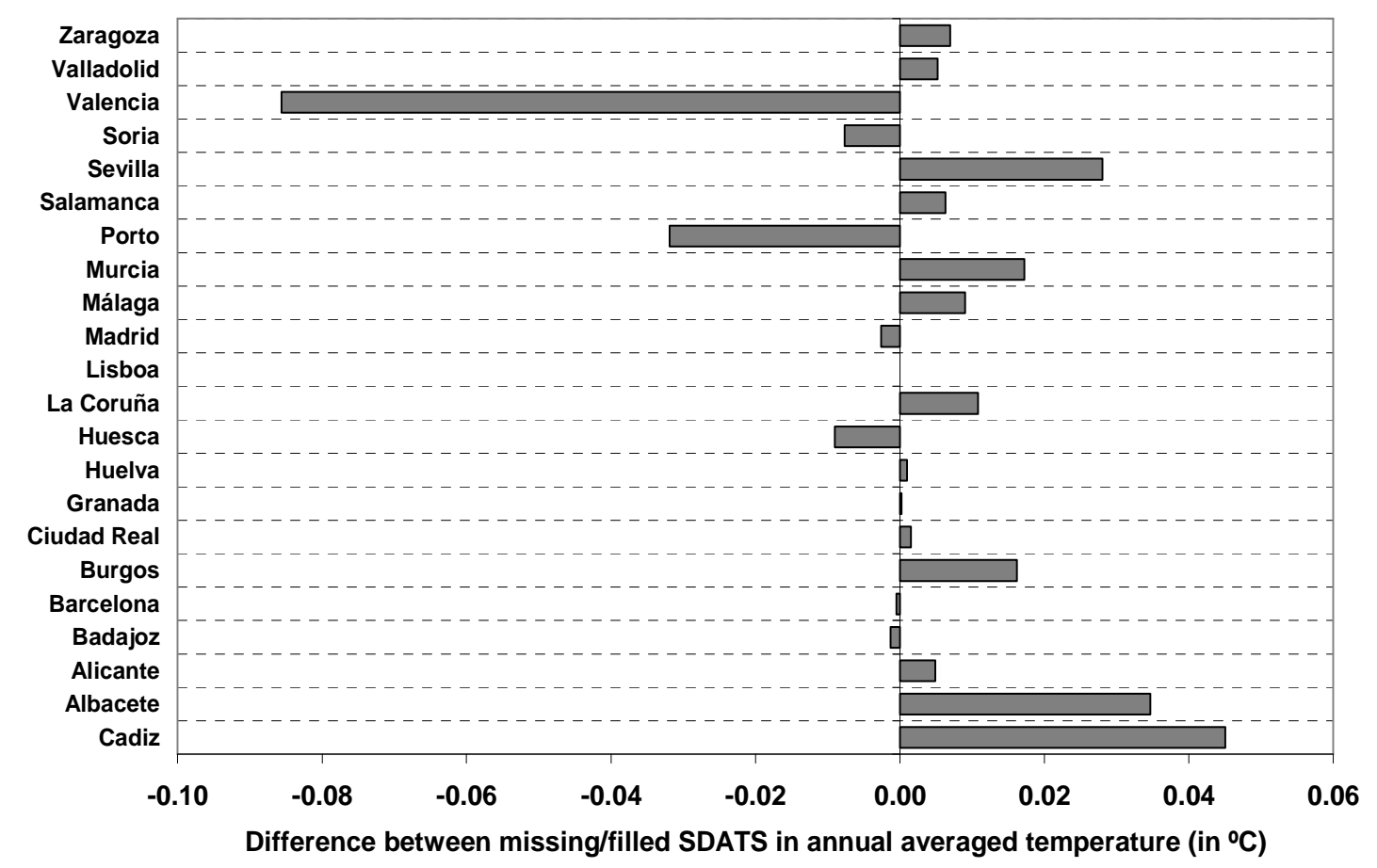




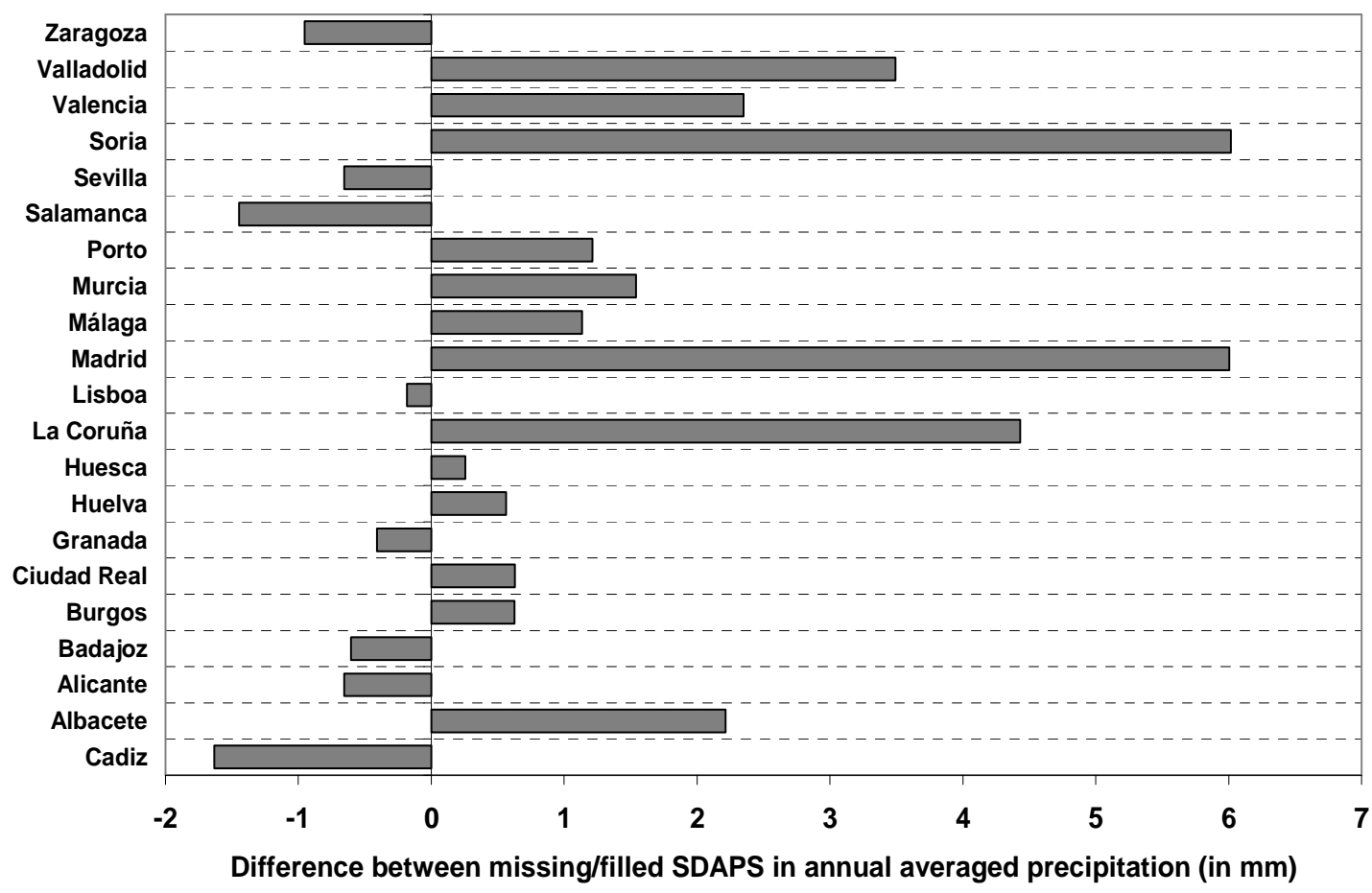

Figure 4-14: Impact of filled data on annual averaged temperature (upper panel) and precipitation (lower panel) for each time-series from 1906 to 2010. Grey bars represent the difference between annual averaged temperature and precipitation from the original dataset (for the whole period 1906-2010) and after filling the gaps.

After the data infilling process, continuity in monthly temperature and precipitation is ensured from 1906 to 2010 for the 22 time-series that represent the Iberian Peninsula. In this way, the simultaneous availability of monthly long-term temperature and precipitation data guarantees the continuity of drought severity values across time which improves the quality and reliability of the final drought analysis. 


\subsection{MITPS analysis workflow}

After the preliminary data treatment of the times series, the Monthly Iberian Temperature Series (MITPS) have been created. As mentioned above, the 22 time-series of daily temperature and precipitation have different lengths of record (see table 4-1). This could affect negatively the reliability of the results taking into account the regional character of this work. Furthermore, the need to have simultaneous temperature and precipitation records to compute drought indices for each location is crucial to obtain reliable drought conditions. For all these reasons, it is necessary to fix a common period to solve this issue. Most of the time-series started in 1890s, but the consistency and continuity of the records is much improved after the 1900s. The common period to compute regional time-series from individual observations has been limited to 19062010, according to the availability and continuity of the records. Although the lost of several decades of worthy information is a drawback of this approach, the reliability and robustness of the results is ensured. The longest time-series are analyzed individually to avoid loosing crucial drought information about some regions of the Iberian Peninsula since the mid- $19^{\text {th }}$ century.

Monthly anomalies for each time series are calculated using the common period 19611990 to avoid that some stations have more weigth on the regional series than others due to its own mean-level. Then, these anomalies are averaged again to create one single regional temperature and precipitation time-series for whole Iberian Peninsula. Annual anomalies of temperature and precipitation for the period 1906-2010 are calculated averaging monthly anomalies from the regional time-series (reference baseperiod mean 1961-1990) according to the Jones and Hulme (1996) method of separating temperature and precipitation into its two components; the climatology and the anomaly.

After the creation of MITPS, drought indices can be computed using individual stations to compare dry conditions among various regions under study or averaging the 22 timeseries to obtain the regional drought time-series over the whole Iberian Peninsula for the common period 1906-2010.

The procedure diagram (Fig. 4-15) shows the methodology applied to obtain the Monthly Iberian Temperature and Precipitation Series (MITPS) before computing the drought indices. 


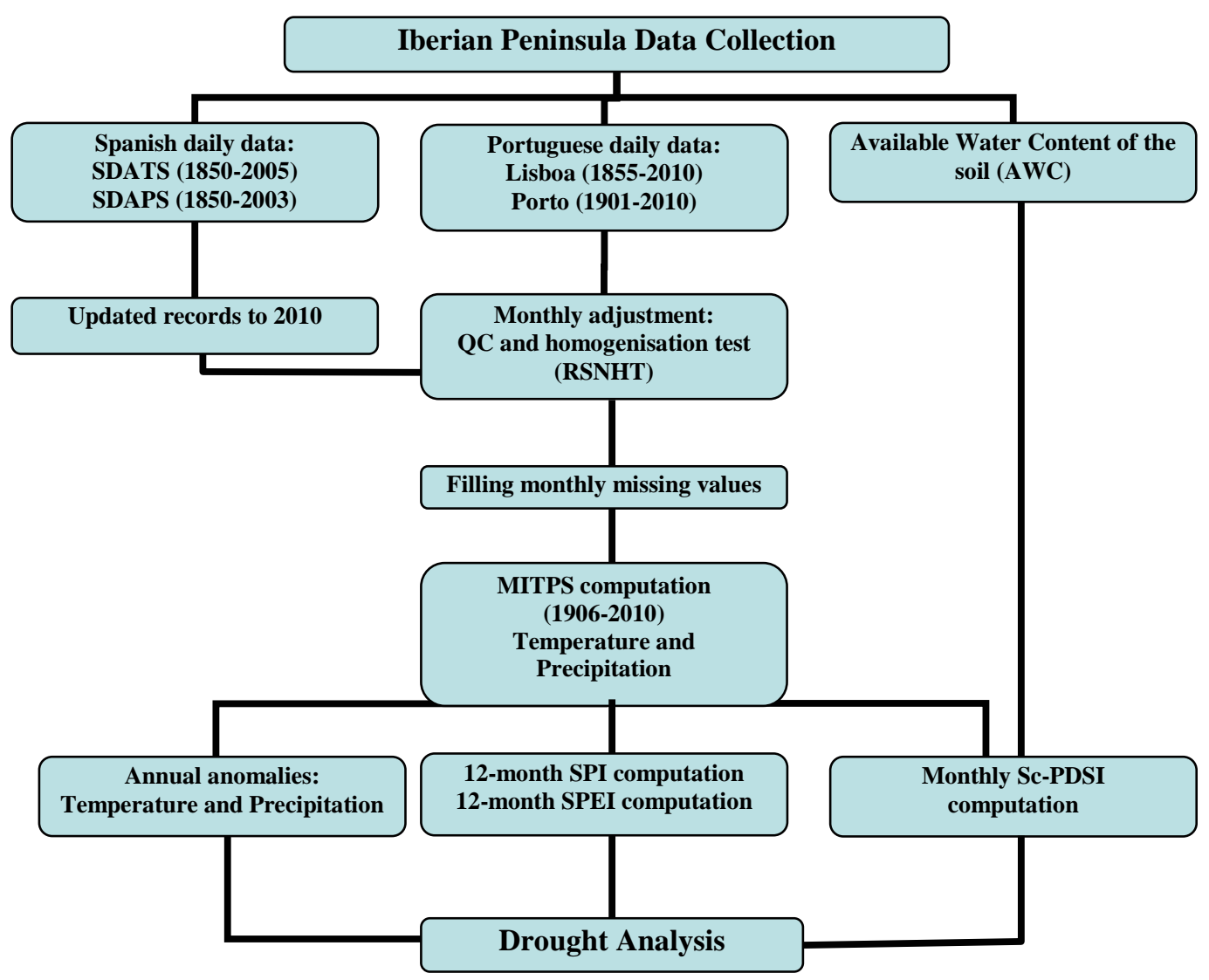

Figure 4-15: Procedure diagram of the methodology applied. 


\subsection{Drought indices computation}

\subsubsection{The PDSI computation and drought severity classification}

The Palmer's Drought Severity Index, PDSI (Palmer, 1965), is based on the supply-anddemand concept of the water balance equation taking into account more than just the precipitation deficit at specific locations (Hayes, 1997). PDSI values are distributed in 9 categories using a comprehensive classification depending of the severity of dry or wet conditions (Table 4-3). The PDSI is calculated based on precipitation and temperature data, as well as the local Available Water Content (AWC) of the soil.

\begin{tabular}{|c|c|}
\hline CATEGORIES & PDSI value \\
\hline Extremely wet & $\geq+4$ \\
\hline Severely wet & $\geq+3$ to $<+4$ \\
\hline Moderately wet & $\geq+2$ to $<+3$ \\
\hline Slightly wet & $\geq+1$ to $<+2$ \\
\hline Near normal & $>-1$ to $<+1$ \\
\hline Slightly dry & $>-2$ to $\leq-1$ \\
\hline Moderately dry & $>-3$ to $\leq-2$ \\
\hline Severely dry & $>-4$ to $\leq-3$ \\
\hline Extremely dry & $\leq-4$ \\
\hline
\end{tabular}

Table 4-3: Classification of PDSI categories defined by Palmer (1965)

Palmer applied what he called Climatologically Appropriate for Existing Conditions (CAFEC) quantities to normalize his computations so he could compare the dimensionless index across space and time. These quantities are related to evapotranspiration values, recharge, runoff, loss, potential evapotranspiration (PET), potential recharge, potential runoff, and potential loss. The calculation of these parameters depends heavily on the available water holding capacity (AWC).

According to Heim (2002) CAFEC procedure enables the index to measure abnormal wetness (positive values) as well as dryness (negative values), with persistently normal precipitation and temperature theoretically resulting in an index of zero in all seasons in all climates. When PDSI value remains positive (or negative) during a few consecutive months it means wet event (or dry) has produced. When PDSI changes the sign, although it only occurs in a month, the last wet or dry event has finished and starts another one. 
The computation of Palmer's index, according to Heim (2002), consists of the following:

1) Carry out a monthly hydrologic accounting for a long series of years using five parameters: precipitation, evapotranspiration, soil moisture, loss and recharge, and runoff. Potential and actual values are computed for the last four parameters. Palmer used monthly averages, but other timescales (such as weeks or days) can be used as well. Means of the potential and actual values for these parameters are computed over a calibration period that is usually, but not necessarily, the data period of record.

2) Summarize the results to obtain coefficients (of evapotranspiration, recharge, runoff, and loss). These coefficients are computed by dividing the mean actual quantity by the mean potential quantity.

3) Reanalyze the series using the derived coefficients to determine the amount of moisture required for "normal" weather during each month. These normal, or CAFEC, quantities are computed for each of the parameters listed above.

4) Compute the precipitation departure (precipitation minus CAFEC precipitation) for each month, then covert the departures to indices of moisture anomaly. This moisture anomaly index has come to be known as the Palmer $\mathrm{Z}$ index and reflects the departure of the weather of a particular month from the average moisture climate for that month, regardless of what has occurred in prior or subsequent months.

5) Analyze the index series to determine the beginning, ending and severity of the drought periods.

The PDSI value for a given month can be calculated using the general formula:

$$
X_{i}=0.897 X_{i-1}+\left(\frac{1}{3}\right) Z_{i}
$$

Where $\mathrm{X}_{\mathrm{i}}$ is the PDSI value and $\mathrm{X}_{\mathrm{i}-1}$ is the previous PDSI value.

Where $\mathrm{Z}_{\mathrm{i}}$ is the moisture anomaly index.

To calculate the current value of $X_{i}$ (PDSI), 0.897 times the previous PDSI value $X_{i-1}$ is added to one-third of the current moisture anomaly $Z_{i}$. Palmer called the values 0.897 and 1/3 the duration factors (Palmer, 1965; Wells et al., 2004).

But, PDSI has been criticized for a variety of reasons of which most significant is perhaps that is not comparable between diverse climatological regions (Alley, 1984 and 
Karl, 1986). This problem has been solved by Wells et al. (2004) creating Self-Calibrated PDSI (Sc-PDSI) that improves upon the "original" PDSI. Where Palmer used weighting and calibration factors in his algorithm, empirically derived from a limited amount of data from the U.S. Great Plains, the Sc-PDSI determines these factors for each location separately. This calibrates the PDSI with a set of factors uniquely appropriate to that location, and affects the range of values of the Sc-PDSI and its sensitivity for changes in the moisture regime. A more detailed description of the modifications of this algorithm to obtain the Sc-PDSI is given by Wells et al., 2004 and van der Schrier et al. (2006a).

Multiple studies have been realized obtaining better results using Sc-PDSI compared with the "original" PDSI (van der Schrier et al., 2006, 2007; Mavromatis, 2007, 2009; Dubrovsky et al., 2008; Wu and Kinter, 2009, Dai, 2012) and other studies applied Sc-PDSI obtaining increased dry conditions (Dubrovsky et al., 2007b; Brázdil et al., 2008; Briffa et al., 2009; VicenteSerrano et al., 2010; Dai, 2011 and 2012; Sheffield et al., 2012).

But, according to Vicente-Serrano et al., (2011), the PDSI still has some deficiencies such as:

a) Limitations of the PDSI as a Soil Water Balance Model: Despite Wells et al., 2004 solved most of the problems of calibration making the index more suitable for drought quantification and monitoring, the PDSI is still highly affected by the selected calibration period. The procedure for its computation is based on several assumptions and simplifications (like neglect other soil properties, ignore the complex role of vegetation, the role of PET,...) and some researchers questioned the PDSI as a physical soil water balance model (Sheffield et al., 2004).

b) The inability of the PDSI to quantify droughts on different time scales (see section $\mathrm{X})$.

c) Problems related to spatial comparability: The PDSI represents water deficit at different time-scales depending on the region under consideration, in other words, the spectral characteristics of the PDSI vary from site to site (Guttman, 1998). The time-scales of the PDSI and the Sc-PDSI are not fixed because they depend on the characteristics of the site and vary spatially. It makes difficult to assess what kind of deficit of the index is representing and, in terms of spatial comparability, the PDSI retains the problem of being an index that represents different drought frequencies among sites.

Nevertheless, this drought index provides undoubtedly valuable information and has been widely used in sound drought studies, such as U.S. Drought Monitor (NCDC and 
NDMC)) and the works of the Intergovernmental Panel on Climate Change (IPCC) in its $4^{\text {th }}$ assessment (2007) (Dai et al., 2004b). As an improvement, Van der Schrier et al. (2006) derived the time series (1901-2002) and maps of Sc-PDSI for Europe and North America compiled by the Climatic Research Unit (CRU).

In this study, the Sc-PDSI was computed for the 22 locations spread over the Iberian Peninsula using the calibration period 1906-2010 (the whole period) to calculate the main parameters of the algorithm. Monthly mean temperature, monthly precipitation and the AWC of the soil were required for each location to compute Sc-PDSI and, averaging the 22 Sc-PDSI time-series, the regional Sc-PDSI time-series was performed. Moreover, the Sc-PDSI was re-computed for each location using the monthly temperature climatology as input data (computed for the common period 1906-2010) instead the actual monthly mean temperature in order to assess the drought variability across the Iberian Peninsula without the effect of global warming.

For this work, a software package was used to compute Sc-PDSI. It was developed by Wells (2003), and it is available at http://greenleaf.unl.edu) (Last visit: 09-05-2013). 


\subsubsection{The SPI computation and drought severity classification}

Understanding that a deficit of precipitation has different impacts on the ground water, reservoir storage, soil moisture, snow pack and stream flow led McKee et al. (1993) to develop the Standardized Precipitation Index (SPI). The SPI was designed to quantify the precipitation deficit for multiple time scales. These time scales reflect the impact of drought on the availability of the different water resources. Soil moisture conditions respond to precipitation anomalies on a relatively short scale, while ground water, stream flow, and reservoir storage reflect the longer-term precipitation anomalies (Hayes, 1997). For these reasons, McKee et al. (1993) originally calculated the SPI for 3, 6, 12, 24 and 48 month time scales.

The definition of drought proposed is based on standardized precipitation. Standardized precipitation is simply the difference of precipitation from the mean for a specified time period divided by standard deviation where the mean and standard deviation are determined from past records. The resulting value is the SPI for the particular precipitation data point.

SPI can be calculated using the following expression:

$$
S P I=\frac{X_{i k}-X_{i}[}{o_{i}}
$$

Where;

$\sigma_{i}=$ standardized deviation for the ith station.

$X_{i k}=$ precipitation for the ith station and kth observation.

$X_{i}=$ mean precipitation for the ith station.

The index has the advantages of being easily calculated, having modest data requirements (only precipitation), and being independent of the magnitude of mean rainfall and hence comparable over a range of climatic zones. It does, however, assume the data are normally distributed, and this can introduce complications for short time periods (Agnew, 2000). The SPI has been accepted by the World Meteorological Organization (WMO) as the reference drought index and it should be used by national meteorological and hydrological services worldwide to characterize meteorological droughts (Hayes et al., 2011). 
McKee et al. (1993) used the classification system shown in the SPI values table to define drought intensities resulting from the SPI. McKee et al. (1993) also defined the criteria for a "drought event" for any of the time scales (see table 4-4). A drought event occurs any time the SPI is continuously negative and the event ends when the SPI becomes positive. Each drought event, therefore, has a duration defined by its beginning and end, and intensity for each month that the events continue. The accumulated magnitude of drought can also be drought magnitude, and it is the positive sum of the SPI for all the months within a drought event.

\begin{tabular}{|c|c|}
\hline CATEGORIES & SPI value \\
\hline Extremely wet & $\geq+2$ \\
\hline Severely wet & $\geq+1.5$ to $<+2$ \\
\hline Moderately wet & $\geq+1$ to $<+1.5$ \\
\hline Near normal & $>-1$ to $<+1$ \\
\hline Moderately dry & $>-1.5$ to $\leq-1$ \\
\hline Severely dry & $>-2$ to $\leq-1.5$ \\
\hline Extremely dry & $\leq-2$ \\
\hline
\end{tabular}

Table 4-4: Classification of SPI categories defined by McKee et al., (1993).

Based on an analysis of stations across Colorado, they determined that the SPI is in mild drought $24 \%$ of the time; in moderate drought $9.2 \%$ of the time; in severe drought $4.4 \%$ of the time; and in extreme drought $2.3 \%$ of the time (McKee et al., 1993). Because the SPI is standardized, these percentages are expected from a normal distribution of the SPI. The $2.3 \%$ of SPI values within the "extreme drought" category is a percentage that is typically expected for an "extreme" event (Wilhite, 1995).

The SPI allows the determination of duration, magnitude and intensity of droughts (Hayes et al., 1999). Its main advantage is that it can be calculated for several time scales (McKee et al., 1995; Komuscu, 1999) and identifies various types of drought; hydrological, agricultural or meteorological. The SPI has been extensively used for drought analysis in many studies (e.g., Hayes et al., 1999; Lana et al., 2001; Vicente-Serrano et al. 2004, 2006, 2008, 2010; Mavromatis, 2007; Kingtse et al. 2008, 2009; Dubrovsky et al. 2007b, 2008; Wu et al. 2009; Subash et al. 2010), and has become an important component in many drought monitoring efforts (i.e., the U.S. Drought Monitor (NCDC and NDMC), North American Drought Monitor (NOAA) and European Drought Observatory (EDC). Lloyd-Hughes and Saunders (2002) developed a high spatial resolution, multi-temporal SPI-based climatology of Europe and SPI maps are operationally available for the U.S.A. as well. 
The main criticism of SPI is that its calculation in based on precipitation data. The index does not consider other variables that can influence droughts, such as temperature, evapotranspiration, wind speed, solar radiation, among others. Knowing that precipitation is the main driver of droughts (Vicente-serrano et al., 2010 and 2011; Dai, 2011 and 2012; Sheffield et al., 2012), other variables as temperature or evapotranspiration can have an important role when a drought episode is developing. In fact, the use of drought indices which include temperature data in their formulation is more suitable than others, especially for applications related to current global warming or future climate scenarios (Vicente-Serrano et al., 2010).

In this study, the SPI was computed for the 22 locations spread over the Iberian Peninsula using the calibration period 1906-2010 (the whole period) to calculate the main parameters of the algorithm. Monthly precipitation was required for each location to compute SPI and, averaging the 22 SPI time-series, the regional SPI time-series was performed.

For this work, a software package has been used to compute SPI available at the web repository of the Spanish National Research Council: http://digital.csic.es/handle/10261/10002.) (Last visit: 09-05-2013). 


\subsubsection{The SPEI computation and drought severity classification}

The recently described Standardized Precipitation-Evapotranspiration Index (SPEI) (Vicente-Serrano et al., 2010) is based on the original SPI calculation procedure. The novelty of SPEI is the integration of the evapotranspiration (PET) in its algorithm and represents a simple climatic water balance which can be calculated at different time scales (VicenteSerrano et al., 2010). The SPEI combines the sensitivity of Palmer's Drought Severity Index to changes in evaporation demand (caused by temperature fluctuations and trends) with the simplicity of calculation and the multi-temporal nature of the SPI. The new index is particularly suited to detect, monitor and study the consequences of global warming on drought conditions. SPI and SPEI are purely statistical, and are not intended to reproduce the water balance of any particular system. The advantages of such indices are that:

a) Their calculation only requires climatological information, which is often available and of reasonable quality.

b) They do not require any assumptions about the system being modelled.

c) They compute the climatological anomalies for periods of exact length (termed the "time scale" of the index.

The ability to calculate these indices at various time scales allows choice of the scale most appropriate to the system under study, and can be achieved using simple statistics such as correlation analysis (Vicente-Serrano et al., 2011). With the development of the SPEI they sought to resolve the main criticism of the SPI, namely that it is based on precipitation data alone.

SPEI values are distributed in 7 categories (as SPI, see table 4-5 and 4-4) using a comprehensive classification depending of the severity of dry or wet conditions.

\begin{tabular}{|c|c|}
\hline CATEGORIES & SPEI value \\
\hline Extremely wet & $\geq+2$ \\
\hline Severely wet & $\geq+1.5$ to $<+2$ \\
\hline Moderately wet & $\geq+1$ to $<+1.5$ \\
\hline Near normal & $>-1$ to $<+1$ \\
\hline Moderately dry & $>-1.5$ to $\leq-1$ \\
\hline Severely dry & $>-2$ to $\leq-1.5$ \\
\hline Extremely dry & $\leq-2$ \\
\hline
\end{tabular}

Table 4-5: Classification of SPEI categories based on McKee et al., (1993). 
The SPEI formulation is based on the following steps:

a) PET estimation.

b) Difference between the precipitation and PET for a given month.

c) A normalization of the water balance into a Log-Logistic probability distribution to obtain the SPEI index series.

The first step to compute SPEI is related to the PET estimation which is clearly explained in section 4.3.4. With a value for PET, the difference between the precipitation (P) and PET for the month $i$ is calculated according to:

$$
D_{i}=P_{i}-P E T_{i},
$$

which provides a simple measure of the water surplus or deficit for the analyzed month. Tsakiris et al., (2007) proposed the ratio of P to PET as a suitable parameter for obtaining a drought index that accounts for global warming processes.

The calculated $D_{i}$ values are aggregated at different time scales, following the same procedure as that for the SPI. The difference $D_{i, j}^{k}$ in a given month $j$ and year $i$ depends on the chosen time-scale, $k$.

SPEI need to use three parameter distributions since in two parameter distributions the variable $(\mathrm{x})$ has a lower boundary of zero $(0>x<\infty)$, whereas in three parameter distributions (x) can take values in the range $(\gamma>x<\infty$, where $\gamma$ is the parameter of origin of the distribution), consequently, $(\mathrm{x})$ can have negative values, which are common in D series. To model $D_{i}$ values at different time-scales are used the probability density function of a three parameter Log-Logistic distribution:

$$
f(x)=\frac{\beta}{\alpha}\left(\frac{x-y}{\alpha}\right)^{\beta}\left(1+\left(\frac{x-y}{\alpha}\right)^{\beta}\right)^{-2}
$$

Where $\alpha, \beta$ and $\gamma$ are scale, shape and origin parameters respectively for $\mathrm{D}$ values in the range $(\gamma>D<\infty)$.

The Log-Logistic distribution adopted for standardizing the D series for all time-scales is given by:

$$
F(x)=\left[1+\left(\frac{\alpha}{x-y}\right)^{\beta}\right]^{-1}
$$

$\mathrm{F}(\mathrm{x})$ value is the transformed to a normal variable by means of the following approximation (Abramowitz and Stegun, 1965): 


$$
S P E I=W-\frac{C_{0}+C_{1} W+C_{2} W^{2}}{1+d_{1}+d_{2} W^{2}+d_{3} W^{3}}
$$

where $C_{0}, C_{1}, C_{2}, d_{1}, d_{2}, d_{3}$ are similar constants as SPI and $\mathrm{W}$ is probability-weighted moments:

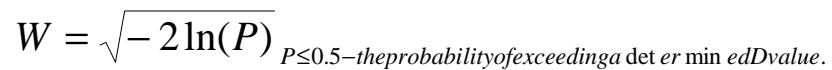

The average value of SPEI is 0 , and the standard deviation is 1 . The SPEI is a standardized variable and it can therefore be compared with other SPEI values across time and space.

The complete calculation procedure for the SPEI can be found in Vicente-Serrano et al., (2010).

Vicente-Serrano et al., (2010b) created a new global $0.5^{\circ}$ gridded dataset (1901-2006) of a multi-scalar drought index (SPEI), which considers the joint effects of temperature and precipitation on droughts. The main advantage of the new dataset lies in its multiscalar character, which allows discrimination between different types of drought. This gridded SPEI dataset is freely available in different file formats in the web repository of the Spanish National Research Council Agency (CSIC), at http://hdl.handle.net/10261/22449. Last visit: 09-05-2013.

Some studies tested the reliability and consistency of SPEI compared with other drought indices obtaining better results as a global gridded map (Vicente-Serrano et al., 2010b) as a few locations around the world (Vicente-Serrano et al., 2010). Therefore, drier conditions were detected using SPEI in Czech Republic (Potop et al., 2011) and for detecting agricultural droughts in Republic of Moldova (Potop, 2011).

In this study, the SPEI was computed for the 22 locations spread over the Iberian Peninsula using the calibration period 1906-2010 (the whole period) to calculate the main parameters of the algorithm. Monthly precipitation was required for each location to compute SPEI and, averaging the 22 SPEI time-series, the regional SPEI time-series was performed. Moreover, the SPEI was re-computed for each location using the monthly temperature climatology as input data (computed for the common period 19062010) instead the actual monthly mean temperature in order to assess the drought variability across the Iberian Peninsula without the effect of global warming.

For this work, a software package has been used to compute SPEI available at the web repository of the Spanish National Research Council: http://digital.csic.es/handle/10261/10002.) (Last visit: 09-05-2013). 


\subsubsection{The PET estimation method}

The estimation of Potential Evapotranspiration (PET) is required to compute the ScPDSI and the SPEI drought indices. There are different methods to compute potential evapotranspiration, such as Thornthwaite (Thornthwaite, 1948), Penman-Monteith (Allen et al., 1994b, Hargreaves, among others The use of one or another PET estimation method strongly depends on the long-term available data to compute them. Generally, PET estimation methods that require greater amount of data to compute PET are physically more realistic than others which less amount of data are needed.

For example, only monthly mean temperature, latitude and month is required to compute Thornthwaite PET estimation (Thornthwaite, 1948) while many climatological variables are implied to the computation of Penman-Monteith PET estimation (parameterization developed by the Food and Agricultural Organization (FAO), Allen et al., 1994b; Ekström et al., 2007). In this way, PET is generally though to be more realistically estimated using Penman-Monteih type approaches (van der Schrier et al., 2011; Dai, 2010, 2011 and 2012; Sheffield et al., 2012, among others). Penman-Monteith developed by FAO defined the reference or potential evapotranspiration as the rate of evapotranspiration from hypothethical reference crop with an assumed height of $0.12 \mathrm{~m}$, a fixed surface resistance of $70 \mathrm{~s} \mathrm{~m}-1$ and an albedo of 0.23 , closely resembling the evapotranspiration from an extensive surface of green grass of uniform height, completely shading the ground and with adequate water (Allen et al., 1994b). The algorithm for the FAO PET estimation is:

$$
P E T=\frac{0.408 \Delta\left(R_{n}-G\right)+\gamma \frac{900}{T+273} U_{2}\left(e_{a}-e_{d}\right)}{\Delta+\gamma\left(1+0.34 U_{2}\right)}
$$

Where $U_{2}$ is the wind speed at $2 \mathrm{~m}$ height; $\mathrm{G}$ is the soil heat flux related to monthly mean of daily averaged temperatures of the preceding and following months; $\Delta$ refers to the slope of the vapour pressure curve based on the saturation vapour pressure and the monthly mean of daily averaged temperatures; $R_{n}$ is the net radiation at the crop surface and it is computed as the difference between short-wave radiation (based on monthly cloud cover data) and long-wave radiation (based on monthly averages of daily total extraterrestrial radiation); effective emissivity of the atmosphere (related to relative humidity); emissivity by the vegetation; and an adjustment for the cloud cover. 
Otherwise, Thornthwaite PET estimation method (Thornthwaite, 1948) uses the relationship between monthly mean of daily averaged temperatures, $T$, to compute PET, which is given by:

$$
P E T=16\left(\frac{10 T}{I}\right)^{a}
$$

Where PET is in mm month-1 and a, is given by a third-order polynomial in the heat index I. The heat index is developed for this purpose and has 12 monthly means of daily averaged temperature values for each year as input.

$$
I=\sum_{i=1}^{12}\left(\frac{T}{5}\right)^{1.514}
$$

The numerical implementation of the last equation is that max $(T, 0)$ is taken as input to the summation rather than $\mathrm{T}$.

Finally, to account for variable day and month lengths, PET is adjusted to:

$$
P E T=P E T(\theta / 30)(h / 12)
$$

Where $\theta$ is the length of the month (in days) and, $\mathrm{h}$ is taken as the duration of daylight (in hours) on the fifteenth day of the month. The latter correction ensures that the Thornthwaite parameterization for PET is related to the latitude of the site considered, next to the monthly means of daily averaged temperatures.

For this study, the only method to be applied to estimate PET was Thornthwaite since there were not long available series of observed wind speed, relative humidity, solar radiation and cloud cover for the period under study (1906-2010). Therefore, other more robust methods like Penman-Monteith unfortunately could not be applied in this case. As is shown, Thornthwaite's method was formulated in 1948 and it is based on the assumption that radiation is the main driver of temperature variability. Therefore, the Thornthwaite's method estimated the radiation based on the temperature. This assumption could be valid under the climate conditions in 1948, but under the current global warming conditions, the temperature increase is not driven by increased radiation but it is caused by increased greenhouse gasses emissions (Solomon et al., 2007; Field et al., 2012). In this way, the Thornthwaite's approach is currently overestimating PET since the method is overestimating solar radiation, which is not increasing in parallel to the temperature increase. Thus, the possible limitations of the followed approach to compute PET and how the observed drought trends could be affected in some way by the method applied will be thoroughly discussed in section 6 . 


\subsubsection{The concept of time-scale}

The concept of time-scale in drought has been widely used by drought scientists because a drought is considered as a multi-scalar phenomenon. McKee et al., (1993) clearly illustrated this essential characteristic of droughts through consideration of usable water resources including soil moisture, ground water, snow-pack, river discharges, and reservoir storages. The time-period from the arrival of water inputs to availability of a given usable resource differs considerably. Thus, the time-scale over which water deficits accumulate becomes extremely important, and functionally separates hydrological, environmental, agricultural and other kinds of droughts. Short time scales are considered an agricultural and/or meteorological drought because they indicate the water content of vegetation and the soil moisture conditions while at a time scale of 12 months or more, droughts are less frequent, but they last longer. These time scales are considered a hydrological drought, because they are used for monitoring surface water resources, e.g. river flows, reservoir or lake level (Vicente-Serrano et al., 2006).

Numerous scientific studies have shown that particular systems and regions can respond to drought conditions at very different time scales in order to identify various types of drought (meteorological, agricultural or hydrological) (Szalai et al., 2000; Vicente-Serrano and López-Moreno, 2005; Vicente-Serrano, 2007 and Vicente-Serrano et al., 2010 and 2011).

As an example, it is common to find that two months without precipitation can produce drought conditions in the soil moisture suffering meteorological and/or agricultural drought. But, this lack of precipitation probably will not have an immediate effect on the discharge of large river systems, or in the level of water stored in the reservoirs of a region. However, the opposite situation can also occur. For example, five years of low precipitation will probably produce a severe hydrological drought in terms of river discharge and reservoir storages, but during the same drought period high precipitation events can produce high levels of soil moisture removing the meteorological and agricultural drought, although hydrological drought is remaining. Thus, it is common for drought conditions to occur in only a part of hydrological cycle (Vicente-Serrano et al., 2011).

For this reason, it is crucial that drought indices are able to detect drought conditions at different time-scales in order to identify various types of droughts. 
The PDSI and the Sc-PDSI represent a fixed time-scale that typically varies between 9 and 18 months, with spatial differences among regions depending on local characteristics (Guttman, 1998; Vicente-Serrano et al., 2010b). The PDSI was designed to be strongly auto-correlated to account for the impact of land memory on drought conditions (Dai, 2011), and for this reason it is not able to detect drought on time-scales shorter than 12 months (Vicente-Serrano et al., 2011). However, time-scales between 2 and 9 months are very useful in some regions for capturing the drought response in several hydrological, agricultural and environmental systems. Otherwise, the PDSI and the ScPDSI are useful for the analysis of hydrological droughts because it is significantly correlated to stream flow (Dai et al., 2009 and 2011; Vicente-Serrano et al., 2011). However, SPI and SPEI are able to detect wet and dry conditions at different time scales taking into account the complexity of drought phenomenon and the exactly period (time-scale) in which the antecedent conditions are affecting the value of the index can be determined. Moreover, SPI and SPEI can be compared at different time-scales between them because a robust statistical meaning is expressed as a standardized anomaly, whereas the units of the PDSI are not so easily interpreted.

Nevertheless, the time-scale selected to quantify droughts strongly depends on the interest of each study. In the case of the Iberian Peninsula (our area of interest), the economic importance of non-irrigated agriculture (mainly cereals) has decreased in the last decades. For this reason, the analysis of short time scales, indicative of agricultural drought, is currently of less interest. Meanwhile, the increase in tourist activities and irrigation in the Iberian Peninsula have raised water demands for life, making hydrological droughts more damaging to the society and the economy, producing water restrictions and losses on irrigated land (Morales et al., 2000 and Del Moral et al., 2003). In this way, Lorenzo-Lacruz et al., (2012) analyzed the streamflow evolution in the whole Iberian Peninsula between 1945 and 2005, providing evidence of a general decrease in river flows between 1-3\% in the Iberian Peninsula over the last 60 years for both regulated and non-regulated rivers. They found general trends of decreasing streamflow for winter and spring (and hence also in annual streamflow) in the Iberian Peninsula can be closely related to a decreasing precipitation (Rodrigo and Trigo, 2007; Mourato et al., 2009) but also to water management. The downward trend of streamflows for the wet season primarily caused by the decreasing precipitation trend can be exacerbated by the typical water management strategy, consisting on filling the reservoirs during the wet season 
(even at the expense of decrease winter and spring streamflows) to guarantee water supply in summer. Together with climate variability, change in land cover or land use may play an important role in the evolution of streamflow. Main changes are related to an increase of the forested land within the Iberian Peninsula and an expansion of the irrigated surface, which is closely related to water management strategies. The development of irrigated agriculture in Spain has increased the extension of irrigated land producing an increase of water demand, especially during drought periods (Causapé and Clavería, 2007). Moreover, there has also been a substantial increase in the population with the consequent growth of the cities, representing a substantial increase in urban water demand. Therefore, tourism is growing in the Iberian Peninsula causing also a markedly increased of water demand, mainly in the Mediterranean coastland areas, while could also be determining the large negative streamflow observed in this area. Water management strategies are one of the main factors explaining the observed streamflows patterns and water is progressively released during the dry season to guarantee the summer water supply for human consumption and irrigation.

The future evolution of river flows in the Mediterranean region present a great uncertainty. Climate models project a decrease in precipitation of approximately $20 \%$ in the Mediterranean region (IPCC, 2007) at the end of $21^{\text {st }}$ century. For these reasons, a large temporal unit of analysis in SPI and SPEI (12 months) is favoured for this study, since it is more suited to monitor hydrological than agricultural droughts in the Iberian Peninsula (Hayes et al., 1999 and Vicente-Serrano, 2006). 


\subsection{Trends computation}

The evolution of annual and seasonal temperature, precipitation, drought variability (from drought time-series) and drought parameters (severity, duration and magnitude) is assessed by computing trends for the period 1906-2010. In this study we use a robust statistical technique to compute the sign and the significance of observed trends called Mann-Kendall test (Mann, 1945; Kendall, 1955 and 1970) and applied according to Wang and Swail, (2001).

The Mann-Kendall test is a nonparametric test for randomness against trend. According to Mann, the null hypothesis of randomness states that the data are a sample of $n$ independent and identically distributed random variables. The test statistic $\mathrm{S}$ is defined as:

$$
S=\sum_{k=1}^{n-1} \sum_{j=k+1}^{n} \operatorname{sgn}\left(Y_{j}-Y_{k}\right)
$$

The distribution of $\mathrm{S}$ under null hypothesis is symmetrical and is normal in the limit $n \rightarrow \infty$. Under null hypothesis, the mean of $S$ is zero and, in case of no ties (e.g. no multiple values for the same sampling time), the variance of $S$ is given by:

$$
V_{S}^{2}=n(n-1)(2 n+5) / 18
$$

When trend exists, the time-series can be described by linear regression $Y_{t}=a+b t+\epsilon_{t}$, where $\epsilon_{t}$ denotes a white noise process, and $\mathrm{a}$ and $\mathrm{b}$ are regression parameters that are usually estimated using a least square estimator. However, the least square estimator of $\mathrm{b}$ is vulnerable to gross errors and the associated confidence interval is sensitive to nonnormality of the parent distribution (Sen, 1968). In this study, the estimator of $b$ proposed by Sen, (1968) is used, which is based on Kendall's rank correlation (see Wang and Swail, (2001) for more details).

The statistical significance of trends is obtained at the 99\% $(\mathrm{p}<0.01)$ and $95 \%(\mathrm{p}<0.05)$ significance level provided by the p-values and the $95 \%$ confidence interval of trends is also computed to fix the margin of error related to trends.

It is evident that time series of drought indices present a strong autocorrelation, given the cumulative character of drought phenomenon (implicit in the algorithms), especially when large time-scales are selected for computation. The result of the Mann-Kendall test depends strongly on the autocorrelation. As example, if there is a positive autocorrelation in the time-series, the test rejects the null hypothesis more often than 
specified by the significance level (von Storch and Navarra, 1995). In other words, the autocorrelation increases the probability that the test detects a significant trend in the time-series, whether it is there or not. For this reason, autocorrelation should be removed from the time-series prior to computing the Mann-Kendall test. Applying that, more reliable trends will be ensured.

The pre-whitening procedure (Von-Storch and Navarra, 1995) is the method selected for this study to remove autocorrelation from observed trends. This is based on the 1-month lag autocorrelation coefficient of the series, as follows:

$$
X p_{t}=X_{t+1}-r X_{t}
$$

Where $X p_{t}$ is the value of the pre-whitened series for the $t$ interval, $\mathrm{X}$ is the value of the original series for the $t$ interval, and $r$ is the estimated autocorrelation coefficient.

Prior to the correction of the effects of autocorrelation, the Trend-free pre-whitening method proposed by Yue et al., (2002) is followed to remove the trend (if present). The procedure involves the following steps:

1. Calculation of the slope (b) of the original series using a linear regression.

2. Calculation of the autocorrelation coefficient $r$, which is the slope of the linear regression between the de-trended series $X_{t}$ and the lag-1 de-trended series $X^{\prime}{ }_{t}-1$. Removal of the autocorrelation coefficient of the de-trended series was performed as follows:

$$
Y_{t}^{\prime}=X_{t}^{\prime}-r_{1} X_{t-1}^{\prime}=X_{t}-T_{t}
$$

Where the resulting series $Y_{t}^{\prime}$ is independent.

3. The predicted $T_{t}$ and the residual series $Y^{\prime}{ }_{t}$ were summed:

$$
Y_{t}=T_{t}+Y^{\prime}
$$

ensuring that the resulting series preserved the original trend and was not affected by autocorrelation.

More detailed information about the application of the explained method can be found at Lorenzo-Lacruz et al., (2012), whom removed autocorrelation to get more reliable trends related to assess the stream-flow evolution in the Iberian Peninsula for the period 1945-2005. 


\subsection{PCA's definition, computation and principal component rotation}

Principal Components Analysis (PCA) is possibly one of the most widely used multivariate statistical techniques in the atmospheric sciences. The technique became popular for analysis of atmospheric data following the paper by Lorenz (1956), who called the technique empirical orthogonal function (EOF) analysis. Both names are commonly used, and refer to the same set of procedures.

Multiple methodological descriptions of PCA can be found in literature (Jollife, 1990, Wilks, 1995), however, the definition and application of PCA on atmospheric sciences are clearly described in Wilks, (2006).

Wilks indicates that PCA reduces a data set containing a large number of variables to a data set containing fewer ("hopefully many fewer") new variables. These new variables (denominated principal component $(P C)$ ) are linear combinations of the original ones, and these linear combinations are chosen to represent the maximum possible fraction of the variability contained in the original data. Data for atmospheric and other geophysical fields generally exhibit many large correlations among the variables, and a PCA results in a much more compact representation of their variations. PCA has the potential for yielding substantial insights into both the spatial and temporal variations exhibited by the field or fields being analyzed, and new interpretations of the original data can be suggested by the nature of the linear combinations that are most effective in compressing the data.

Usually it is convenient to calculate de PCs as linear combinations of the anomalies. The first PC is that linear combination of anomalies having the largest variance. The subsequent PCs are the linear combinations having the largest possible variances. The result is that all the PCs are mutually uncorrelated. A small set of uncorrelated variables is much easier to understand and handle for further analyses than a larger set of correlated variables (Dae Ha et al., 2011).

For any PC, the defined vector for the coefficients of different variables is called eigenvector and the sum of the eigenvector components results the eigenvalue for a PC. Multiplying this value per 100 and divided with the number of variables provides the percentage of the explained variance for each component. 
The subject of PCA is sometimes regarded as a difficult and confusing one, but much of this confusion derives from a proliferation of the associated terminology, especially in writings by analysts of atmospheric data (Wilks, 2006). The term coefficient is also a usual one in the statistical literature and, for this reason this coefficient will be called weight from now to avoid confusions. The term weight expresses better the contribution of each variable to the component than others.

Obviously, the main purpose of PCA is not to obtain the same number of components than original variables, but to obtain a reduced number of principal components explaining most of the variance of the original variables. In this way, most of the information content of the data may be represented using some smaller number of the principal components. There is no clear criterion that can be used to choose the number of principal components that are best retained in a given circumstance. The choice of the truncation level can be aided by one or more of the many available principal component selection rules, but it is ultimately a subjective choice that will depend in part on the data at hand the purposes of PCA. Perhaps the most basic criterion is to retain enough of the principal components to represent a sufficient fraction of the variances of the original variables. Of course the difficulty comes in determining how large the fraction must be in order to be considered sufficient. Jolliffe (2002) suggests that between $70 \%$ and $90 \%$ of explained variance may often be a reasonable range. Basically, there are two main criterions to choose how many principal components are needed to extract for each PCA (Wilks, 2006).

The first one is called Kaiser's rule (Kaiser, 1960) and involves comparing each eigenvalue (and therefore the variance described by its principal component) to the amount of the joint variance reflected in the average eigenvalue. Principal components whose eigenvalues are above this threshold are retained. Kaiser proposed the threshold parameter T $>1$. Jolliffe $(1972,2002)$ has argued that Kaiser's rule is too strict (typically seems to discard too many principal components). He suggested that the alternative $\mathrm{T}>0.7$ often will provide a roughly correct threshold, which allows for the effects of sampling variations.

On the other hand, Cattell (1966) proposed the scree graph for determining the number of principal components to be retained. Plotting the eigenvalue spectrum with a linear vertical scale produces what is known as the scree graph. When using the scree graph qualitatively, the goal is to locate a point separating a steeply sloping portion to the left, and a more shallowly sloping portion to the right. The principal component number at 
which the separation occurs is then taken as the truncation cutoff. As described above, the scree-slope criterion does not involve quantitative statistical inference.

Finally, the application of PCA for climatic series can be performed in six possible operational modes that can be specified in PCA according to Richman (1986). But, basically $\mathrm{S}$ or $\mathrm{T}$ modes are the most used for climatic series depending on the role which plays the various elements (variables or cases) (Vicente-Serrano et al., 1999). T-mode identifies sub-groups of observations to obtain similar spatial patterns being the time observations as variables and the observatories as cases. Meanwhile, S-mode is used to obtain general temporal patterns of climatic series: the observatories are the variables; and the time observations the cases.

However, the orthogonality constraint on the eigenvectors can lead to problems with these interpretations, especially for the second and subsequent principal components (Wilks, 2006). Although the orientation of the first eigenvector is determined solely by the direction of the maximum variation in the data, subsequent vectors must be orthogonal to previously determined eigenvectors, regardless of the nature of the physical processes that may have given rise to the data. The first principal component may represent an important mode of variability or physical process, but it may well also include aspects of other correlated modes or processes. Thus, the orthogonality constraint on the eigenvectors can result in the influences of several distinct physical processes being jumbled together in a single principal component.

When physical interpretation rather than data compression is a primary goal of PCA, it is often desirable to rotate a subset of the initial eigenvectors to a second set of new vectors referred to different coordinates. The principal component rotation consists basically in a mathematical transformation that replaces the retained PCs obtained in PCA by the same number of derived variables. The explained variance in the PCs is not altered by the rotation and the rotated eigenvectors are less prone to the artificial features resulting from the orthogonality constraint on the unrotated eigenvectors (Richman, 1986).

Following rotation of the eigenvectors, a second set of new variables is defined, called rotated principal components (RPCs). The rotated principal components are obtained from the original data analogously, as de dot products of data vectors and the rotated eigenvectors. Depending on the method used to rotate the eigenvectors, the resulting rotated principal components may or may not be mutually uncorrelated. 
Richman (1986) lists 19 approaches to defining the rotation matrix in order to achieve simple structure, although his list is not exhaustive. However, by far the most commonly used approach is the orthogonal rotation called the Varimax (Kaiser, 1958). This type of orthogonal rotation of the PCs minimizes the number of variables which have high weights in a particular component. The objective is to obtain a more interpretative results being the best correlated variables which have high weights in the same component and less weights to other components. The results of eigenvector rotation can depend on how many of the original eigenvectors are selected for rotation. Moreover, Varimax rotation simplifies the spatial structure by isolating regions with similar temporal variations, being the most orthogonal method to improve the creation of regions of maximum correlation between the variables and the components (Santos et al., 2010).

There are many studies applying principal component analysis (PCA) on drought indices to obtain spatial-temporal variability of droughts in a global or regional time scale. Day (2004) applied PCA in PDSI series from 1882 to 2002 for global land areas on a $2.5^{\circ}$ grid in order to detect wetter or drier conditions across time on monthly and seasonal basis. Day (2011) updated and improved the results obtained from the global PDSI dataset (1850-2008) applying PCA again to investigate the drying effect of global warming. Otherwise, Bordi et al., (2006) studied the behaviour of droughts in some regions of the world using ERA-40 and NCEP/NCAR re-analysis precipitation data. Then, the leading spatial-temporal variability of dryness and wetness has been assessed by applying PCA to the SPI time series. Moreover, Dae Ha et al., (2011) applied PCA to the SPI time series in order to evaluate the vulnerability of agricultural drought of major river basins in Korea, and Zuluaga (2009) found spatial-temporal patterns of droughts in Colombia computing PCA in SPI time series. Finally, Sousa et al., (2011) have performed a PCA on the PDSI and Sc-PDSI datasets for the Mediterranean basin to obtain regions that can be considered relatively homogeneous in terms of drought characteristics.

On the other hand, Vicente-Serrano (2005) investigated the differences in spatial patters of drought on different time scales applying PCA to the SPI series focused in the Iberian Peninsula from 1910 to 2000. Boroneant et al., (2011) investigated drought variability over Iberian Peninsula using two monthly global datasets; the Sc-PDSI and SPEI having a spatial resolution of $0.5^{\circ}$ of gridded data for the period 1901-2006. They compared both datasets in terms of explained variance, patterns of variability and temporal 
evolution of PCs computing PCA. Finally, Lana et al., (2001) and Santos et al., (2010) identified spatial patterns of drought using PCA on SPI time series for Catalonia and Portugal respectively.

In this study, Principal Component Analysis (PCA) was applied at annual and seasonal time-scale in 12-month SPEI time-series from 1906 to 2010 for detecting spatialtemporal variations of droughts along the year. S-mode was used to obtain general temporal patterns of climatic series: the observatories were the variables; and the time observations were the cases. Kaiser's rule was applied to truncate the number of principal components under the two recommended thresholds $\mathrm{T}>0.7$ (Jolliffe, 1986) and T>1 (Kaiser, 1958, Serrano et al., 1999 and 2005). To achieve more stable spatial patterns, a rotation of the principal components with Varimax procedure was performed (White et al., 1991, Serrano et al., 1999 and 2005 and Santos et al., 2010). The patterns defined in this way were referred as rotated principal components (RPCs). 


\subsection{Defining droughts and wet events and their parameter estimation}

After choosing the appropriate drought index for the Iberian Peninsula and the time scale of interest, wet and dry events are computed. Using Monthly SPEI, we can identify a dry or wet event as the time period which a determined number of consecutive months remain in dry or wet conditions. A dry or wet period indicates the dominance of abnormally dry or wet conditions across time (in average), although some interruptions in these conditions can exist. For example, an abnormally dry period was identified from early-1980s to mid-1990s (see fig. 4-16). Note that not all the months comprised in the dry period need to be dry themselves, but various dry events could be detected in the dry period. Obviously, from early 1880s to mid-1990s, there were some dry and wet events simultaneously, but in general the period was abnormally dry.

McKee et al., (1993) defined a drought event as a period in which the SPI is continuously negative and reaches a value of -1 or less. The same criteria can be applied to SPEI. However, some drought events may have prolonged drought duration, but a moderate SPEI for each period that does not reach -1 or less. The cumulative SPEI for such events (e.g. the $5^{\text {th }}$ event in fig. 4-16), however, are likely greater than those for events with a short duration that have a SPEI less than -1. Serious water supply and other drought-related problems are also caused by this type of event (Mirabbasi et al., 2011). As a result, according to Loukas and Vasiliades (2004), a drought event is defined as a continuous period for which the SPEI is below zero (Shiau, 2006). Obviously, a wet event will be defined as a continuous period for which the SPEI is $=0>0$.

In addition, some parameters related to drought and wet event can be computed from the identification of dry and wet events. Maximum and averaged severity, duration, magnitude, the onset and offset months and the inter-arrival time of droughts and wet events are the selected parameters to identify changes in their behaviours across time.

Maximum severity refers to the maximum monthly index value recorded for each drought or wet event $\left(m s_{i}\right.$ in fig. 4-16), while the average severity is related to the average index value for each drought or wet event. 


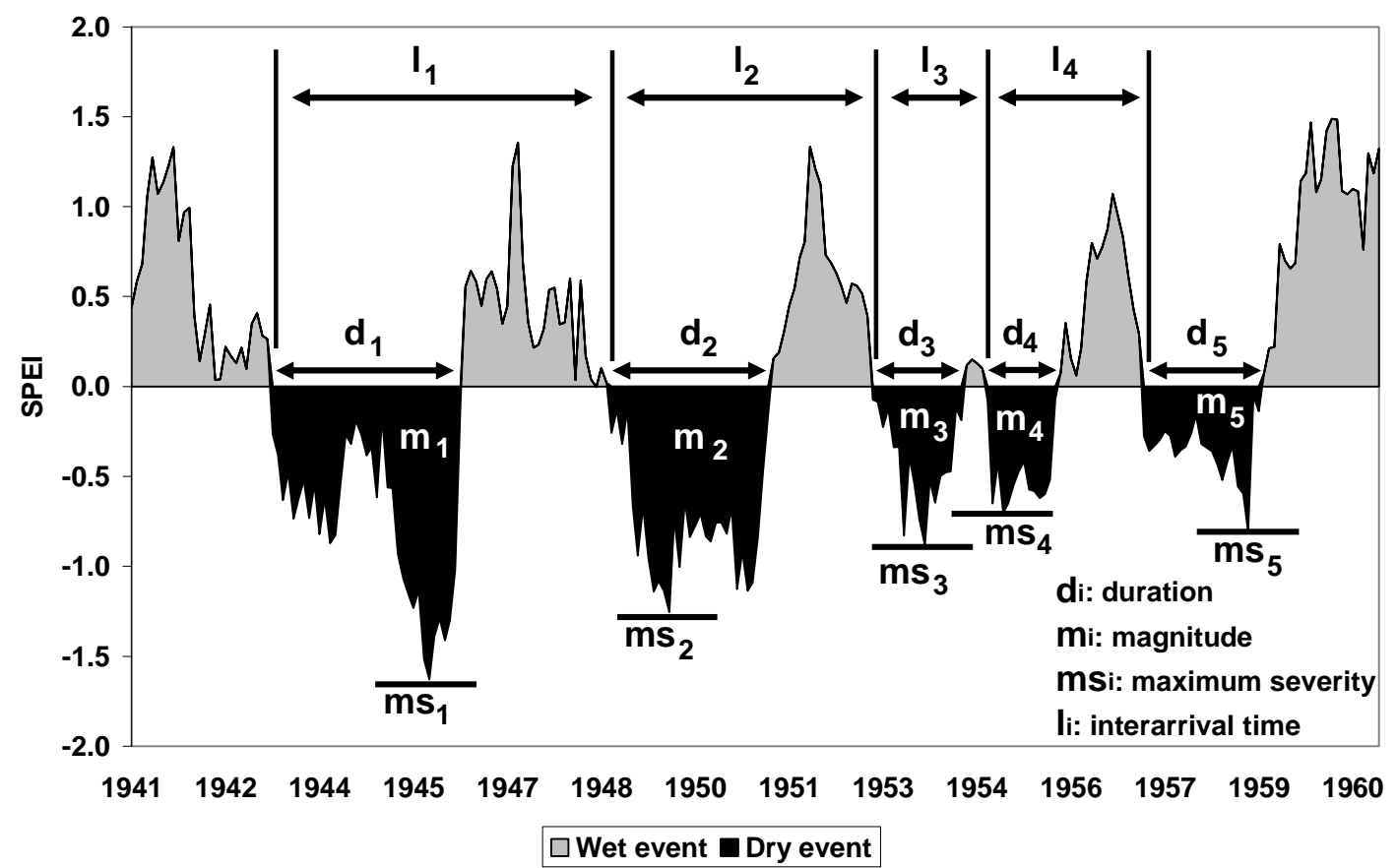

Figure 4-16: Definition sketch of drought events. Detected droughts and wet events are shown over Iberian Peninsula for the period 1941-1960 as an example.

Drought length or duration (D) is taken as the number of consecutive intervals (months) where SPEI remains below zero (or upper zero in the case of wet events). Since the drought event is defined at aggregation of monthly time scale, the minimum duration of drought or wet event is one month (Reddy et al., 2011). Drought magnitude (M) is the cumulative values of SPEI within the drought duration (or wet event). For convenience, magnitude of drought event $i, M_{i}(i=1,2, \ldots)$ is taken to be positive, which is given by McKee et al., (1993).

$$
M_{i}=-\sum_{i=1}^{D} S P E I_{i}
$$

Where $S P E I_{i}$ is value of $i^{\text {th }}$ period SPEI for a D duration drought event.

The inter-arrival time (L) is defined as the period (number of months) between the beginning of a drought (or wet event) and the beginning of the next drought (or next wet event). This parameter is related to drought frequency (Mirakbari et al., 2010).

Finally, the onset of a drought (or wet event) refers to the first month which SPEI value is below zero (negative in droughts and positive in wet events) and the offset is the first month which the sign changed in monthly SPEI values (from negative to positive in the case of droughts or vice versa in wet events). 
After obtaining these parameters from observed droughts and wet events, some changes in temporal evolution of droughts and wet events can be found out. In order to detect changes on their behaviours, the trend values are computed using simple linear leastsquares regressions. Statistical significance is obtained through Mann-Kendall test (Kendall, 1970) at a $0.05(95 \%)$ and 0.01 (99\%) levels. Moreover, the 95\% confidence intervals of the trend coefficients are also estimated from tabulated values (see section 4.4). 


\section{Chapter 5}

\section{RESULTS}

This section results from the application of the methodology described above over the new MITPS dataset previously created. First of all, the climate fluctuations over the Iberian Peninsula are described in terms of temperature and precipitation at annual and seasonal time-scale. Then, we discuss the drought variability, which is approached by the application of the most widely used drought indices (Sc-PDSI, SPEI and the SPI) across the Iberian Peninsula for the common period 1906-2010. A trend analysis is carried out on drought time-series in order to understand the behaviour of drought conditions along the $20^{\text {th }}$ century and the first decade of the $21^{\text {st }}$ century. The relation between temperature change and drought trends under global warming is also evaluated. Principal Component Analysis (PCA) is applied at annual and seasonal time-scale at 12month SPEI time-series for the common period 1906-2010 in order to detect spatialtemporal variations of droughts across the $20^{\text {th }}$ century and in the first decade of the $21^{\text {st }}$ century.

Finally, the characteristics and trends of the main parameters related to dry and wet events are analyzed for the whole Iberian Peninsula and for the spatial-temporal patterns found at annual time-scale. The severity, duration, magnitude and other interesting parameters such as the seasonal distribution of the onset, offset and the period of the maximum severity reached by dry or wet events are also studied. 


\subsection{Climate fluctuations in the Iberian Peninsula}

The variability of temperature and precipitation data is treated in this section for the whole Iberian Peninsula from 1906 to 2010 at annual and seasonal time-scale. Moreover, the linear trends and their statistical significance are also analyzed. This analysis provides relevant information related to the behaviour of the main climate variables in the Iberian Peninsula under the current climate change conditions.

\subsubsection{Annual and seasonal temperature variability}

Annual temperature anomalies computed from 1906 to 2010 show a clear increasing trend of $0.126^{\circ} \mathrm{C} /$ decade, statistically significant at the $99 \%$ level (Table 5-1). This is consistent with the Spanish temperature increase described by Brunet et al., 2006 for the period 1850-2003. Other regional studies showed a qualitative concordance with this one (e.g. for the interior of Valencia, Miró et al., 2006; Castilla-León, del Río et al., 2005; Andalucía, Castro-Díez et al., 2007 and Catalonia, Martínez et al., 2009).

The observed temperature increase is not constant across time (Fig. 5-1). A first period of warming took place between 1904 and 1929, followed by a stabilization of temperatures during the 1930s and another short period of increasing temperatures during the 1940s. A period of falling temperatures was identified from 1948 to 1973, but the final 1973 to present warming episode was the period having the highest rates of change. The warmest years appear between 1996 and 2010, being 2006 the warmest of the whole Iberian time series.

\begin{tabular}{|c|c|c|c}
\hline Time-scale & Linear trend (ㅇ/decade) & 95\% confidence intervals & p-value \\
\hline Annual & $\mathbf{0 . 1 2 6}$ & $(0.097 / 0.155)$ & $2.03 \mathrm{E}-08$ \\
\hline DJF (Winter) & $\mathbf{0 . 1 2 1}$ & $(0.063 / 0.174)$ & $4.37 \mathrm{E}-05$ \\
\hline MAM (Spring) & $\mathbf{0 . 1 4 0}$ & $(0.084 / 0.190)$ & $1.05 \mathrm{E}-04$ \\
\hline JJA (Summer) & $\mathbf{0 . 1 4 3}$ & $(0.089 / 0.189)$ & $2.28 \mathrm{E}-06$ \\
\hline SON (Autumn) & $\mathbf{0 . 1 0 8}$ & $(0.062 / 0.151)$ & $2.04 \mathrm{E}-05$ \\
\hline
\end{tabular}

Table 5-1: Summary of linear trends (in ${ }^{\circ} \mathrm{C} /$ decade) computed for annual and seasonal temperature in the Iberian Peninsula (1906-2010). The associated 95\% confidence intervals and p-values are also shown. Bold (or Italic) values are referred to statistical significance at the $99 \%$ level (or 95\%). 


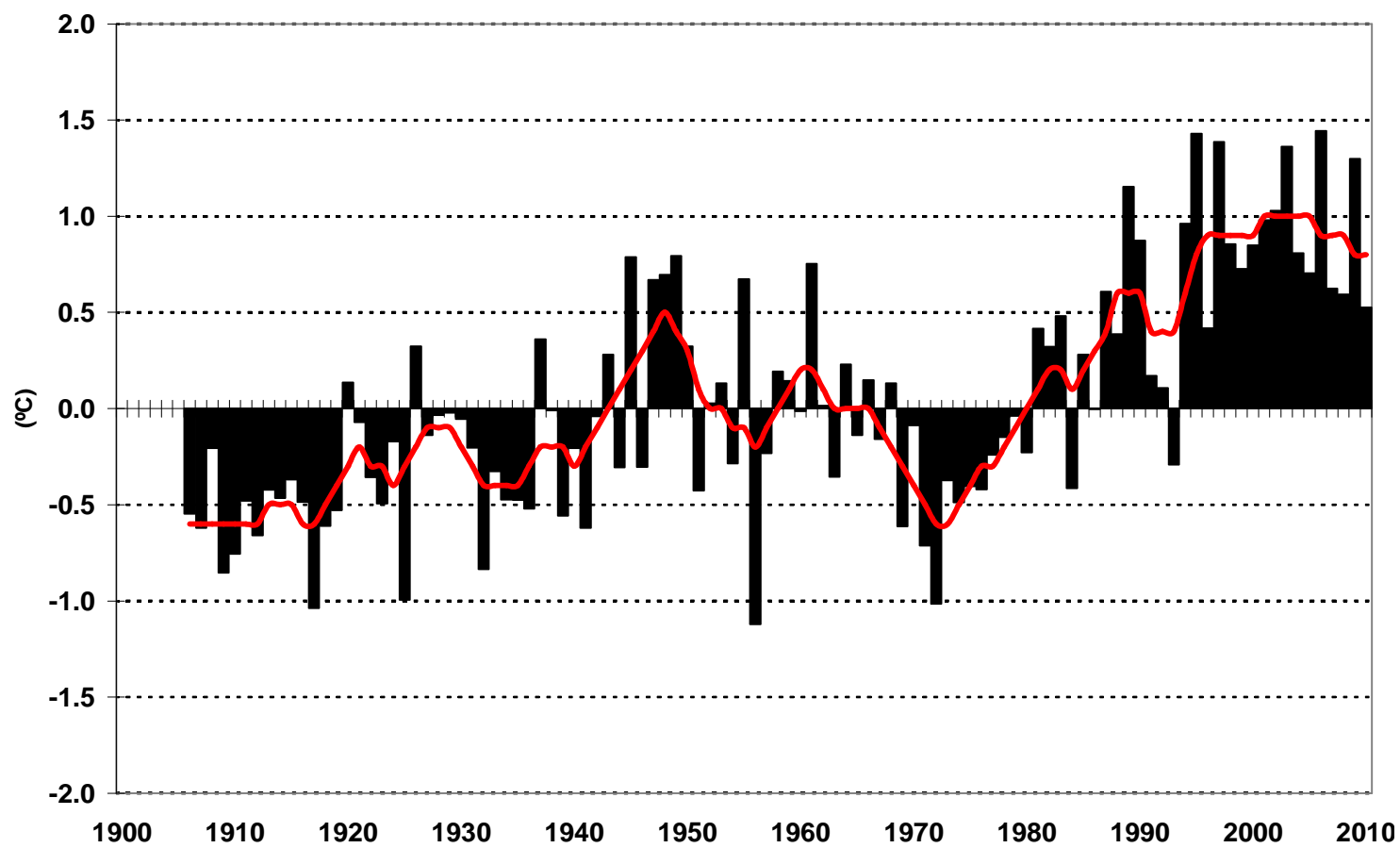

Figure 5-1: Annual temperature anomalies (base-period 1961-1990) in the Iberian Peninsula for the period 1906-2010. Red line represents a 10-year Gaussian filter applied over the annual series.

Moreover, seasonal temperature anomalies also show a clear increase of $0.121^{\circ} \mathrm{C} / \mathrm{dec}$ de for winter (DJF); $0.140^{\circ} \mathrm{C} /$ decade for spring (MAM); $0.143^{\circ} \mathrm{C} /$ decade for summer (JJA); and $0.108^{\circ} \mathrm{C} /$ decade for autumn (SON), all statistically significant at the $99 \%$ level (Table 5-1). Summer and spring are the seasons with the highest rates of change while winter and autumn show lower trends. But, as described for the annual temperature anomalies, the increase is not also constant across time in seasonal temperatures. Figure 5-2 represents the seasonal temperature variability over the Iberian Peninsula from 1906 to 2010 using the base-period 1961-1990. The variability of winter temperatures does not show high rates of change during a long period (from 1906 to 1970), dominated by alternating warm and cold winters. The first period of a clear warming took place since 1970 followed by a stabilization of temperatures between 1980 and 1990 . The second warming period began in 1991 until 1998 followed by a stabilization of temperatures during the last years of the time-series. Otherwise, the variability of spring temperatures is higher than in winter because the first warming period took place earlier, between 1939 and 1945, followed by a stabilization of temperatures until 1961. A clear decrease of temperatures was identified from 1962 to 1971, being the last one the coldest spring of the time-series. Finally, a clear warming period was recorded from 1972 to 1997, being the last one the warmest spring over the Iberian Peninsula. The last years of the time-series were dominated by a slight decrease of temperatures in spring. 

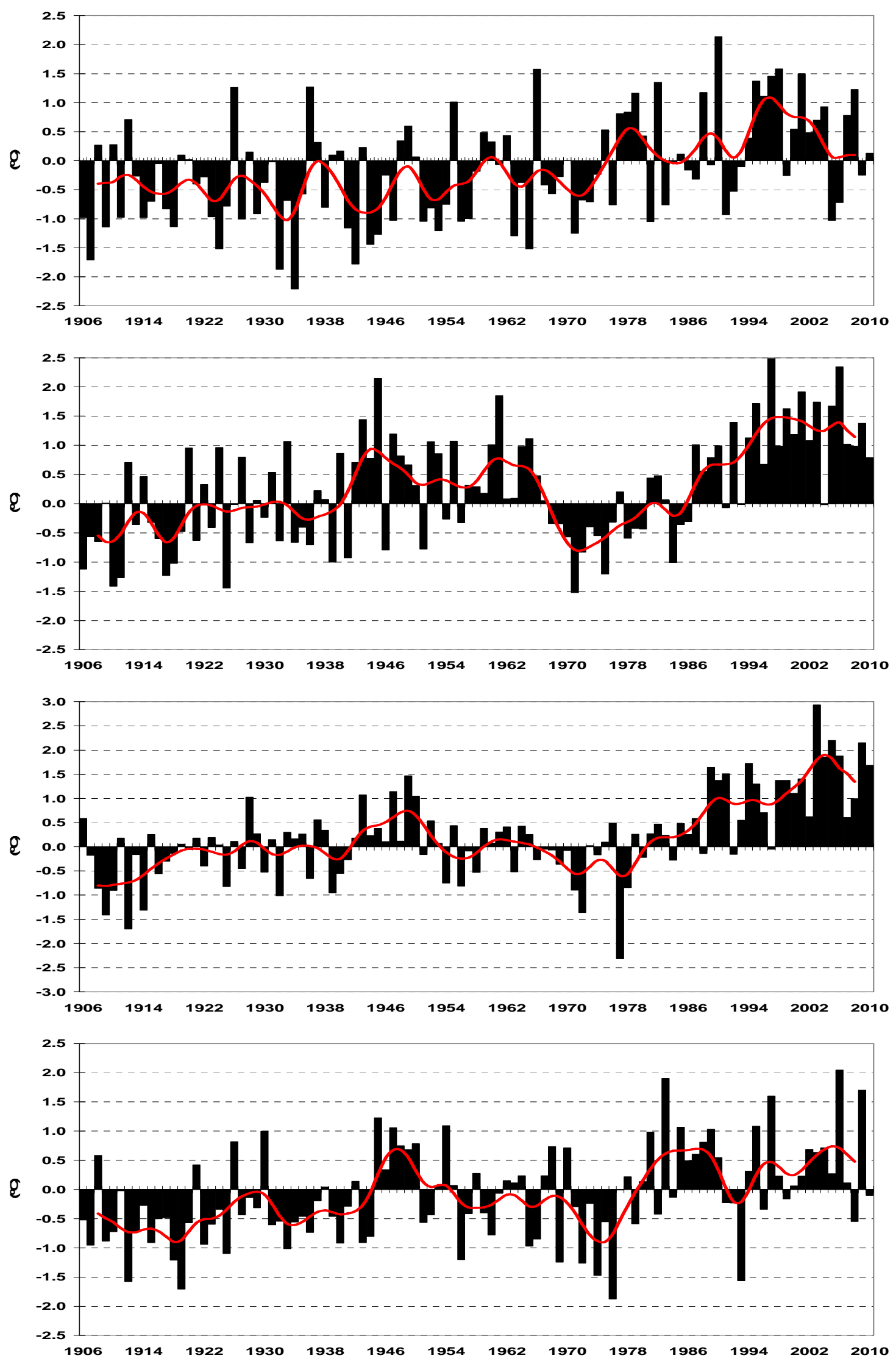

Figure 5-2: Seasonal temperature anomalies ordered as winter (DJF, upper panel), spring (MAM), summer (JJA) and autumn (SON, lower pannel) (base-period 1961-1990) in the Iberian Peninsula for the period 1906-2010. Red line represents a 10-year Gaussian filter applied over the annual series. 
Furthermore, the variability of summer temperatures show a short warming period at the beginning of the time-series, from 1912 to 1921, followed by a stabilization of temperatures until 1939. As occurred in spring temperatures, another warming period was identified from 1939 to 1949, although a decreasing period began in 1950 and prolonged until 1977, being the last one the coldest summer in the time-series. From then, a clear warming period was detected until 2005, being the summer of 2003 the warmest summer ever recorded in the Iberian Peninsula with an anomaly of almost $+3^{\circ} \mathrm{C}$. Finally, the variability of autumn temperatures show a first period of warming between 1919 and 1947 followed by a decreasing of temperatures until 1976 (the coldest autumn of the time-series). The last warming period began in 1977 and prolonged until 2010 in spite of this warmer period was not constant across time. 


\subsubsection{Annual and seasonal precipitation variability}

Annual precipitation anomalies for the whole period in the Iberian Peninsula are dominated by a high inter-annual variability accompanied by a slight increase statistically non-significant at the $95 \%$ level of $2.4 \mathrm{~mm} / \mathrm{decade}$ (Fig. 5-3). This is consistent with Trenberth et al., (2007), who did not detect a generalized and significant decrease of precipitation in the Mediterranean basin including the Iberian Peninsula. Other studies which dealt the evolution of the precipitation during the $20^{\text {th }}$ century or before concluded annual precipitation does not show appreciable changes in secular time scale (Lana and Burgueño, 2000; Llasat and Quintas, 2004; Saladié, 2004; Barrera-Escoda, 2008; CLIVAR, 2010).

Despite the high inter-annual variability, some dry and wet periods can be identified. From 1906 to 1935 dry conditions dominated but, between 1936 and 1942, wet conditions were more frequent, but dry conditions came back from 1943 to 1958. Then, very wet years appeared in 1960s and early 1970s, followed by a progressive dry conditions produced at the end of 1970s, 1980s, and more intense in 1990s. Finally, the first decade of $21^{\text {st }}$ century was generally dry with 2005 being the driest year of the Iberian time series.

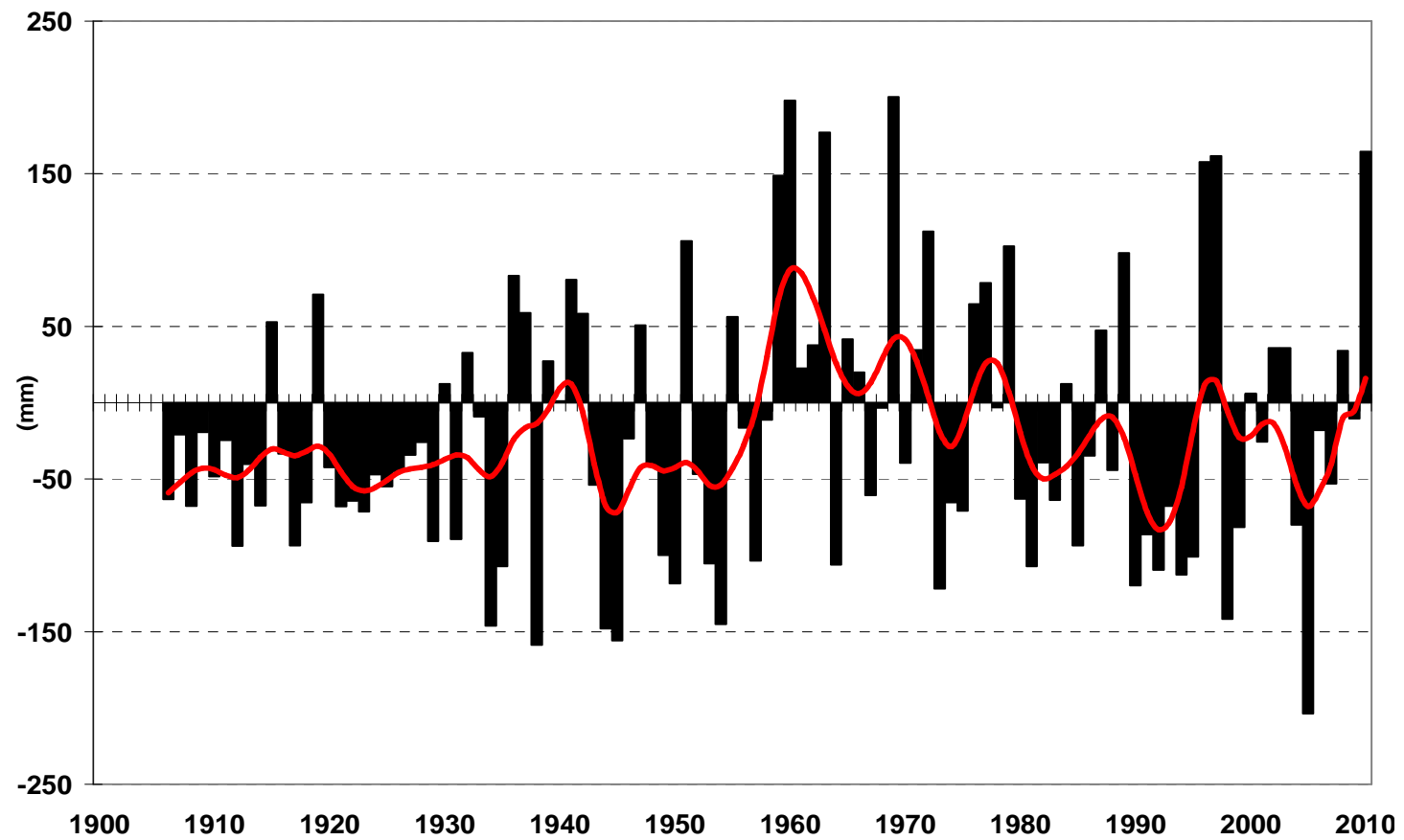

Figure 5-3: Annual precipitation anomalies (base-period 1961-1990) in the Iberian Peninsula for the period 1906-2010. Red line represents a 10-year Gaussian filter applied over the annual series. 
As occurred in annual precipitation, seasonal anomalies show a very high variability among years in all seasons and during all time-series long (Fig. 5-4). The variability of winter precipitation is based on the dominance of dry winters from 1906 to 1935 followed by a balanced combination of dry and wet winters between 1936 and 1958 . Wetter conditions dominated in 1960s and 1970s while dry winters came back in 1980s, 1990s and 2000s taking into account the isolated wettest winters of 1979, 1996 and 2010 ever recorded in the Iberian Peninsula. The variability of spring precipitation shows a balanced distribution of wet and dry springs during most of the time-series, although the dominance of wet springs was between mid-1940s and early-1960s while dry springs were focused from early-1980s to late-1990s. Moreover, the variability of summer precipitation shows a high variability among summers, but dry summers were found in 1910s, mid-1920s, mid-1930s, mid-late-1940s, 1960s and from 1978 to 2010. This last dry period was interrupted by wet summers occurred in 1982, 1983, 1987, 1988, 1992, 1997, 2002 and 2010, being 1992 the wettest summer of the time-series. Finally, the variability of autumn precipitation shows dry periods in late-1910s, from late-1920s to 1950s and in 1970s, wet periods in mid-1900s, early-1920s, in 1960s and in 1980s while the last three decades of the time-series were dominated by a high variability in autumn precipitation.

The linear trends computed for the seasonal precipitation anomalies show a nonsignificant increasing trend in winter and autumn precipitation (at the 95\% level) while a non-significant decreasing trend is also detected in spring and summer precipitation (Table 5-2).

\begin{tabular}{|c|c|c|c}
\hline Time-scale & Linear trend (mm/decade) & 95\% confidence intervals & p-value \\
\hline Annual & 2.442 & $(-2.857 / 8.072)$ & 0.457 \\
\hline DJF (Winter) & 2.139 & $(-1.797 / 6.300)$ & 0.401 \\
\hline MAM (Spring) & -0.338 & $(-2.681 / 1.977)$ & 0.696 \\
\hline JJA (Summer) & -0.140 & $(-1.228 / 1.078)$ & 0.713 \\
\hline SON (Autumn) & 0.450 & $(-2.919 / 3.876)$ & 0.663 \\
\hline
\end{tabular}

Table 5-2: Summary of linear trends (in mm/decade) computed for annual and seasonal precipitation in the Iberian Peninsula (1906-2010). The associated 95\% confidence intervals and p-values are also shown. Bold (or Italic) values are referred to statistical significance at the $99 \%$ level (or $95 \%$ ). 

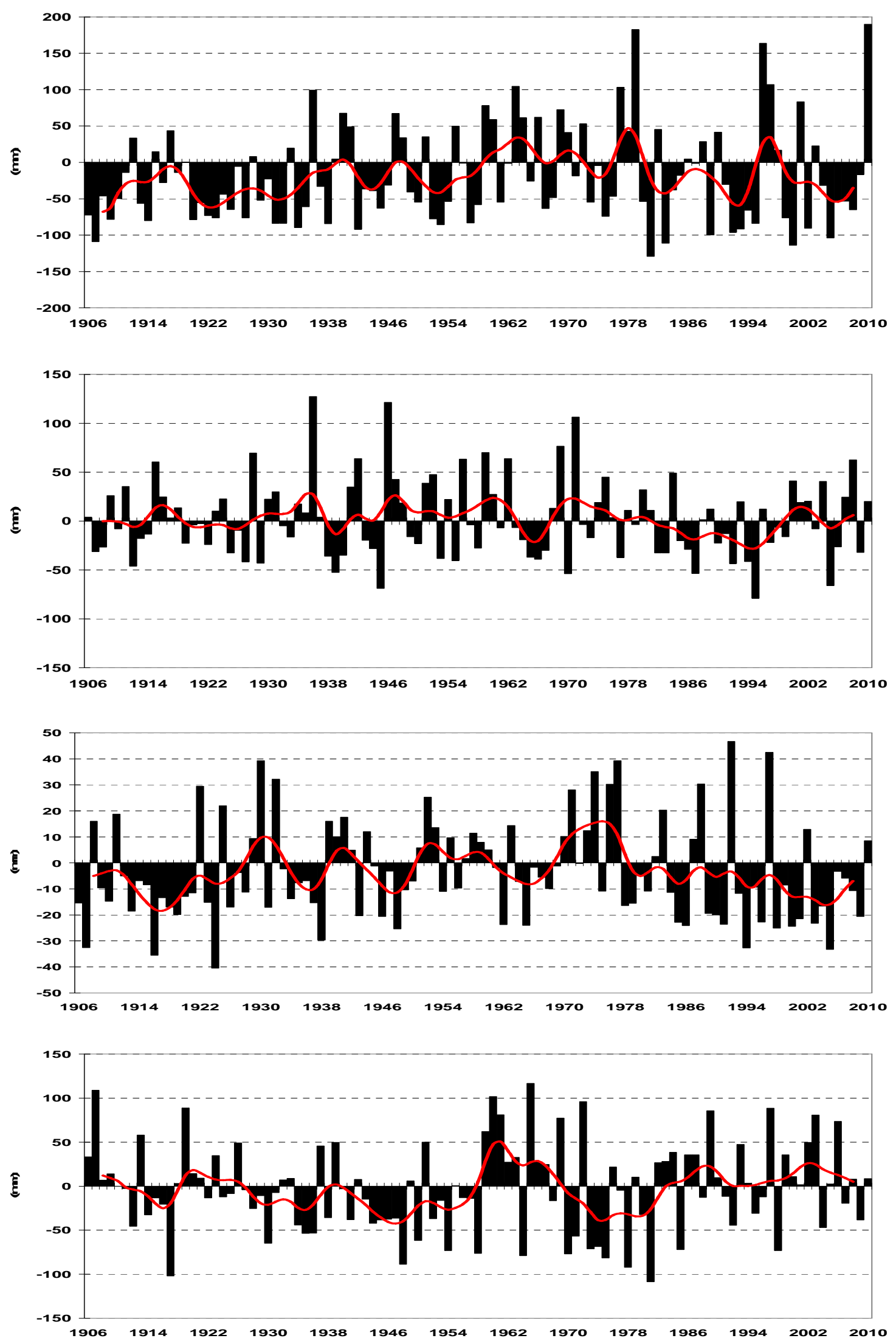

Figure 5-4: Seasonal precipitation anomalies ordered as winter (DJF, upper pannel), spring (MAM), summer (JJA), and autumn (SON, lower pannel) (base-period 1961-1990) in the Iberian Peninsula for the period 1906-2010. Red line represents a 10-year Gaussian filter applied over the annual series. 


\subsubsection{Summary}

Climate fluctuations over the Iberian Peninsula across the $20^{\text {th }}$ century and the first decade of the $21^{\text {st }}$ century show a remarkable increase in annual and seasonal temperatures being summer and spring the seasons with the highest rates of change. A high inter-annual and seasonal variability in precipitation is identified, but a clear signal related to the obtained trends is not found, although winter and autumn become slightly wetter while spring and summer are slightly drier currently than before.

But the increase in temperatures was not uniform across time taking into account that three different warming periods took place along the $20^{\text {th }}$ century; in the first quarter of the twentieth century, during the 1940s, and the warmest period with the highest rates of change began in early-1970s to present being 2006 the warmest year of the Iberian time series.

Despite the high inter-annual variability found in precipitation, dry periods can be identified in 1910s, 1920s, early-1930s, mid-1940s, 1950s and from 1980s to the present while wet periods can be found in mid-late-1930s, early-1940s, 1960s and 1970s. Finally, the first decade of $21^{\text {st }}$ century was generally dry with 2005 being the driest year of the Iberian time series. 


\subsection{Drought variability across the Iberian Peninsula}

In this section, we expose the results obtained after different analyses. First, the most widely used drought indices such as Sc-PDSI, 12-month SPEI and 12-month SPI are computed at monthly time scale to identify wet and dry periods across Iberian Peninsula along the 1906-2010 period. The most relevant droughts are identified and validated using documental sources. To ensure the quality of our results, the calibration of drought indices is checked. Afterwards, a trend analysis is carried out for the whole region under study as well as for each location individually in order to find out significant fluctuations in drought conditions. Furthermore, the role of temperature in drought indices is also assessed to quantify the effect of global warming on drought trends. Finally, we study the evolution of the drought spatial coverage across time.

\subsubsection{Identification and documentary validation of dry events}

Drought variability is analyzed over the whole Iberian Peninsula computing over regional series derived from MITPS the monthly Sc-PDSI (Fig. 5-5), 12-month SPI (Fig. 5-6) and 12-month SPEI outputs (Fig. 5-7) for the period 1906-2010 to detect wet and dry periods.

Drought variability according to Sc-PDSI (Fig. 5-5) shows wet conditions in late-1900, mid-1930s, early and late-1940s, early and late-1950s, early-1960s, in 1970s, mid-1990s and late-2000. Moreover, dry conditions are found in early-1900s, most of the 1920s and 1930s, mid-1940s, early-mid-1950s, late-1960s and in most of the last three decades of the time-series in which the driest conditions were identified over the Iberian Peninsula in 1995 and in 2005 respectively. Note that extremely dry conditions (less or equal than -4 in PDSI categories) are identified only in 1995 for the whole Iberian Peninsula (regional average) while extremely wet conditions (greater or equal than +4 in PDSI categories) are not found in the Iberian time-series.

Drought variability according to 12-month SPI (Fig. 5-6) shows higher frequency of wet and dry conditions than Sc-PDSI time-series, but wet conditions are detected in midlate-1930s, early and late-1940s, early and late-1950s, early-1960s, in 1970s, early1990s and in early and late-2000s. Furthermore, dry conditions are found in mid-1910s, early-mid-1920s, most of the 1930s, mid-1940s, mid-1950s, most of the 1960s and 
1970s, early-1980s, mid-1990s and mid-2000s. Extremely wet (greater or equal than +2 in SPI categories) or dry conditions (less or equal than -2 in SPI categories) are not found in regional SPI time-series.

Finally, drought variability according to 12-month SPEI (Fig. 5-7) shows wet conditions in late-1900s, early-1910s, mid-late-1930s, late-1940s, early-1950s, most of the 1960s and 1970s, late-1990s and late-2000s. Dry conditions are found in most of the 1920s and 1930s, mid-late-1940s, mid-late-1950s and in most of the last three decades of the SPEI time-series. Extremely dry conditions (less or equal than -2 in SPEI categories) are identified in 1995 and in 2005 respectively while extremely wet conditions (greater or equal than +2 in SPEI categories) are not found in regional SPEI time-series.

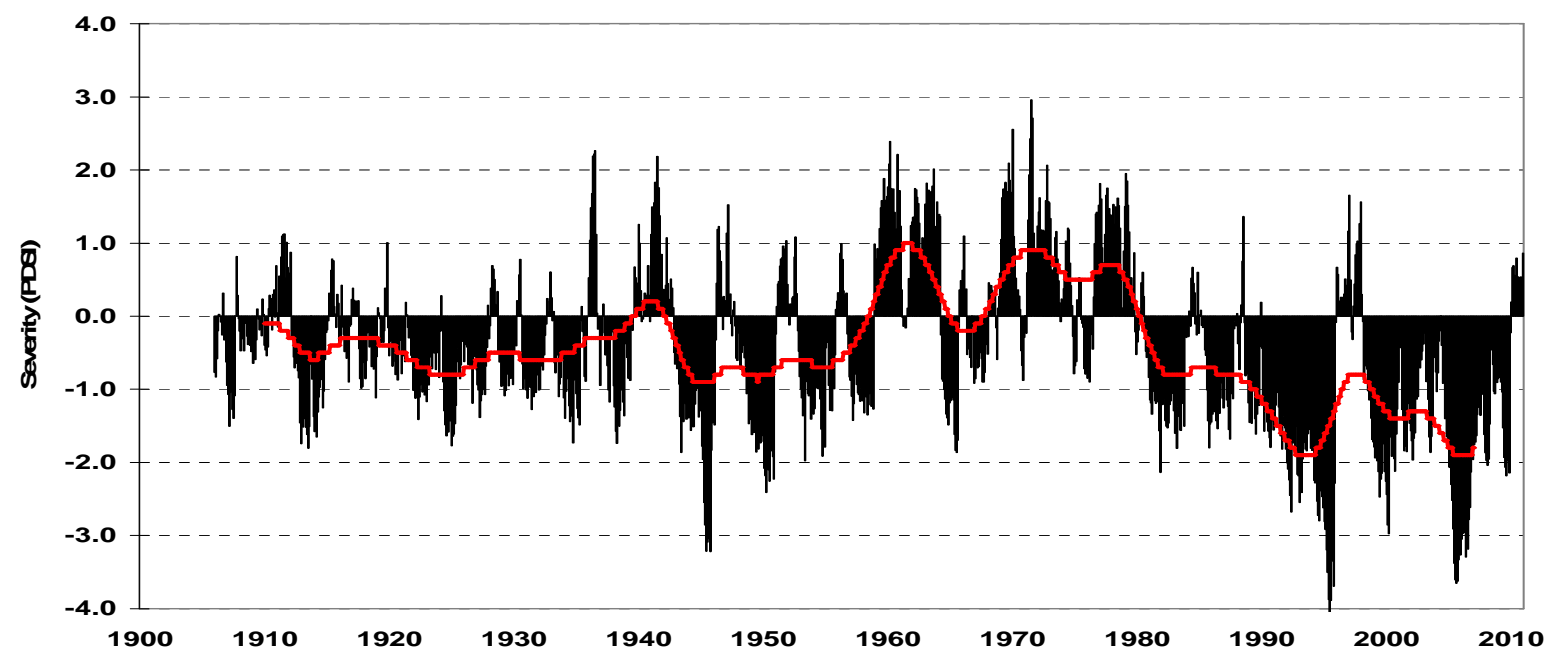

Figure 5-5: Variability of wet and dry conditions over the Iberian Peninsula (1906-2010) using Sc-PDSI. Red line represents a 10-year Gaussian filter applied over the annual series.

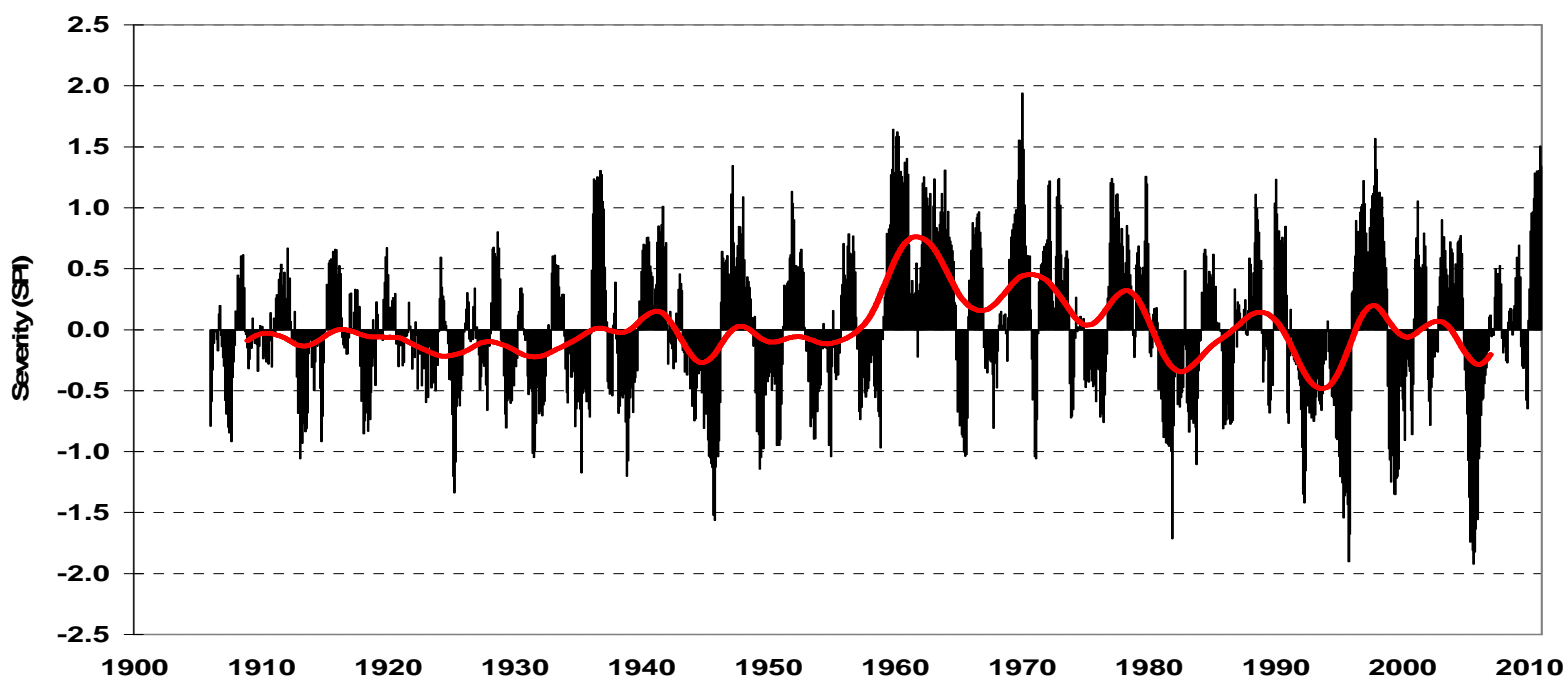

Figure 5-6: Variability of wet and dry conditions over the Iberian Peninsula (1906-2010) using 12-month SPI. Red line represents a 10-year Gaussian filter applied over the annual series. 


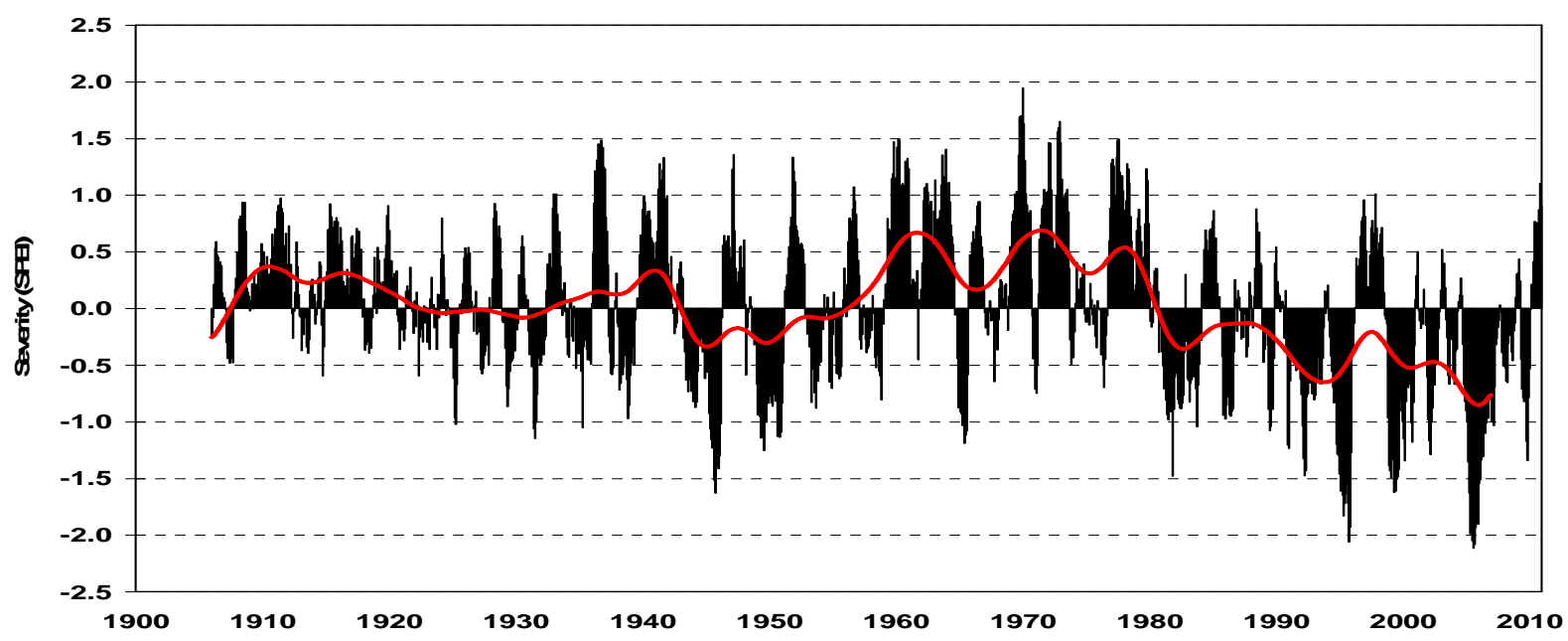

Figure 5-7: Variability of wet and dry conditions over the Iberian Peninsula (1906-2010) using 12-month SPEI. Red line represents a 10-year Gaussian filter applied over the annual series.

In general terms, the variability of wet and dry conditions computed over the three different drought indices for the Iberian Peninsula, shows quite a good agreement. The decades of 1920, 1940 and 1950 are abnormally dry in average while the decades of 1930, 1960 and 1970 are abnormally wet in all drought indices. The decade of 1910 is wet according to the 12-month SPEI time-series, but it is slightly dry in Sc-PDSI and 12-month SPI time-series. Moreover, the last three decades of the time-series are identified as abnormally dry in Sc-PDSI and 12-month SPEI while changing wet and dry conditions are identified by the 12-month SPI. The increase in severity and duration of abnormally dry periods from 1980 to present in Sc-PDSI and 12-month SPEI could be related to the role of the evapotranspiration in drought indices, because the last three decades are dominated by the maximum increase of temperatures in the Iberian Peninsula, in phase with less precipitation than normal. This fact highlights the importance of including temperature or evaporation in the evaluation of drought.

It is necessary to note that Sc-PDSI time-series show dry conditions during most of the time-period with the exception of 1960 and 1970 decades while 12-month SPI and 12month SPEI represented higher frequency of dry and wet conditions than Sc-PDSI during all the period. This statement could be related to some differences in calibration among drought indices. For this reason, an analysis of the frequency distribution of drought categories is needed to assess the statistical consistency and robustness of the drought indices.

Available documentary sources are inspected in order to validate the detected driest conditions from Sc-PDSI, 12-month SPI and 12-month SPEI. The most remarkable dry 
conditions are identified in 1945, in 1995 and in 2005. This can be seen in figures 5-5, 5-6 and 5-7. Documents obtained from official meteorological services or other publications provide valuable objective information about drought impacts occurred across time in the Iberian Peninsula.

EuskalMet (official regional meteorological service of the Basque Country autonomous government) provides crucial information about the dry event occurred from 1942 to 1945 in a document entitled "Recurrencia y efectos de las sequías" (Recurrence and effects of droughts) available at www.euskalmet.euskadi.net (Last visit 21-11-2010). This document provides insights not only about the meteorological situation during the event, compatible with a dry event, but also shows evidence of the occurrence droughtrelated impacts. For example, most reservoirs were under minimum levels after three consecutives dry years and most river flow levels were at their lowest value in 50 years. Furthermore, strong restrictions in water consumption, hydroelectric energy production and crop irrigation were applied in 1945, the driest year of this dry period. The drought impacts described in this document corroborate the fact that this dry event was remarkable in terms of severity, especially in 1945, and its duration prolonged during three years. Sc-PDSI, 12-month SPI and 12-month SPEI results totally agree with this document in terms of severity and duration of this event.

The most severe dry event in terms of severity identified by the Sc-PDSI, 12-month SPI and 12-month SPEI time series (1906-2010) is the 1990-1995 period. It is also the second worst in duration. Llamas (1995) indicated that this dry event affected especially central and southern Iberian Peninsula from 1991 to 1995. Llamas work "Consideraciones sobre la sequía de 1991 a 1995 en España" (Considerations about the drought occurred between 1991 and 1995 in Spain), described the severity and impacts of this dry event. In 1995, politicians called it "the worst drought in a century" and six million people suffered water restrictions in south and southeast of Spain. New water policies were applied by policymakers, such as regulations for saving water in crop irrigation, projects to transfer water from the Rhone river to Barcelona. Also sea water desalinization was explored for a first time as a futurible option to provide fresh water. Obviously, this drought caused territorial conflicts in the influence areas of TagusSegura transfer due to the lack of water in rivers and reservoirs. This information offers confirmation of the severe impacts of this dry event. 
Finally, the dry event occurred from 2004 to 2009 reached the maximum severity in 2005. At this time, the Spanish Meteorological Office (Agencia Estatal de Meteorología, AEMET) posted on its website www.aemet.es (Last visit: 09-06-2011) a map of the whole Iberian Peninsula showing the amount of precipitation recorded respect to the average (anomalies). Most of the months in this period were qualified as dry or very dry (less than $25 \%$ of normal precipitation) in the south, southwest, northeast and central area of Spain. This situation caused political conmotion and controversial measures as the preparation of a National Hydrological Plan, in order to provide water resources from Ebro's basin to other river basins located in the south of Spain. This intention - which never materialized due to political changes - was associated with strong demonstrations agains it by people in the Ebro's area. In 2008 the drought worsened in the northeast of Iberian Peninsula causing water restrictions and again some political conflicts in Catalonia. The Catalan government projected and started to build a water pipe across the highway from the Ebro's area to Barcelona to provide water to this city and its population of more than 3 million inhabitants. The end of the dry event timely arrived and the water pipe project was abandoned.

This valuable information is able to validate the results obtained from Sc-PDSI, 12month SPI and 12-month SPEI computation, because the detected dry events are supported by documented impacts demonstrating the negative effects of the severity and duration of the most relevant droughts identified in the Iberian Peninsula from 1906 to 2010. 


\subsubsection{Frequency distribution analysis}

In the application of the Self-calibrated version of PDSI, 12-month SPI and 12-month SPEI it is important to check how the drought index values are distributed into their different categories. Figures 5-8, 5-9 and 5-10 show the frequency distribution of ScPDSI values, 12-month SPI values and 12-month SPEI values, respectively, for the 22 stations located in the Iberian Peninsula using the whole period (1906-2010). The most common values fall in the near-normal category. This is a sign of good calibration, especially in 12-month SPEI frequency distribution, although a few stations show deviances from the expected behaviour in the case of 12-month SPI and in the Sc-PDSI computation. Some of these deviances might be linked to problems in the drought index calibration. On the other hand, Wells et al., (2004) described that between 1\% and 3\% of PDSI values for each time series should be located in extremely wet or dry categories in order to provide a good calibration. In this case, the $91.7 \%$ of the 22 time series accomplish this requirement, because between $1 \%$ and $3 \%$ of PDSI values remained in extremely wet category and the $87.5 \%$ accomplished the same, but in extremely dry category. These results are similar to those obtained by Wells et al. (2004) and Briffa et al. (2009) from the computation of the Sc-PDSI using various time series. But the $77.3 \%$ of the 22 time-series relative to 12 -month SPI remain in the extremely wet category while the $86.4 \%$ are in the extremely dry category. Otherwise, the $100 \%$ of the 22 12-month SPEI time series accomplish this purpose in extremely wet category, and the $87.5 \%$ of the 22 12-month SPEI series remain in extremely dry category. The conclusion of this analyisis is that we find a better calibration in 12-month SPEI values than in Sc-PDSI and 12-month SPI values over the Iberian Peninsula in terms of robustness and statistical consistency. Thus, the SPEI is our preferred index for further analysis. 
Frequency distribution of PDSI values

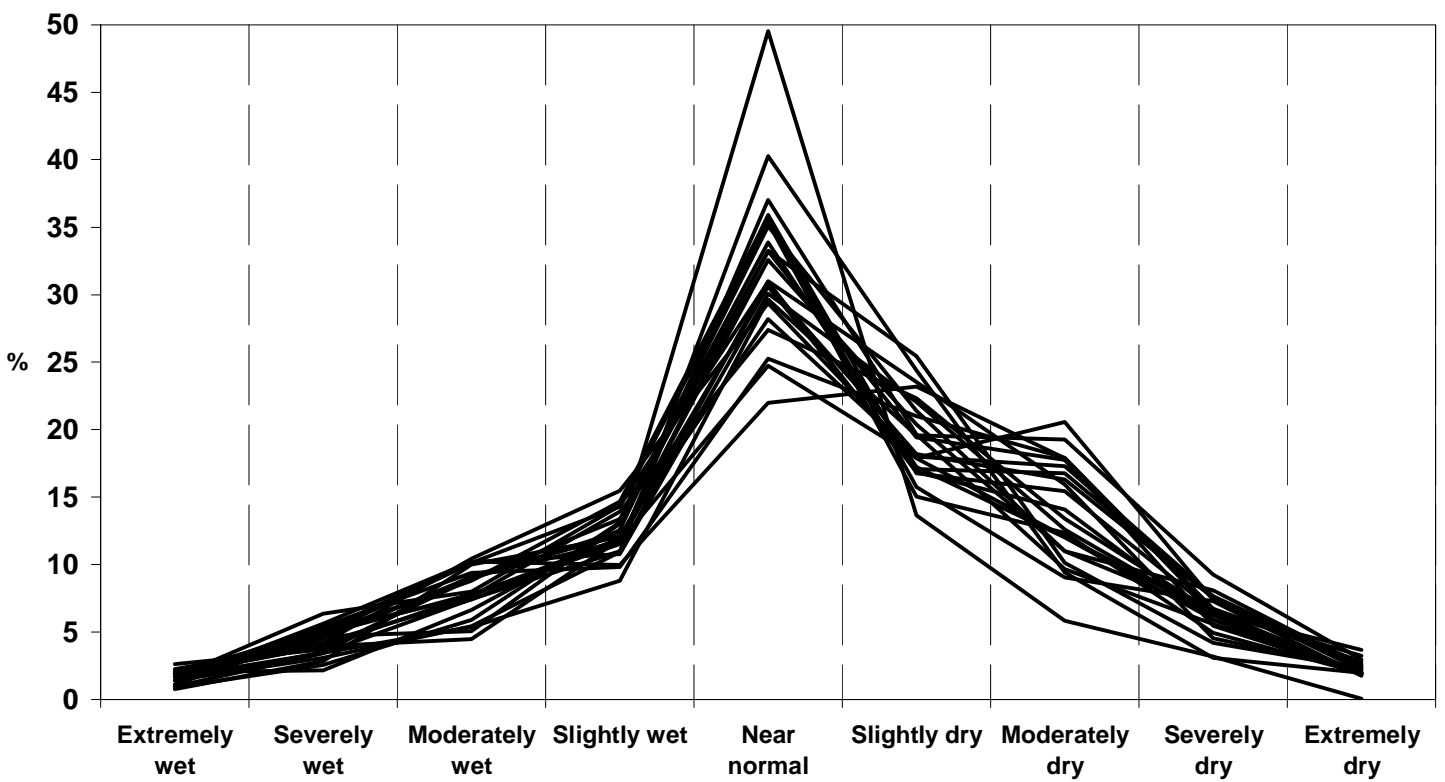

Figure 5-8: Frequency distribution (in \%) of monthly Sc-PDSI values over the major PDSI categories computed from the 22 Iberian stations (1906-2010).

\section{Frequency distribution of SPI values}

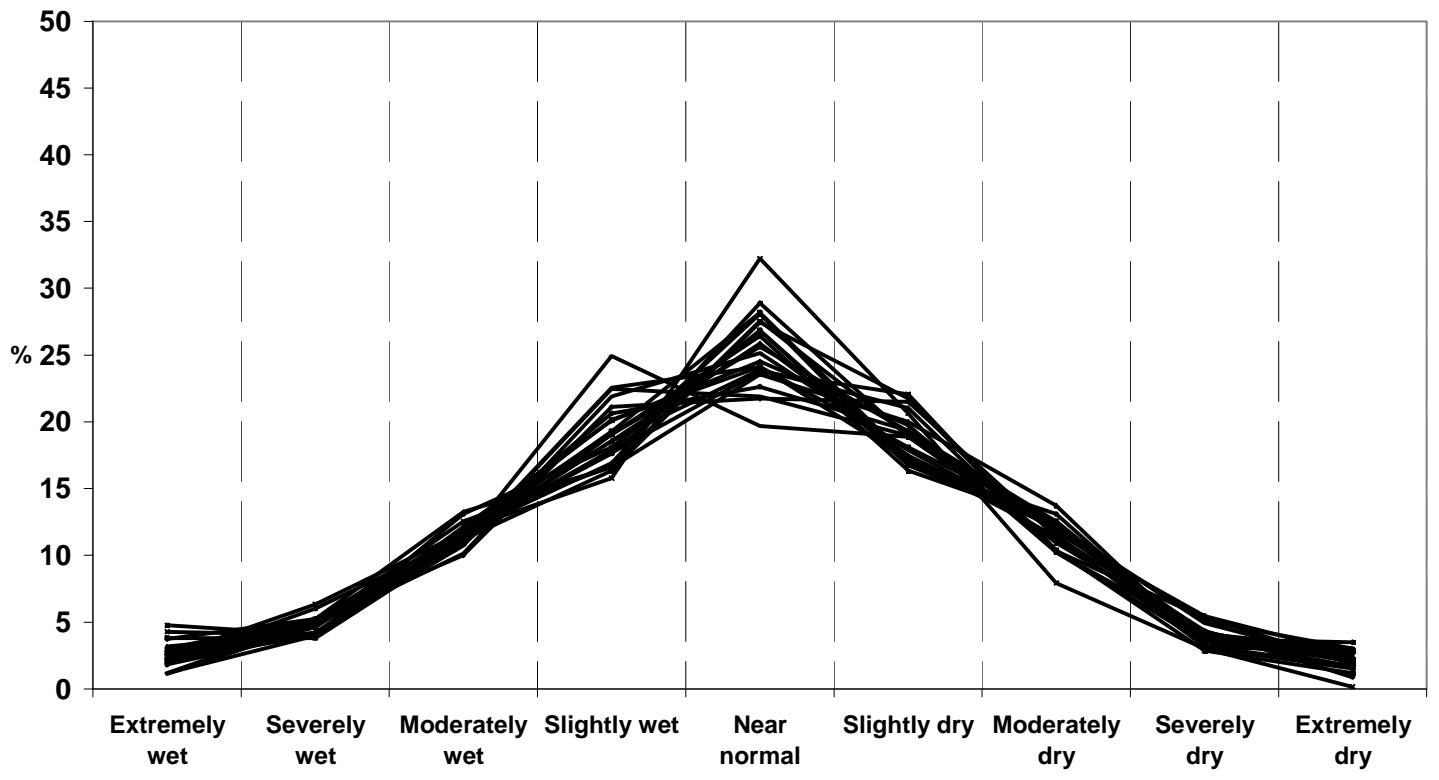

Figure 5-9: Frequency distribution (in \%) of 12-month SPI values over the major SPI categories computed from 22 Iberian stations (1906-2010). 


\section{Frequency distribution of SPEI values}

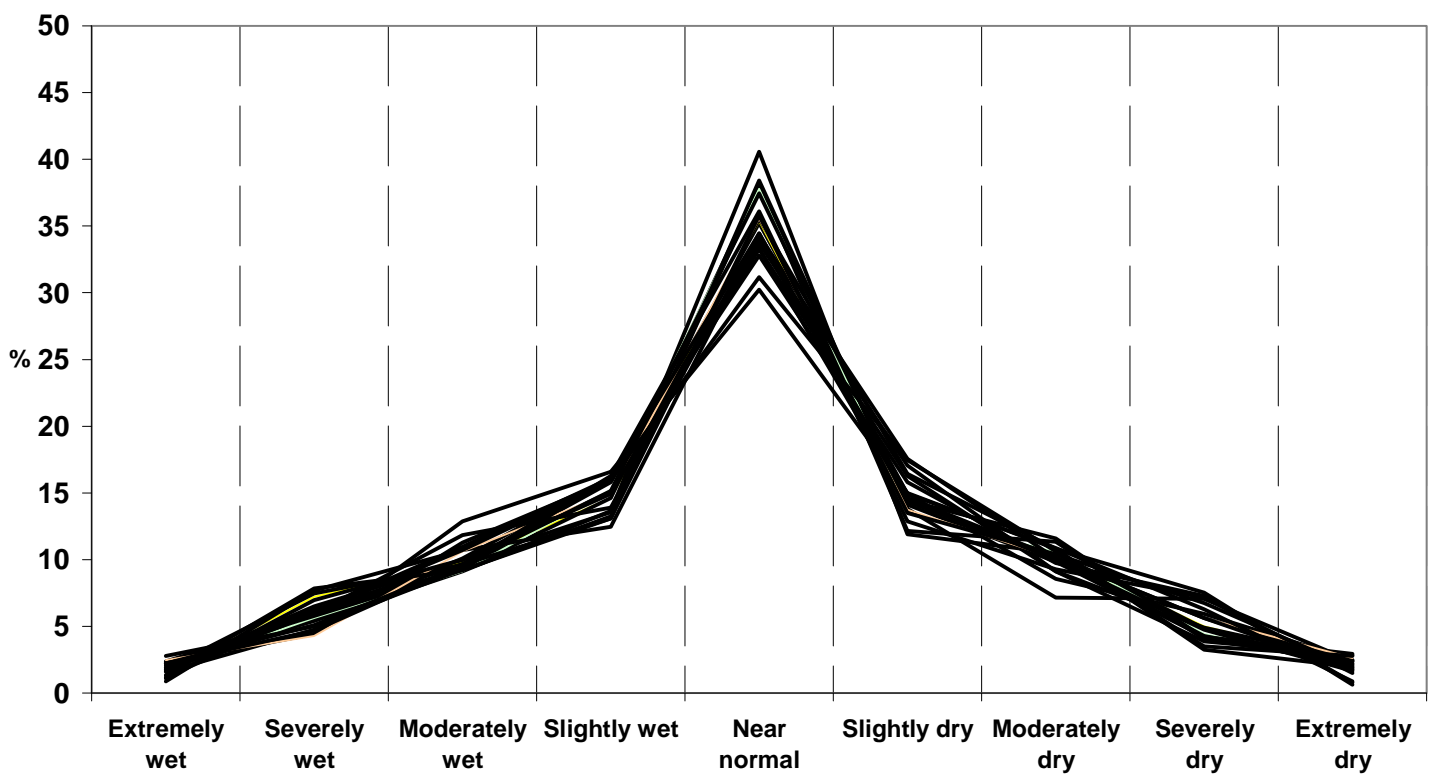

Figure 5-10: Frequency distribution (in \%) of 12-month SPEI values over the major SPEI categories computed from 22 Iberian stations (1906-2010). 


\subsubsection{Spatial coverage of droughts}

Besides the computation of a regional time series from each one of the selected drought indices, it is interesting to study the spatial distribution of dry conditions in the Iberian Peninsula across time. This is done by checking the percentage of stations simultaneously affected by different categories of drought. This analysis provides us complementary but important information: do the three drought indices obtain similar areas for the different categories of drought in the different events? Figures 5-11, 5-12 and 5-13 represent the percentages of stations affected by various categories of drought across time according to PDSI categories (Table 4-3), SPI categories (Table 4-4) and SPEI categories (Table 4-5).

It can be seen that the highest percentages of stations affected by dry conditions (values below 0 in drought indices) coincide with the longest and driest periods described above (see fig. 5-5, 5-6 and 5-7). In fact, Pearson Product-Moment Correlation coefficient between the drought Iberian time-series (severity) and the percentage of stations affected by dry conditions across time (surface area) is -0.88 for Sc-PDSI, -0.94 for 12-month SPI and 0.95 for 12-month SPEI (all statistically significant at the $99 \%$ level).

Dry conditions affected $100 \%$ of stations under study during a few months in mid1910s, mid-1920s, late-1930s, mid-1940s, early-1950s, early-mid-1980s, four times in 1990s, and three time in early-mid-2000s using Sc-PDSI time-series (Fig. 5-11). It is remarkable that more than $30 \%$ of stations remained permanently in dry conditions during the 2001-2009 period. Severe conditions affected greater than 50\% of stations in 1945, 1950, 1992, 1995, 1999, 2000, 2005 and 2006 while greater than $70 \%$ of stations reached this drought category in 1945, 1995 and 2005. The extremely dry category was reached by more than $25 \%$ of stations in 1945, 1950, 1992, 1995, 2000, 2005 and 2006, while more than $40 \%$ of stations reached this category only in 1945, 1995 and 2005.

Otherwise, dry conditions affected $100 \%$ of stations during a few months in 1925, 1935, 1981, 1995, 1999 and 2005 using 12-month SPI time-series (Fig. 5-12). However, more than $50 \%$ of stations were affected by severe dry conditions in 1945, 1949, 1981, 1992, 1995 and 2005, while greater than $70 \%$ of stations reached this drought category only in 2005. The extremely dry category was reached by greater than $25 \%$ of stations in 1945 , 1949, 1981, 1992, 1995 and 2005, while greater than $40 \%$ of stations reached this category only in 1995 and 2005. 
Dry conditions affected $100 \%$ of stations under study during a few months in mid1930s, mid-1940s, mid-1960s, early-1980s, three times in 1990s and in early-mid-2000s using 12-month SPEI time-series (Fig. 5-13). Note that around 25\% of stations were almost permanently in dry conditions during the last decade (except in 2010). Moreover, more than $50 \%$ of stations were affected by severely dry conditions in 1945 , 1949, 1992, 1995, 1999, 2005 and 2009, while greater than $70 \%$ of stations reached this drought category in 1945, 1995, 1999 and 2005. Furthermore, greater than 25\% of stations were affected by extremely dry conditions in 1945, 1949, 1992, 1995 and 2005 reaching more than $60 \%$ of stations during these two last events.

All drought indices have been able to identify a similar surface area affected by dry conditions in the Iberian Peninsula across time. Moreover, the driest periods in terms of severity identified through the regional series analyisis are found again as the driest periods in terms of affected area. All drought indices coincide to attribute the driest conditions (in terms of severity and area affected by drought) identified in the Iberian Peninsula along the $20^{\text {th }}$ century to years 1945,1995 and 2005.

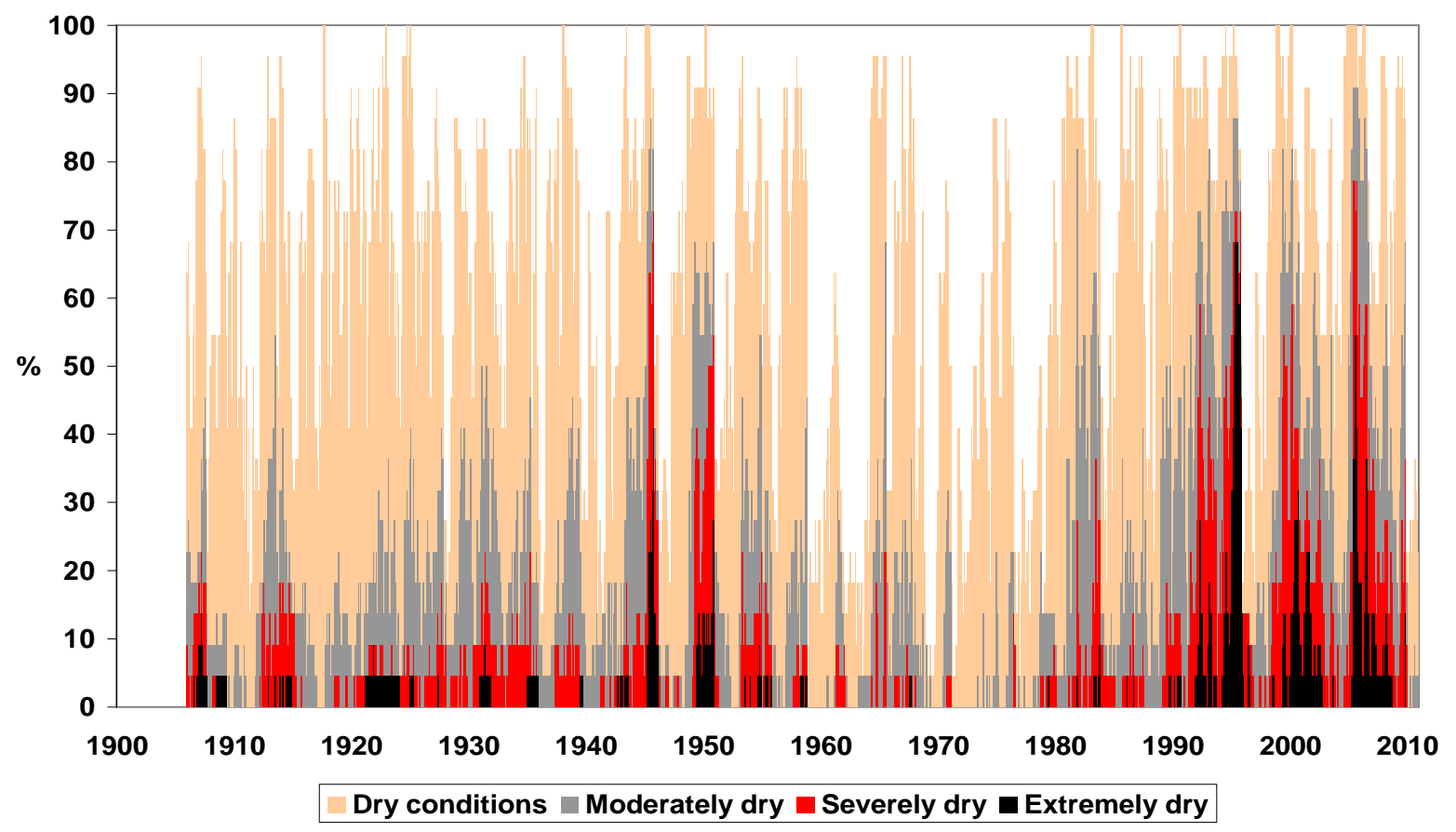

Figure 5-11: Percentages of stations affected by various categories of drought in Sc-PDSI individual stations in the Iberian Peninsula from 1906 to 2010. 


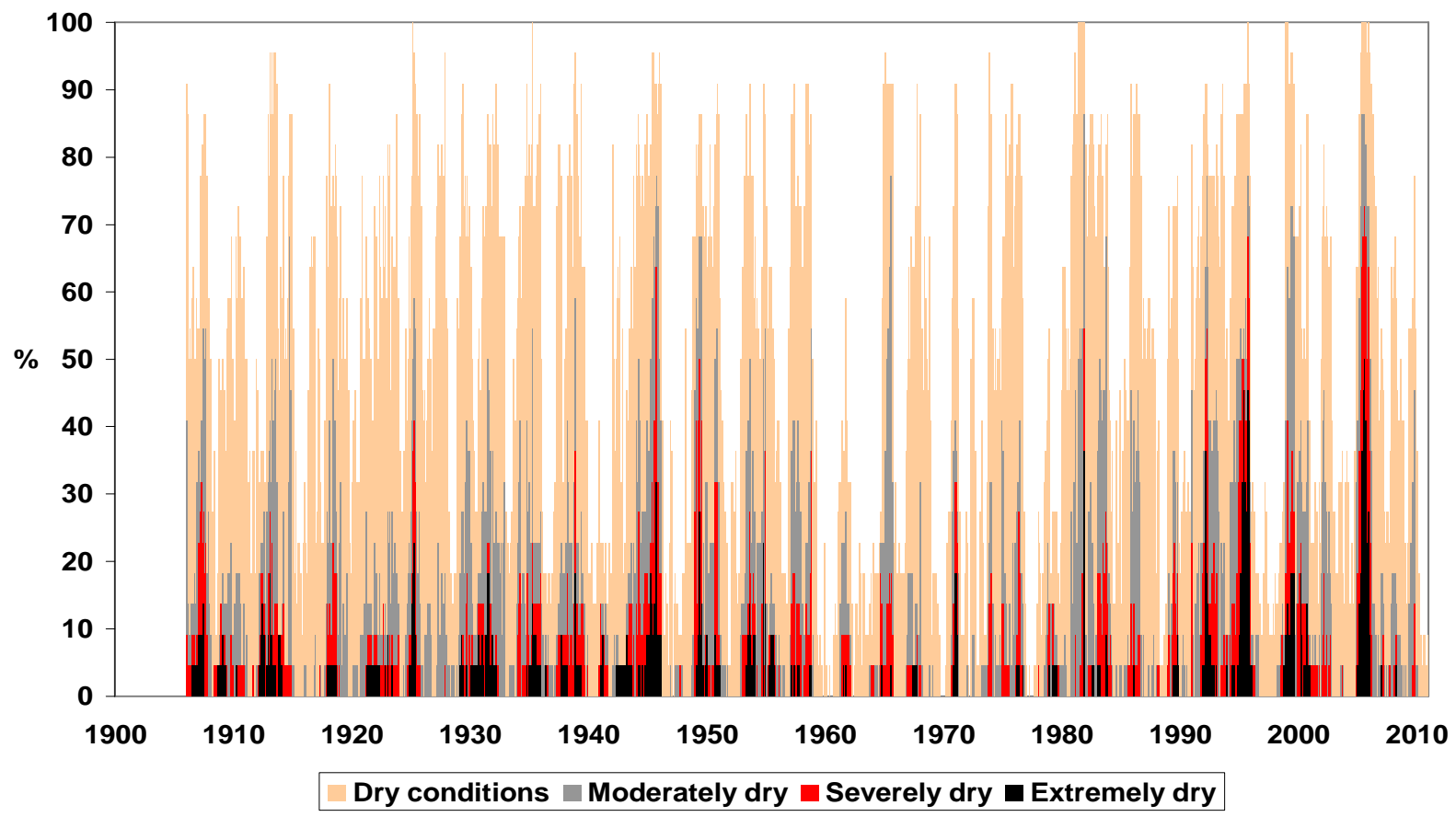

Figure 5-12: Percentages of stations affected by various categories of drought in 12-month SPI individual stations in the Iberian Peninsula from 1906 to 2010.

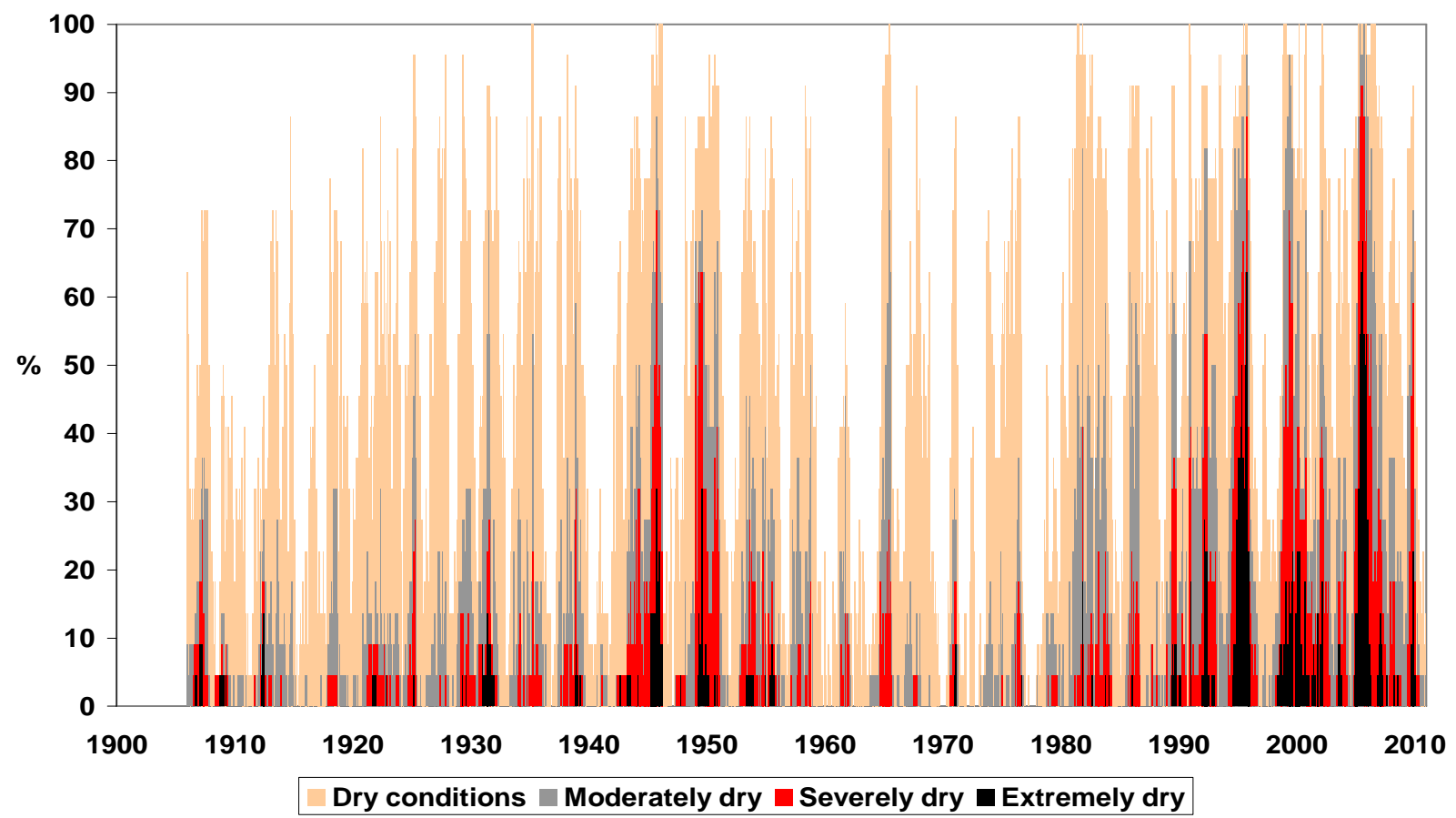

Figure 5-13: Percentages of stations affected by various categories of drought in 12-month SPEI individual stations in the Iberian Peninsula from 1906 to 2010. 


\subsubsection{Drought trends analysis}

This section shows the annual trends computed from the Sc-PDSI, 12-month SPI and 12-month SPEI for both; the regional Iberian time-series and also for the 22 Iberian stations. Moreover, the impact of global warming on drought indices and trends is also assessed to demonstrate the role of PET on droughts in a climate change context.

\subsubsection{Drought evolution across the regional Iberian time series}

After computing the three drought indices used in this work for the 22 Iberian time series individually, the 22 drought time series are averaged to create the regional drought time-series. We compute the annual trends and their statistical significance using the three regional drought time-series (one for each drought index) over the entire Iberian Peninsula for the whole period (1906-2010). Table 5-3 shows annual trends with the associated $95 \%$ confidence intervals and p-values computed using the three drought indices for the whole Iberian Peninsula (1906-2010).

Sc-PDSI and 12-month-SPEI show a non-statistically significant drying trend while a non-significant wetting trend is obtained using 12-month SPI (all at the 95\% level) for the regional drought time-series for the entire Iberian Peninsula.

The results obtained using the Sc-PDSI and 12-month SPEI are in good agreement with other drying trends found across Europe (Brázdil et al., 2008 (for Czech Republic), Mavromatis 2007 (for Greece), Briffa et al., 2009 (for Europe in summer), Vicente-Serrano et al., 2010 (for selected locations around the world), and Vicente-Serrano et al., 2006; Sousa et al., 2010 and Lorenzo-Lacruz et al., 2012 (for the Iberian Peninsula).

\begin{tabular}{|c|c|c|c|}
\hline Drought index & Linear trend & 95\% confidence intervals & p-values \\
\hline Sc-PDSI & $-0.076 \mathrm{PDSI}$ value/decade & $(-0.167 / 0.035)$ & 0.17 \\
\hline 12-month SPI & $0.022 \mathrm{SPI}$ value/decade & $(-0.024 / 0.064)$ & 0.38 \\
\hline 12-month SPEI & $-0.049 \mathrm{SPEI}$ value/decade & $(-0.101 / 0.004)$ & 0.07 \\
\hline
\end{tabular}

Table 5-3: Summary of annual trends (in drought index value/decade) computed for the whole Iberian Peninsula (1906-2010) using all drought indices. The associated 95\% confidence intervals and pvalues are also shown. Bold (or Italic) values are referred to statistical significance at $99 \%$ level (or 95\%). 


\subsubsection{Drought evolution across the 22 Iberian stations}

Once drought trends were computed for the regional Iberian time series, trend values from the Sc-PDSI, 12-month SPI and 12-month SPEI are calculated for each station at annual time-scale for the common period 1906-2010 in order to find spatial differences in drought trend evolution over the Iberian Peninsula. The maps show the annual trends and the associated statistical significance of the 22 locations spread over the Iberian Peninsula for the common period 1906-2010 using Sc-PDSI (Fig. 5-14, a), 12-month SPI (Fig. 5-14, b) and 12-month SPEI (Fig. 5-14, c). The kriging's spatial interpolation method has been applied to cover the entire study area. This method is based on the idea that the value at an unknown point should be the average of the known values at its neighbours; weighted by neighbours distance to the unknown point. The trend values, the $95 \%$ confidence intervals and the associated p-values for each location are also shown for ScPDSI (Table 5-4), for 12-month SPI (Table 5-5) and for 12-month SPEI (Table 5-6).

Figure 5-14a shows a map of trends computed over the Sc-PDSI series. Negative trends (drying trend) are identified over most of the Iberian Peninsula reaching maximum rates of change in the Pyrenees, Cantabrian range, North and South Plateau and, especially, in the southernmost region. These trends are statistically significant in the southern area (Cadiz, Málaga and Granada; at the 99\% level) and in Madrid and Sevilla (at the 95\% level). However, positive trends (wetting trend) are detected in western Iberian Peninsula although they are statistically significant only in Lisboa (at the 95\% level).

Figure 5-14b shows the trends obtained with the 12-month SPI-series. A nonstatistically significant drying trend (at the 95\% level) is found in the Ebro basin and in the central-western Iberia reaching maximum rates of change in the Pyrenees and in the south and south-eastern area. However, a wetting trend is identified in the north and central Mediterranean coast, in the North and South Plateau and in the northern Iberia. Maximum rates of change are found in the north-western and western area, especially in Lisboa, where the wetting trend is statistically significant at the $95 \%$ level.

Finally, figure 5-14c shows the trends obtained with 12-month SPEI. A drying trend is found over most of the Iberian Peninsula, reaching maximum rates of change in the Ebro basin, central and southern Iberia and, especially in the south-eastern area This is statistically significant in Granada (at the 99\% level), Zaragoza, Madrid, Sevilla, Càdiz, 
Málaga, Alicante and Murcia (at the 95\% level). A non-significant (95\% level) wetting trend is identified in the western and north-western Iberia.

a)
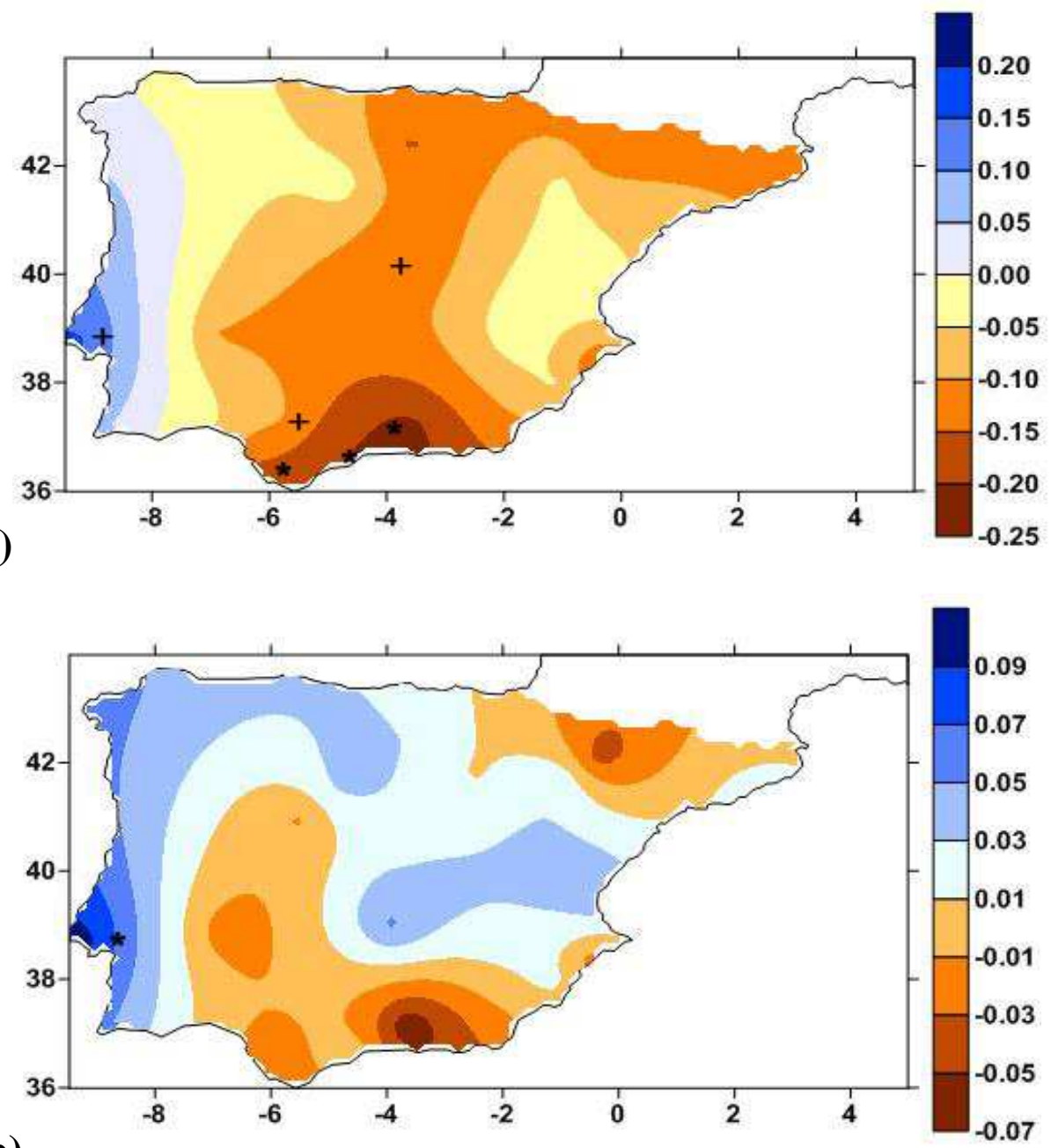

b)

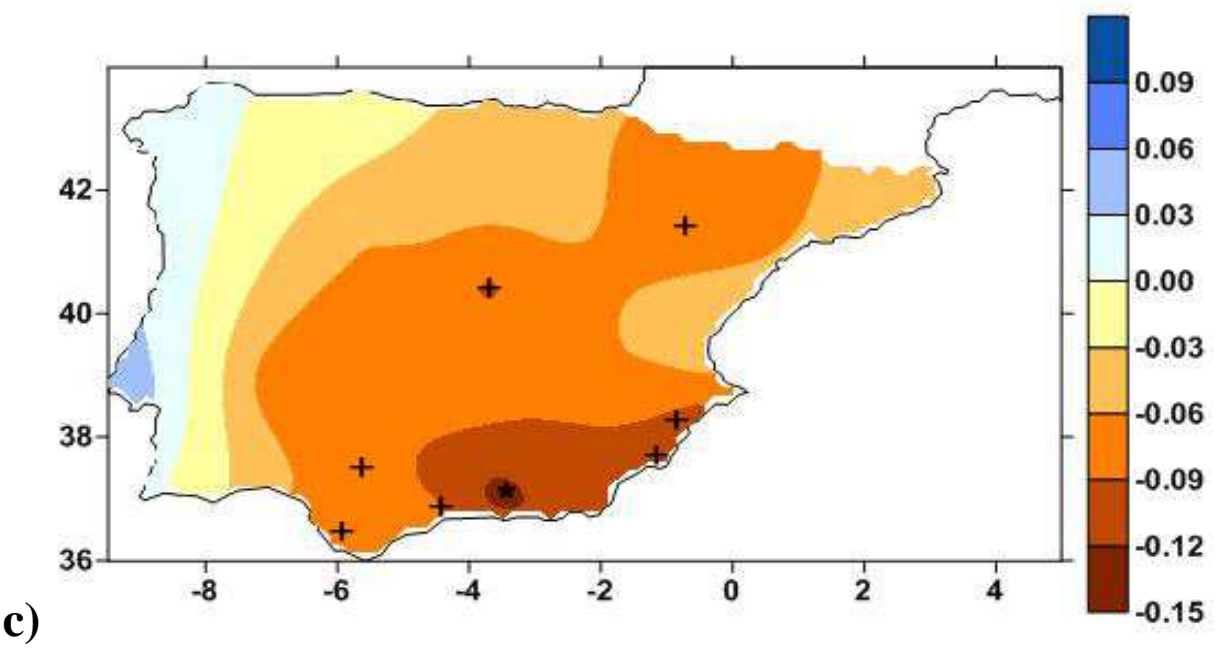

Figure 5-14: Maps of annual trends (in drought index value/decade) computed for the 22 locations (19062010) using Sc-PDSI (a); 12-month SPI (b); and 12-month SPEI (c). Negative (or positive) trends represent drier (or wetter) conditions. * (or + ) symbol are referred to statistical significance at the $99 \%$ level (or 95\%). Spatial interpolation is applied using the Kriging method. 
To summarize, all drought indices show a drying trend in the Pyrenees, Ebro basin, central Iberia and in the south, south-western and south-eastern area while a wetting trend is found in the western and north-western Iberian Peninsula. These results are consistent with Sousa et al., (2011) (using Sc-PDSI), Vicente-Serrano et al., (2011) (using SPI and SPEI indices) and Lacruz et al., (2012) (using stream-flow data), whom detected that droughts increased over most of the Iberian Peninsula with the exception of the north-west area of the region for the $20^{\text {th }}$ century. Moreover, an increase of regional drought severity was also found in the Ebro basin (Vicente-Serrano and CuadratPrats, 2006; Vicente-Serrano and López-Moreno, 2006), in some areas of Valencia region (Vicente-Serrano et al., 2004) and in Tagus basin (Lorenzo-Lacruz et al., 2010).

\begin{tabular}{|c|c|c|c|}
\hline Location & Annual coefficient (Sc-PDSI value/decade) & 95\% confidence intervals & p-values \\
\hline Albacete & -0.017 & $(-0.207 / 0.219)$ & 0.877 \\
\hline Alicante & -0.102 & $(-0.265 / 0.061)$ & 0.217 \\
\hline Badajoz & -0.129 & $(-0.277 / 0.043)$ & 0.123 \\
\hline Barcelona & -0.132 & $(-0.294 / 0.035)$ & 0.116 \\
\hline Burgos & -0.181 & $(-0.415 / 0.042)$ & 0.134 \\
\hline Cadiz & -0.176 & $(-0.294 /-0.064)$ & 0.002 \\
\hline Ciudad Real & -0.112 & $(-0.217 / 0.041)$ & 0.168 \\
\hline Granada & -0.230 & $(-0.381 /-0.075)$ & 0.004 \\
\hline Huelva & -0.046 & $(-0.264 / 0.071)$ & 0.572 \\
\hline Huesca & -0.144 & $(-0.342 / 0.040)$ & 0.106 \\
\hline La Coruña & 0.001 & $(-0.194 / 0.159)$ & 0.899 \\
\hline Lisboa & 0.155 & $(0.058 / 0.249)$ & 0.021 \\
\hline Madrid & -0.147 & $(-0.253 /-0.049)$ & 0.022 \\
\hline Málaga & -0.222 & $(-0.379 /-0.006)$ & 0.009 \\
\hline Murcia & -0.046 & $(-0.249 / 0.057)$ & 0.807 \\
\hline Porto & 0.064 & $(-0.143 / 0.272)$ & 0.824 \\
\hline Salamanca & -0.077 & $(-0.186 / 0.117)$ & 0.423 \\
\hline Sevilla & -0.085 & $(-0.270 /-0.005)$ & 0.040 \\
\hline Soria & -0.113 & $(-0.233 / 0.004)$ & 0.277 \\
\hline Valencia & 0.012 & $(-0.101 / 0.217)$ & 0.619 \\
\hline Valladolid & -0.025 & $(-0.224 / 0.068)$ & 0.557 \\
\hline Zaragoza & -0.040 & $(-0.165 / 0.162)$ & 0.284 \\
\hline
\end{tabular}

Table 5-4: Summary of annual trends (in PDSI value/decade) computed for the 22 locations (1906-2010) using Sc-PDSI. The associated $95 \%$ confidence intervals and p-values are also shown. Negative (or positive) trends represent drier (or wetter) conditions. Bold (or Italic) values are referred to statistical significance at the $99 \%$ level (or 95\%). 


\begin{tabular}{|c|c|c|c|}
\hline Location & Annual coefficient (SPI value/decade) & 95\% confidence intervals & p-values \\
\hline Albacete & 0.024 & $(-0.031 / 0.110)$ & 0.248 \\
\hline Alicante & -0.017 & $(-0.066 / 0.066)$ & 0.877 \\
\hline Badajoz & -0.021 & $(-0.082 / 0.048)$ & 0.524 \\
\hline Barcelona & 0.017 & $(-0.032 / 0.065)$ & 0.535 \\
\hline Burgos & 0.029 & $(-0.039 / 0.094)$ & 0.407 \\
\hline Cadiz & -0.021 & $(-0.102 / 0.043)$ & 0.460 \\
\hline Ciudad Real & 0.054 & $(-0.001 / 0.137)$ & 0.053 \\
\hline Granada & -0.067 & $(-0.137 / 0.003)$ & 0.061 \\
\hline Huelva & 0.001 & $(-0.064 / 0.083)$ & 0.726 \\
\hline Huesca & -0.039 & $(-0.119 / 0.047)$ & 0.401 \\
\hline La Coruña & 0.053 & $(-0.024 / 0.122)$ & 0.165 \\
\hline Lisboa & 0.096 & $(0.028 / 0.169)$ & 0.006 \\
\hline Madrid & 0.024 & $(-0.039 / 0.093)$ & 0.436 \\
\hline Málaga & -0.001 & $(-0.085 / 0.065)$ & 0.734 \\
\hline Murcia & 0.016 & $(-0.064 / 0.109)$ & 0.679 \\
\hline Porto & 0.050 & $(-0.025 / 0.108)$ & 0.217 \\
\hline Salamanca & -0.012 & $(-0.077 / 0.066)$ & 0.859 \\
\hline Sevilla & -0.010 & $(-0.095 / 0.065)$ & 0.717 \\
\hline Soria & 0.008 & $(-0.049 / 0.086)$ & 0.659 \\
\hline Valencia & 0.046 & $(-0.026 / 0.124)$ & 0.197 \\
\hline Valladolid & 0.038 & $(-0.033 / 0.104)$ & 0.272 \\
\hline Zaragoza & 0.027 & $(-0.047 / 0.085)$ & 0.599 \\
\hline
\end{tabular}

Table 5-5: Summary of annual trends (in SPI value/decade) computed for the 22 locations (1906-2010) using 12-month SPI. The associated 95\% confidence intervals and p-values are also shown. Negative (or positive) trends represent drier (or wetter) conditions. Bold (or Italic) values are referred to statistical significance at the $99 \%$ level (or 95\%).

Some differences in annual trends among drought indices could be identified in both; individual and regional time-series. The annual trends are larger in drought indices which temperature is included in their computation (Sc-PDSI and 12-month SPEI) than in which the main driver of drought variability is only precipitation (12-month SPI). For this reason, it is interesting to assess the role of temperature in drought indices computation to quantify the impact of current global warming on drought trends. 


\begin{tabular}{|c|c|c|c|}
\hline Location & Annual coefficient (SPEI value/decade) & 95\% confidence intervals & p-values \\
\hline Albacete & -0.065 & $(-0.133 / 0.026)$ & 0.188 \\
\hline Alicante & -0.105 & $(-0.161 /-0.018)$ & 0.019 \\
\hline Badajoz & -0.085 & $(-0.135 / 0.001)$ & 0.052 \\
\hline Barcelona & -0.046 & $(-0.103 / 0.011)$ & 0.112 \\
\hline Burgos & -0.042 & $(-0.118 / 0.031)$ & 0.256 \\
\hline Cadiz & -0.086 & $(-0.172 /-0.013)$ & 0.021 \\
\hline Ciudad Real & -0.065 & $(-0.095 / 0.069)$ & 0.734 \\
\hline Granada & -0.125 & $(-0.194 /-0.055)$ & 0.001 \\
\hline Huelva & -0.048 & $(-0.127 / 0.026)$ & 0.180 \\
\hline Huesca & -0.088 & $(-0.182 / 0.001)$ & 0.054 \\
\hline La Coruña & 0.015 & $(-0.069 / 0.079)$ & 0.802 \\
\hline Lisboa & 0.052 & $(-0.026 / 0.131)$ & 0.193 \\
\hline Madrid & -0.091 & $(-0.162 /-0.020)$ & 0.014 \\
\hline Málaga & -0.078 & $(-0.154 /-0.001)$ & 0.049 \\
\hline Murcia & -0.097 & $(-0.189 /-0.004)$ & 0.041 \\
\hline Porto & 0.023 & $(-0.055 / 0.090)$ & 0.679 \\
\hline Salamanca & -0.063 & $(-0.133 / 0.026)$ & 0.205 \\
\hline Sevilla & -0.089 & $(-0.176 /-0.005)$ & 0.037 \\
\hline Soria & -0.045 & $(-0.108 / 0.023)$ & 0.193 \\
\hline Valencia & -0.034 & $(-0.117 / 0.063)$ & 0.587 \\
\hline Valladolid & -0.043 & $(-0.126 / 0.039)$ & 0.373 \\
\hline Zaragoza & -0.086 & $(-0.166 /-0.020)$ & 0.018 \\
\hline
\end{tabular}

Table 5-6: Summary of annual trends (in SPEI value/decade) computed for the 22 locations (1906-2010) using 12-month SPEI. The associated 95\% confidence intervals and p-values are also shown. Negative (or positive) trends represent drier (or wetter) conditions. Bold (or Italic) values are referred to statistical significance at the $99 \%$ level (or 95\%). 


\subsubsection{The impact of global warming on indices and trends}

As described in methods section, the Sc-PDSI and the 12-month SPEI is re-computed for each location using the monthly temperature climatology as input data (computed for the common period 1906-2010) instead the of the actual monthly mean temperature in order to assess the drought variability across the Iberian Peninsula without the effect of global warming. Moreover, the difference between 12-month SPEI and 12-month SPI is studied for the entire Iberian Peninsula (regional series) and for the 22 Iberian stations separately to investigate the role of temperature among drought indices. This valuable information about the impact of global warming on drought indices will help us to assess how much of the drying/wetting trends and their statistical significance might be forced by the influence of global warming.

\subsubsection{Analysis over the regional Iberian time series}

Figure 5-15 shows the variability of wet and dry conditions over the whole Iberian Peninsula (for the period 1906-2010) using the Sc-PDSI-all forcing (upper panel), the Sc-PDSI-without temperature changes (middle panel), and the difference between the two indices (lower panel). Similar drought conditions are represented by the Sc-PDSIall forcing and the Sc-PDSI-without temperature changes showing wet conditions in early-1940s, 1960s and 1970s while dry conditions are focused in mid-1940s, 1950s, 1980s, 1990s and 2000s.

Nevertheless, the difference between Sc-PDSI-all forcing and the Sc-PDSI-without temperature changes identifies a temporal pattern with negative differences of about 0.11 standard deviations for the whole period. This confirms that the Sc-PDSI-all forcing shows higher severity of droughts compared with the Sc-PDSI-without temperature changes.

Moreover, figure 5-16 shows the variability of wet and dry conditions over the whole Iberian Peninsula (for the period 1906-2010) using 12-month SPEI-all forcing (upper panel), 12-month SPEI-without temperature changes (in the middle), and the difference between the two indices (lower panel). Similar drought conditions are found by the 12month SPEI-all forcing and the 12-month SPEI-without temperature changes showing wet conditions in early-1910s, early-1940s, 1960s and 1970s while dry conditions are 
found in mid-1940s, 1950s, 1980s, 1990s and 2000s. Both 12-month SPEI time-series show higher frequency in drought variability than both Sc-PDSI time-series. In fact, the difference between 12-month SPEI-all forcing and 12-month SPEI-without temperature changes identifies a temporal pattern with positive differences at the beginning of the time-series and negative differences at the end of about 0.07 standard deviation for the 1990s and 2000s decades. This confirms that 12-month SPEI-all forcing shows higher severity of droughts compared with the 12-month SPEI-without temperature changes due to the increase of PET caused by global warming.
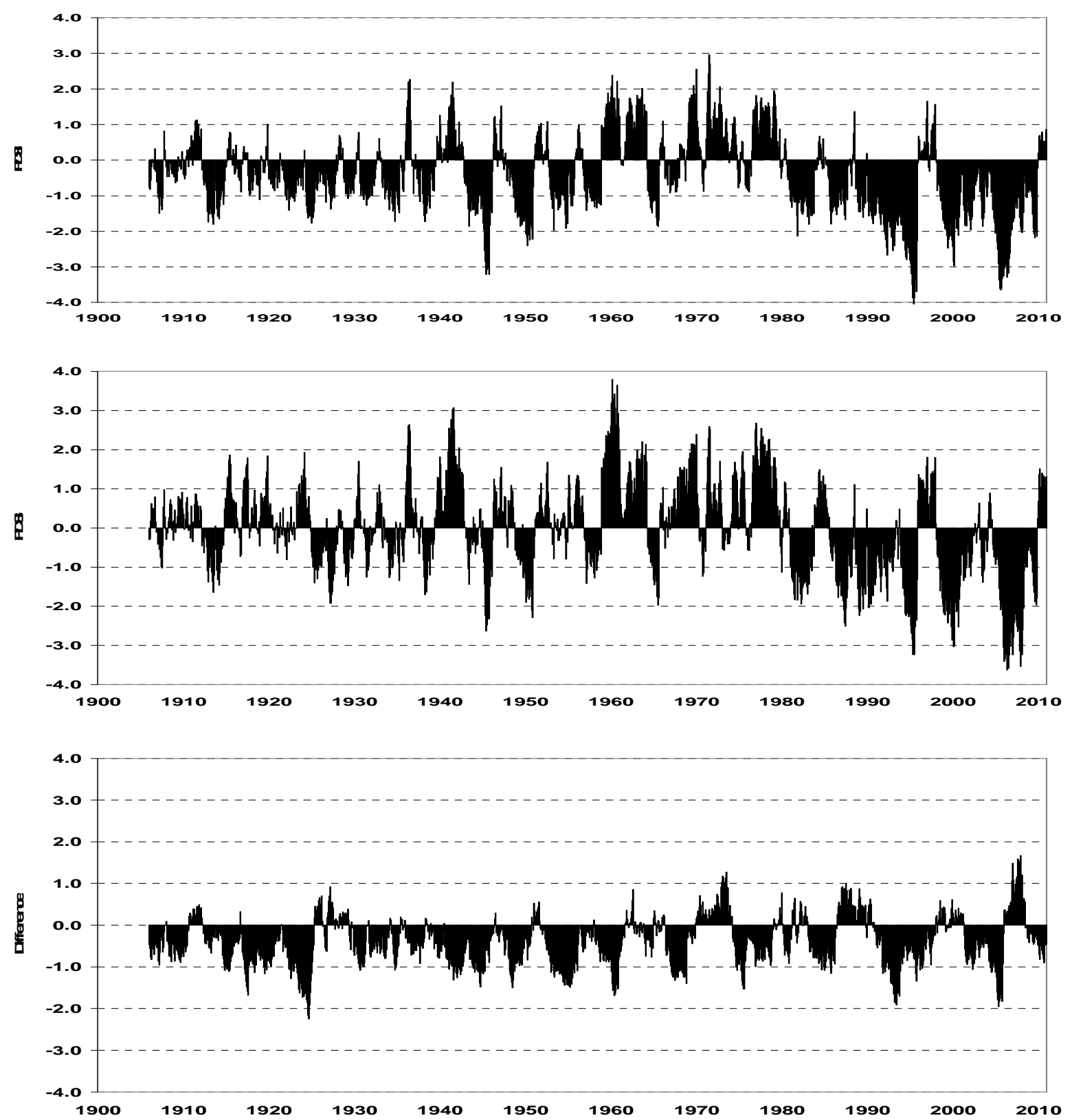

Figure 5-15: Variability of wet and dry conditions over the Iberian Peninsula (1906-2010) using ScPDSI-all forcing (upper panel), Sc-PDSI-without temperature changes (applying the monthly temperature climatology computed using the period 1906-2010) (in the middle panel), and the difference between the two indices (lower panel). 

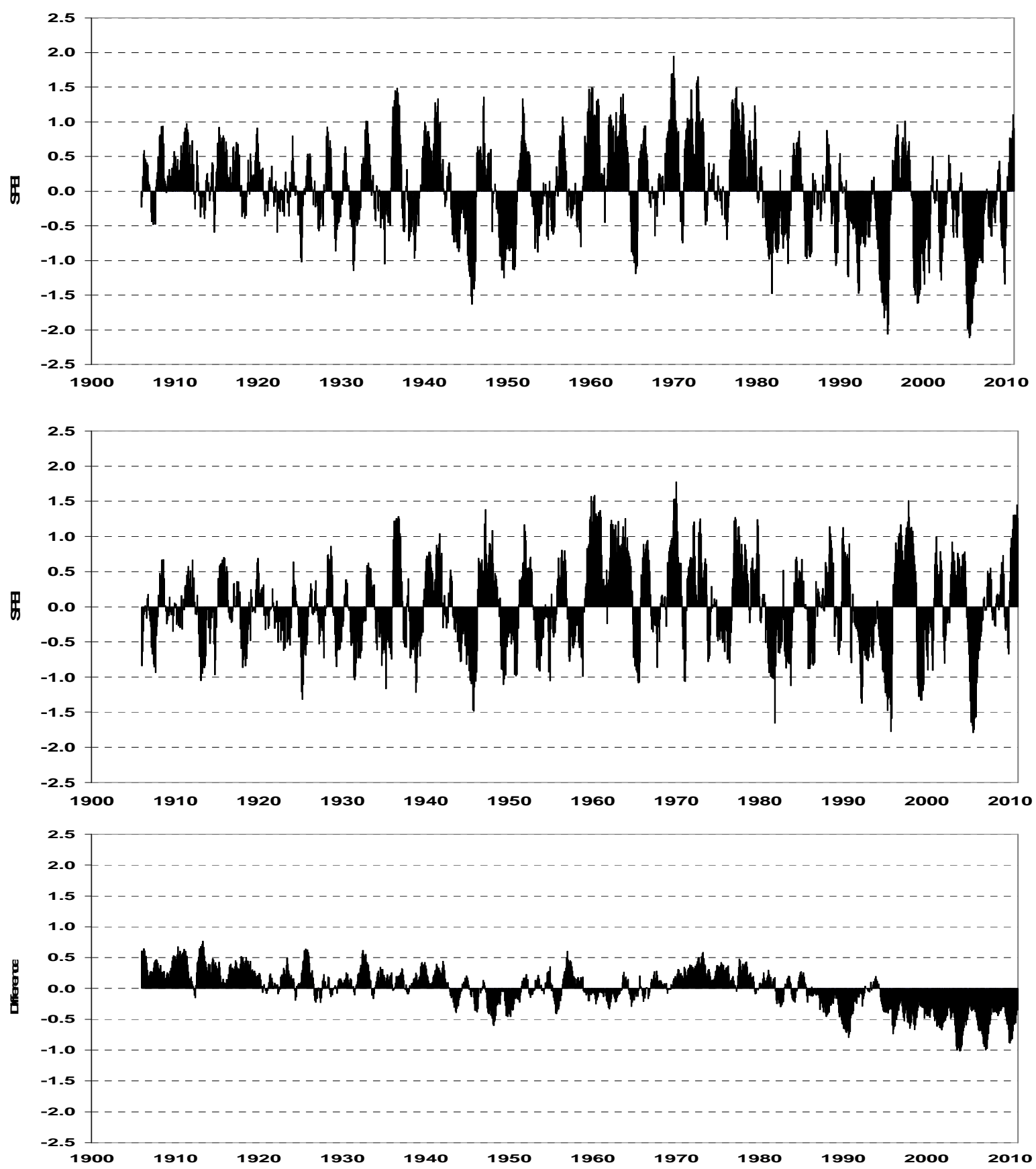

Figure 5-16: Variability of wet and dry conditions over the Iberian Peninsula (1906-2010) using 12month SPEI-all forcing (upper panel), 12-month SPEI-without temperature changes (applying the monthly temperature climatology computed using the period 1906-2010) (in the middle panel), and the difference between the two indices (lower panel).

Finally, figure 5-17 shows the variability of wet and dry conditions over the whole Iberian Peninsula (for the period 1906-2010) using 12-month SPEI-all forcing (upper panel), 12-month SPI (in the middle), and the difference between the two indices (lower panel). Similar drought conditions are identified by the 12-month SPEI-all forcing and the 12-month SPI showing wet conditions in early-1910s, early-1940s, 1960s and 1970s 
while dry conditions are found in mid-1940s, 1950s, 1980s, 1990s and 2000s. However, 12-month SPI shows lower fluctuations than 12-month SPEI-all forcing because it is only driven by precipitation and without the role of temperature. Both 12-month SPEI and 12-month SPI show higher frequency in drought variability than both Sc-PDSI time-series again. Thus, the difference between 12-month SPEI-all forcing and 12month SPI identifies a temporal pattern with positive differences at the beginning of the time-series and negative differences at the end of about 0.07 standard deviation for the 1990s and 2000s decades. Obviously, similar results are found between 12-month SPEIall forcing, 12-month SPEI-without temperature changes, and 12-month SPI due to not large differences in drought indices computation. These results confirm that 12-month SPEI-all forcing shows higher severity of droughts compared with the 12-month SPI caused by the role of temperature leading an increase of PET under global warming.

Furthermore, drought trends and their statistical significance are re-computed from drought indices for each Iberian regional time-series. Table 5-7 shows the linear trends computed taking into account the forcing applied to each drought index, the $95 \%$ confidence intervals and p-values.

As seen in previous sections, a non-significant drying trend (at the 95\% level) is found for the whole Iberian Peninsula (1906-2010) using the Sc-PDSI-all forcing and 12month SPEI-all forcing, but these trends became slightly wetter when using drought indices without temperature changes (Sc-PDSI and 12-month SPEI) or without temperature in its algorithm (12-month SPI). All wetting trends are statistically nonsignificant at the $95 \%$ level. The results suggest that, even precipitation variability is the main driver of droughts, temperature and the strongly related PET play an important role in terms of drought severity to explain drought changes over the whole Iberian Peninsula. Moreover, the increase in PET during last decades reinforced the drying trend found under climate change conditions. 

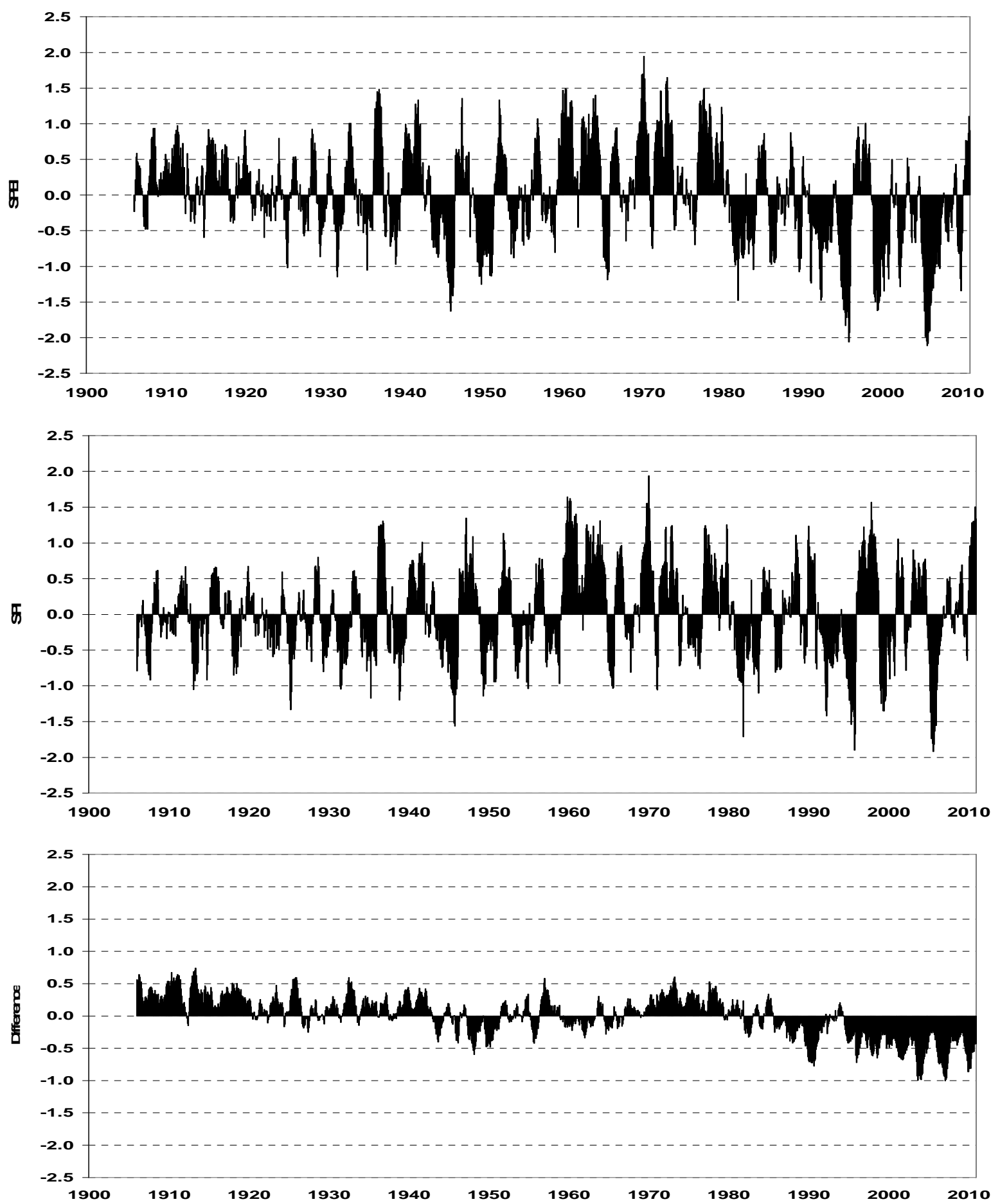

Figure 5-17: Variability of wet and dry conditions over the Iberian Peninsula (1906-2010) using 12month SPEI (upper panel), 12-month SPI (in the middle panel), and the difference between the two indices (lower panel). 


\begin{tabular}{|c|c|c|c|c|}
\hline Drought index & Forcing & Linear trend & 95\% confidence intervals & p-values \\
\hline \multirow{2}{*}{ Sc-PDSI } & All forcing & -0.076 PDSI value/decade & $(-0.166 / 0.035)$ & 0.17 \\
\cline { 2 - 5 } & without temperature changes & $0.021 \mathrm{PDSI}$ value/decade & $(-0.014 / 0.037)$ & 0.68 \\
\hline \multirow{2}{*}{ 12-month SPI } & All forcing & 0.022 SPI value/decade & $(-0.024 / 0.064)$ & 0.38 \\
\hline \multirow{2}{*}{ 12-month SPEI } & All forcing & -0.049 SPEI value/decade & $(-0.101 / 0.035)$ & 0.07 \\
\cline { 2 - 5 } & without temperature changes & 0.017 SPEI value/decade & $(-0.021 / 0.054)$ & 0.39 \\
\hline
\end{tabular}

Table 5-7: Summary of annual trends (in drought index value/decade) computed for the whole Iberian Peninsula (1906-2010) using all drought indices. Linear trends from Sc-PDSI and 12-month SPEI using all forcing without temperature changes (applying the monthly temperature climatology using the period 1906-2010) are also computed. The associated 95\% confidence intervals and pvalues are also shown. Bold (or Italic) values are referred to statistical significance at $99 \%$ level (or $95 \%$ ).

\subsubsection{Analysis over the 22 Iberian stations}

The spatial distribution of drought trends computed for the 22 locations spread over Iberian Peninsula is also analyzed in order to detect changes in drought variability when temperature was included in drought indices computation or when the effect of global warming was removed previously.

Figure 5-18 (together with the associated table 5-8 and 5-9) represents the annual trends computed for each location using Sc-PDSI-all forcing, Sc-PDSI-without temperature changes, 12-month SPEI-all forcing and 12-month SPEI-without temperature changes. Moreover, the trend differences between all forcing-drought indices and drought indices without temperature changes are also shown. The Sc-PDSI-all forcing and 12-month SPEI-all forcing shows a drying trend over most of the Iberian Peninsula becoming statistically significant in Cadiz, Málaga, Granada (at the $99 \%$ level), Sevilla and Madrid (at the 95\% level) using the Sc-PDSI-all forcing, and Granada (at the 99\% level), Sevilla, Cadiz, Málaga, Madrid, Zaragoza, Murcia and Alicante (at the 95\% level) using 12-month SPEI-all forcing. A wetting trend is identified in the western Iberian Peninsula only statistically significant in Lisboa (at the 95\% level) using the ScPDSI-all forcing. On the contrary, we find a wetting trend over most of the Iberian Peninsula stations when both drought indices were computed without temperature changes, even the wetting trend became statistically significant in Lisboa (at the $99 \%$ level) in the case of 12-month SPEI-without temperature changes. The drying trends only remain in the south and south-eastern Iberia becoming statistically significant only in Granada (at the 99\% level) using the Sc-PDSI-without temperature changes. Finally, the higher rates of change were identified in the north and north-eastern Iberian in the 
a)

case of the Sc-PDSI, and in the central and south-eastern area using 12-month SPEI.

Meanwhile lower rates of change are found in the south-western and south-eastern

Iberian using the Sc-PDSI and in western and north-western Iberian applying 12-month

SPEI.

)
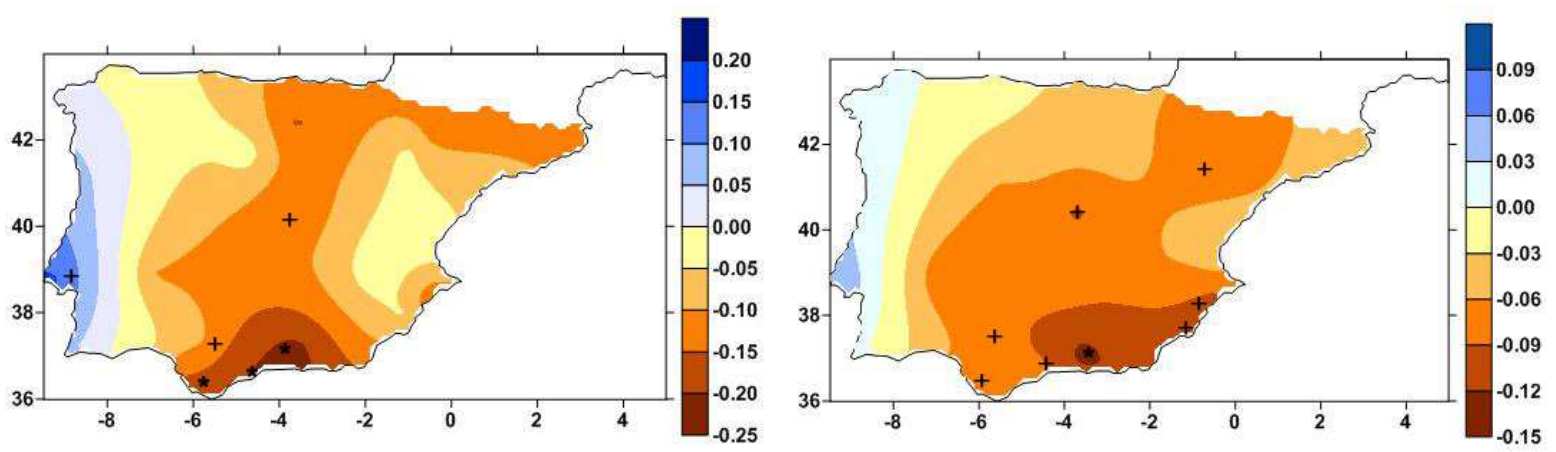

b)
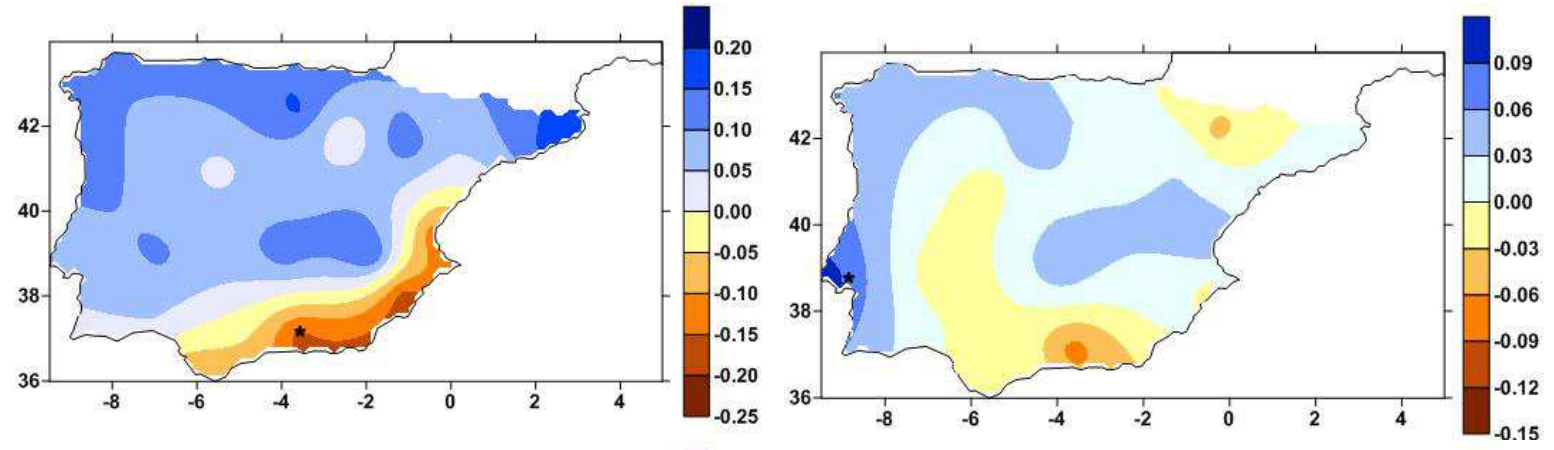

c)
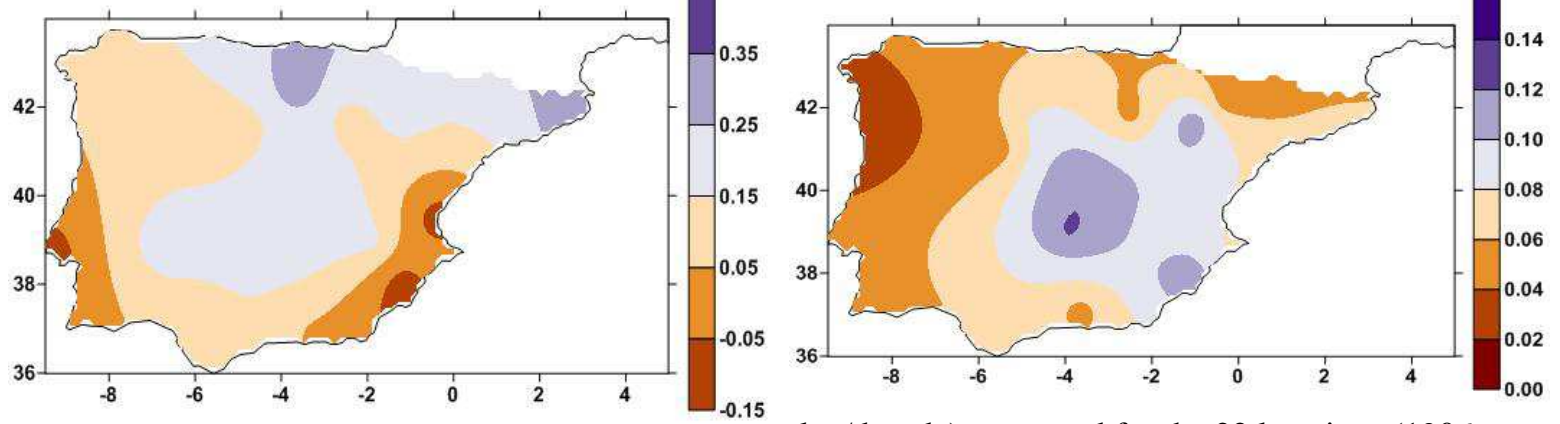

Figure 5-18: Maps of annual trends (in drought index value/decade) computed for the 22 locations (19062010) using Sc-PDSI-all forcing (a)-left), Sc-PDSI-without temperature changes (b)-left), 12month SPEI-all forcing (a)-right) and 12-month SPEI-without temperature changes (b)right). The trend differences between Sc-PDSI-all forcing minus Sc-PDSI-without temperature changes (c)-left), and between 12-month SPEI-all forcing minus 12-month SPEIwithout temperature changes (c)-right) are also shown. Negative (or positive) trends represent drier (or wetter) conditions while * (or + ) symbol are referred to statistical significance at the 99\% level (or 95\%) in figures a)-left and right, and b)-left and right. Spatial interpolation is applied using the kriging method.

Figure 5-19 (together with the associated table 5-8 and 5-9) represents the decadal trends computed for each location using 12-month SPI, 12-month SPEI-all forcing and 12-month SPEI-without temperature changes. Moreover, the trend differences between 12-month SPEI-all forcing minus 12-month SPI, between 12-month SPEI-all forcing minus 12-month SPEI-without temperature changes, and between 12-month SPEI- 
without temperature changes minus 12-month SPI are also shown. A non-statistically significant drying trend (at the 95\% level) is found in the Ebro basin and in the centralwestern Iberia reaching maximum rates of change in the Pyrenees and in the south and south-eastern area using 12-month SPI. However, a wetting trend is identified in the north and central Mediterranean coast, in the North and South Plateau and in the northern Iberia. Maximum rates of change are found in the north-western and western area, especially in Lisboa, where the wetting trend becomes statistically significant (at the $95 \%$ level). However, a drying trend is found over most of the Iberian Peninsula reaching maximum rates of change in the Ebro basin, central and southern Iberia and, especially in the south-eastern area using 12-month SPEI-all forcing. Moreover, the drying trend becomes statistically significant in Granada (at the 99\% level), Zaragoza, Madrid, Sevilla, Cadiz, Málaga, Alicante and Murcia (at the 95\% level). However, a non-significant wetting trend (at the 95\% level) is identified in the western and northwestern Iberia.

\begin{tabular}{|c|c|c|c|}
\hline Location & Annual coefficient (Sc-PDSI value/decade) & 95\% confidence interval & $\mathbf{p}$-value \\
\hline Albacete & 0.158 & $(-0.017 / 0.304)$ & 0.201 \\
\hline Alicante & -0.111 & $(-0.234 / 0.019)$ & 0.414 \\
\hline Badajoz & 0.106 & $(-0.013 / 0.230)$ & 0.143 \\
\hline Barcelona & 0.160 & $(-0.034 / 0.275)$ & 0.102 \\
\hline Burgos & 0.158 & $(-0.033 / 0.277)$ & 0.171 \\
\hline Cadiz & -0.071 & $(-0.176 / 0.023)$ & 0.242 \\
\hline Ciudad Real & 0.132 & $(-0.001 / 0.254)$ & 0.260 \\
\hline Granada & -0.161 & $(-0.273 /-0.045)$ & 0.009 \\
\hline Huelva & 0.041 & $(-0.085 / 0.163)$ & 0.700 \\
\hline Huesca & 0.046 & $(-0.064 / 0.173)$ & 0.700 \\
\hline La Coruña & 0.099 & $(-0.001 / 0.211)$ & 0.495 \\
\hline Lisboa & 0.068 & $(-0.132 / 0.115)$ & 0.659 \\
\hline Madrid & 0.063 & $(-0.060 / 0.186)$ & 0.584 \\
\hline Málaga & -0.072 & $(-0.274 / 0.041)$ & 0.319 \\
\hline Murcia & -0.177 & $(-0.008 / 0.227)$ & 0.074 \\
\hline Porto & 0.115 & $(-0.069 / 0.134)$ & 0.379 \\
\hline Salamanca & 0.032 & $(-0.086 / 0.096)$ & 0.738 \\
\hline Sevilla & 0.008 & $(-0.138 / 0.131)$ & 0.855 \\
\hline Soria & 0.001 & $(-0.259 / 0.040)$ & 0.948 \\
\hline Valencia & -0.137 & $(-0.015 / 0.205)$ & 0.404 \\
\hline Valladolid & 0.087 & $(-0.048 / 0.258)$ & 0.647 \\
\hline Zaragoza & 0.148 & & 0.084 \\
\hline
\end{tabular}

Table 5-8: Summary of annual trends (in PDSI value/decade) computed for the 22 locations for the common period 1906-2010 using Sc-PDSI-without temperature changes. The associated 95\% confidence intervals and p-values are also shown. Negative (or positive) trends represent drier (or wetter) conditions. Bold (or Italic) values are referred to statistical significance at the $99 \%$ level (or 95\%). 
a)

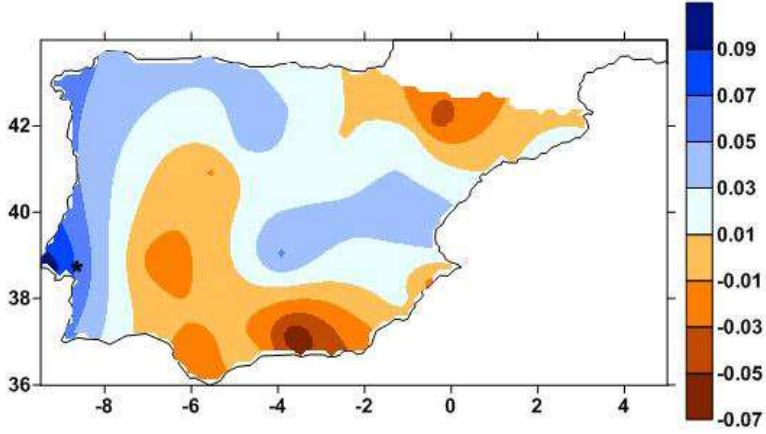

b)
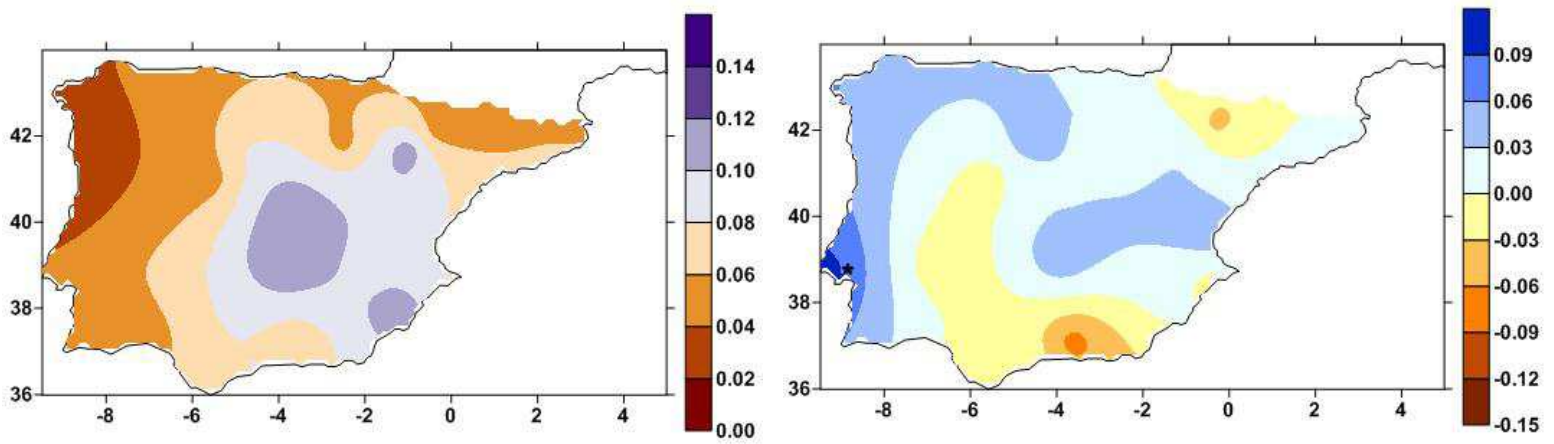

c)

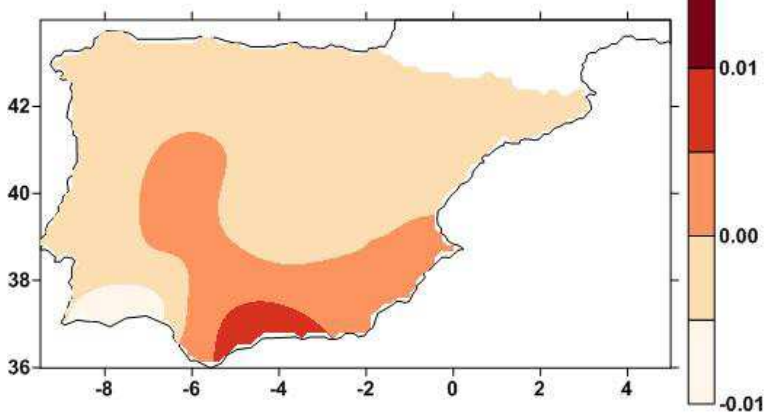

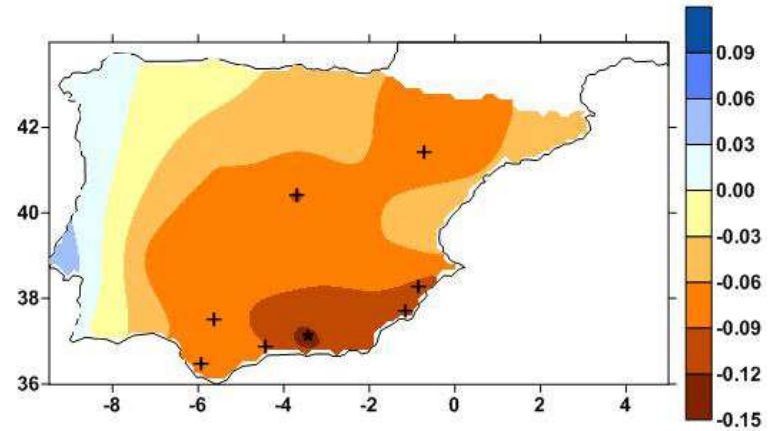

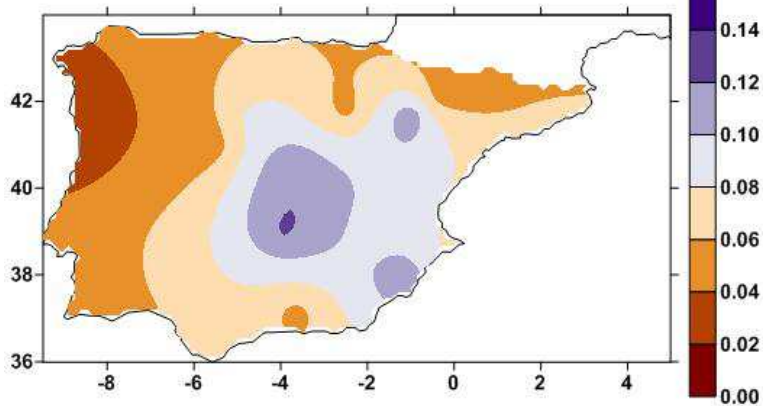

Figure 5-19: Maps of annual trends (in drought index value/decade) computed for the 22 locations (19062010) using 12-month SPI (a)-left), 12-month SPEI-all forcing (a)-right) and 12-month SPEIwithout temperature changes (b)-right). The trend differences between 12-month SPEI-all forcing minus 12-month SPI (b)-left), between 12-month SPEI-all forcing minus 12-month SPEI-without temperature changes (c)-right), and between 12-month SPEI-without temperature changes minus 12-month SPI (c)-left) are also shown. Negative (or positive) trends represent drier (or wetter) conditions while* (or + ) symbol are referred to statistical significance at the $99 \%$ level (or 95\%) only in figures a)-left and right, and b)-right. Spatial interpolation is applied using the kriging method.

Obviously, similar results in spatial trends are expected from the computation of 12month SPI and 12-month SPEI-without temperature changes since temperature evolution is not included in both drought indices. In fact, figure 5-18 shows the same drought patterns and figure 5-19 reproduces almost the same differences in trends between 12-month SPEI-all forcing minus 12-month SPI and between 12-month SPEIall forcing minus 12-month SPEI-without temperature changes. Thus, the trend 
difference between 12-month SPEI-without temperature changes and 12-month SPI is almost negligible.

\begin{tabular}{|c|c|c|c|}
\hline Location & Annual coefficient (SPEI value/decade) & 95\% confidence interval & p-values \\
\hline Albacete & 0.024 & $(-0.029 / 0.083)$ & 0.291 \\
\hline Alicante & -0.019 & $(-0.077 / 0.032)$ & 0.857 \\
\hline Badajoz & -0.022 & $(-0.077 / 0.033)$ & 0.557 \\
\hline Barcelona & 0.019 & $(-0.036 / 0.071)$ & 0.513 \\
\hline Burgos & 0.030 & $(-0.024 / 0.089)$ & 0.398 \\
\hline Cadiz & -0.022 & $(-0.081 / 0.037)$ & 0.429 \\
\hline Ciudad Real & 0.058 & $(-0.001 / 0.118)$ & 0.052 \\
\hline Granada & -0.074 & $(-0.133 / 0.014)$ & 0.057 \\
\hline Huelva & 0.011 & $(-0.048 / 0.073)$ & 0.747 \\
\hline Huesca & -0.038 & $(-0.091 / 0.019)$ & 0.361 \\
\hline La Coruña & 0.055 & $(-0.003 / 0.116)$ & 0.154 \\
\hline Lisboa & 0.100 & $(0.040 / 0.158)$ & 0.006 \\
\hline Madrid & 0.026 & $(-0.030 / 0.087)$ & 0.443 \\
\hline Málaga & -0.013 & $(-0.074 / 0.047)$ & 0.721 \\
\hline Murcia & 0.016 & $(-0.044 / 0.075)$ & 0.647 \\
\hline Porto & 0.052 & $(-0.072 / 0.0410)$ & 0.228 \\
\hline Salamanca & -0.013 & $(-0.074 / 0.050)$ & 0.738 \\
\hline Sevilla & -0.012 & $(-0.048 / 0.070)$ & 0.705 \\
\hline Soria & 0.008 & $(-0.011 / 0.011)$ & 0.663 \\
\hline Valencia & 0.046 & $(-0.025 / 0.098)$ & 0.199 \\
\hline Valladolid & 0.041 & $(-0.024 / 0.085)$ & 0.277 \\
\hline Zaragoza & 0.028 & & 0.639 \\
\hline
\end{tabular}

Table 5-9: Summary of annual trends (in SPEI value/decade) computed for the 22 locations for the common period 1906-2010 using 12-month SPEI-without temperature changes. The associated 95\% confidence intervals and p-values are also shown. Negative (or positive) trends represent drier (or wetter) conditions. Bold (or Italic) values are referred to statistical significance at the $99 \%$ level (or $95 \%)$. 


\subsubsection{Discussion on the applicability of the different drought indices}

The Sc-PDSI, the 12-month SPI and the 12-month SPEI are computed to detect hydrological droughts across Iberian Peninsula using the common period 1906-2010.

In general, the three drought indices represent similar variability of wet and dry conditions in the Iberian Peninsula across time clearly identifying the most important dry and wet events, which were thoroughly validated. It means that 12-month SPEI and 12-month SPI are able to provide similar results than Sc-PDSI with less data requirements (only monthly precipitation in the case of 12-month SPI; monthly precipitation and temperature for the 12-month SPEI). The Sc-PDSI computation requires monthly precipitation, temperature and Available Water Content of the soil. Available information on soil water content is very poor in most regions of the world and it is often a local and fixed value normally associated with current soil conditions, knowing that soil properties may change across time (Vicente-Serrano et al., 2011). It could lead the use of inaccurate values when applying Sc-PDSI in the Iberian Peninsula.

Additionaly, 12-month SPEI and 12-month SPI show better calibration in terms of the frequency distribution of values into the drought categories than the Sc-PDSI over the Iberian Peninsula. Despite Wells et al., (2004) solved most of the calibration problems from the original PDSI, making the index more suitable for drought quantification and monitoring (Sc-PDSI), some calibration problems appear in the computation of ScPDSI over the Iberian Peninsula. The 12-month SPEI maintains robust units with statistical consistency obtained from cumulative antecedent climate conditions and it provides more reliability than Sc-PDSI in the region under study.

Moreover, all drought indices are able to identify similar surface area affected by dry conditions in the Iberian Peninsula across time. Moreover, the driest periods detected before in terms of severity (see section 5.2.1) are found again as the driest periods in terms of affected area too (see section 5.2.3). All drought indices coincide to attribute the driest conditions (in terms of severity and area affected by drought) to years 1945, 1995 and 2005 over the Iberian Peninsula along the $20^{\text {th }}$ century.

Despite the similar results found in terms of temporal drought variability and surface area affected by droughts, some differences in trends among all drought indices are identified in both; individual and regional time-series. The annual trends are larger in drought indices which temperature is included in their computation (the Sc-PDSI and 12-month SPEI) than in which the main driver of drought variability is only 
precipitation (12-month SPI). The Sc-PDSI and SPEI indices represent better drought conditions under global warming than other indices since evapotranspiration process is included in their algorithms (Vicente-Serrano et al., 2010 and 2011, Dai 2004 and 2011, Van der Schrier et al., 2006 and 2011). There is general agreement on the importance of precipitation in explaining drought variability, but the observed and predicted global warming by IPCC (2007) have important implications for evapotranspiration processes, increasing the influence of this parameter on drought severity (Vicente-Serrano et al., 2010).

For all these reasons, the 12-month SPEI is the most suitable drought index to identify wet and dry conditions over the Iberian Peninsula along the $20^{\text {th }}$ century. Thus, the analysis of the spatial-temporal patterns of droughts and the univariate performing of severity, duration and magnitude of droughts and wet events will be carried out using only the 12-month SPEI in the next sections. 


\subsubsection{Summary}

The results obtained from the analysis of drought variability across the Iberian Peninsula along the $20^{\text {th }}$ century and the first decade of the $21^{\text {st }}$ century show lack of significant changes for the Iberian Peninsula as a whole, but drying trends in good parts of the Iberian Peninsula such as in the Pyrenees, Ebro basin and in the central Iberia, but the highest rates of change are mainly identified in the south and south-eastern area. On the contrary, a wetting trend is found in the western and north-western Iberian Peninsula.

The analysis of temporal evolution of droughts confirms that dry conditions dominated in 1920s, 1940s and in 1950s while wet conditions were present in 1930s, 1960s and in 1970s. The last three decades of the time-period (1980-2010) were abnormally dry mainly due to less precipitation than normal. But the severity and duration of dry conditions were reinforced during that period caused by the increase of the evapotranspiration rate coinciding with the maximum increase of temperatures in the Iberian Peninsula in a climate change context. In this way, the most remarkable droughts occurred in 1945, 1995 and 2005 and have been thoroughly validated using documental sources. Moreover, the driest periods identified in terms of severity in the Iberian Peninsula are also found as the driest periods in terms of the area affected by droughts.

The results found from the inspection of the impact of global warming on drought indices and trends suggest that, despite precipitation variability is the main driver of drought fluctuations, temperature and the strongly related PET play an important role in terms of drought severity and duration to explain drought changes over the whole Iberian Peninsula. Despite these results, drought severity and trends could be affected by some uncertainties derived from the applied method to estimate PET (Thornthwaite) since it is demonstrated (Sheffield et al., 2012) that it tends to overestimate PET conditions. This fact highlights the importance of including evapotranspiration in the evaluation of droughts while, at the same time, it warns that the use of unsuitable methods to estimate PET could compromise the final results.

Finally, the 12-month SPEI has been selected as the most suitable drought index to identify wet and dry conditions over the Iberian Peninsula along the $20^{\text {th }}$ century according to the reasons already discussed in section 5.2.6. 


\subsection{Drought fluctuations since the second half of the nineteenth century}

The previous section has studied the drought variability and trends for the whole Iberian Peninsula as well as for each station using the common period 1906-2010. As mentioned in previous sections, this common period is selected according to the availability and consistency of precipitation and temperature data to compute drought indices in order to obtain reliable and continuous results. But there are some stations in which the precipitation and temperature data began to be recorded since the second half of the nineteenth century (see table 4-1). In this section, and in order to approach the evolution of drougths for a longer period, we study the five longest time-series available according to table $4-1$, going back to the 1850 s. The individual time-series avaliable to analyse drought variability since the second half of the nineteenth century are Cadiz (1854-2010), Madrid (1855-2010), Huesca (1963-2010), Murcia (1864-2010) and Lisboa (1865-2010) (see figure 4-1 to see the geographical location). Note that the records of drought time-series start 12 months later than the original time-series (table 4-1) due to the time-scale used to compute the drought index. The 12-month SPEI is chosen to identify the drought variability in the five long-term time-series because - as discussed in section 5.2.6, it is found to be the best performer over the Iberian Peninsula. Redundant information would be obtained whether all drought indices tested before were computed again in this section.

Figure 5-20 shows the evolution of drought conditions using 12-month SPEI for the five longest time-series of the Iberian Peninsula since the second half of the nineteenth century. Cadiz (1854-2010) shows wet conditions in mid-1850s, mid-1870s, in 1880s, early-1890s, in 1910s, in 1930s, early and mid-1940s, late-1950s, 1960s, 1970s, late 1990s and late-2000s while dry conditions were focused in 1860s, late-1870s, mid-late1890s, 1900s, mid-1920s, mid-1930s, mid-1940s, 1950s, 1980s, early and late-1990s and early-mid-2000s. The wettest conditions are found in 1970, while the driest year is in 1869. Otherwise, Madrid (1855-2010) shows wet conditions in mid-1850s, mid1860s, 1880s, early-mid-1890s, 1910s, 1920s, mid-1930s, early and late-1940s, midlate-1950s, 1960s and 1970s while dry conditions are identified in early-1860s, 1870s, early-1900s, mid-late-1930s, early-1950s, and from 1980s to 2000s interrupted by short wet periods. The wettest conditions occurred in 1972 while the driest year was in 2005. 
Huesca (1863-2010) drought time-series represented wet conditions in mid-1860s, early-1870s, mid-late-1880s, early-1900s, mid-late-1910s, early-1920s, mid-1930s, 1940s, 1960s, 1970s and late-1990s while dry conditions were detected in early 1870s, early-1880s, mid-late-1890s, mid-late-1900s, mid-1920s, early and late-1950s and from 1980s to 2000s with the exception of the wet period focused in late-1990s. The wettest conditions occurred in 1973 while the driest year was identified in 1995.

Murcia (1864-2010) showed wet conditions in mid-1860s, early-1870s, mid-late-1880s, early-mid-1890s, early-mid-1920s, mid-1930s, early-1950s, 1970s, late-1980s and early-1990s while dry periods were in late-1860s, late-1870s, early-1880s, late-1890s, 1900s, 1910s, late-1920s, early-mid-1940s, early-1960s, early-1980s and from mid1990s to 2000s. The wettest conditions were in 1949 while the driest year is identified in 1878 .

Finally, Lisboa (1865-2010) represented wet conditions in mid-1860s, early-1870s, 1880s, early-mid-1890s, early-1910s, late-1930s, early and late-1940s, mid-late-1950s, 1960s, 1970s, mid-1990s and late-2000s while dry periods were focused in late-1860s, mid-1870s, late-1890s, 1900s, 1920s, 1930s, mid-1940s, early-1950s, 1980s, early1990s and early-mid-2000s. The wettest conditions were in 2010 while the driest year was identified in 2005 .

In general, the time-series show common wet conditions in mid-1850s (only data available for Cadiz and Madrid), mid-1860s, early-1870s (except in Madrid), during all the decade of 1880 (in all time-series), in most of the 1910s (except in Lisboa), in 1930s and early-1940s (except in Murcia), in 1960s and 1970s (except in Murcia only in 1960s and Lisboa in 1970s), mid-1990s (except in Murcia) and in really late-2000s (except in Huesca). Otherwise, common dry periods among time-series took place in early-1870s (except in Murcia and Lisboa), late-1890s and 1900s (in all time-series), mid-late-1920s (except in Madrid), the decade of 1950 (except in Murcia). Note that dry conditions dominated during the last three decades in all time-series except in Murcia (in early1990s) and in Lisboa, where dry conditions were not identified during this period. 

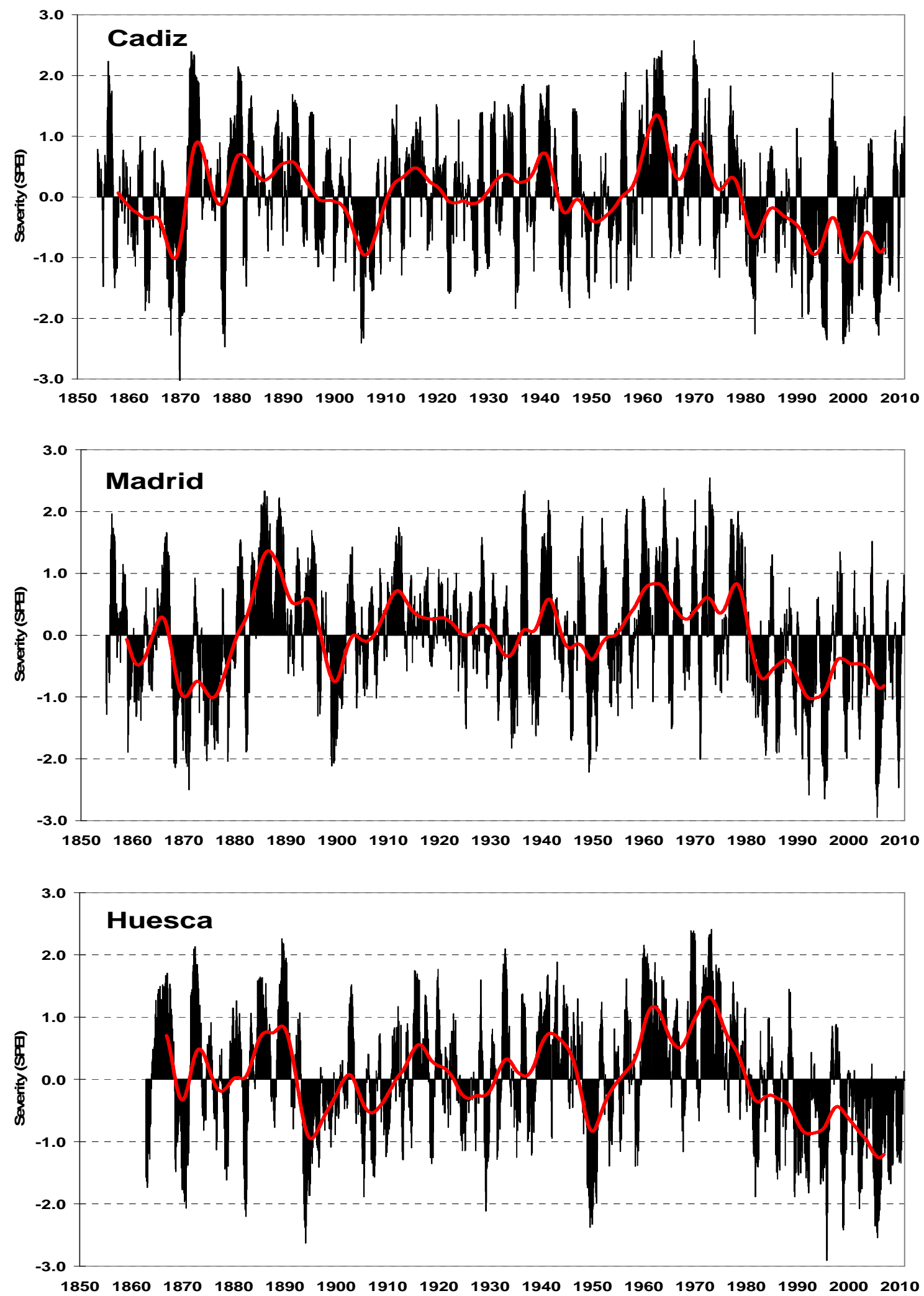

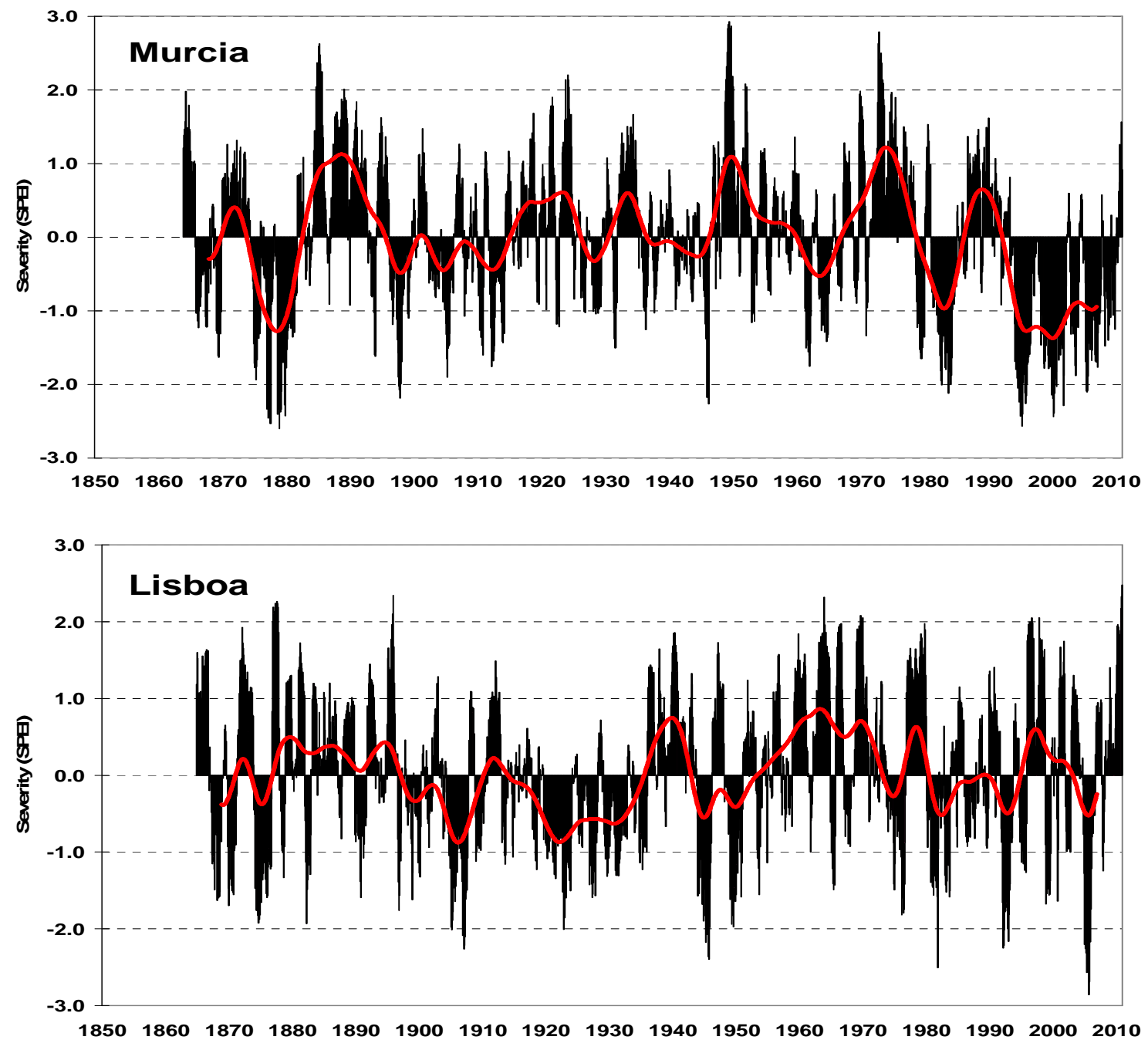

Figure 5-20: 12-month SPEI time series for Cadiz (1854-2010), Madrid (1855-2010), Huesca (18632010), Murcia (1864-2010) and Lisboa (1865-2010). In red, 10-year gaussian filter. 


\subsection{Drought regionalization of the Iberian Peninsula}

\subsubsection{PCAs application and spatial-temporal patterns selection}

In this study, Principal Component Analysis (PCA) is applied at the annual and seasonal time-scales using 12-month SPEI time-series for the common period 1906-2010 to identify spatial-temporal variations of droughts across the $20^{\text {th }}$ century.

In order to determinate the adequate number of RPCs to be extracted we essayed two different cutting criteria $(T>0.7$ and $T>1$, (Kaiser's rule; where $T=$ eigenvalue) see section 4.5 for further details on these thresholds), plus the qualitative inspection of the scree plots. Five rotated principal components are extracted at the annual time-scale using the threshold $\mathrm{T}>0.7$ that explains the $77.9 \%$ of accumulated variance (table 5.10 ), while three components are found applying the threshold $\mathrm{T}>1$ explaining the $70.8 \%$ of accumulated variance. $\mathrm{T}>0.7$ threshold provides two components more than $\mathrm{T}>1$ threshold explaining only an additional $7.1 \%$ of variance. Five components are also extracted in winter (DJF) using $\mathrm{T}>0.7$, explaining the $76.7 \%$ of accumulated variance, meanwhile four components are found with $\mathrm{T}>1$, explaining the $73 \%$ of accumulated variance. In this case, the lost of variance in $\mathrm{T}>1$ is only $3.7 \%$. For Spring (MAM) the 0.7 threshold determinates the extraction of 3 components $(77.8 \%$ of explained variance), meanwhile the $\mathrm{T}>1$ threshold accounts for $70.2 \%$ of the variance with distributed in 3 RPCs. In summer (JJA), five components are extracted with $\mathrm{T}>0.7$ (79.5\% of accumulated variance), while three components are found with $\mathrm{T}>1$, explaining the $72.7 \%$ of accumulated variance. Two components more are found applying $\mathrm{T}>0.7$ than $\mathrm{T}>1$ that explaining only a $6.8 \%$ of variance. Finally, in autumn (SON), four components are extracted using $\mathrm{T}>0.7$ explaining the $76.5 \%$ of accumulated variance and three components are found using $\mathrm{T}>1$ explaining the $72.9 \%$ of accumulated variance. 


\begin{tabular}{|c|c|c|c|}
\hline & RPCs & $\mathrm{T}>0.7$ & $T>1$ \\
\hline Time-scale & Component number & $\%$ variance & $\%$ variance \\
\hline \multirow{6}{*}{ Annual } & 1 & 49.3 & 49.3 \\
\hline & 2 & 14.9 & 14.9 \\
\hline & 3 & 6.5 & 6.5 \\
\hline & 4 & 3.8 & \\
\hline & 5 & 3.3 & \\
\hline & Total & 77.9 & 70.8 \\
\hline \multirow{6}{*}{$\begin{array}{c}\text { DJF } \\
\text { (Winter) }\end{array}$} & 1 & 47.4 & 47.4 \\
\hline & 2 & 14.1 & 14.1 \\
\hline & 3 & 6.8 & 6.8 \\
\hline & 4 & 4.6 & 4.6 \\
\hline & 5 & 3.8 & \\
\hline & Total & 76.7 & 73.0 \\
\hline \multirow{6}{*}{$\begin{array}{c}\text { MAM } \\
\text { (Spring) }\end{array}$} & 1 & 48.7 & 48.7 \\
\hline & 2 & 14.7 & 14.7 \\
\hline & 3 & 6.8 & 6.8 \\
\hline & 4 & 4.2 & \\
\hline & 5 & 3.4 & \\
\hline & Total & 77.8 & 70.2 \\
\hline \multirow{6}{*}{$\begin{array}{c}\text { JJA } \\
\text { (Summer) }\end{array}$} & 1 & 50.2 & 50.2 \\
\hline & 2 & 16.2 & 16.2 \\
\hline & 3 & 6.4 & 6.4 \\
\hline & 4 & 3.6 & \\
\hline & 5 & 3.2 & \\
\hline & Total & 79.5 & 72.7 \\
\hline \multirow{5}{*}{$\begin{array}{c}\text { SON } \\
\text { (Autumn) }\end{array}$} & 1 & 51.6 & 51.6 \\
\hline & 2 & 15.1 & 15.1 \\
\hline & 3 & 6.3 & 6.3 \\
\hline & 4 & 3.6 & \\
\hline & Total & 76.5 & 72.9 \\
\hline
\end{tabular}

Table 5-10: Number of extracted components and percentages of variance explained by the rotated principal components using $\mathrm{T}>0.7$ and $\mathrm{T}>1$ thresholds at annual and seasonal time-scales using 12-month SPEI time series.

The comparison between $\mathrm{T}>0.7$ and $\mathrm{T}>1$ shows that the explained variance obtained by the inclusion of additional RPCs in $\mathrm{T}>0.7$ is relatively small and does not justify the selection of this criteria. The qualitative analysis of the scree plots (Fig 5-21) also recommends the selection of the same number of RPCs derived by the application of the $\mathrm{T}>1$ criteria. The selected number of components ensures that the accumulated variance falls in the range of 70-90\% recommended by Jolliffe (2002).

In summary, the principal componments analysis is finally applied over the 22 12month SPEI time series at annual and seasonal time scales for the 1906 to 2010 period. For our regionalization purposes, the S-mode of PCA is selected using the truncation threshold $\mathrm{T}>1$ and applying Varimax rotation of the components. The results provide 
spatial-temporal patterns of droughts over Iberian Peninsula in order to identify homogeneous areas with similar behaviour of drought conditions across time (19062010).

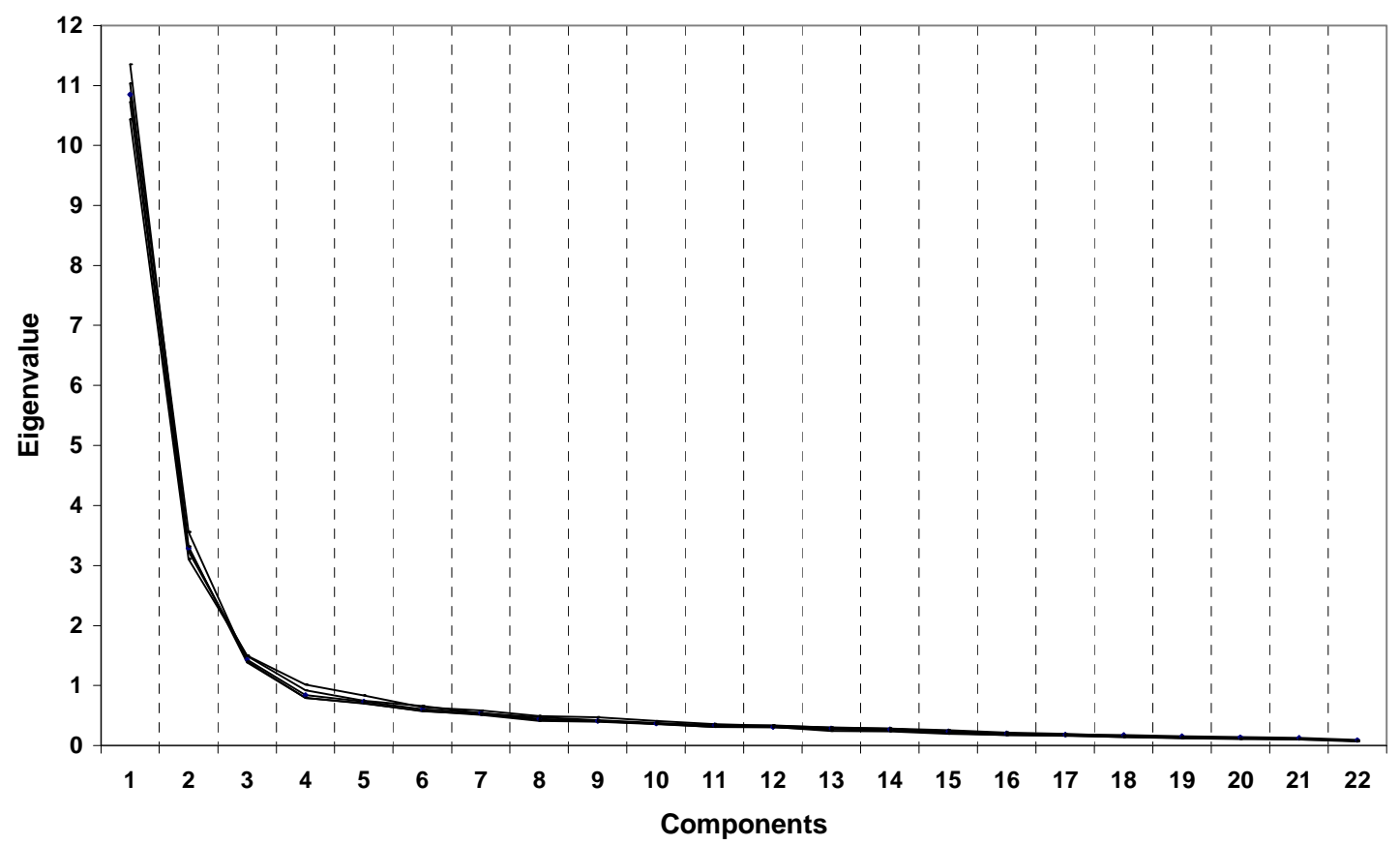

Figure 5-21: Scree graph showing the eigenvalue spectrum related with different components found in rotated principal components at annual and seasonal time-scales.

From the extraction of the Rotated Principal Component Analysis (RPCA) to the 12month SPEI series over Iberian Peninsula for the period 1906-2010, the spatial patterns together with the associated time series are obtained at annual and seasonal time scales. In this section, annual and seasonal time scales are analyzed separately in order to distinguish the spatial patterns found across the year. Moreover, the areas with similar temporal behaviour of droughts, suggested by RPCAs analysis, are identified and the variability and trends of the time series associated to the spatial-temporal patterns are also described in the following sections.

Three Rotated Principal Components (RPCs) are extracted to represent the variability over Iberian Peninsula at annual time scale explaining the $70.8 \%$ of total variance. The first component (RPC1) explains the $49.3 \%$ of total variance and it will be called as South-western pattern (SWP) from now onwards. The second component (RPC2) explains the $14.9 \%$ of variance and will be called as North-western pattern (NWP) from now. The third component (RPC3) just explains the 6.5\% of variance and will be called as Mediterranean pattern (MedP) hereafter. The South-western pattern focuses its 
maximum weights in the south-west and central area of the Iberian Peninsula while the North-western pattern covers the north and north-western Iberia. Finally, the Mediterranean pattern is focused mainly in the Mediterranean region of the Iberian Peninsula.

The RPCs are also extracted at seasonal time scale from the RPCA computed over the Iberian Peninsula. Four RPCs are extracted explaining the $73 \%$ of total variance in winter (DJF); three RPCs in spring (MAM) explaining the $70.2 \%$; three RPCs in summer (JJA) explaining the 72.7\%; and three RPCs in autumn (SON) explaining the $72.9 \%$ of total variance (see table 5-10). Similar spatial patterns to those found at annual scale are extracted at the sesasonal time scale, and the associated time series are also computed. The South-western pattern, the North-western pattern and the Mediterranean pattern are the spatial-temporal patterns also identified at seasonal basis and they will be described and analyzed below one by one. 


\subsubsection{The South-western pattern}

\subsubsection{Annual and seasonal spatial structure}

The South-western pattern (Fig. 5-22) shows the maximum weights located in the southwest of the Iberian Peninsula (Cadiz Gulf) but also reaching the central area of the region with a weaker signal (Central System) at annual time-scale. This spatial pattern spreads over Iberian Peninsula following the Guadiana, Guadalquivir and Tagus basins and covers the western part of the South Plateau and the southern part of the Central Plateau.
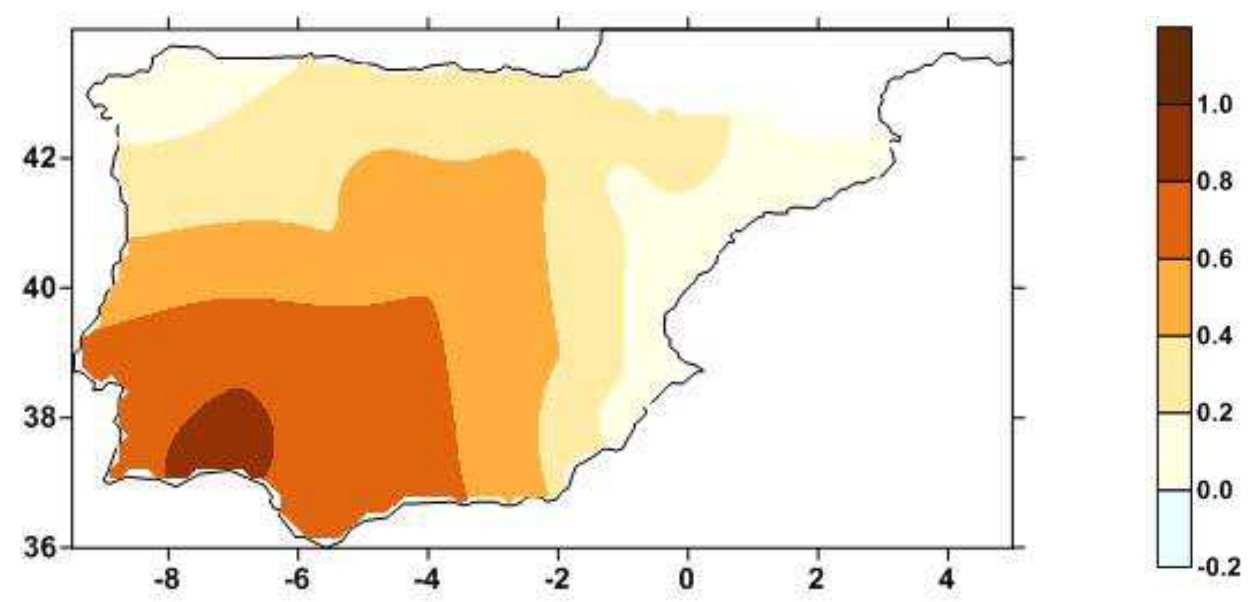

Figure 5-22: Spatial distribution of the maximum weights referred to the South-western pattern (SWP) computed over the 22 12-month SPEI series at annual time-scale over the Iberian Peninsula. This component explains the $49.3 \%$ of total variance. Spatial interpolation is applied using the kriging method.

The spatial distribution of the South-western pattern is also identified over the Iberian Peninsula at seasonal time-scale, with maximum weights located in the south-west of the Iberian Peninsula (Fig. 5-23). This pattern spreads over the region under study from the Cadiz Gulf to the Central System reaching the south-west and central area of the Iberian Peninsula. It involved the Guadiana, Tagus and Guadalquivir basins, and extends to the western area of South Plateau and in the Central Plateau with a weaker signal. Most of the variance explained in summer (50.2\%) and autumn (51.6\%) over the Iberian Peninsula is related to the South-western pattern coinciding with its maximum weights located at the Cadiz Gulf and maximum expansion of the pattern along to the Central Plateau. 

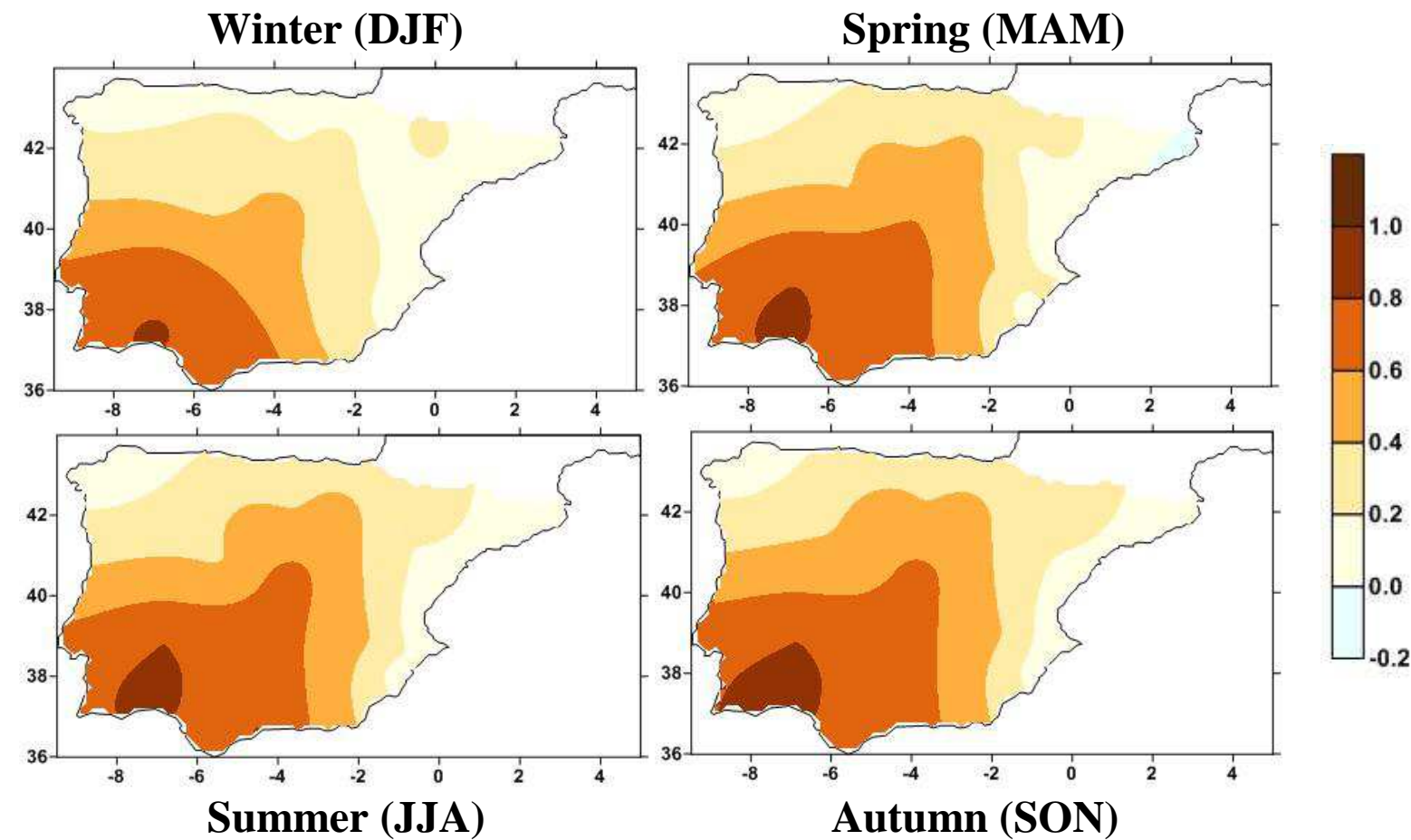

Summer (JJA)

Autumn (SON)

Figure 5-23: Spatial distribution of the maximum weights related to the South-western pattern identified over the Iberian Peninsula at seasonal time-scale. This pattern explains the $14.1 \%$ of total variance in winter (DJF), the $14.7 \%$ in spring (MAM), the 50.2\% in summer (JJA) and the $51.6 \%$ of total explained variance in autumn (SON). Spatial interpolation is applied using the kriging method.

\subsubsection{Annual and seasonal temporal evolution}

Figure 5-24 presents the variability of 12-month SPEI time series associated to the South-western pattern determined by the RPC analysis over the Iberian Peninsula for the period 1906-2010 at annual time-scale. The driest periods identified in the Southwestern pattern (SWP) time series are the 1930s, mid-1940s, mid-1970s, 1980s, early and mid-1990s and 2000s while the wettest periods were identified in 1900s, 1910s, early-1940s, 1960s, early-1970s, early and late-1990s and late-2000s. Otherwise, a high variability between shorter dry and wet periods than in other decades characterises the 1920s and 1950s decades. The time-series associated to the South-western pattern shows a statistically significant (at the $95 \%$ significance level) decreasing trend of 0.064/decade for the period 1906-2010 (Table 5-11). 


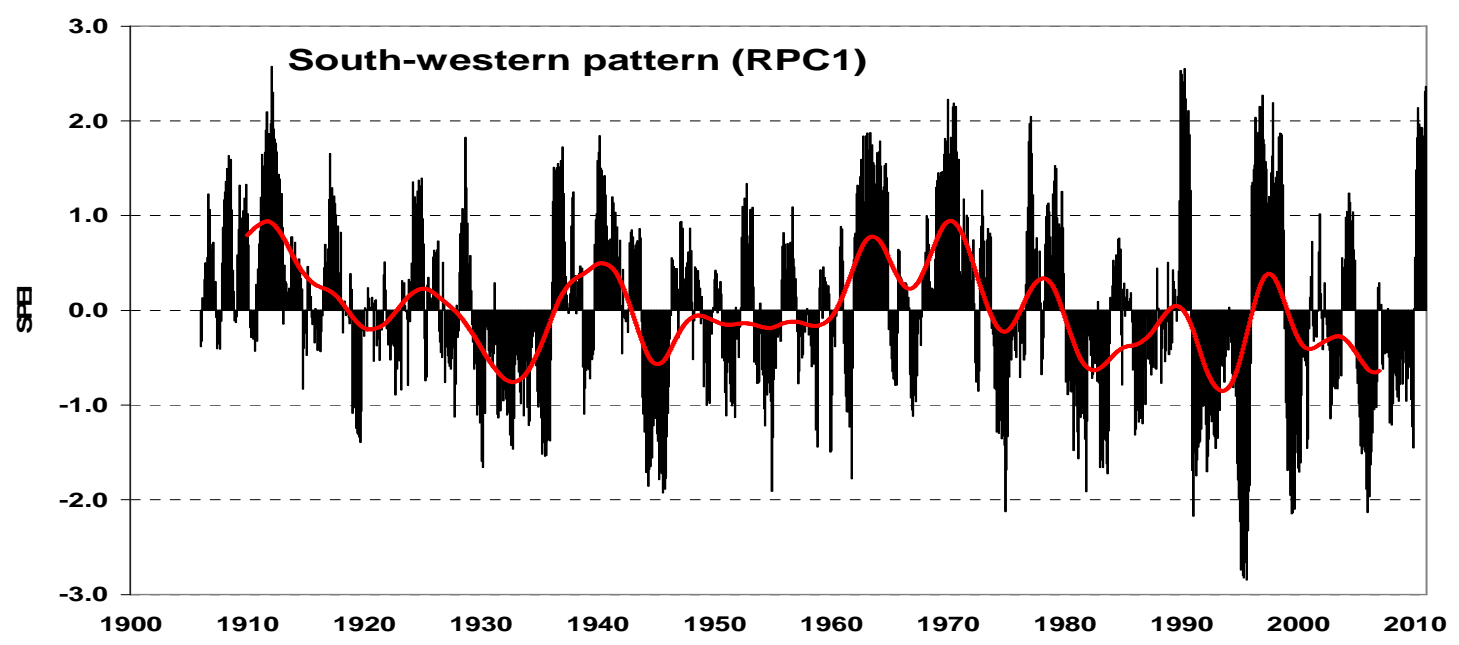

Figure 5-24: Fluctuations of 12-month SPEI time series associated to the South-western pattern found at annual time-scale over Iberian Peninsula for the period 1906-2010. Red line; 10-year Gaussian filter.

The fluctuations of averaged 12-month SPEI time series associated to the South-western pattern at seasonal time scale for the period 1906-2010 are shown in figure 5-25. The time series show similar variability across time independently of the chosen season detecting the driest conditions in 1930s, mid-1940s, mid-1970s, 1980s, early-mid-1990s and 2000s. The wettest periods are identified in 1900s, 1910s, late-1930s and early1940s, 1960s, 1970s and late-1990s while the alternation of shorter dry and wet conditions occurred in 1920s and 1950s.

The wettest winter (DJF) was in $1990(+1.77$ SPEI value) in the time-series associated to the South-western pattern at seasonal scale, however, the driest winter occurred in 1995 according to figure 6-25 (-2.24 SPEI value). The wettest spring was found in 1990 $(+2.43)$ and the driest one was recorded in $1995(-2.83)$. The wettest summer was identified in $1970(+2.07)$, but the driest summer occurred in $1995(-2.72)$. Finally, the wettest autumn was in $1996(+2.20)$, while the driest autumn was in $1995(-2.10)$. These results show that the wettest and driest seasons are identified basically in 1990s in the South-west of the Iberian Peninsula. According to the 12-month SPEI, the year 1995 is the driest one of the time-series in the South-west of the Iberian Peninsula because major seasonal records are found during all seasons in 1995. 

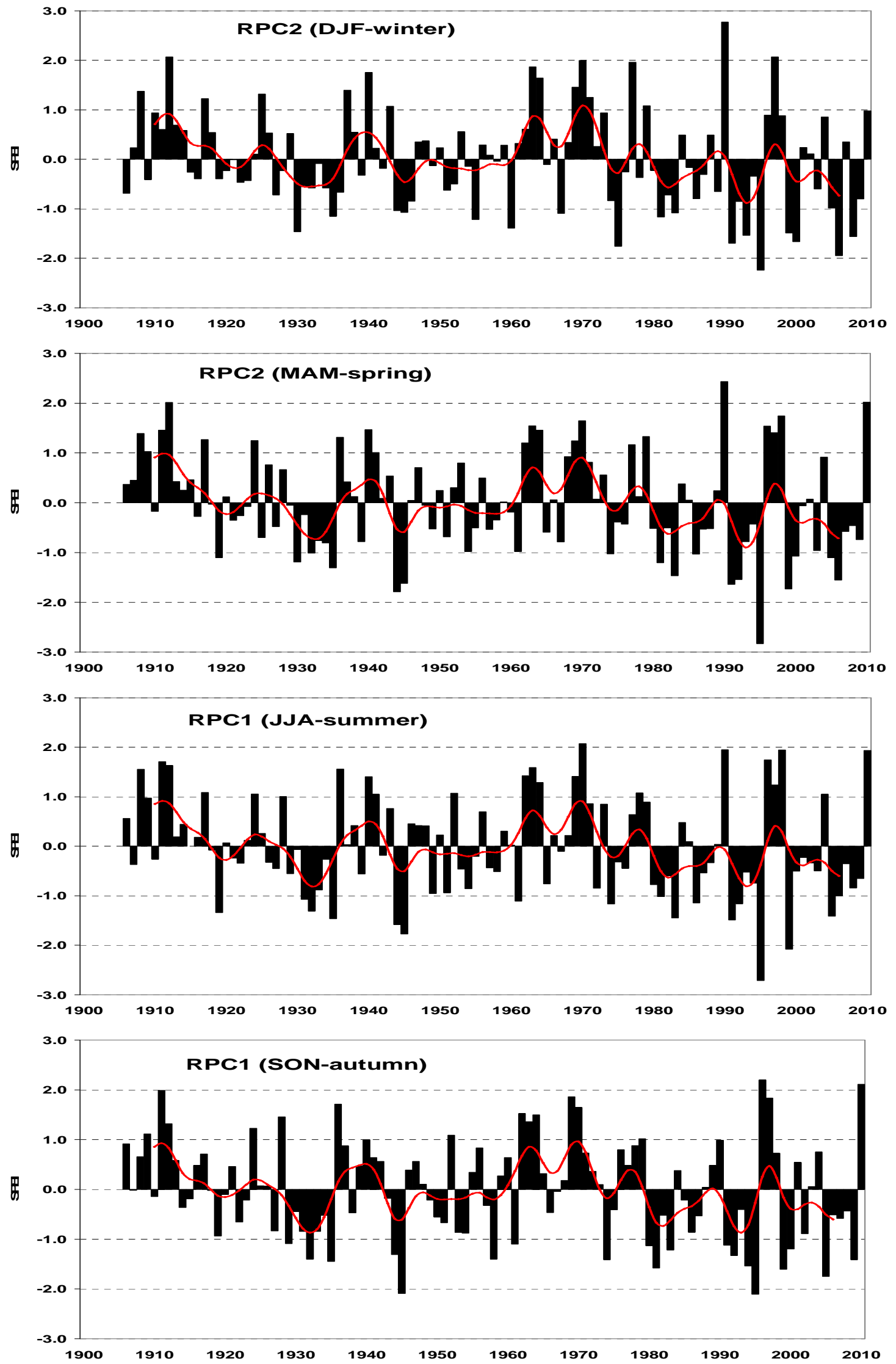

Figure 5-25: Fluctuations of averaged 12-month SPEI time series associated to the South-western pattern found over Iberian Peninsula at seasonal time scale for the period 1906-2010 (with smoothed by Gauss filter over 10 years). 


\subsubsection{The North-western pattern}

\subsubsection{Annual and seasonal spatial structure}

The North-western pattern (NWP) (Fig. 5-26) represents a spatial pattern with maximum weights located in the north and north-west of the Iberian Peninsula at annual timescale, but its influence also reaches some areas of central part of the region (Central System). The spatial pattern spreads over the north-west and north of the Iberian Peninsula (from the north of Portugal and Galicia to the Western Pyrenees) covering the Cantabrian range and also the North Plateau till Central System and Iberic System.

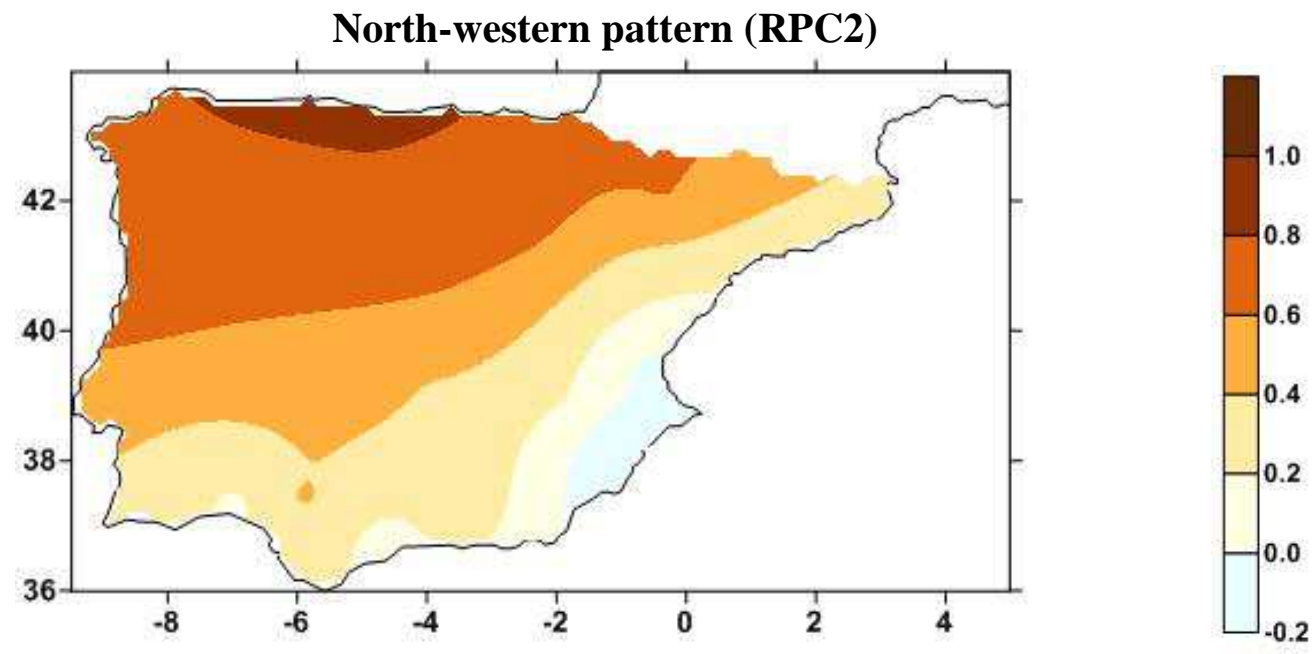

Figure 5-26: Spatial distribution of the maximum weights referred to the North-western pattern (NWP) computed over the 22 12-month SPEI series at annual time-scale over the Iberian Peninsula. This component explains the $14.9 \%$ of total variance. Spatial interpolation is applied using the kriging method.

The North-western pattern analyzed at seasonal time-scale concentrates the maximum weights in the north and north-west of the Iberian Peninsula in spring, summer and autumn (Fig. 5-27). This pattern spreads over the Iberian Peninsula from the Cantabrian coast to the Central System reaching the north of Portugal, Galicia, all the North Plateau and the Cantabrian range. But, two sub-patterns were identified in winter, named as Sub-pattern 1 and Sub-pattern 2 in fig. 5-27. The sub-pattern 1 shows the maximum weights in the north and central area of the Iberian Peninsula from the Cantabrian coast to the north-western part of the South Plateau reaching the Cantabrian range, all the North Plateau and also the Central System. Otherwise, the sub-pattern 2 is located in the north-western corner of the Iberian Peninsula with maximum weights just covering Galicia and the north-west of Portugal. These two sub-patterns found in winter (DJF) 
over the Iberian Peninsula belong to the North-western pattern detected at annual time scale. Most of the variance explained in spring over Iberian Peninsula is related to the North-western pattern $(48.7 \%)$ while most of the variance explained in winter is related to the sub-pattern $1(47.4 \%)$.

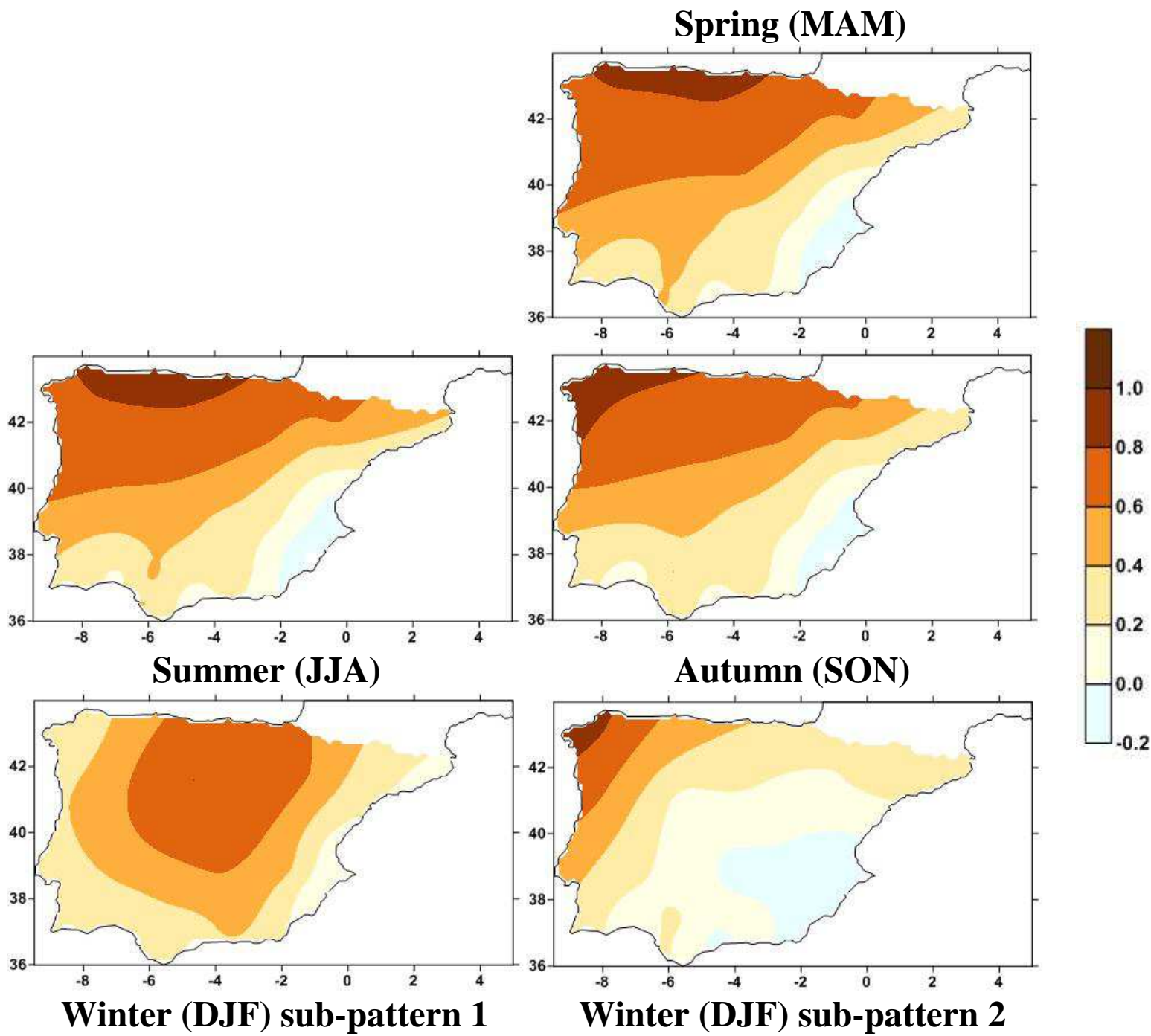

Figure 5-27: Spatial distribution of the maximum weights related to the North-western pattern identified over the Iberian Peninsula at seasonal time-scales. Note that two sub-patterns were found in winter (DJF) related to the North-western pattern. The North-western pattern explains the $48.7 \%$ of total variance in spring (MAM), the $16.2 \%$ in summer (JJA) and the $15.1 \%$ of total explained variance in autumn (SON). The sub-patterns 1 and 2 found in winter (DJF) represents the $47.4 \%$ and $4.6 \%$ of total variance respectively. Spatial interpolation is applied using the kriging method. 


\subsubsection{Annual and seasonal temporal evolution}

Figure 5-28 presents the variability of 12-month SPEI time series associated to the North-western pattern determined by the RPC analysis over the Iberian Peninsula for the period 1906-2010 at annual time-scale. The driest periods identified in the time series associated to the North-western pattern are detected in 1900s, late-1940s, late1980, early-1990s and mid-late-2000s. The wettest periods are identified in late-1920s, 1930s, 1960s, late-1970s and early-2000s while periods based on high variability are shown in 1910s, early-mid-1920s, 1950s, early-mid-1970s, mid-1980s and mid-1990s. The time-series associated to the North-western pattern show a non-significant decreasing trend of $-0.001 /$ decade (at the $95 \%$ level).

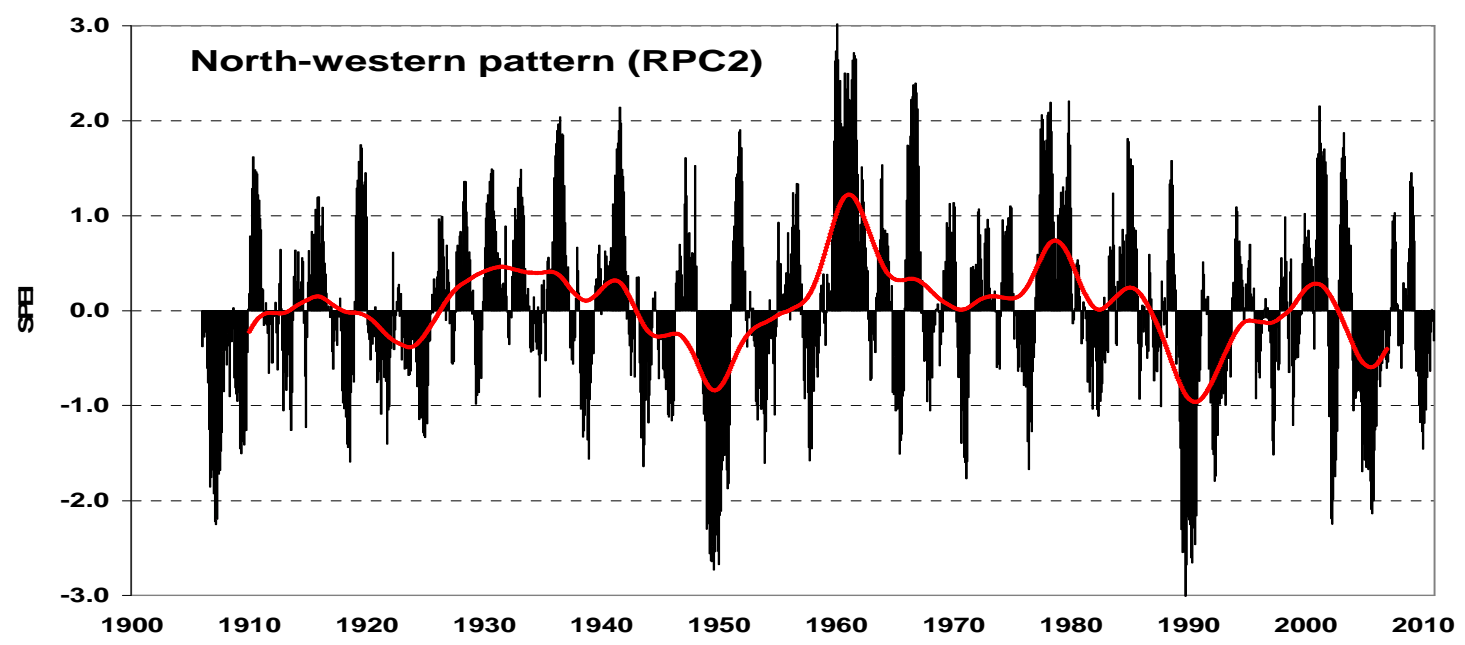

Figure 5-28: Fluctuations of 12-month SPEI time series associated to the North-western pattern found at annual time-scale over Iberian Peninsula for the period 1906-2010. Red line; 10-year Gaussian filter.

The variability of averaged 12-month SPEI time series associated to the North-western pattern found at seasonal time scale in the Iberian Peninsula for the period 1906-2010 together with sub-patterns 1 and 2 are shown in figure 5-29. The driest periods recorded in the time series associated to the North-western pattern in spring, summer and autumn occurred in 1900s, early-1920s, 1940s and early-1990s while the wettest conditions are identified in 1930s, early-1960s and late-1970s. Otherwise, the 1910s, late-1920s, 1950s, late-1960, early-1970s, 1980s, late-1990s and 2000s are characterized by the alternation of dry and wet conditions. In this way, the wettest spring occurred in 1960 (+2.40 SPEI value), while the driest spring was recorded in $1949(-2.55)$ for the Northwest of the Iberian Peninsula. The wettest summer is identified in $1961(+2.63)$, but the 
driest summer is shown in 1949 (-2.53). Finally, the wettest autumn occurred in 1960 (+2.35), however, the driest autumn (-2.92) was found in 1989.

The driest periods detected in the time series associated to the sub-pattern 1 are concentrated in 1940s, late-1960s, 1980s and 1990s while wettest periods are identified in 1900s, 1910s, mid-1930s, 1950s, early-mid-1960s and 1970s. However, a high variability between dry and wet periods is shown in 1920s, early 1930s and 2000s. The wettest winter according to the time series associated to sub-pattern 1 occurred in 1958 $(+1.88)$, but the driest winter identified in the North and central area of the Iberian Peninsula was recorded in 1971 (-2.25). Furthermore, the driest periods recorded in the time series associated to the sub-pattern 2 occurred in 1900s, 1910s 1920s, late-1940s, mid-1970s, early-1990s and mid-late-2000s while wettest conditions were identified in 1930s, early-mid-1940s, 1960s, early and late-1970s, early-mid-1980s and early-2000s. The alternation of wet and dry periods occurred just in 1950s and 1990s. Moreover, the wettest winter found in the time-series associated to the sub-pattern 2 was identified in 1960 (+2.37) while the driest winter occurred in $1907(-3.07)$.
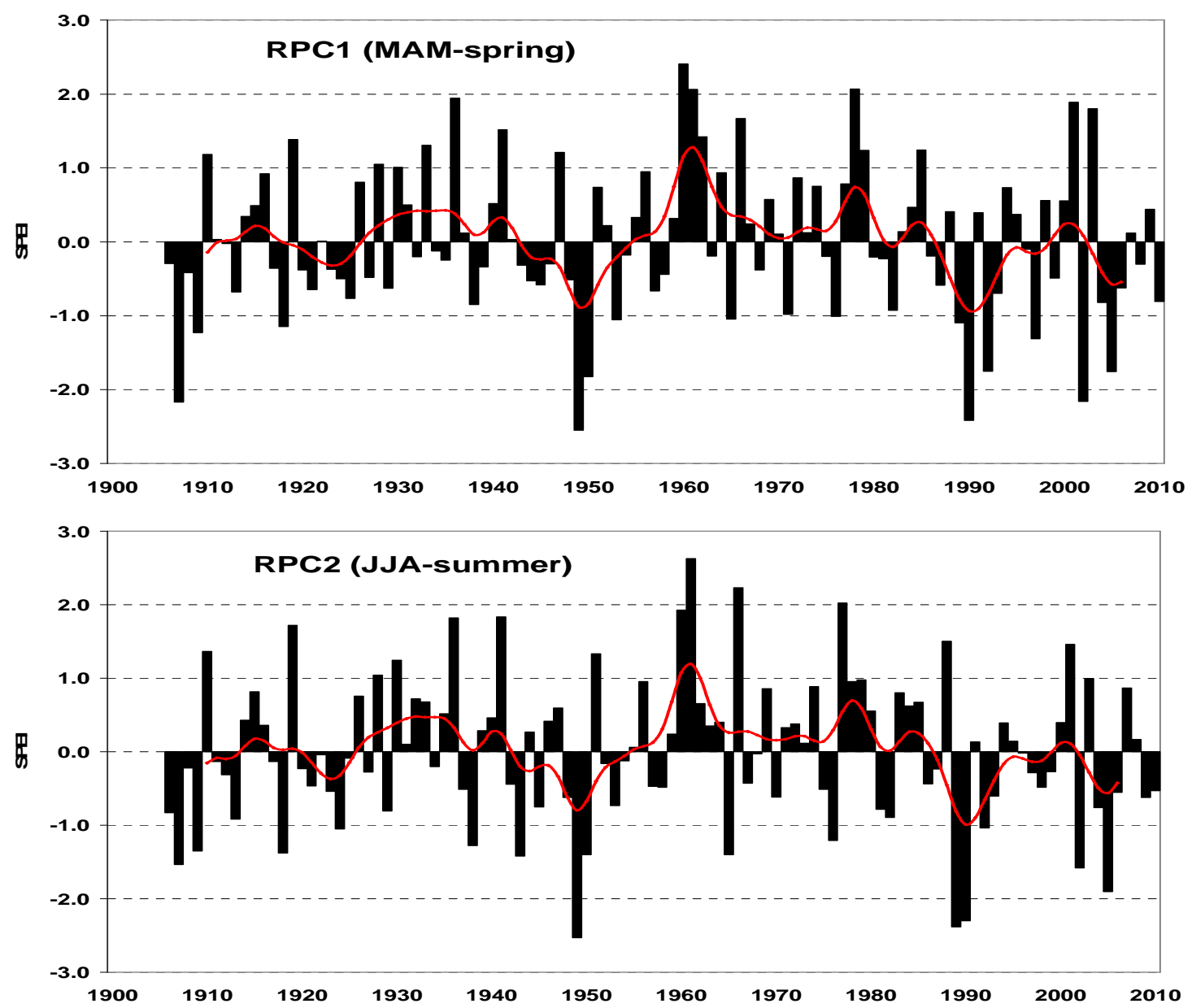

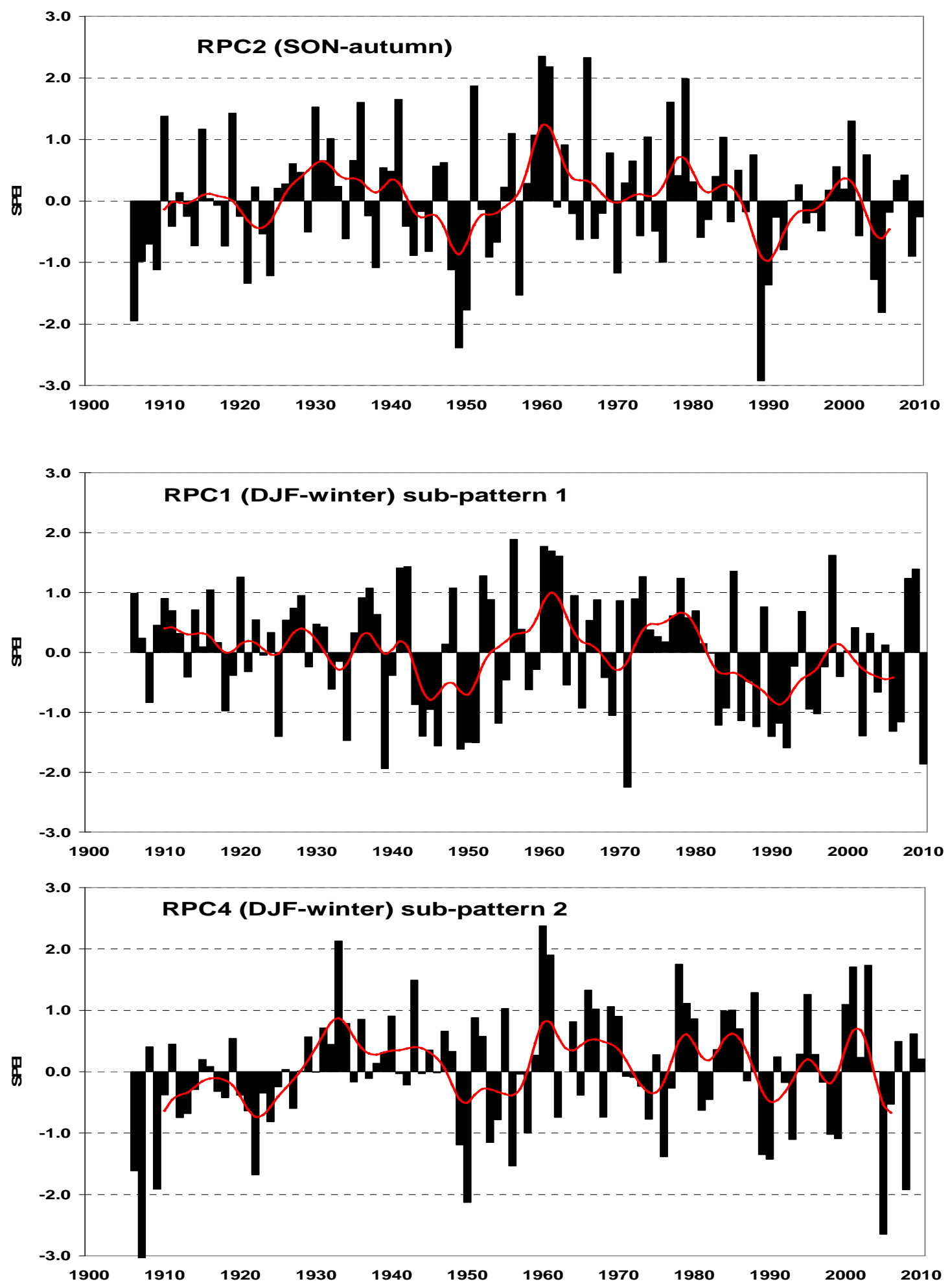

Figure 5-29: Fluctuations of averaged 12-month SPEI time series associated to the North-western pattern found over Iberian Peninsula at seasonal time scale for the period 1906-2010 (with smoothed by Gauss filter over 10 years). 


\subsubsection{The Mediterranean pattern}

\subsubsection{Annual and seasonal spatial structure}

Finally, the Mediterranean pattern (Fig. 5-30) shows a spatial pattern clearly influenced by the Mediterranean Sea, reaching the maximum weights in the east side of the Iberian Peninsula. This pattern spreads over Iberian Peninsula through the Mediterranean coast reaching oriental Pyrenees to the Betic System and covering the eastern part of Iberic System and the eastern part of the South Plateau.

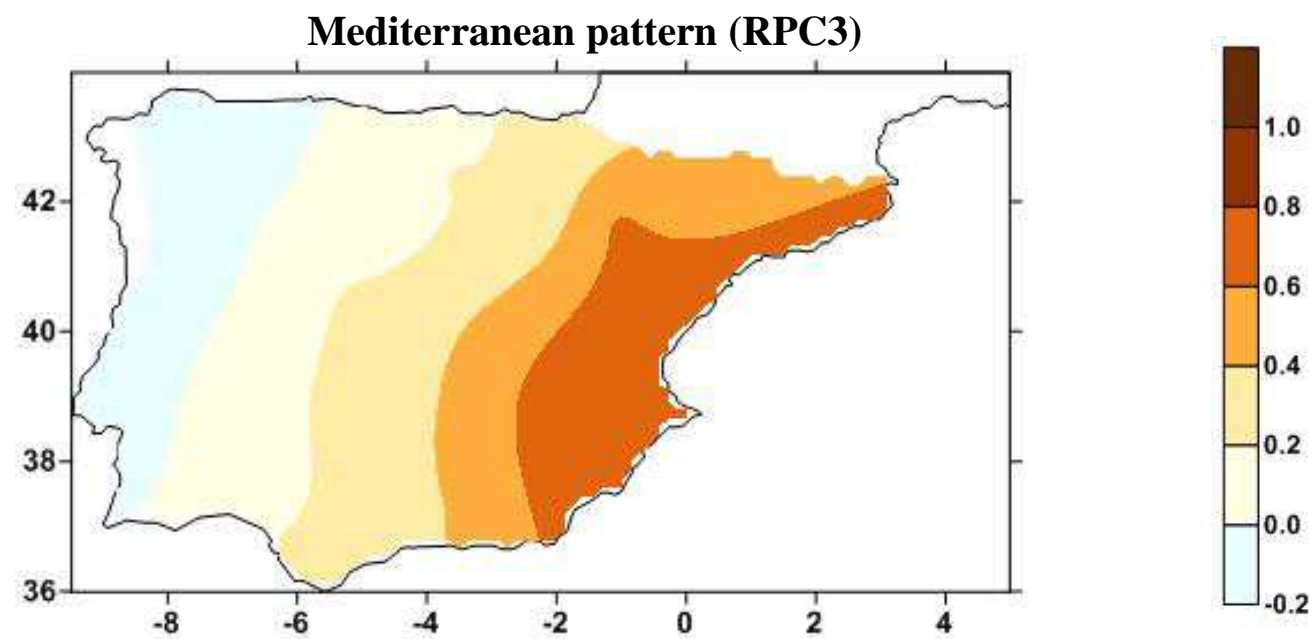

Figure 5-30: Spatial distribution of the maximum weights referred to the Mediterranean pattern (MedP) computed over the 22 12-month SPEI series at annual time-scale over the Iberian Peninsula. This component explains the $6.5 \%$ of total variance. Spatial interpolation is applied using the kriging method.

The Mediterranean pattern found at seasonal time-scale shows a spatial structure strongly influenced by the Mediterranean shoreline, locating the maximum weights at the east and south-east of the Iberian Peninsula in all seasons (Fig. 5-31). This pattern reaches the Mediterranean coast extending to the eastern part of the South Plateau and following the Segura and Jucar basins. The Mediterranean pattern explains less variance than other patterns (around $6 \%$ or $7 \%$ of total variance during all seasons) and the maximum weights reach more Iberian extension in spring and autumn. 


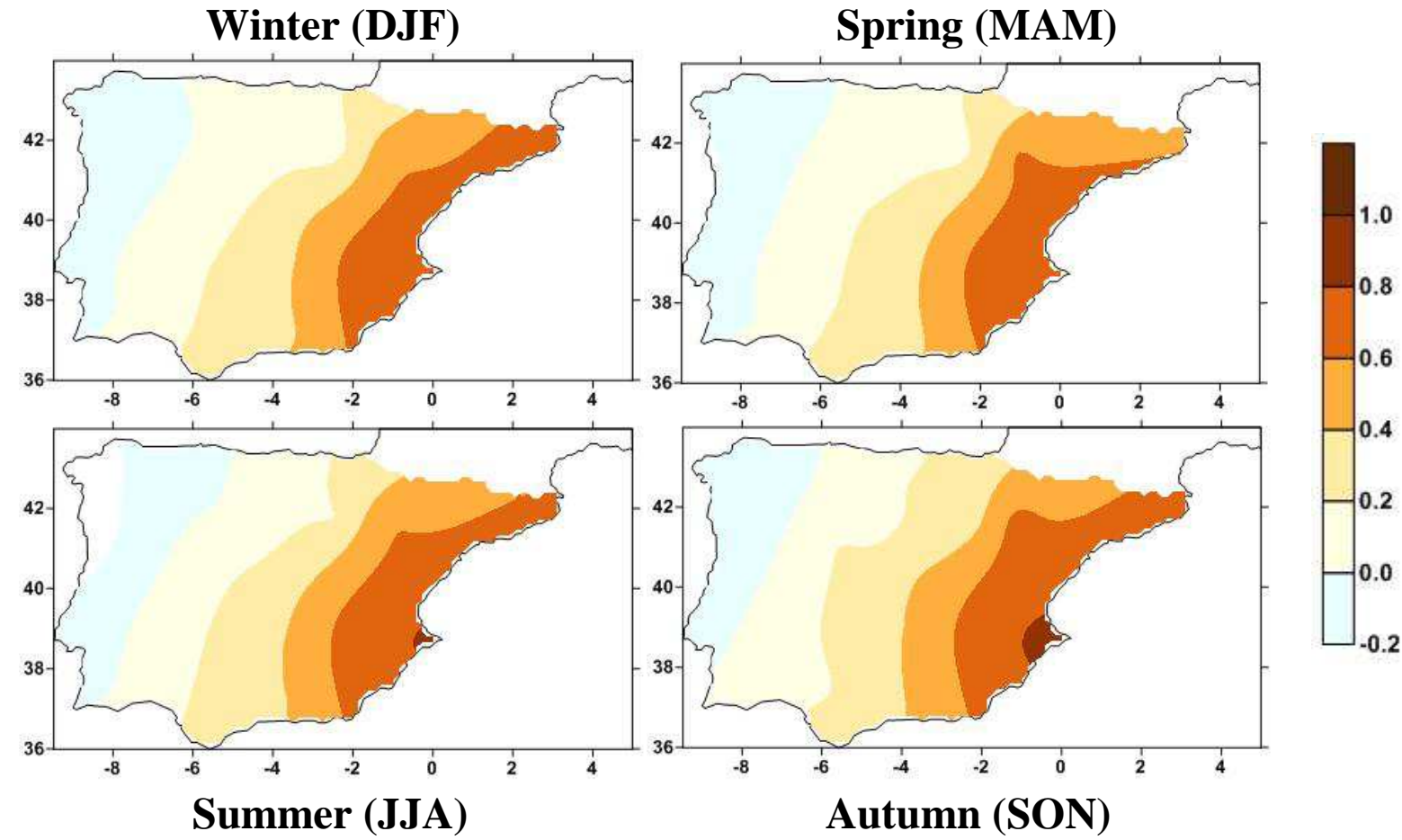

Figure 5-31: Spatial distribution of the maximum weights related to the Mediterranean pattern identified over the Iberian Peninsula at seasonal time-scales. This pattern explains the $6.8 \%$ of total variance in winter (DJF), the $6.8 \%$ in spring (MAM), the $6.4 \%$ in summer (JJA) and the $6.3 \%$ of total explained variance in autumn (SON). Spatial interpolation is applied using the kriging method.

\subsubsection{Annual and seasonal temporal evolution}

Figure 5-32 presents the variability of 12-month SPEI time series associated to the Mediterranean pattern determined by the RPC analysis over the Iberian Peninsula for the period 1906-2010 at annual time-scale. The time series associated to the Mediterranean pattern (MedP) shows the driest periods in early-1910s, mid-late-1920s, 1960s, early-mid-1980s, mid-late-1990s and 2000s. The wettest periods are identified in 1900s, mid-late-1910s, early-1920s, early-1930s and 1970s, while a high variability between dry and wet periods were detected in 1940s, 1950s, late-1980s and early-1990s. The time-series associated to the Mediterranean pattern shows a statistically significant decreasing trend of the $-0.101 /$ decade (at the 99\% level) for the period 1906-2010. 


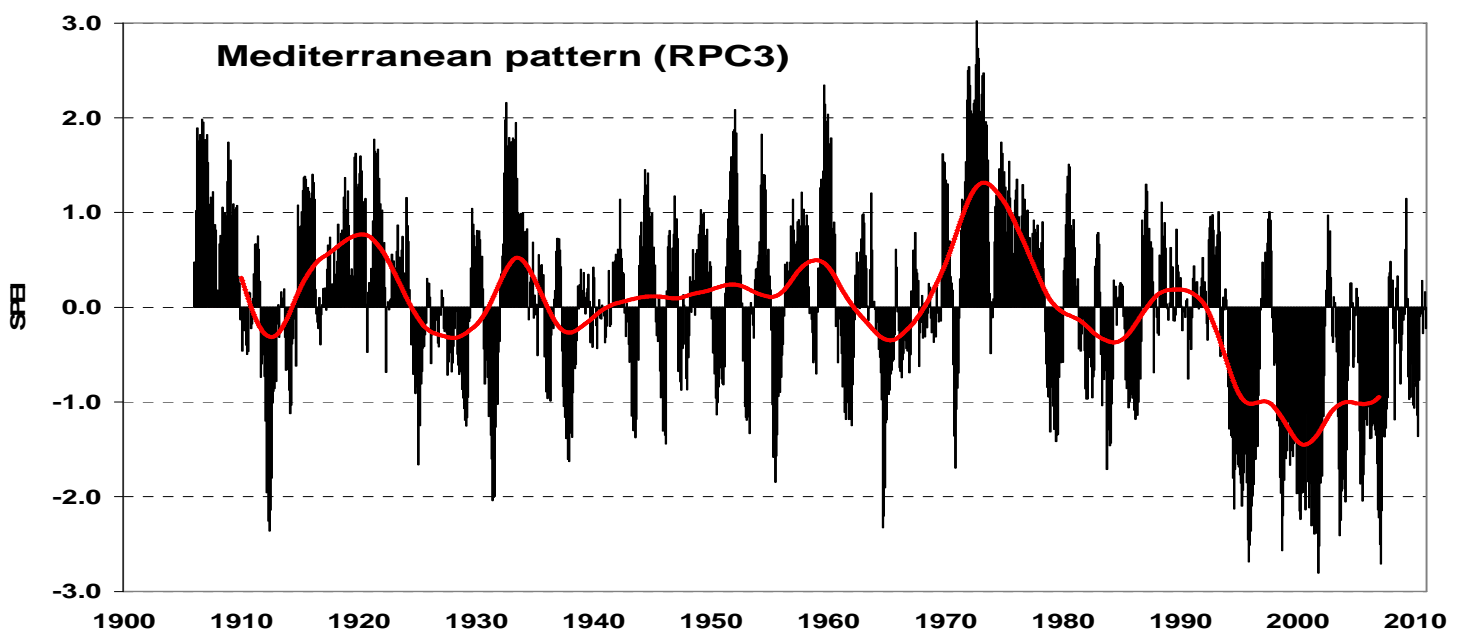

Figure 5-32: Fluctuations of 12-month SPEI time series associated to the Mediterranean pattern found at annual time-scale over Iberian Peninsula for the period 1906-2010. Red line; 10-year Gaussian filter.

The fluctuations of averaged 12-month SPEI time series associated to the Mediterranean pattern found in the Iberian Peninsula at seasonal time scale for the period 1906-2010 are shown in figure 5-33. The time series associated to the Mediterranean pattern showed similar behaviour across time during all seasons. The driest periods identified in the time series occurred in early-1910s, 1920s, mid-1960s, early-1980s, mid-late-1990s and 2000s while the wettest conditions were referred to 1900s, late-1910s, early-1930s, 1970s, and late-1980s. Otherwise, shorter dry and wet periods combined alternatively were detected in 1940s, 1950s and 1960s.

The wettest winter found in the Mediterranean region occurred in $1972(+2.36)$, but the driest winter was identified in 2007 (-2.22). Moreover, the wettest spring was recorded in $1973(+2.43)$, while the driest spring occurred in $2001(-2.34)$. The wettest summer was identified in $1972(+2.37)$, but the driest summer was detected in $2001(-2.33)$. Finally, the wettest autumn occurred in $1972(+2.85)$ and the driest autumn was shown in 1995 (-2.35). The wettest seasonal records was found in early-1970s, meanwhile the driest seasons of the Mediterranean time-series occurred between mid-1990s and 2000s when most of the seasons remained in dry conditions. 

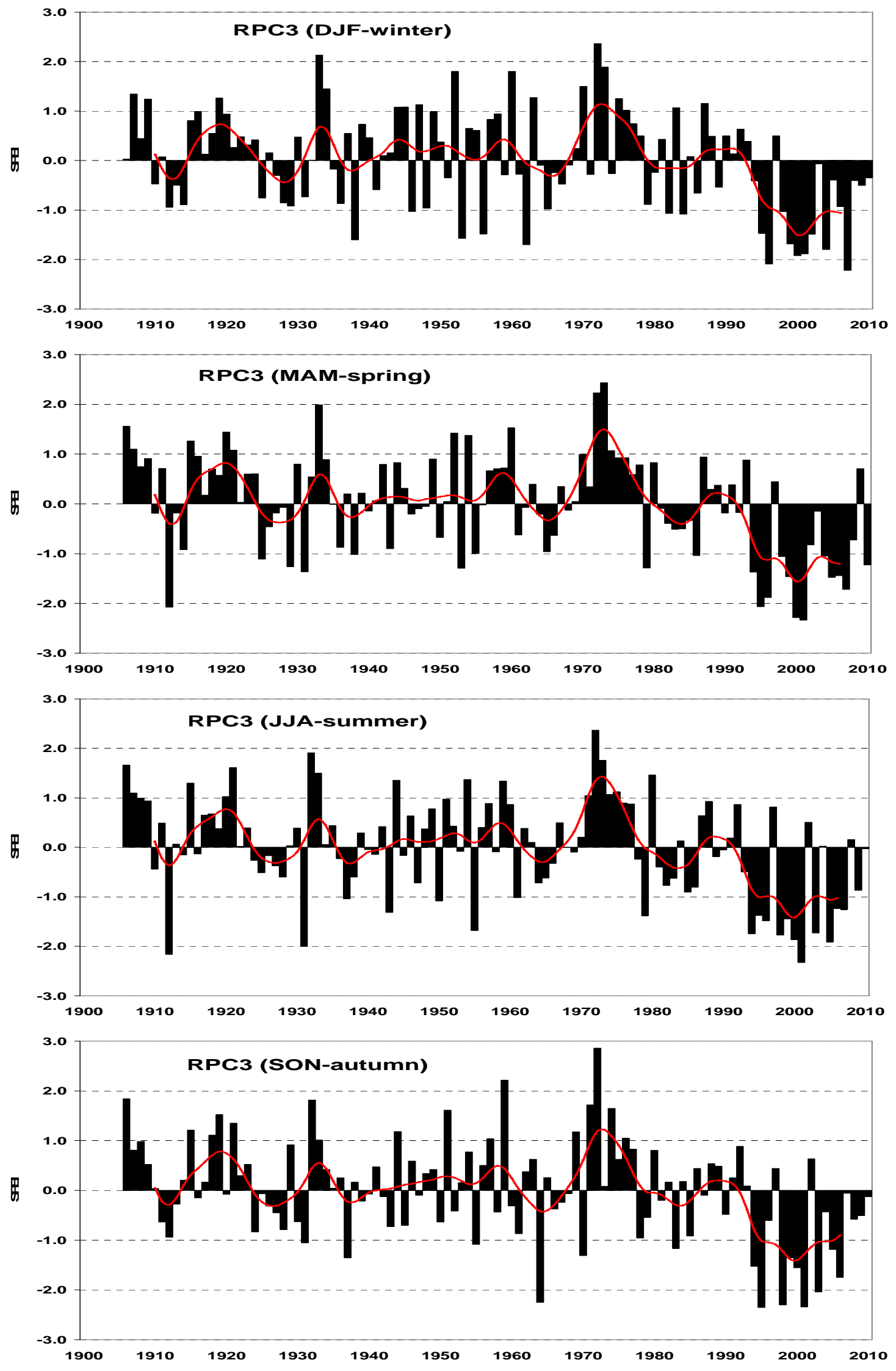

Figure 5-33: Fluctuations of averaged 12-month SPEI time series associated to the Mediterranean pattern found over the Iberian Peninsula at seasonal time scale for the period 1906-2010 (with smoothed by Gauss filter over 10 years). 


\subsubsection{Summary}

Three Rotated Principal Components (RPCs) are extracted from PCAs to represent the variability over Iberian Peninsula at annual time scale explaining the $70.8 \%$ of total variance. Similar spatial-temporal patterns to those found at annual scale are also extracted at the sesasonal time scale. The South-western pattern (RPC1) focuses its maximum weights in the south-west and central area of the Iberian Peninsula while the North-western pattern (RPC2) covers the north and north-western Iberia. Finally, the Mediterranean pattern (RPC3) is mainly focused in the Mediterranean region of the Iberian Peninsula.

The time-series associated to the South-western pattern and the Mediterranean pattern shows a statistically significant decreasing trend (95\% significance level) reaching $0.064 /$ decade and $-0.101 /$ decade (significant at the $99 \%$ level) respectively for the period 1906-2010 (Table 5-11). Otherwise, the time-series associated to the North-western pattern show a non-significant decreasing trend of $-0.001 /$ decade (at the $95 \%$ level). A plausible interpretation is that the south and south-west of the Iberian Peninsula (SWP) is suffering drier conditions currently than before, but the Mediterranean region does it duplicating the drying trend, caused basically by the driest last decades observed in this region. However, the north and north-west of the Iberian Peninsula (NWP) do not show a significant trend in drought conditions. These results are in good agreement with Vicente-Serrano et al., (2011) whom found that dry conditions did not increase in the north-west of the Iberian Peninsula between 1930 and 2006 using SPI and SPEI drought indices. This contrasts with the general trends found in other Iberian regions, in which dry conditions have increased (Vicente-Serrano 2006a). On a regional scale, there is evidence of a significant increase in the severity of drought in the Ebro basin (VicenteSerrano \& Cuadrat-Prats 2006, Vicente-Serrano \& López-Moreno 2006), in some areas of the Valencia region (Vicente-Serrano et al., 2004) and in the Tagus basin (Lorenzo-Lacruz et al., 2010). Sousa et al., (2011) have also shown that north-west of Iberian Peninsula is an exception to the predominant trend in the $20^{\text {th }}$ century towards drier conditions using PDSI, which has been recorded for most of the western Mediterranean. 


\begin{tabular}{|c|c|c|c|}
\hline Patterns & Linear trend (SPEI value/decade) & 95\% confidence intervals & p-values \\
\hline South-western & -0.064 & $(-0.117 /-0.001)$ & 0.045 \\
\hline North-western & -0.001 & $(-0.053 / 0.054)$ & 0.993 \\
\hline Mediterranean & $-\mathbf{0 . 1 0 1}$ & $(-0.153 /-0.049)$ & 0.005 \\
\hline
\end{tabular}

Table 5-11: Summary of annual trends (in SPEI value/decade) computed for the spatial patterns found at annual time scales in the Iberian Peninsula (1906-2010). The associated 95\% confidence intervals are also shown. Bold (or Italic) values are referred to statistical significance at the $99 \%$ level (or $95 \%$ ). 


\subsection{Univariate analysis of droughts and wet events}

The characteristics and trends of the main parameters related to dry and wet events are analyzed for the whole Iberian Peninsula and also for the spatial-temporal patterns found at annual time-scale. According to Burton et al., (1978), the main parameters to analyse dry and wet events are severity, duration and magnitude, all described in section 4.6. Perhaps, magnitude is the most relevant parameter because combines severity and duration (referred to the accumulated severity for a dry or wet period) and it is interesting to see the fluctuations of these parameters across time. Moreover, other interesting parameters are also studied, such as the seasonal distribution of the onset, offset and the period of the maximum severity reached by dry or wet events. It provides information about the seasons in which dry or wet events tend to begin or to end and in which seasons these extreme events reach their maximum severity from 1906 to 2010.

\subsubsection{Characteristics and trends for the whole Iberian Peninsula}

As described in methods section, a drought event is defined as a continuous period in months for which the SPEI remains below zero (Shiau, 2006). Fluctuations in wet and dry events in the Iberian Peninsula from 1906 to 2010 are shown in figure 5-34.

In total, 155 events are identified, from which 77 are dry events and 78 are wet events. This, similar number of wet and dry events is detected over the Iberian Peninsula being consistent with the $50.5 \%$ of months for the whole period with dry conditions and the rest of $49.5 \%$ with wet conditions according to the 12-month SPEI time series. Fig. 6-30 shows how the most severe wet event occurred between 1969 and 1970, when maximum severity index was slightly shorter than +2 (severely wet in SPEI categories; table 4-5). The longest wet event occurred between 1976 and 1980 (Table 5-12) in which wet conditions prolonged during 40 consecutive months, although the maximum severity was moderately wet and, in average, it was slightly wet. Note the wettest events occurred in late-1950s, 1960s and 1970s over the Iberian Peninsula coinciding with temperatures lower than normal and an increase in precipitation in average. 


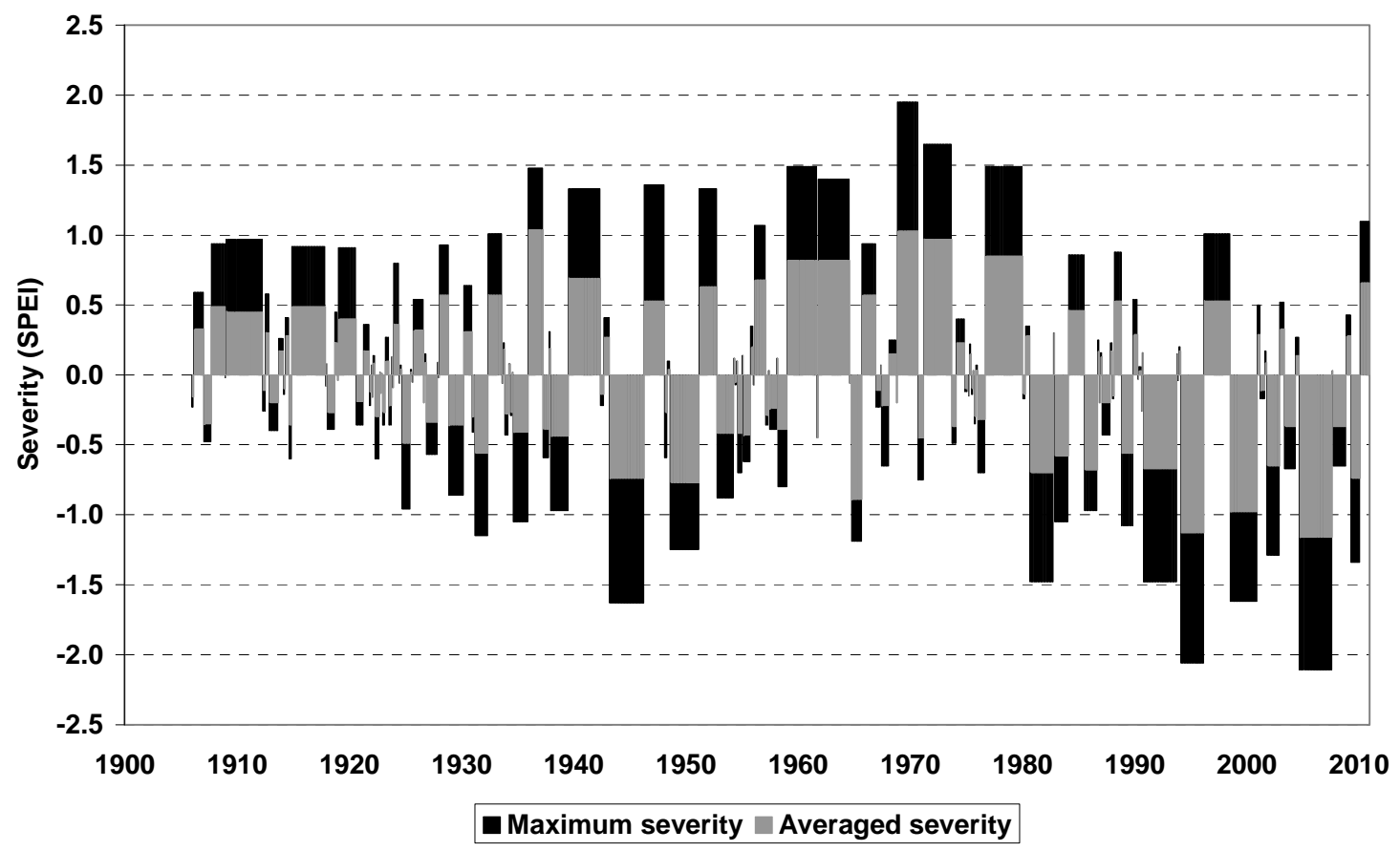

Figure 5-34; Dry and wet events detected in the Iberian Peninsula (1906-2010) using 12-month SPEI. Black bars refer to the maximum monthly index value (maximum severity) recorded for each event, while grey bars indicate the average index value for each event. The duration in months for each event is represented in the $\mathrm{x}$ axis: bars' widths are proportional to duration.

The maximum severity of the driest event identified (between 2004 and 2007) reached the category of extremely dry in a given month and, in average, it was considered moderately dry during 35 months. The second driest event was from 1994 to 1996 reaching extremely dry category and lasted 25 months. Finally, the longest dry event occurred between 1943 and 1946 along 37 months becoming a severely dry event according to the comprehensive categories. Note the driest events occurred during the last two decades coinciding with the warmest years of the time series and, in general, less precipitation than normal.

Fluctuations of magnitude identified for wet and dry events over the Iberian Peninsula across time are shown in figure 5-35. As described in the methods section, magnitude is defined as the accumulation of monthly severity index value related to duration of the analysed drought. The highest magnitudes in wet events appeared in 1910s, late-1930s, 1960s and 1970s. The highest drought magnitudes were recorded in mid-late-1940s, early-1950s and during the last three decades of the records (from 1980 to 2010). 


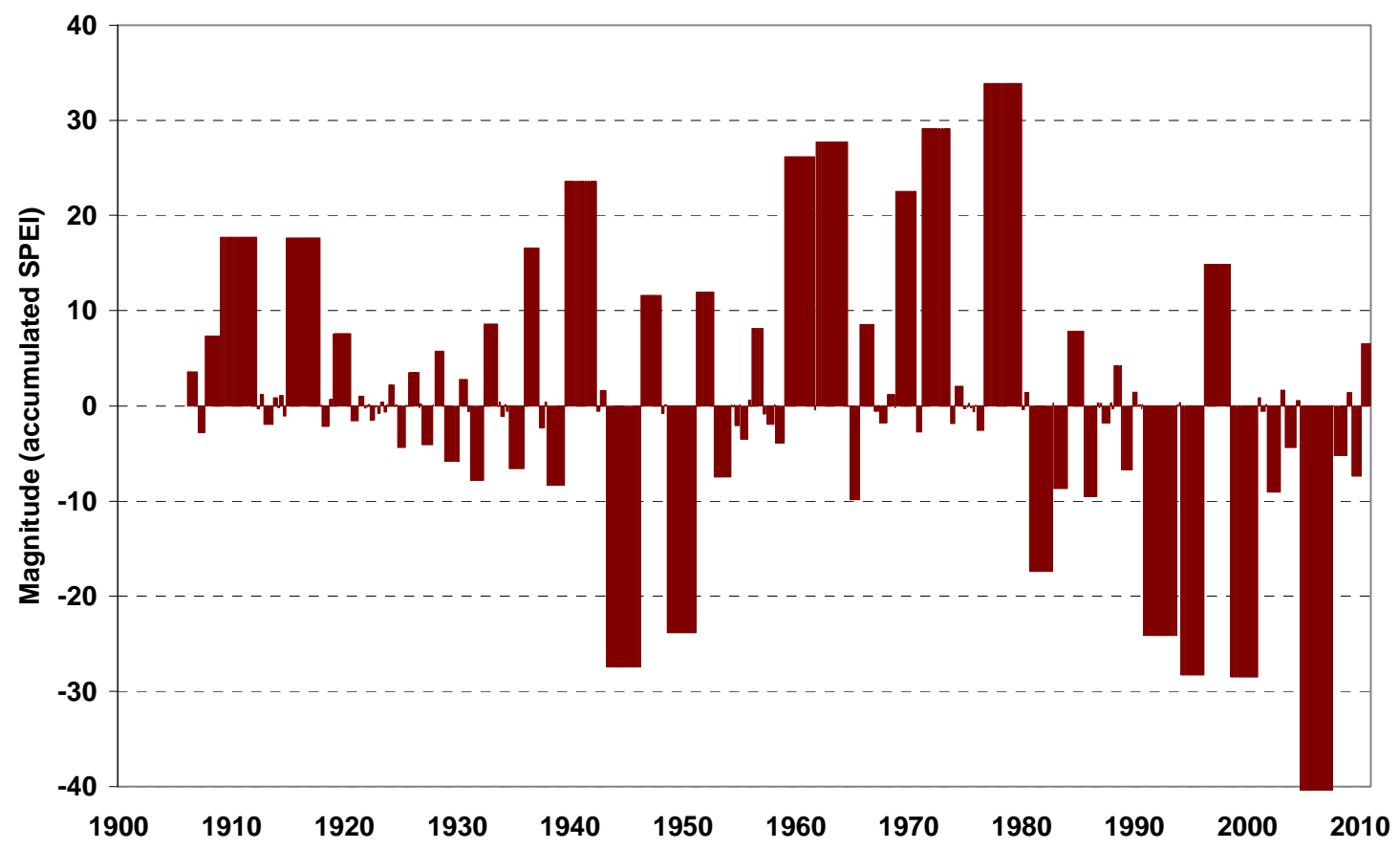

Figure 5-35: Magnitude of wet and dry events identified over Iberian Peninsula (1906-2010) using 12month SPEI. Red bars refer to the accumulated SPEI severity (magnitude) recorded for each event related to the duration in months represented in the $\mathrm{x}$ axis: bars' widths are proportional to duration.

The major magnitude of dry and wet events identified over the Iberian Peninsula from 1906 to 2010 are shown in table 5-12 related with the maximum severity reached for each event, averaged severity and duration in months. In this way, the wet event detected between 1976 and 1980 was the major wet event reaching the maximum magnitude of the time-series while the drought occurred from 2004 to 2007 reached the maximum magnitude becoming the major drought identified over the Iberian Peninsula since $20^{\text {th }}$ century. Other major wet and dry events were included in table 5-12 that occurred in 1960s and 1970s (in the case of wet events) and in 1940s and two of them in 1990s (in the case of droughts). In fact, the driest and wettest event (in terms of magnitude) did not coincide with the most severe and longest ones because the maximum magnitudes were reached when both severity and duration of dry and wet events were very high simultaneously.

Table 5-13 shows the statistics of maximum severity reached for each event, averaged severity, duration in months and magnitude of wet and dry events. The mean of maximum severity and averaged severity of dry events is slightly higher than the equivalent paraeters for wet events, demonstrating that dry events tend to be more severe than wet events. However, the duration of wet events is found to be higher than 
in dry events. Wet periods last on average 8.26 months, contrasting with the lower value of 7.88 months for dry events. Although the severity of dry events is found to be slightly higher than in wet events, the longer duration of wet events results in similar average magnitudes compared to those found for dry events over the Iberian Peninsula. However, maximum severity index value and maximum magnitude reached by a particular dry event is higher than the equivalent parameters reached for particular wet events, although the highest maximum duration was reached by a wet event.

\begin{tabular}{|c|c|c|c|c|c|}
\cline { 2 - 6 } \multicolumn{1}{c|}{} & $\begin{array}{c}\text { Major } \\
\text { events }\end{array}$ & $\begin{array}{c}\text { Maximum } \\
\text { severity }\end{array}$ & $\begin{array}{c}\text { Averaged } \\
\text { severity }\end{array}$ & $\begin{array}{c}\text { Duration in } \\
\text { months }\end{array}$ & Magnitude \\
\hline \multirow{4}{*}{ Wet } & $1959-1961$ & 1.49 & 0.82 & 32 & 26.19 \\
\cline { 2 - 6 } & $1961-1964$ & 1.40 & 0.82 & 34 & 27.73 \\
\cline { 2 - 6 } & $1969-1970$ & 1.95 & 1.03 & 22 & 29.12 \\
\cline { 2 - 6 } & $1976-1980$ & 1.49 & 0.85 & 40 & 33.87 \\
\hline \multirow{4}{*}{ Dry } & $1943-1946$ & 1.63 & 0.74 & 37 & 27.44 \\
\cline { 2 - 6 } & $1994-1996$ & 2.06 & 1.13 & 25 & 28.28 \\
\cline { 2 - 6 } & $1998-2001$ & 1.62 & 0.98 & 29 & 28.48 \\
\cline { 2 - 6 } & $2004-2007$ & 2.11 & 1.16 & 35 & 40.76 \\
\hline
\end{tabular}

Table 5-12; Summary statisitics of the most remarkable wet and dry events in terms of maximum severity reached for each event, averaged severity and magnitude in absolute values. Duration in months is also shown.

\begin{tabular}{|c|c|c|c|c|c|}
\hline & Parameters & Mean & Maximum & STD & Linear trend \\
\hline \multirow{4}{*}{ 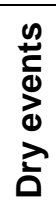 } & Max. Severity & 0.55 & 2.11 & 0.50 & $0.059 \mathrm{SPEl} / 10$ events \\
\hline & Avg. Severity & 0.32 & 1.16 & 0.26 & $0.039 \mathrm{SPEl} / 10$ events \\
\hline & Duration (months) & 7.88 & 37 & 8.99 & 0.588 month $/ 10$ events \\
\hline & Magnitude & 4.46 & 40.76 & 8.03 & $0.211 \mathrm{SPEl} / 10$ events \\
\hline \multirow{4}{*}{ 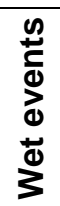 } & Max. Severity & 0.49 & 1.95 & 0.49 & 0.003 SPEI/10 events \\
\hline & Avg. Severity & 0.28 & 1.04 & 0.26 & $0.007 \mathrm{SPEl} / 10$ events \\
\hline & Duration (months) & 8.26 & 40 & 10.40 & -0.330 month/10 events \\
\hline & Magnitude & 4.53 & 33.87 & 7.94 & $0.050 \mathrm{SPEI} / 10$ events \\
\hline
\end{tabular}

Table 5-13: Summary statistics of all dry and wet events detected over Iberian Peninsula from 1906 to 2010. Maximum severity reached for each event, averaged severity, magnitude and duration in months are the parameters analyzed and the mean, maximum value, standard deviation, linear trend and its statistical significance (linear trend calculated for each 10 events) are the statistics in absolute values. Bold (Italic) values are referred to statistical significant trends at $99 \%$ level $(95 \%)$.

To assess time evolution of the different wet/dry events related parameters, their linear trends are computed (Table 5-13). Linear trends in maximum severity, averaged severity and magnitude of the SPEI index values of wet events show a slight and non-significant increase while the duration (in months) tended to decrease also not reaching the the $95 \%$ 
significance level (Table 5-13). In comparison, the same parameters of severity computed over dry events show a statistically significant (99\% level) increase of the 0.059SPEI/10 events in maximum severity and of the $0.039 \mathrm{SPEI} / 10$ events in average severity. This new unit (drought index value/10 events) is used to quantify trends in severity and magnitude (using the pertinent drought index value of SPEI trend in this case) of wet and dry events for each 10 events. Linear trends of drought magnitude and duration show a significant increase of the $0.211 \mathrm{SPEI} / 10$ events and of the 0.588 months $/ 10$ events at the 95\% and 99\% level respectively for the whole period (1906-2010). This means that the severity, magnitude and duration of droughts is experiencing a significant increase over the Iberian Peninsula while the same parameters computed for wet events are not changing their behaviour significantly.

Otherwise, a joint analysis of severity, magnitude and duration could give us an idea about the relationship among these relevant parameters in wet and dry events, for this reason it is better to study them together. In fact, the correlation coefficient (Pearson) between maximum severity reached and duration in dry events is 0.89 , while in wet events is 0.85 , and between averaged severity and duration is 0.82 in both; wet and dry events.

The behavior of identified dry and wet events according to the maximum and averaged severity related with its duration is shown in figure 5-36. The accumulative character of droughts can be identified by noting that when the duration of the drought increases so does the severity drawing a logarithmic trend.

Obviously, most of the dry and wet events remain in low severity and duration due to high variability between wet and dry months that do not allow to produce dry or wet conditions in a long time, but this is not so in a few cases. The 1990s and 2000s were abnormally warm due to climate change (Salomon et al., 2007) and abnormally dry (in precipitation) causing the three driest events of the series mentioned above (recovering table 5-12). 

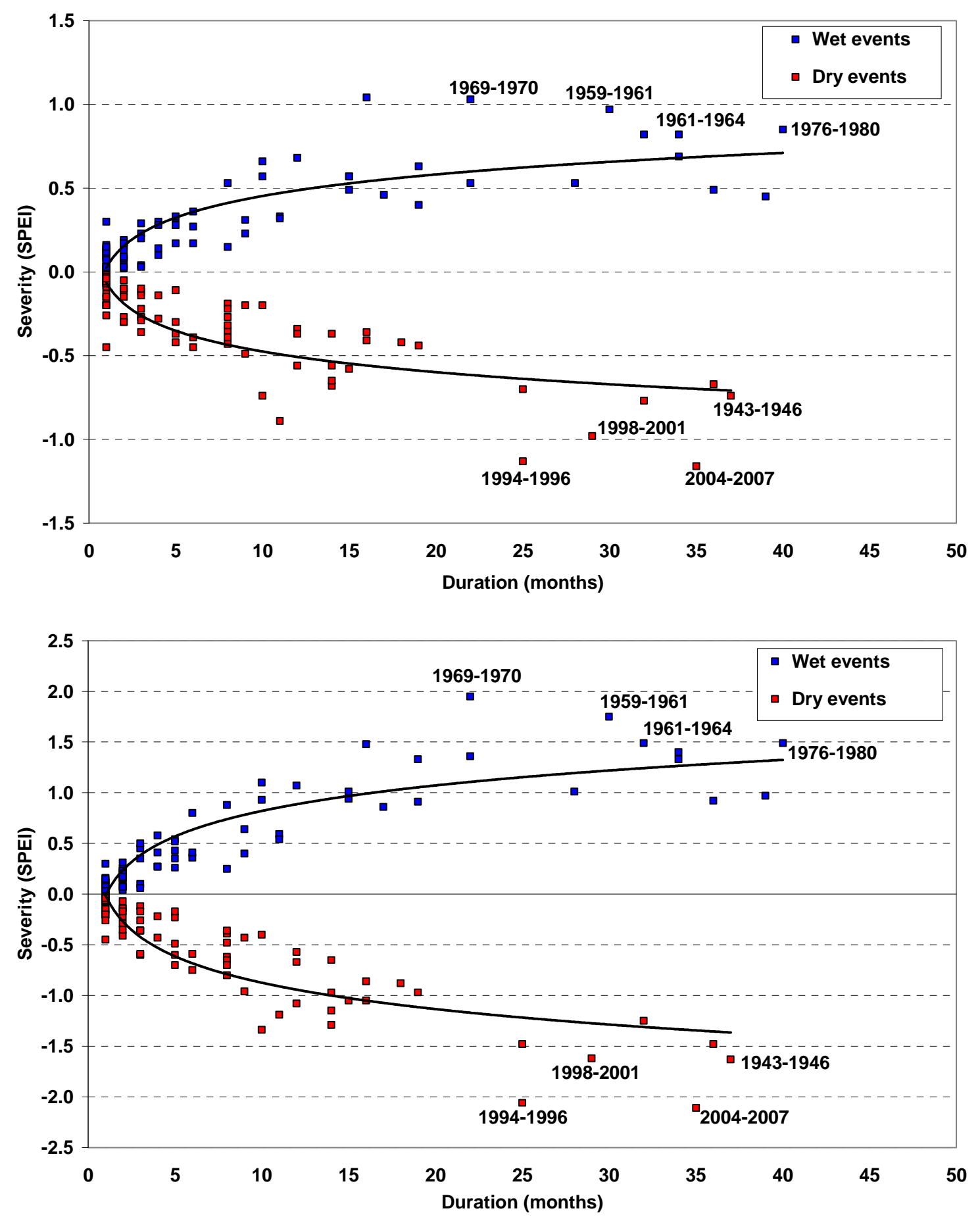

Figure 5-36; Behavior of identified dry and wet events according to the average index value for each event (upper panel) and the maximum monthly index value (maximum severity) recorded for each event (lower panel) related with the duration of each event. Most remarkable wet and dry events detected previously are also shown and black lines draw logarithmic trends.

As occurred when maximum and averaged severity of dry and wet events were analyzed together with duration, magnitude and duration can also be treated jointly. Obviously, drought magnitude also has a strong correlation with duration of dry events. In fact, the correlation coefficient (Pearson) between magnitude and duration is 0.94 in wet events 
and is 0.93 in dry events. The behaviour of magnitude according to the respective duration in months is represented in figure 5-37. The most remarkable wet and dry events described above are highlighted as well, but most of wet and dry events remain in lower magnitude and duration caused basically by the high variability of droughts that did not allow prolonged dry and wet periods with some exceptions called as major droughts described before. Note that when the duration of wet and dry events increases so did the magnitude of these events because the duration in time implied more or less accumulated severity, so more or less magnitude recorded in wet and dry events.

This exercise clearly demonstrates that there is a strong relationship between severity, magnitude and duration in wet and dry events.

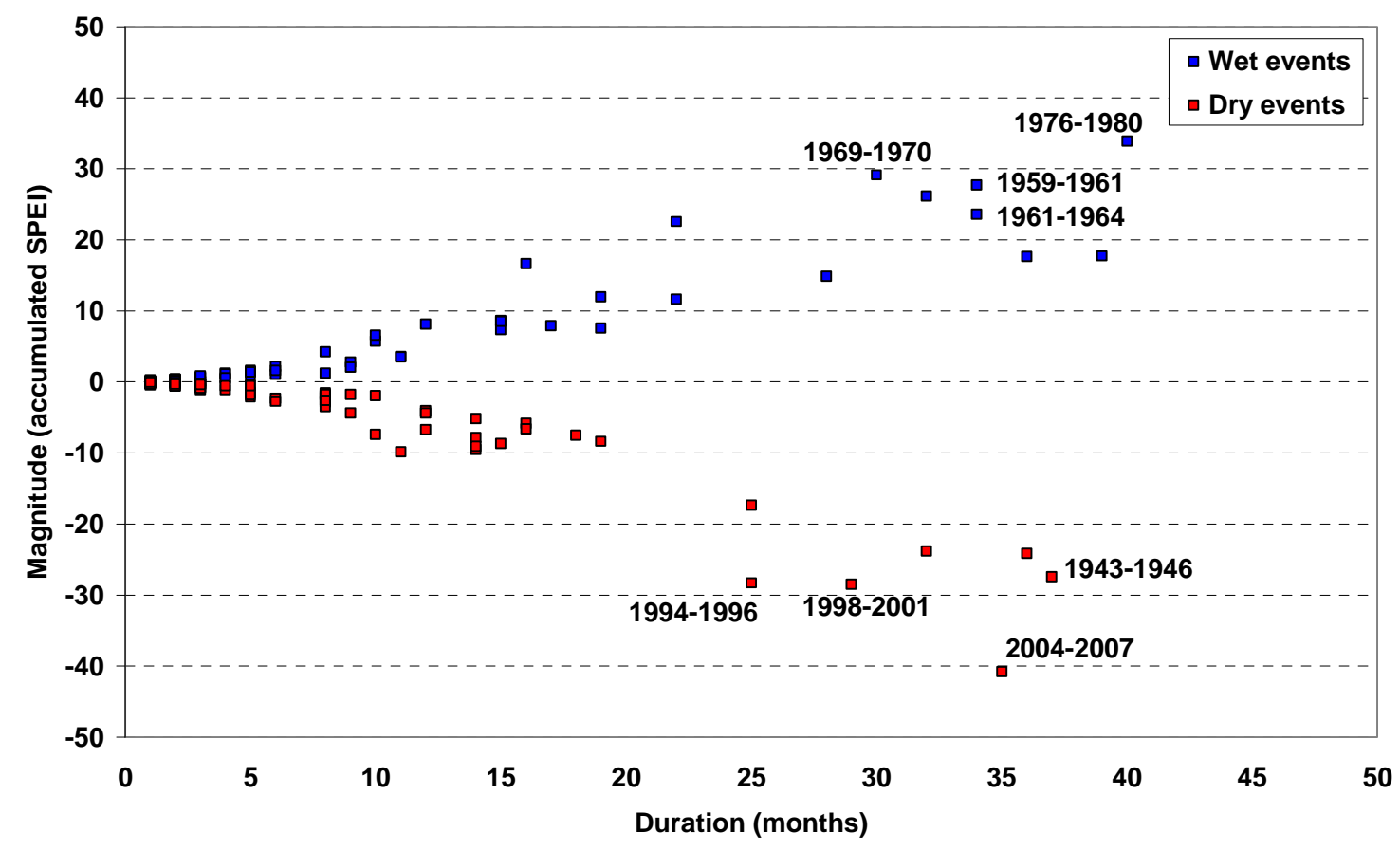

Figure 5-37: Behaviour of identified wet and dry events according to the magnitude reached for each event related with the duration in months. Most remarkable wet and dry events are also shown.

Finally, seasonal distribution of the onset and offset of identified droughts and wet events are also described together with the season in which the dry or wet events reached their maximum severity. This information provides knowledge about which seasons are prone to accumulate onsets, offsets or maximum severities related to dry and wet events for the whole Iberian Peninsula taking into account the extreme events found in SPEI time-series. Figures 5-38 and 5-39 show the seasonal distribution of the percentages related to the onset, offset and maximum severity reached in wet (Fig. 5-38) and dry events (Fig. 5-39) for the whole Iberian Peninsula from 1906 to 2010. Note that 
the coldest colours in the plots are referred to the parameters about wet events meanwhile the warmest ones represent the parameters related to droughts.

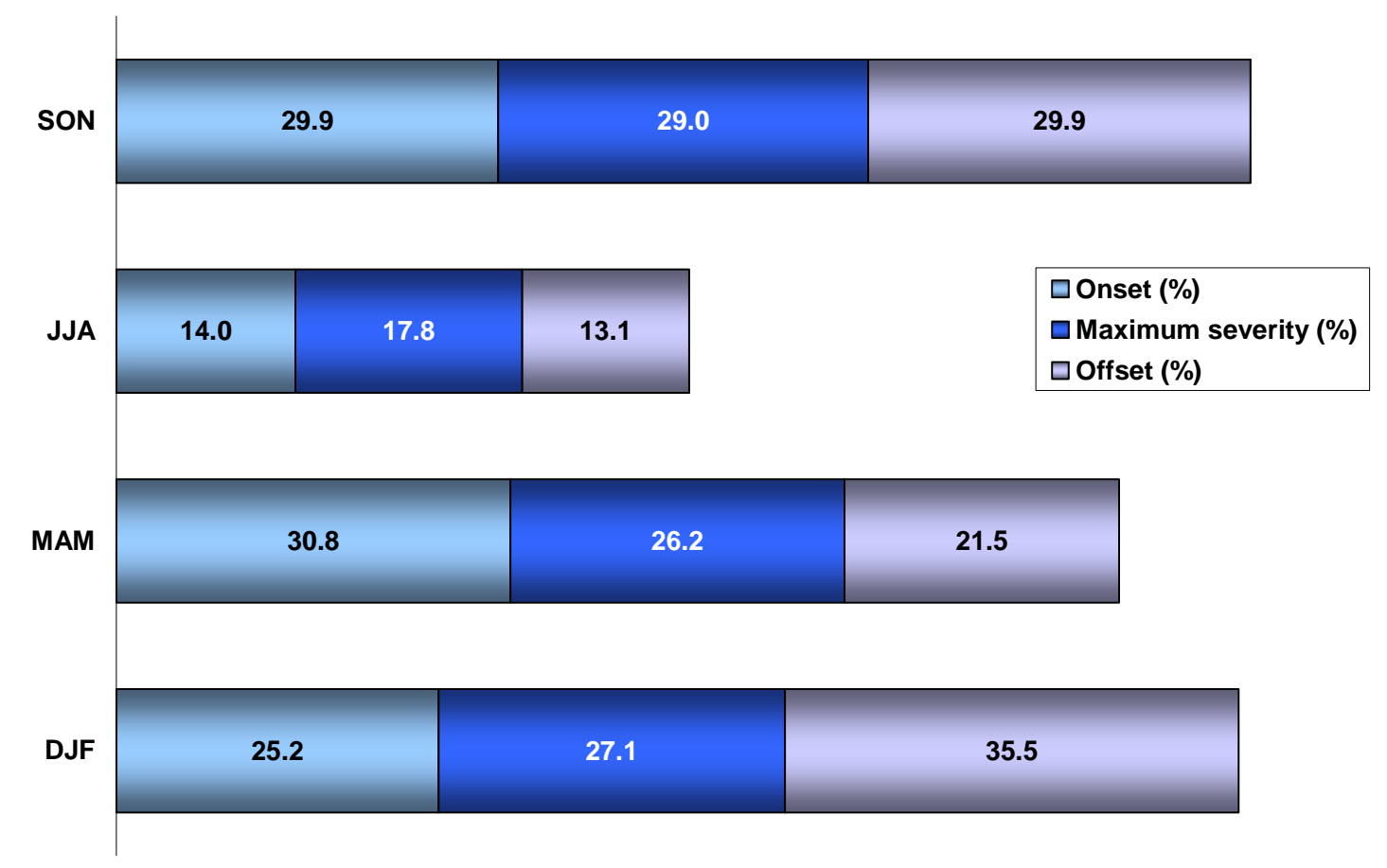

Figure 5-38: Seasonal distribution of the percentages referred to the onset, offset and maximum severity reached by wet events in the Iberian Peninsula. Seasons are shown in the y axis; where DJF is referred to winter, MAM to spring, JJA to summer and SON to autumn. Seasonal percentages for each parameter are also included inside the bars.

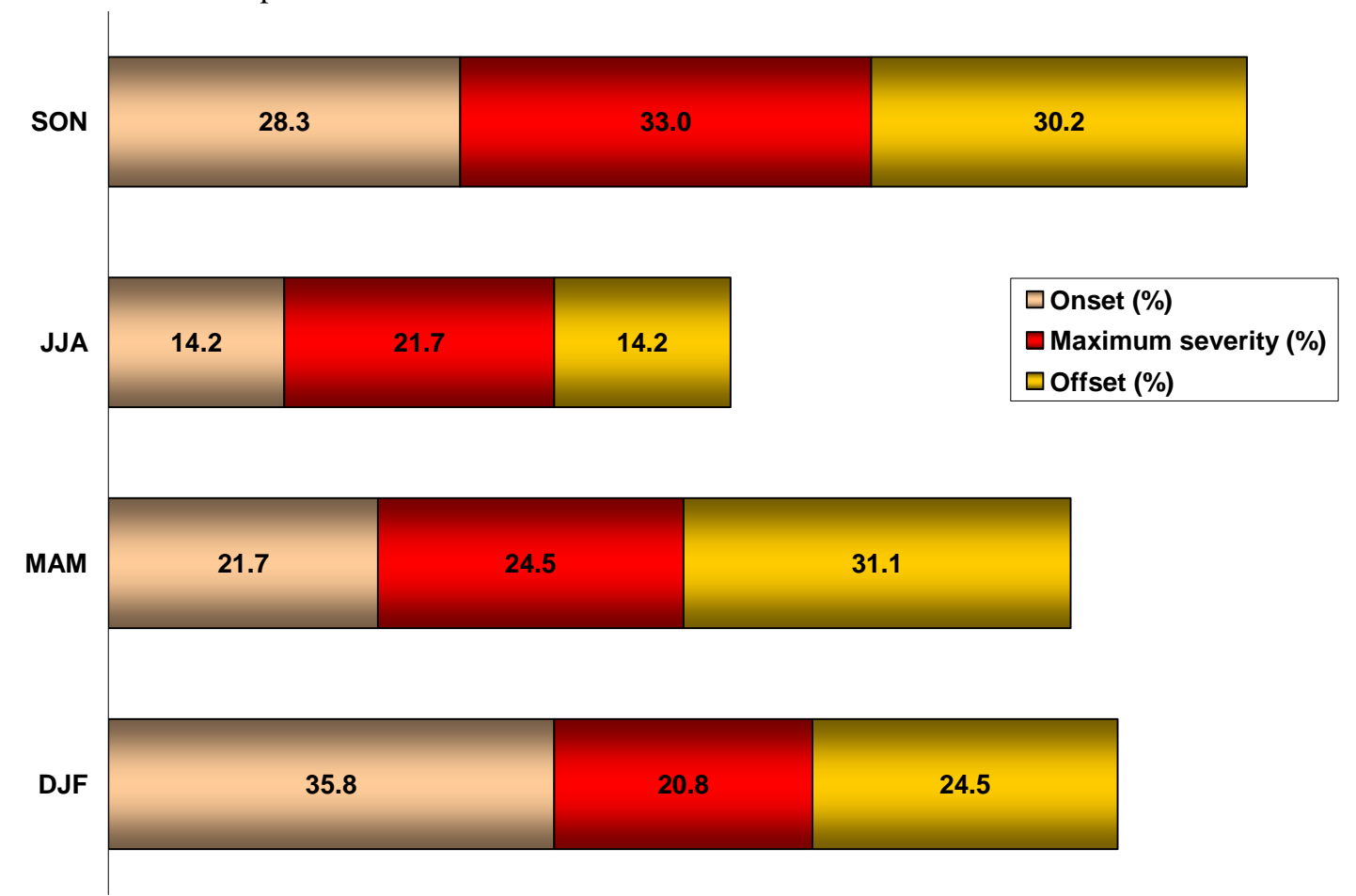

Figure 5-39: Seasonal distribution of the percentages referred to the onset, offset and maximum severity reached by droughts in the Iberian Peninsula. Seasons are shown in the y axis; where DJF is referred to winter, MAM to spring, JJA to summer and SON to autumn. Seasonal percentages for each parameter are also included inside the bars. 
Around 60\% of wet events found in the Iberian Peninsula from 1906 to 2010 began in the equinoccial seasons, spring or autumn, meanwhile the $25 \%$ of wet events started in winter; the reamaining 14\% started in summer (Fig. 5-38). That is logical taking into account that summer is the climatologically driest and warmest season in the Iberian Peninsula. Similar results are found identifying the seasons in which wet events reached maximum severity. The $29 \%$ of wet events reached maximum severity in autumn, the $27 \%$ in winter, the $26 \%$ in spring and less than $18 \%$ in summer. These results show that winter, spring and autumn has a similar capacity to reach maximum severity in wet events, meanwhile in summer, the lack of precipitation together with the highest temperatures of the year cause higher evapotranspiration and, in consequence, less capacity to reach maximum severity of wet events during this season. Finally, more than $35 \%$ of wet events finished in winter, the $30 \%$ in autumn, around $21 \%$ in spring and $13 \%$ in summer. As shown, most of wet events began, finished and reached maximum severity basically in winter or autumn coinciding with the seasons that record higher amounts of precipitation along the year in the Iberian Peninsula. In fact, the behaviour of wet events in terms of the onset, the offset and maximum severity reached is mainly regulated by winter and autumn (lesser extent in spring) in the region under study.

On the other hand, almost the $36 \%$ of droughts identified in the Iberian Peninsula began in winter, the $28 \%$ in autumn, almost the $22 \%$ in spring and the $14 \%$ in summer (Fig. 5 39). Moreover, the $33 \%$ of droughts reached their maximum severity in autumn, the $24.5 \%$ in spring, almost the $22 \%$ in summer and almost the $21 \%$ in winter. Finally, the $31 \%$ of droughts finished in spring, the $30 \%$ in autumn, the $24.5 \%$ in winter and the $14 \%$ in summer. As shown in wet events, the behaviour of droughts related to the onset, the offset and maximum severity reached is basically regulated by winter, autumn and spring in the Iberian Peninsula. The role of summer related to the beginning and end of droughts is less than other seasons (as in wet events), but the percentage of maximum severity reached in droughts during summer is slightly greater than in winter due to higher temperatures and less precipitation recorded in summer than in winter, leading that maximum severity is greater in summer than in winter. The high percentage recorded in maximum severity of droughts reached in autumn $(33 \%)$ is related to climate conditions given in summer (less precipitations and the highest temperatures) 
that can cause a worsening of droughts reaching maximum severity if dry conditions prolong during autumn.

\subsubsection{Characteristics and trends for the spatial-temporal patterns}

Once major droughts and wet events were identified and linear trends and their statistical significance were analyzed for magnitude, severity and duration of the events over the whole Iberian Peninsula, the same parameters and their statistics are obtained for the time-series associated to the spatial-temporal patterns found previously. The aim of this analysis is to find differences on the behaviour of droughts and wet events in terms of magnitude, severity and duration for each pattern. As known from previous section, the spatial-temporal patterns found in the Iberian Peninsula at annual time scale are: The South-western pattern, the North-western pattern and the Mediterranean pattern. The results are analyzed separately for each pattern.

\subsubsection{The South-western pattern}

A drying trend was found in the time series associated to the South-western pattern in previous section, so it will also be interesting to investigate how these drier conditions can affect the parameters related to wet and dry events identified from 1906 to 2010 (Fig. 5-40). The same number of dry and wet events is determined in the time series associated to the South-western pattern. In total, 134 events; 67 are wet events and 67 are referred to droughts. Six events reach the category of extremely wet (greater or equal to +2 in SPEI categories, table 4-5) in 1910, 1967, 1976, 1989, 1996 and 2010, while five events reach the extremely dry category (less or equal to -2 in SPEI categories) in 1973, 1990, 1994, 1998 and 2005. Note that the extremely wet and extremely dry events are concentrated basically during the last four decades of the timeseries. The wettest event occurred between 1910 and 1913 reached the extremely wet category during a few months and, in average, it is considered a severely wet event during 26 consecutive months. Otherwise, the longest wet event was detected between 1967 and 1972 reaching also the extremely wet category and, in average, the severely wet category during 54 consecutive months (Table 5-14). However, the driest event occurred between 1994 and 1995 reaching the extremely dry category and, in average, the severely dry category during 22 consecutive months. Furthermore, the longest 
drought was identified between 1931 and 1936 and prolonged during 58 consecutive months, but it does not reach the extremely dry category, just the severely dry category during a few months.

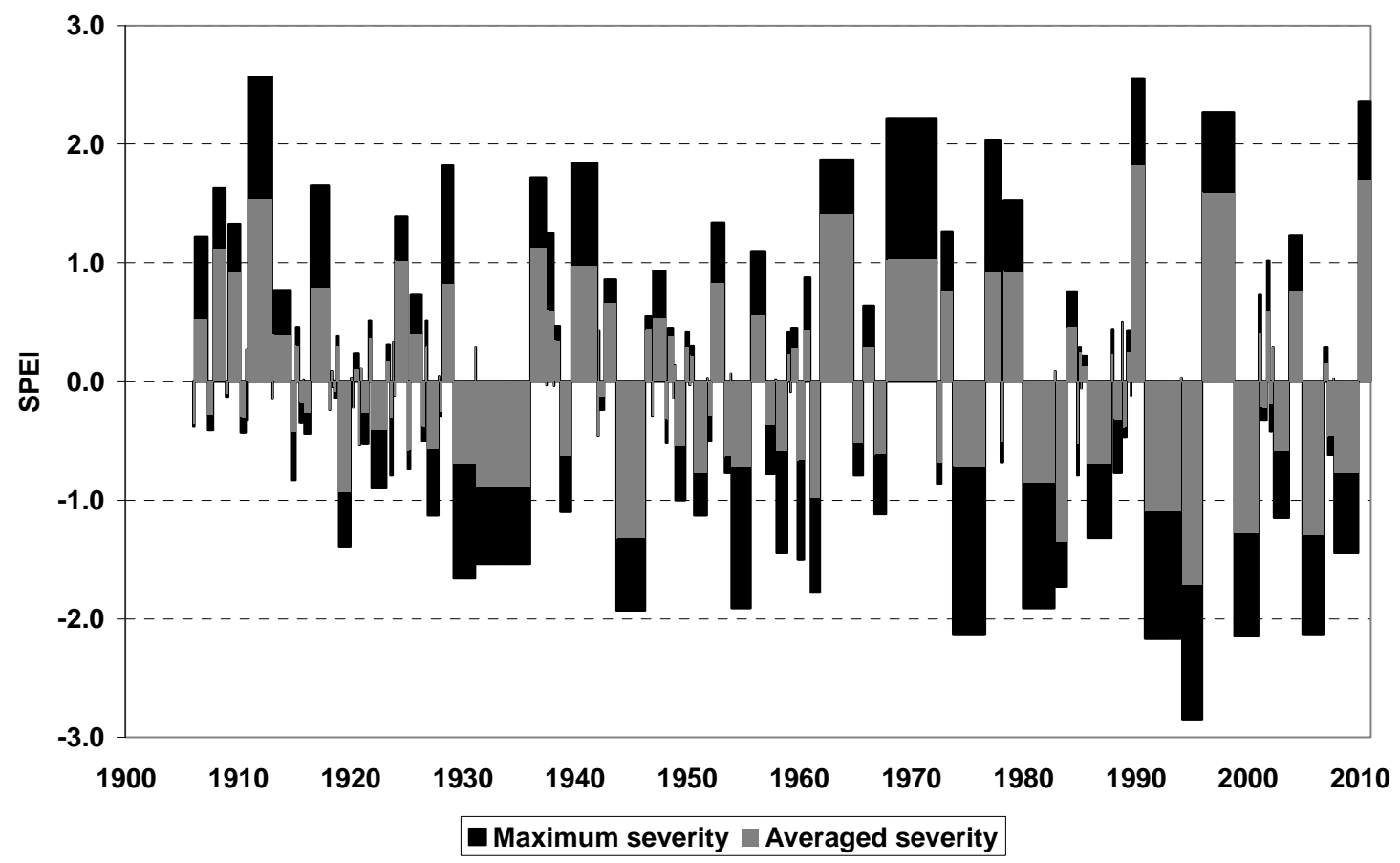

Figure 5-40; Dry and wet events detected in the time-series associated to the South-western pattern (1906-2010) using 12-month SPEI. Black bars refer to the maximum monthly index value (maximum severity) recorded for each event, while grey bars indicate the average index value for each event. The duration in months for each event is represented in the $\mathrm{x}$ axis: bars' widths are proportional to duration.

The fluctuations of the magnitude of wet and dry events (accumulated SPEI for a particular duration) are shown in figure 5-41. As shown, the highest magnitudes are recorded in wet events in early-1910s, late-1930s, early-1940s, early-1960s, early and late-1970s, in early and late-1990s and late-2000s. Otherwise, the highest magnitudes in droughts appear in early-mid-1930s, mid-1940s, mid-1970s, early-mid-1980s, mid1990s and early-mid-2000s.

In this way, table 5-14 shows the major wet and dry events detected in the time-series associated to the South-western pattern in terms of magnitude, maximum severity reached, averaged severity and duration in months. The major wet event occurred between 1967 and 1972 reaching the maximum magnitude of the time series promoted by 54 consecutive months remaining in wet conditions, although this was not the most severe wet event. Otherwise, the major drought was detected between 1931 and 1936 during 58 consecutive months, but it was not also the most severe drought. In both cases, major extreme events coincide with the longest events, but not with the most 
severe ones, demonstrating that the duration of wet and dry events plays an important role when computing magnitudes in the South-western pattern. Other major events are shown in table 5-14 jointly with their magnitude, severity and duration in months.

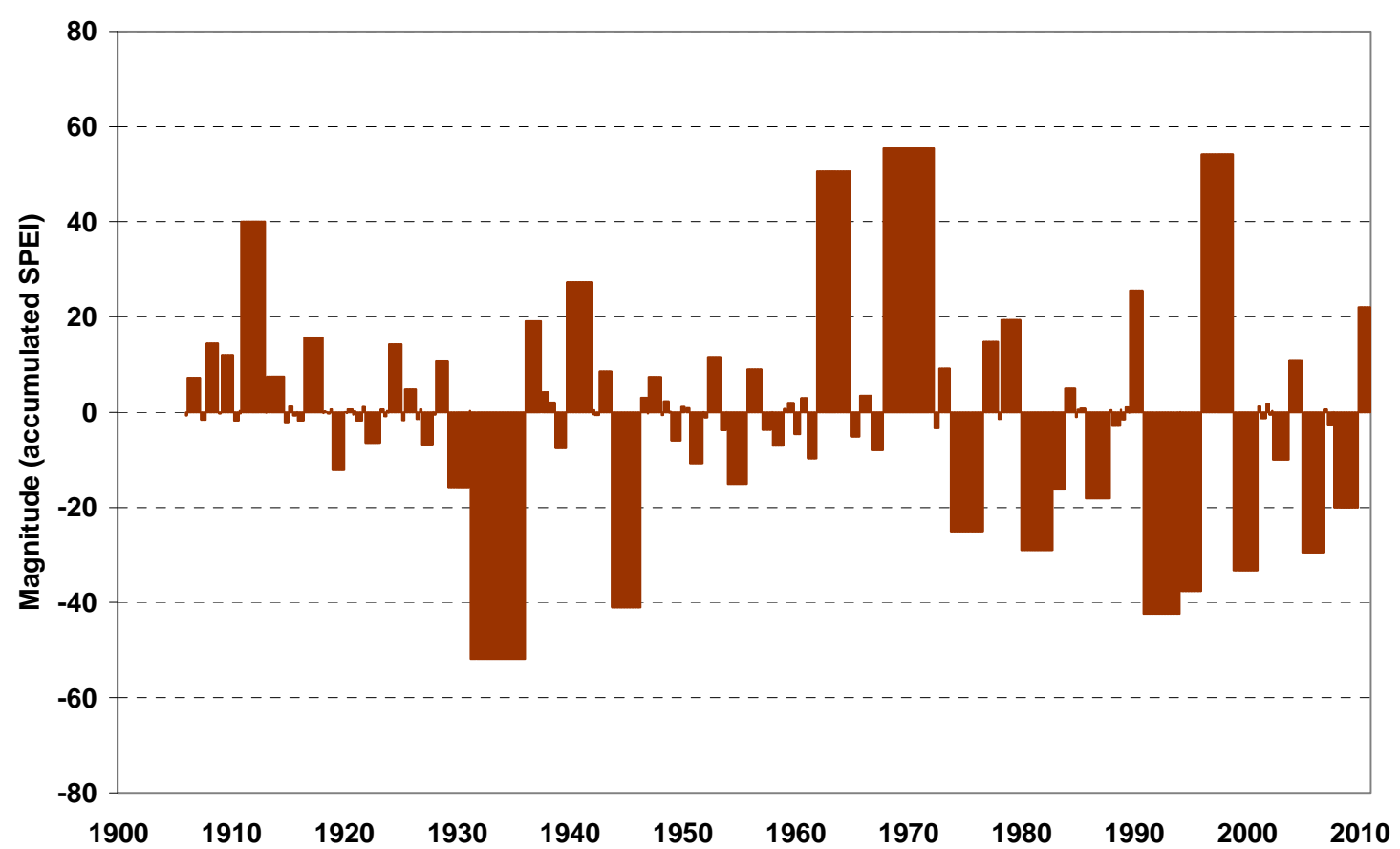

Figure 5-41: Magnitude of wet and dry events identified in the time-series associated to the Southwestern pattern (1906-2010) using 12-month SPEI. Red bars refer to the accumulated SPEI severity (magnitude) recorded for each event related to the duration in months represented in the $\mathrm{x}$ axis: bars' widths are proportional to duration.

\begin{tabular}{|c|c|c|c|c|c|}
\cline { 2 - 6 } \multicolumn{1}{c|}{} & $\begin{array}{c}\text { Major } \\
\text { events }\end{array}$ & $\begin{array}{c}\text { Maximum } \\
\text { severity }\end{array}$ & $\begin{array}{c}\text { Averaged } \\
\text { severity }\end{array}$ & $\begin{array}{c}\text { Duration in } \\
\text { months }\end{array}$ & Magnitude \\
\hline \multirow{4}{*}{ Wet } & $1910-1913$ & 2.57 & 1.54 & 26 & 40.08 \\
\cline { 2 - 6 } & $1939-1942$ & 1.84 & 0.98 & 28 & 27.32 \\
\cline { 2 - 6 } & $1961-1964$ & 1.87 & 1.41 & 36 & 50.60 \\
\cline { 2 - 6 } & $1967-1972$ & 2.22 & 1.03 & 54 & 55.39 \\
\cline { 2 - 6 } & $1996-1998$ & 2.27 & 1.59 & 34 & 54.18 \\
\hline \multirow{4}{*}{ Dry } & $1931-1936$ & 1.54 & 0.89 & 58 & 51.86 \\
\cline { 2 - 6 } & $1943-1946$ & 1.93 & 1.32 & 31 & 41.06 \\
\cline { 2 - 6 } & $1990-1994$ & 2.17 & 1.09 & 39 & 42.43 \\
\cline { 2 - 6 } & $1994-1995$ & 2.85 & 1.71 & 22 & 37.68 \\
\cline { 2 - 6 } & $1998-2000$ & 2.15 & 1.28 & 26 & 33.31 \\
\hline
\end{tabular}

Table 5-14; The most remarkable wet and dry events detected in terms of maximum severity reached for each event, averaged severity and magnitude in absolute values. Duration in months is also shown.

Some basic statistics are computed to see the main characteristics of dry and wet events in terms of maximum severity reached in a single month, averaged severity, magnitude and duration in months for the South-western pattern (Table 5-15). Similar statistics are found comparing dry and wet events caused basically by the standardized drought 
index, but the main difference detected in the South-western pattern is that duration of droughts lasts, more or less, 1 month more in average than duration in wet events $(9.84$ and 8.97 months respectively).

Finally, linear trends and their statistical significance are computed to identify variations on the behaviour of wet and dry events (Table 5-15). The maximum severity reached in a single month, the averaged severity, duration in months and magnitude of wet events show an increasing trend, but statistically non-significant at the $95 \%$ level. However, the same parameters computed in droughts experience a statistically significant increase at the $99 \%$ level except the magnitude that does it at the $95 \%$ level. In summary, the time-series associated to the South-western pattern shows changes on the behaviour of all main parameters related to droughts, while wet events do not present significantly variations.

\begin{tabular}{|c|c|c|c|c|c|}
\hline & Parameters & Mean & Maximum & STD & Linear trend \\
\hline \multirow{4}{*}{ 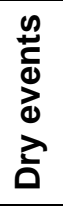 } & Max. Severity & 0.83 & 2.85 & 0.68 & $0.136 \mathrm{SPEl} / 10$ events \\
\hline & Avg. Severity & 0.49 & 1.71 & 0.37 & $0.071 \mathrm{SPEl} / 10$ events \\
\hline & Duration (months) & 9.84 & 58 & 11.33 & 1.163 month $/ 10$ events \\
\hline & Magnitude & 7.66 & 51.86 & 11.98 & $0.735 \mathrm{SPEl} / 10$ events \\
\hline \multirow{4}{*}{ 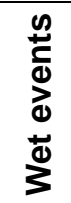 } & Max. Severity & 0.80 & 2.57 & 0.72 & $0.021 \mathrm{SPEl} / 10$ events \\
\hline & Avg. Severity & 0.50 & 1.82 & 0.44 & 0.012 SPEl/10 events \\
\hline & Duration (months) & 8.97 & 54 & 9.95 & 0 month/10 events \\
\hline & Magnitude & 7.66 & 55.39 & 12.78 & $0.036 \mathrm{SPEl} / 10$ events \\
\hline
\end{tabular}

Table 5-15: Summary statistics of all dry and wet events detected in the time-series associated to the South-western pattern from 1906 to 2010. Maximum severity reached for each event, averaged severity, magnitude and duration in months are the parameters analyzed and the mean, maximum value, standard deviation, linear trend and its statistical significance (linear trend calculated for each 10 events) are the statistics in absolute values. Bold (Italic) values are referred to statistical significant trends at $99 \%$ level $(95 \%)$.

Finally, seasonal distribution of the onset and offset of identified droughts and wet events are also assessed in the time series associated to the South-western pattern together with the season in which dry or wet events reached their maximum severity. Figures 5-42 and 5-43 show the seasonal distribution of the percentages related to the onset, offset and maximum severity reached in wet (Fig. 5-42) and dry events (Fig. 5-43) for the South-western pattern from 1906 to 2010. Note that the coldest colours in the plots are referred to the parameters about wet events meanwhile the warmest ones represent the parameters related to droughts. 


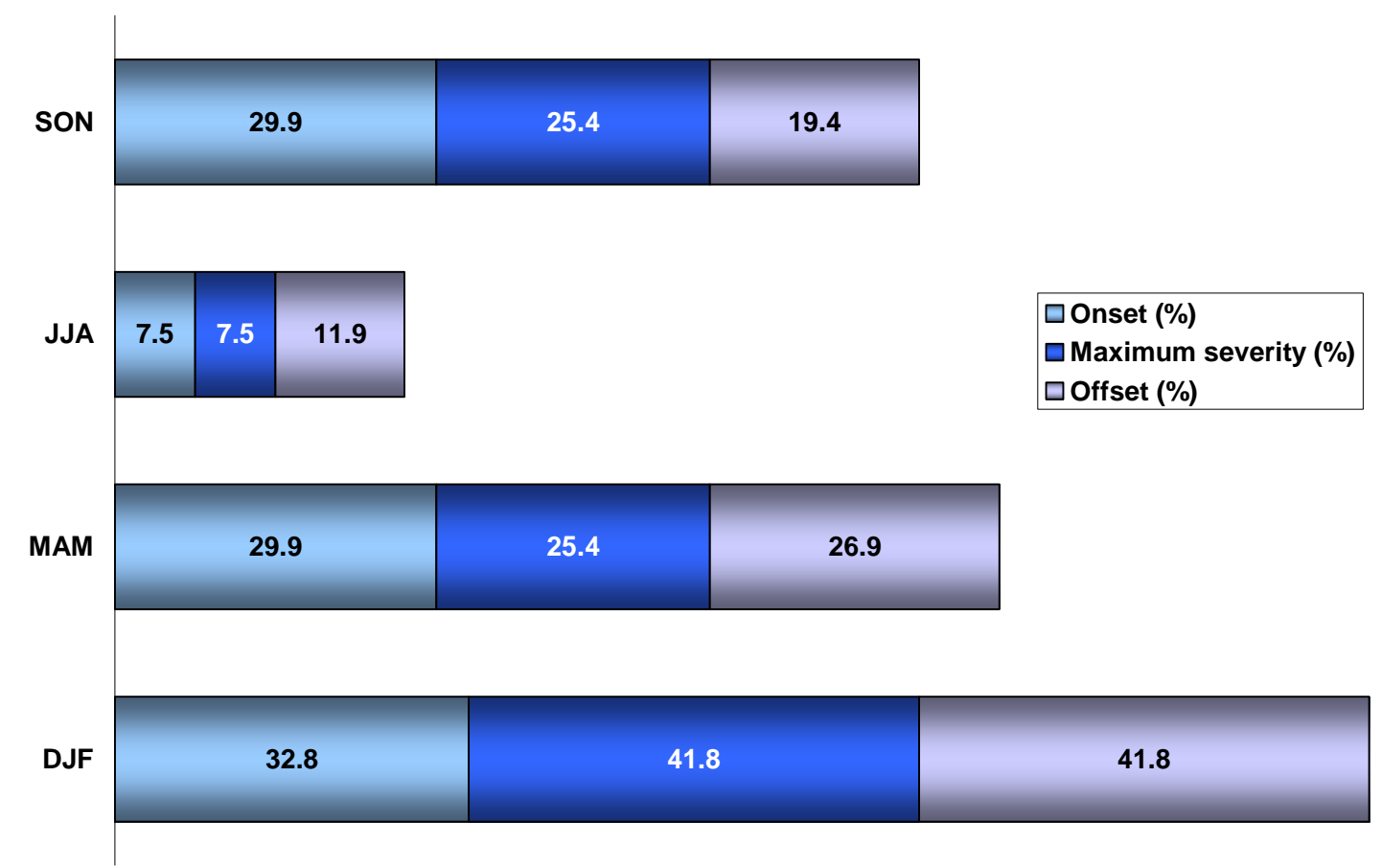

Figure 5-42: Seasonal distribution of the percentages referred to the onset, offset and maximum severity reached by wet events in the time-series associated to the South-western pattern. Seasons are shown in the y axis; where DJF is referred to winter, MAM to spring, JJA to summer and SON to autumn. Seasonal percentages for each parameter are also included inside the bars.

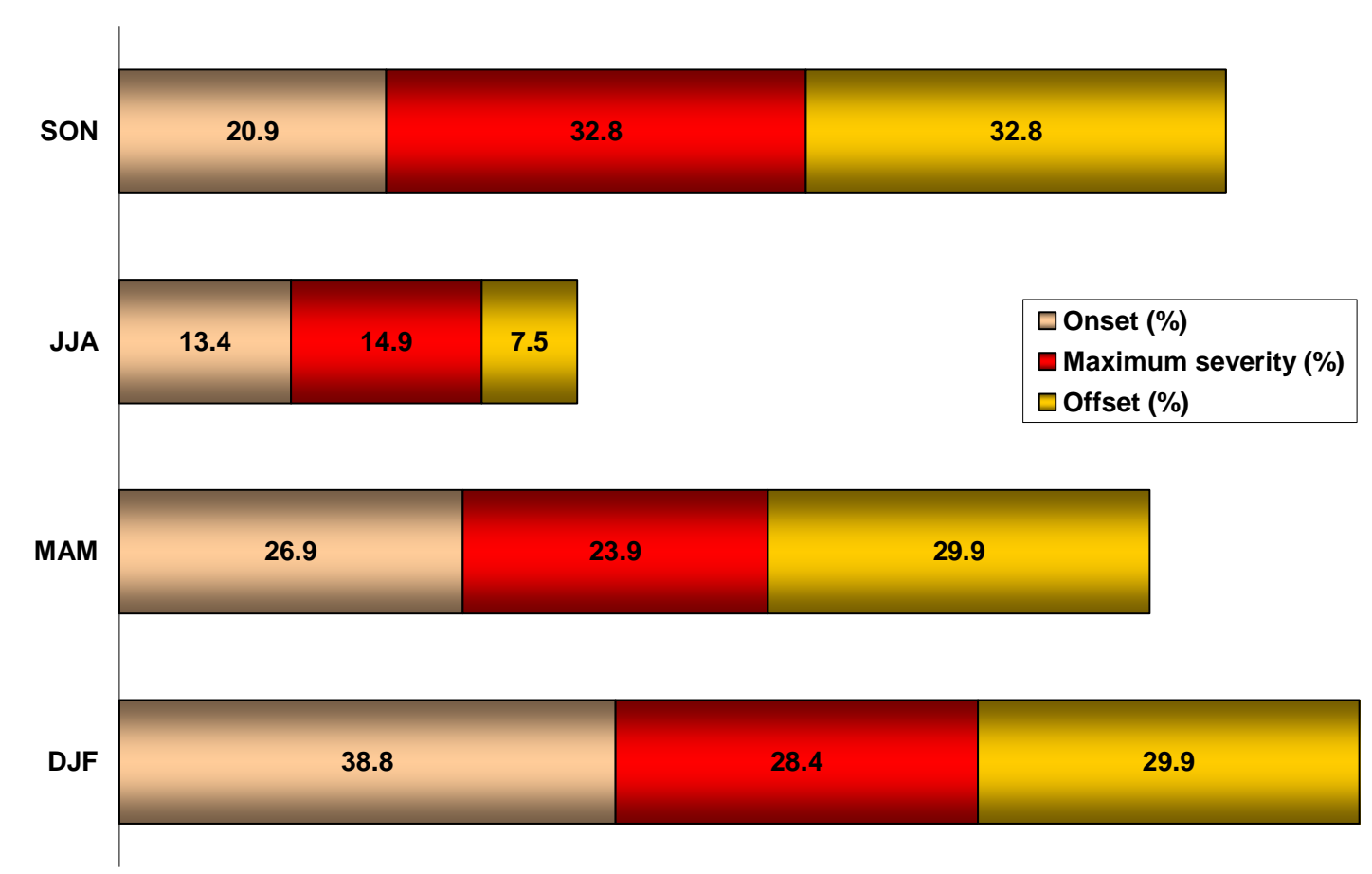

Figure 5-43: Seasonal distribution of the percentages referred to the onset, offset and maximum severity reached by droughts in the time-series associated to the South-western pattern. Seasons are shown in the y axis; where DJF is referred to winter, MAM to spring, JJA to summer and SON to autumn. Seasonal percentages for each parameter are also included inside the bars.

As shown in figure 5-42, almost the $33 \%$ of wet events began in winter, around $30 \%$ did it in spring and autumn while just the $7.5 \%$ started in summer. Moreover, the $42 \%$ of 
wet events reached their maximum severity in winter, the $25.4 \%$ did it in spring and autumn, but the $7.5 \%$ in summer. Finally, the $42 \%$ of wet events ended in winter, the $27 \%$ in spring, the $19.4 \%$ in autumn and the $12 \%$ in summer. As identified, winter is the season in which the highest percentage of wet events started, ended and reached the maximum severity in the South-western pattern. This fact can be related to the winter maxima in the annual cycle of precipitation which characterizes the south-west of the Iberian Peninsula. For this reason, winter is more conducive to accumulate onsets, offsets and maximum severities reached by wet events. However, the driest and warmest season (summer) plays a minor role in terms of the onset, the offset and maximum severity reached by wet events in the South-west of the Iberian Peninsula. Similar results are found in spring and autumn related to the onset and the maximum severity reached by wet events, but the percentage about offsets of wet events is greater in spring than in autumn. It means that wet events tend to end basically in winter, but if it is not so, probably it will be finished in spring.

Furthermore, almost the $39 \%$ of droughts began in winter, the $27 \%$ in spring, the $21 \%$ in autumn and the $13.4 \%$ in summer in the inspection of figure 5-43. Moreover, the $32.8 \%$ of droughts reached their maximum severity in autumn, the $28.4 \%$ in winter, the $24 \%$ in spring and the $15 \%$ in summer. Finally, the $32.8 \%$ of droughts ended in autumn, almost the $30 \%$ did it in winter and spring while just the $7.5 \%$ finished in summer. Droughts tend to start in winter or spring (followed by autumn), while they tend to reach maximum severity in winter or autumn (followed by spring). Similar results are obtained in winter, spring and autumn related to the end of droughts, although the percentages are slightly greater in autumn. Finally, as shown in wet events, summer is the season that has less weight on the behaviour of droughts in terms of the onset, the offset and maximum severity reached in the South-western pattern. 


\subsubsection{The North-western pattern}

The time series associated to the North-western pattern did not show a significant trend (at the 95\% level) in dry conditions across time when it was computed in previous section. Despite it will also be interesting how the main parameters related to wet and dry events are distributed in the time-series from 1906 to 2010. In total, 161 extreme events are found in the North-western pattern of which 80 are wet events and 81 are droughts. Six wet events reach the extremely wet category (greater or equal to +2 in SPEI categories) and occurred in mid-1930s, early-1940s, early-1960s, mid-1960s, late1970s and early-2000s. Otherwise, five droughts reach the extremely dry category in SPEI values and occurred in mid-1900s, late-1940s, late-1980s, early-2000s and mid2000s (Fig. 5-44). The wettest event was identified between 1959 and 1962 when the SPEI index reached +3 in a few single months and it was considered severely wet in average during 42 consecutive months. In this case, the wettest event (the most severe) coincides with the longest wet event for the North-western pattern. On the other hand, the driest event was identified between 1989 and 1991 when the maximum severity reached -3 in SPEI index and the averaged severity remained severely dry during 26 consecutive months. In this case, the driest event does not coincide with the longest one, because the longest occurred between 2004 and 2007 and lasted 39 months becoming an extremely drought.

The fluctuations in magnitude of wet and dry events found in the time-series associated to the North-western pattern for the period 1906-2010 are shown in figure 5-45. The highest magnitudes identified in wet events were recorded in 1930s, early-1940s, early1960s, mid-1960s and late-1970s, while the highest magnitudes detected in droughts were observed in mid-1900s, early-1920s, late-1940s, early-1990s and mid-2000s. 


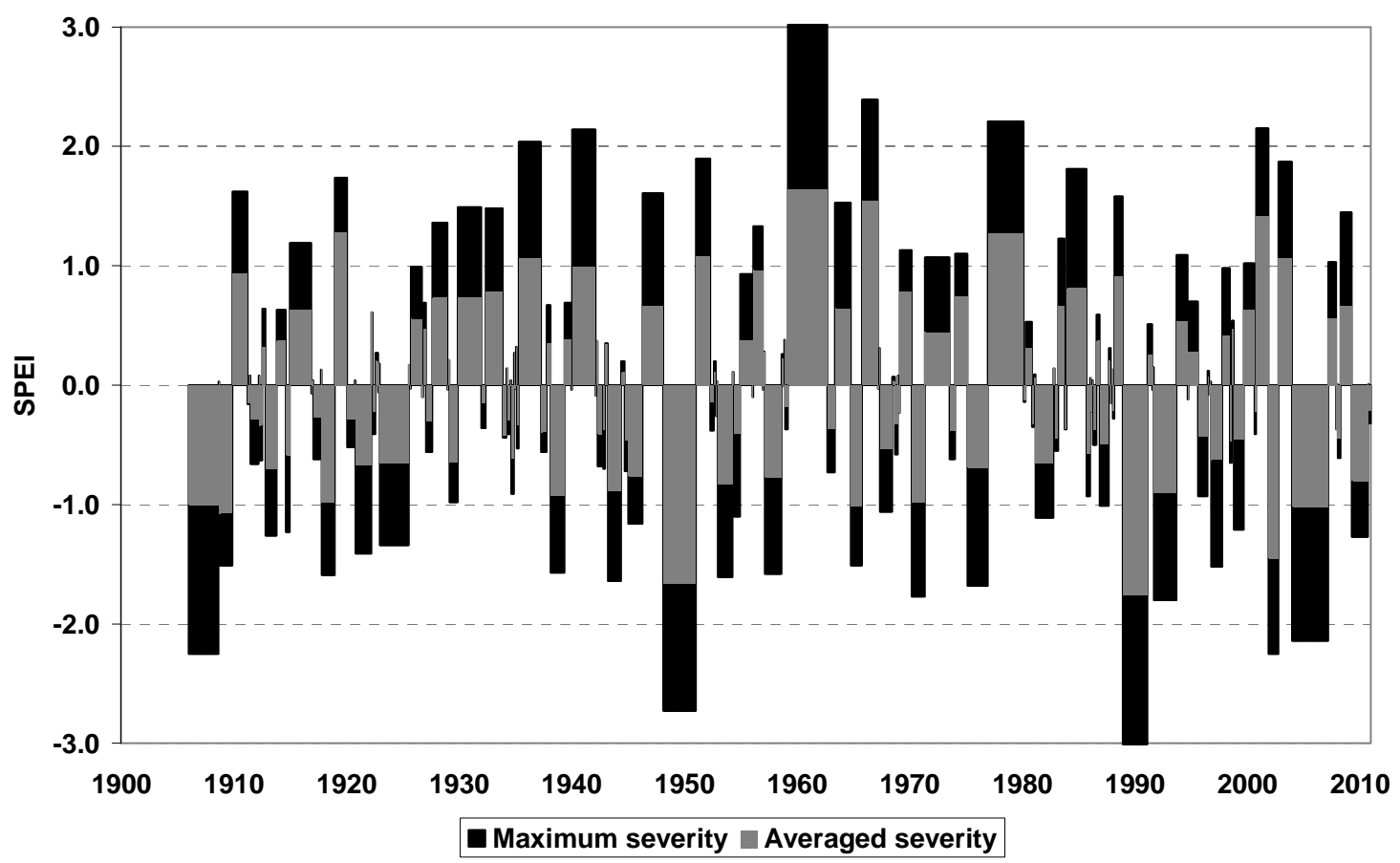

Figure 5-44; Dry and wet events detected in the time-series associated to the North-western pattern (1906-2010) using 12-month SPEI. Black bars refer to the maximum monthly index value (maximum severity) recorded for each event, while grey bars indicate the average index value for each event. The duration in months for each event is represented in the $\mathrm{x}$ axis: bars' widths are proportional to duration.

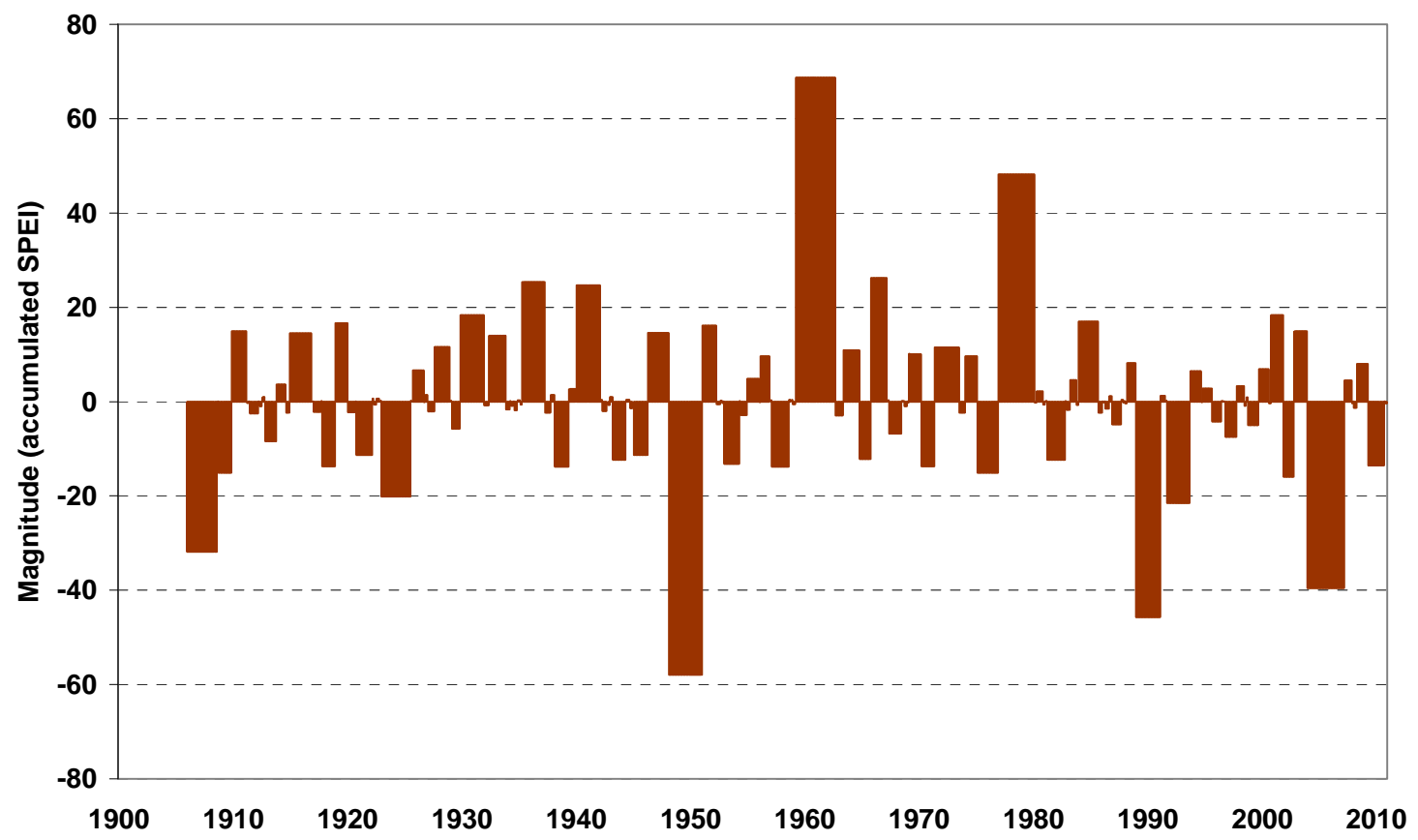

Figure 5-45: Magnitude of wet and dry events identified in the time-series associated to the Northwestern pattern (1906-2010) using 12-month SPEI. Red bars refer to the accumulated SPEI severity (magnitude) recorded for each event related to the duration in months represented in the $\mathrm{x}$ axis: bars' widths are proportional to duration.

The major wet events and major droughts are shown in table 5-16 taking into account the magnitude of each event, the maximum severity reached, the averaged severity and 
duration in months for the North-western pattern. In this way, the major wet event occurred between 1959 and 1962 promoted by the highest severity reached during 42 consecutive months under wet conditions. In contrast, the major drought was identified between 1948 and 1951 reaching the highest magnitude of droughts, but it was not the most severe and the longest of the records too. A high severity during 35 consecutive months characterizes this drought as the largest in the North-western pattern time-series. Other major wet and dry events can also be consulted in table 5-16.

\begin{tabular}{|c|c|c|c|c|c|}
\cline { 2 - 6 } \multicolumn{1}{c|}{} & $\begin{array}{c}\text { Major } \\
\text { events }\end{array}$ & $\begin{array}{c}\text { Maximum } \\
\text { severity }\end{array}$ & $\begin{array}{c}\text { Averaged } \\
\text { severity }\end{array}$ & $\begin{array}{c}\text { Duration in } \\
\text { months }\end{array}$ & Magnitude \\
\hline \multirow{4}{*}{ Wet } & $1935-1937$ & 2.04 & 1.06 & 24 & 25.42 \\
\cline { 2 - 6 } & $1940-1942$ & 2.14 & 0.99 & 25 & 24.68 \\
\cline { 2 - 6 } & $1959-1962$ & 3.02 & 1.64 & 42 & 68.71 \\
\cline { 2 - 6 } & $1965-1967$ & 2.39 & 1.54 & 17 & 26.24 \\
\cline { 2 - 6 } & $1977-1980$ & 2.21 & 1.27 & 38 & 48.45 \\
\hline \multirow{4}{*}{ Dry } & $1906-1908$ & 2.25 & 1.00 & 32 & 31.92 \\
\cline { 2 - 6 } & $1948-1951$ & 2.73 & 1.66 & 35 & 57.94 \\
\cline { 2 - 6 } & $1989-1991$ & 3.01 & 1.78 & 26 & 45.74 \\
\cline { 2 - 6 } & $1991-1993$ & 1.80 & 0.90 & 24 & 21.52 \\
\cline { 2 - 6 } & $2004-2007$ & 2.14 & 1.02 & 39 & 39.61 \\
\hline
\end{tabular}

Table 5-16; The most remarkable wet and dry events detected in terms of maximum severity reached for each event, averaged severity and magnitude in absolute values. Duration in months is also shown.

The main statistics (Table 5-17) of the parameters related to wet and dry events show the severity and duration are slightly higher in dry events, but the magnitude of wet events is slightly higher than in droughts. However, linear trends show an increasing in severity, duration and magnitude in wet events and droughts simultaneously, but they are statistically non-significant at the $95 \%$ level in all cases. The results demonstrate that the time-series associated to the North-western pattern is not experiencing linear changes on the behaviour of wet and dry events, but the fluctuations of drought timeseries is just the result of the temporal variability without clearly trends recorded in the main drought parameters.

On the other hand, seasonal distribution of the onset and offset of identified droughts and wet events are also determined in the time series associated to the North-western pattern together with the season in which dry or wet events reached their maximum severity. Figures 5-46 and 5-47 show the seasonal distribution of the percentages related to the onset, offset and maximum severity reached in wet (Fig. 5-46) and dry events (Fig. 5-47) for the North-western pattern from 1906 to 2010. Note that the coldest colours in 
the plots are referred to the parameters about wet events meanwhile the warmest ones represent the parameters related to droughts.

\begin{tabular}{|c|c|c|c|c|c|}
\hline & Parameters & Mean & Maximum & STD & Linear trend \\
\hline \multirow{4}{*}{ 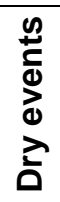 } & Max. Severity & 0.79 & 3.01 & 0.68 & 0.019 SPEI/10 events \\
\hline & Avg. Severity & 0.45 & 1.78 & 0.37 & 0.014 SPEI/10 events \\
\hline & Duration (months) & 7.89 & 39 & 8.68 & 0.031 month $/ 10$ events \\
\hline & Magnitude & 6.12 & 57.94 & 10.47 & $0.241 \mathrm{SPEl} / 10$ events \\
\hline \multirow{4}{*}{ 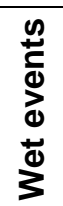 } & Max. Severity & 0.74 & 3.02 & 0.72 & 0.032 SPEI/10 events \\
\hline & Avg. Severity & 0.44 & 1.64 & 0.40 & 0.012 SPEI/10 events \\
\hline & Duration (months) & 7.75 & 42 & 9.00 & 0.132 month/10 events \\
\hline & Magnitude & 6.20 & 68.71 & 10.99 & $0.173 \mathrm{SPEI} / 10$ events \\
\hline
\end{tabular}

Table 5-17: Summary statistics of all dry and wet events detected in the time-series associated to the North-western pattern from 1906 to 2010. Maximum severity reached for each event, averaged severity, magnitude and duration in months are the parameters analyzed and the mean, maximum value, standard deviation, linear trend and its statistical significance (linear trend calculated for each 10 events) are the statistics in absolute values. Bold (Italic) values are referred to statistical significant trends at $99 \%$ level $(95 \%)$.

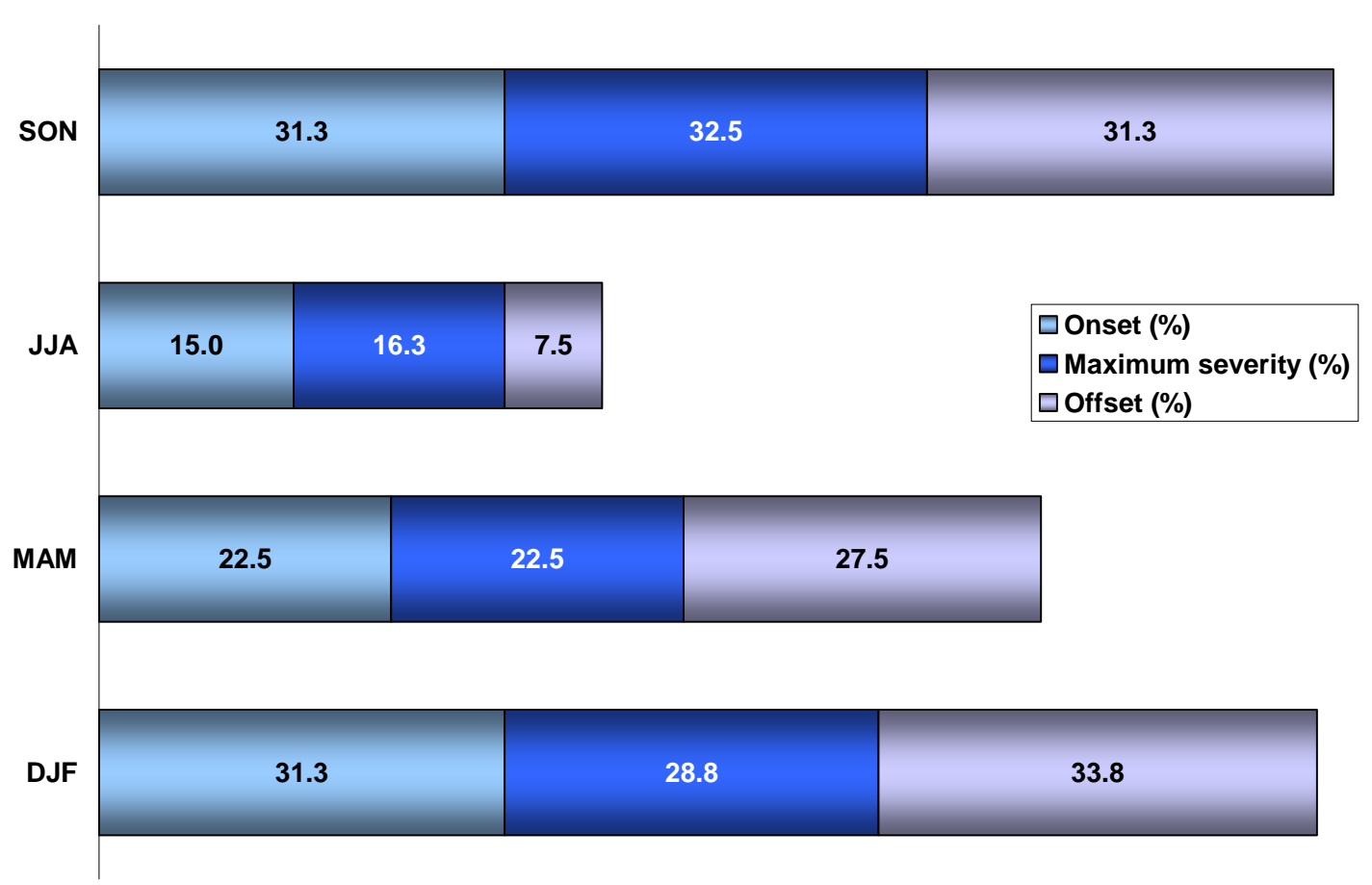

Figure 5-46: Seasonal distribution of the percentages referred to the onset, offset and maximum severity reached by wet events in the time-series associated to the North-western pattern. Seasons are shown in the y axis; where DJF is referred to winter, MAM to spring, JJA to summer and SON to autumn. Seasonal percentages for each parameter are also included inside the bars. 


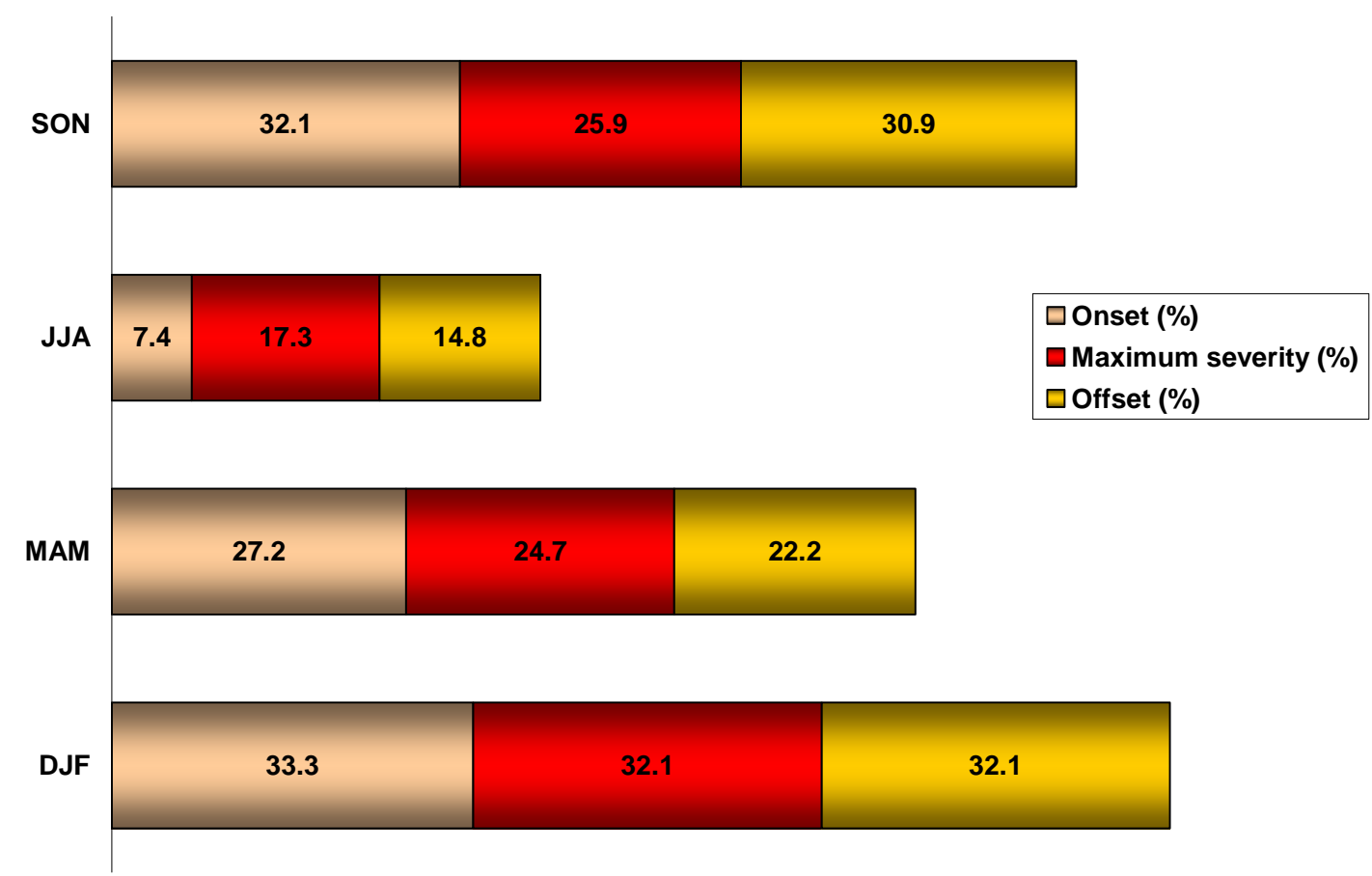

Figure 5-47: Seasonal distribution of the percentages referred to the onset, offset and maximum severity reached by droughts in the time-series associated to the North-western pattern. Seasons are shown in the y axis; where DJF is referred to winter, MAM to spring, JJA to summer and SON to autumn. Seasonal percentages for each parameter are also included inside the bars.

As shown in figure 5-46, the $31.3 \%$ of wet events began in winter and autumn, the $22.5 \%$ in spring and the $15 \%$ in summer. Moreover, the $32.5 \%$ of wet events reached maximum severity in autumn, the $28.8 \%$ in winter, the $22.5 \%$ in spring and the $16.3 \%$ in summer. Finally, the $33.8 \%$ of wet events ended in winter, the $31.3 \%$ in autumn, the $27.5 \%$ in spring and just the $7.5 \%$ in summer. As occurred in the case related to the South-western pattern, winter and autumn are the most conducive seasons to accumulate the highest percentages related to the onset, the offset and maximum severity reached in wet events in the North-western pattern. These results are similar results to those previously obtained for the South-west of the Iberian Peninsula taking into account that winter and autumn tend to accumulate the highest amount of precipitation of the year in the North and North-western area of the Iberian Peninsula. More or less precipitation in autumn or winter can determine a change on the behaviour of a particular wet event in the region under study. Otherwise, summer has not a remarkable role in the North-western pattern too.

On the other hand, the $33.3 \%$ of droughts began in winter, the $32.1 \%$ did it in autumn, the $27.2 \%$ in spring and the $7.4 \%$ in summer (Fig. 5-47). Moreover, the $32.1 \%$ of droughts reached maximum severity in winter, the $25.9 \%$ did it in autumn, the $24.7 \%$ in 
spring and the $17.3 \%$ in summer. Finally, the $32.1 \%$ of droughts ended in winter, the $30.9 \%$ did it in autumn, the $22.2 \%$ in spring and the $14.8 \%$ in summer. The onset of droughts tends to concentrate during winter or autumn (followed by spring) in the North and North-west area of the Iberian Peninsula, but the maximum severity of droughts can be reached either during winter, autumn or spring. The highest percentages of the offset of drought are basically found during winter or autumn and followed by spring. Finally, summer shows the lowest percentage of occurrence of onset, the offset and maximum severity reached in the North-western pattern. 


\subsubsection{The Mediterranean pattern}

Finally, the time-series associated to the Mediterranean pattern shows a statistically significant increase in dry conditions at the 99\% level (duplicating the drying trend computed to the South-western pattern), so from these results, it will be necessary to find out how the drying trend is affecting on the main parameters in wet and dry events for the period 1906-2010. Similar extreme events are found in the Mediterranean pattern (164 events) compared to the North-western pattern (161 events) being 82 wet events and 82 are droughts. Just four wet events reach the extremely wet category (greater or equal to +2 in SPEI categories) and occurred in mid-1930s, early-1950s, late-1950s and early-1970s, while seven droughts are considered extremely dry events and they were recorded in early-1910s, early-1930s, mid-1960s, and from mid-1990s to mid-2000s. Note the presence of driest events is concentrated during the last two decades coinciding with the less presence of relevant wet events compared with other decades of the timeseries (Fig. 5-48). The wettest event is clearly identified between 1971 and 1973 when the SPEI index reached +3 in the extremely wet category and it prolonged during 31 consecutive months reaching the severely wet category in average. But the longest wet event occurred between 1974 and 1978 (53 consecutive months under wet conditions), although it was not considered an extremely wet event, but a severely wet event during a few months and a moderately wet event in average.

The longest and driest events are identified between 1994 and 2007 reaching the extremely dry category with similar severities and various durations in four times almost consecutively. This category was neither achieved in other periods of the Mediterranean time-series nor in the other patterns.

Associated to this fact, the magnitude of wet and dry events across time (Fig. 5-49) shows the highest magnitudes of wet events in mid-1900s, late-1910s and early-1920s, mid1930s and 1970s and the highest magnitudes of droughts from 1994 to 2007, obviously coinciding with the driest events across the different patterns. 


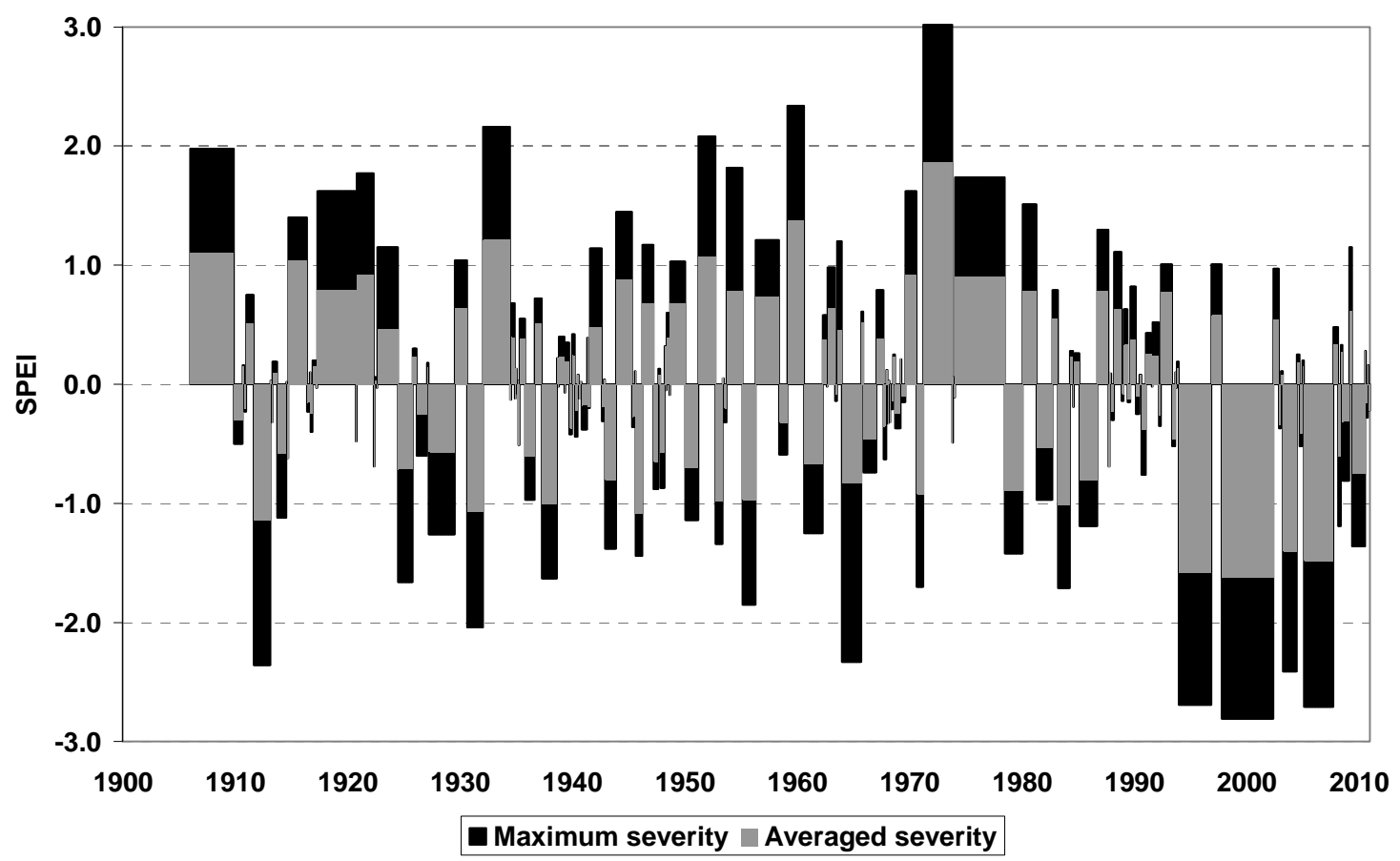

Figure 5-48; Dry and wet events detected in the time-series associated to the Mediterranean pattern (1906-2010) using 12-month SPEI. Black bars refer to the maximum monthly index value (maximum severity) recorded for each event, while grey bars indicate the average index value for each event. The duration in months for each event is represented in the $\mathrm{x}$ axis: bars' widths are proportional to duration.

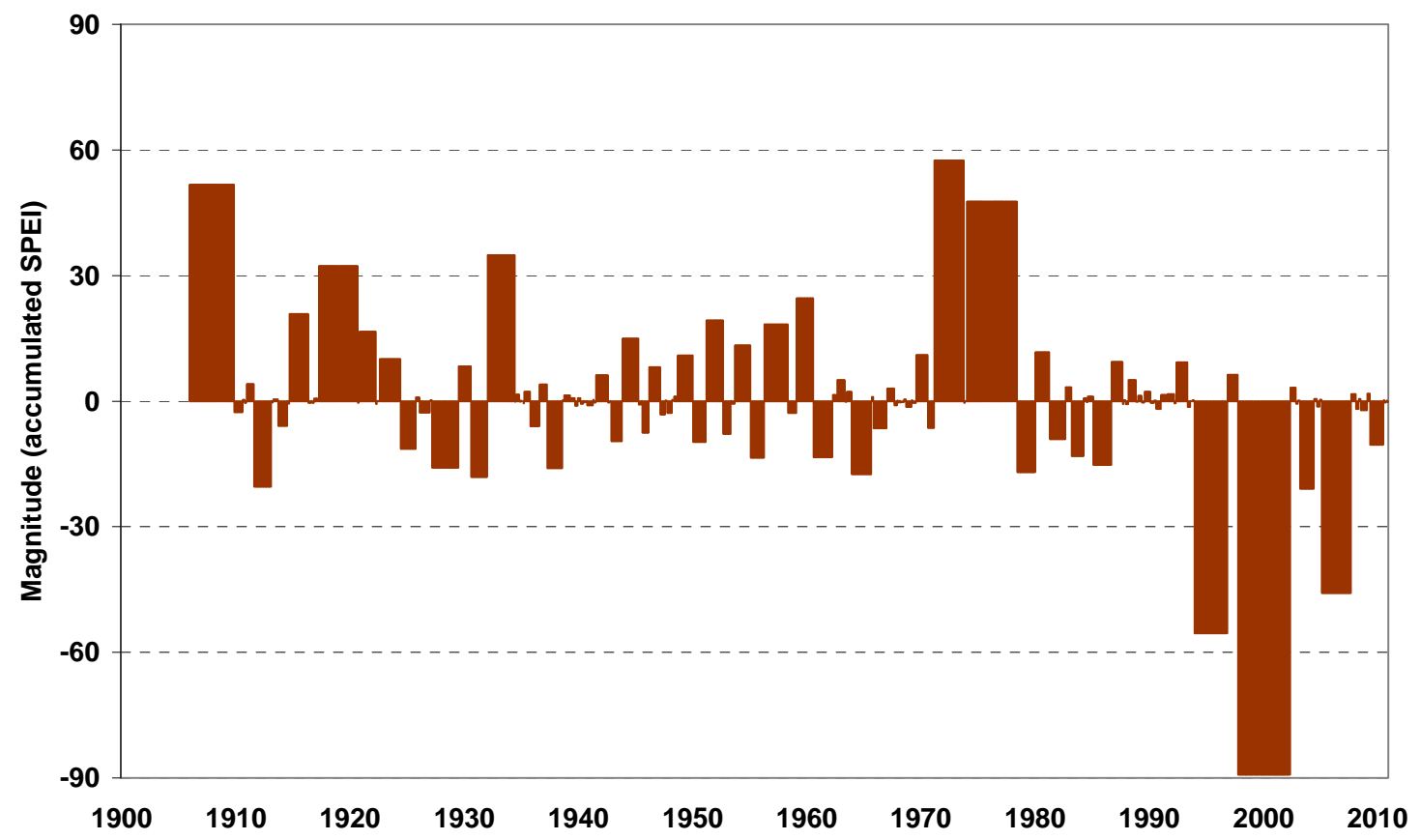

Figure 5-49: Magnitude of wet and dry events identified in the time-series associated to the Mediterranean pattern (1906-2010) using 12-month SPEI. Red bars refer to the accumulated SPEI severity (magnitude) recorded for each event related to the duration in months represented in the $\mathrm{x}$ axis: bars' widths are proportional to duration. 
Table 5-18 shows the major droughts and wet events of the time-series associated to the Mediterranean pattern together with the maximum severity reached, the averaged severity, duration in months and the magnitude of each one. The major wet event occurred between 1971 and 1973 reaching the maximum magnitude accumulated during 31 consecutive months, but the major drought was found between 1997 and 2002 reaching the maximum severity of the SPEI series, maximum magnitude and maximum duration (55 consecutive months).

\begin{tabular}{|c|c|c|c|c|c|}
\cline { 2 - 6 } \multicolumn{1}{c|}{} & $\begin{array}{c}\text { Major } \\
\text { events }\end{array}$ & $\begin{array}{c}\text { Maximum } \\
\text { severity }\end{array}$ & $\begin{array}{c}\text { Averaged } \\
\text { severity }\end{array}$ & $\begin{array}{c}\text { Duration in } \\
\text { months }\end{array}$ & Magnitude \\
\hline \multirow{4}{*}{ Wet } & $1906-1909$ & 1.98 & 1.10 & 47 & 51.73 \\
\cline { 2 - 6 } & $1917-1920$ & 1.62 & 0.79 & 41 & 32.27 \\
\cline { 2 - 6 } & $1932-1934$ & 2.16 & 1.21 & 29 & 34.95 \\
\cline { 2 - 6 } & $1971-1973$ & 3.02 & 1.86 & 31 & 57.52 \\
\cline { 2 - 6 } & $1974-1978$ & 1.74 & 0.90 & 53 & 47.70 \\
\hline \multirow{4}{*}{ Dry } & $1911-1913$ & 2.36 & 1.14 & 18 & 20.49 \\
\cline { 2 - 6 } & $1994-1996$ & 2.69 & 1.58 & 35 & 55.47 \\
\cline { 2 - 6 } & $1997-2002$ & 2.81 & 1.62 & 55 & 89.27 \\
\cline { 2 - 6 } & $2003-2004$ & 2.41 & 1.40 & 15 & 20.94 \\
\cline { 2 - 6 } & $2005-2007$ & 2.71 & 1.48 & 31 & 45.86 \\
\hline
\end{tabular}

Table 5-18: The most remarkable wet and dry events detected in terms of maximum severity reached for each event, averaged severity and magnitude in absolute values. Duration in months is also shown.

\begin{tabular}{|c|c|c|c|c|c|}
\hline & Parameters & Mean & Maximum & STD & Linear trend \\
\hline \multirow{4}{*}{ 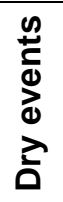 } & Max. Severity & 0.75 & 2.81 & 0.72 & $0.020 \mathrm{SPEI} / 10$ events \\
\hline & Avg. Severity & 0.46 & 1.62 & 0.39 & $0.011 \mathrm{SPEI} / 10$ events \\
\hline & Duration (months) & 7.34 & 55 & 9.26 & 0.633 month $/ 10$ events \\
\hline & Magnitude & 6.14 & 89.27 & 13.13 & 1.202 SPEl/10 events \\
\hline \multirow{4}{*}{ 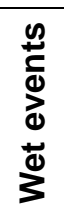 } & Max. Severity & 0.68 & 3.02 & 0.66 & $-0.010 \mathrm{SPEl} / 10$ events \\
\hline & Avg. Severity & 0.41 & 1.86 & 0.37 & $-0.003 \mathrm{SPEl} / 10$ events \\
\hline & Duration (months) & 8.05 & 53 & 10.35 & -0.752 month/10 events \\
\hline & Magnitude & 6.14 & 57.52 & 11.59 & $-0.700 \mathrm{SPEI} / 10$ events \\
\hline
\end{tabular}

Table 5-19: Summary statistics of all dry and wet events detected in the time-series associated to the Mediterranean pattern from 1906 to 2010. Maximum severity reached for each event, averaged severity, magnitude and duration in months are the parameters analyzed and the mean, maximum value, standard deviation, linear trend and its statistical significance (linear trend calculated for each 10 events) are the statistics in absolute values. Bold (Italic) values are referred to statistical significant trends at the $99 \%$ level (95\%).

The statistics of the main parameters (Table 5-19) show the mean severity is slightly higher in droughts than in wet events, the mean magnitude is the same for both and the duration of wet events is slightly higher than in droughts. Despite the remarkable and significant linear trend computed for the Mediterranean time-series, the recent linear trends re-computed for the main parameters of wet and dry events show a non- 
significant increase of severity and duration of droughts (95\% level), but a statistically significant increase of magnitude at the $95 \%$ level. It means that the magnitude of droughts is increasing significantly +1 accumulated SPEI value every 8 droughts in the Mediterranean time-series. Otherwise, the evolution of main parameters of wet events experiences a non-significant decrease at the $95 \%$ significance level.

Finally, seasonal distribution of the onset and offset of identified droughts and wet events are also detected in the time series associated to the Mediterranean pattern together with the season in which dry or wet events reached their maximum severity. Figures 5-50 and 5-51 show the seasonal distribution of the percentages related to the onset, offset and maximum severity reached in wet (Fig. 5-50) and dry events (Fig. 5-51) for the Mediterranean pattern from 1906 to 2010. Note that the coldest colours in the plots are referred to the parameters about wet events meanwhile the warmest ones represent the parameters related to droughts.

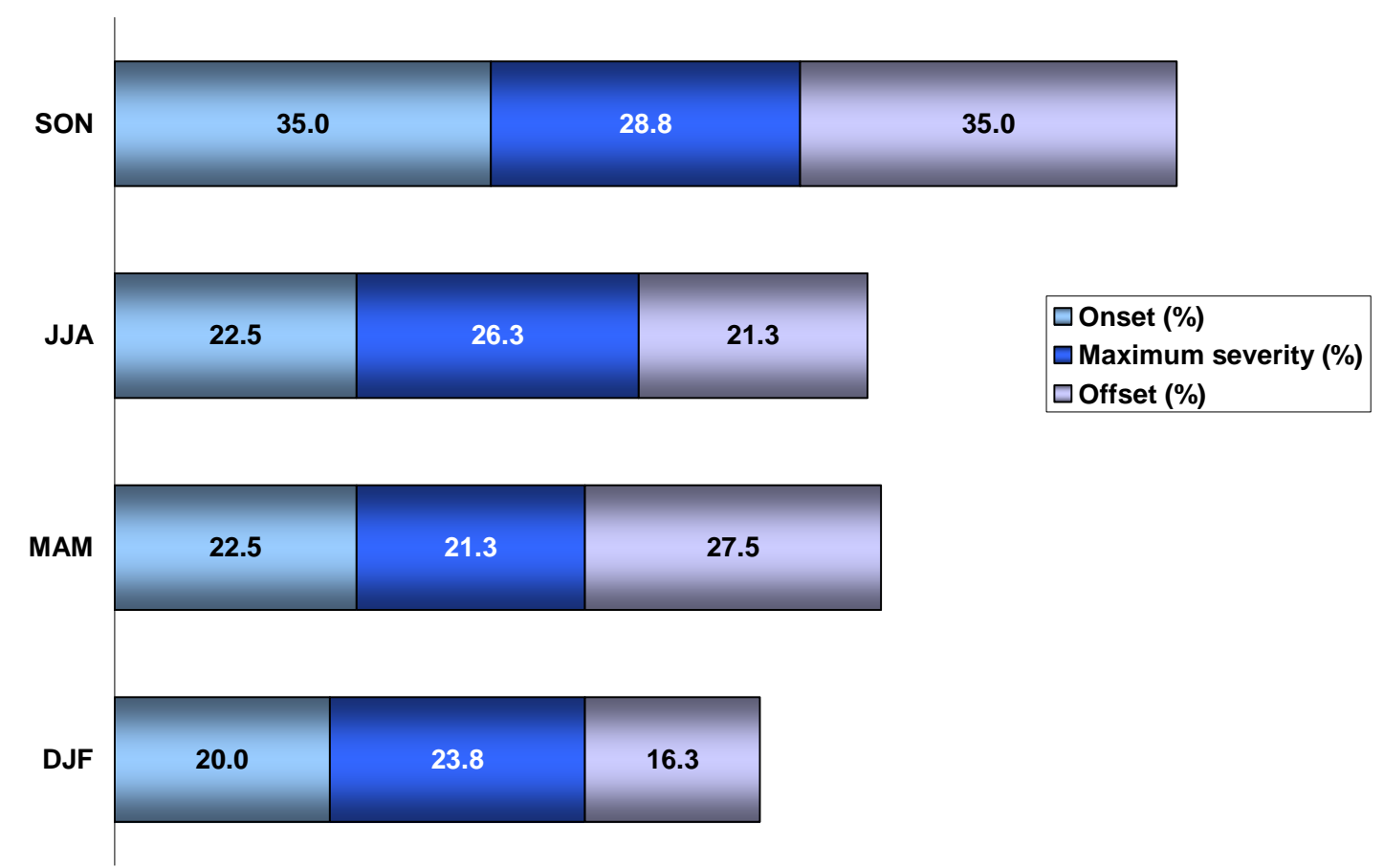

Figure 5-50: Seasonal distribution of the percentages referred to the onset, offset and maximum severity reached by wet events in the time-series associated to the Mediterranean pattern. Seasons are shown in the y axis; where DJF is referred to winter, MAM to spring, JJA to summer and SON to autumn. Seasonal percentages for each parameter are also included inside the bars. 


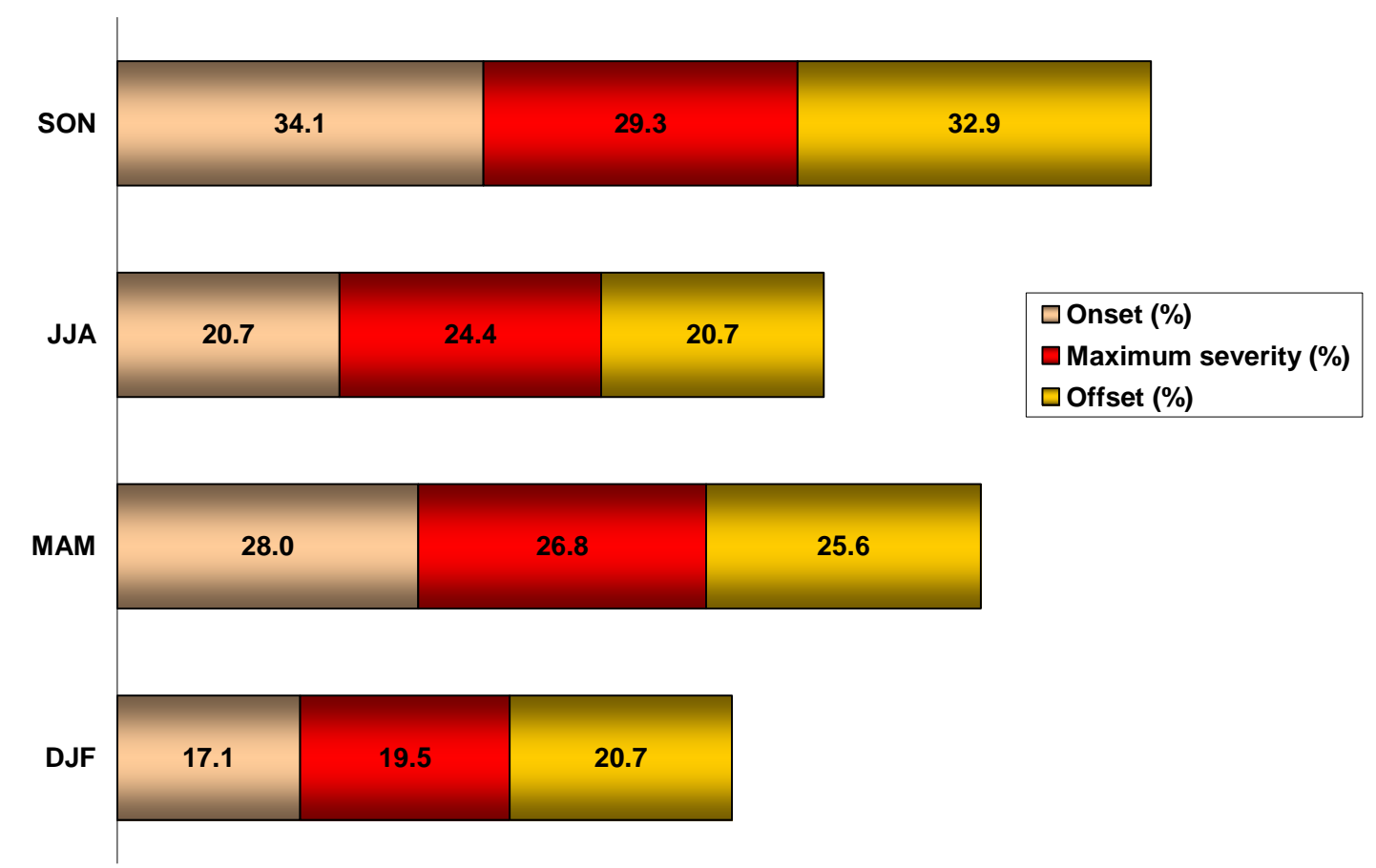

Figure 5-51: Seasonal distribution of the percentages referred to the onset, offset and maximum severity reached by droughts in the time-series associated to the Mediterranean pattern. Seasons are shown in the y axis; where DJF is referred to winter, MAM to spring, JJA to summer and SON to autumn. Seasonal percentages for each parameter are also included inside the bars.

As shown in figure 5-50, the $35 \%$ of wet events began in autumn, the $22.5 \%$ did it in summer and spring and the rest of $20 \%$ in winter. Moreover, the $28.8 \%$ of wet events reached maximum severity in autumn, the $26.3 \%$ did it in summer, the $23.8 \%$ in winter and the rest of $21.3 \%$ in spring. Finally, the $35 \%$ of wet events ended in autumn, the $27.5 \%$ did it in spring, the $21.3 \%$ in summer and the $16.3 \%$ in winter. The highest percentages related to the onset, the offset and maximum severity reached by wet events are exclusively concentrated during autumn in the Mediterranean region. Similar results are obtained during summer or spring meanwhile the season in which wet events present lower percentages is winter.

Figure 5-51 shows the $34.1 \%$ of droughts started in autumn, the $28 \%$ did it in spring, the 20.7 in summer and the rest of $17.1 \%$ in winter. Moreover, the $29.3 \%$ of droughts reached maximum severity in autumn, the $26.8 \%$ did it in spring, the $24.4 \%$ in summer and the $19.5 \%$ in winter. Finally, the $32.9 \%$ of droughts ended in autumn, the $25.6 \%$ did it in spring, and the $20.7 \%$ during summer or winter. Similar results are obtained from wet events and droughts in the Mediterranean region highlighting that the season which has the most important role related to the parameters analyzed is unquestionably autumn. However, winter is the season in which the beginning and ending of droughts and wet events is less prominent in the Mediterranean region. 


\subsubsection{Changes in severity, magnitude and duration for different periods}

This section shows the changes identified in terms of severity, magnitude and duration of droughts and wet events for the whole Iberian Peninsula and also for the spatialtemporal patterns found at annual time-scale. The common periods 1921-1950, 19511980 and 1981-2010 are used to find out changes in drought parameters. Tables 5-20, 521 and 5-22 represent the values of averaged severity, averaged magnitude and averaged duration of droughts and wet events respectively for each time-period and for each region or pattern. All regions show higher rates of severity, magnitude and duration of wet events for the period 1951-1980 than in the other two time-periods analyzed. This is consistent knowing that the decades of 1960s and 1970s were abnormally wet according to the results described before. Otherwise, the severity, magnitude and duration of wet events have represented similar characteristics for all regions between the periods 1921-1950 and 1981-2010 without showing a clear increase or decrease of these parameters. This is in good agreement with the non-significant trends computed in section 5.5 for the same parameters referred to wet events for the period 1906-2010.

Figures 5-52, 5-53 and 5-54 show the averaged severity, magnitude and duration of droughts for the whole Iberian Peninsula and also for each spatial-temporal pattern using the three 30 -year periods.

\begin{tabular}{|c|c|c|c|c|c|}
\hline & Periods & IP & SWP & NWP & MedP \\
\hline \multirow{3}{*}{ 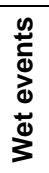 } & $1921-1950$ & 0.23 & 0.47 & 0.40 & 0.34 \\
\hline & $1951-1980$ & 0.35 & 0.56 & 0.57 & 0.59 \\
\hline & $1981-2010$ & 0.26 & 0.55 & 0.39 & 0.33 \\
\hline \multirow{3}{*}{ 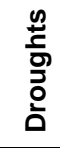 } & $1921-1950$ & 0.29 & 0.42 & 0.41 & 0.40 \\
\hline & $1951-1980$ & 0.30 & 0.59 & 0.40 & 0.44 \\
\hline & $1981-2010$ & 0.49 & 0.70 & 0.51 & 0.55 \\
\hline
\end{tabular}

Table 5-20: Averaged severity (in SPEI values) of droughts and wet events for the whole Iberian Peninsula (IP), for the South-western pattern (SWP), for the North-western pattern (NWP) and for the Mediterranean pattern (MedP) using the periods 1921-1950, 1951-1980 and 1981-2010. 


\begin{tabular}{|c|c|c|c|c|c|}
\hline & Periods & IP & SWP & NWP & MedP \\
\hline \multirow{3}{*}{$\begin{array}{l}0 \\
\frac{0}{0} \\
\Phi \\
d \\
\pm \\
3\end{array}$} & $1921-1950$ & 3.06 & 5.22 & 5.21 & 4.00 \\
\hline & $1951-1980$ & 7.58 & 12.79 & 11.00 & 10.86 \\
\hline & $1981-2010$ & 2.19 & 7.34 & 3.97 & 2.14 \\
\hline \multirow{3}{*}{ 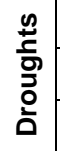 } & $1921-1950$ & 3.76 & 7.06 & 5.70 & 3.91 \\
\hline & $1951-1980$ & 2.50 & 8.39 & 4.33 & 4.74 \\
\hline & $1981-2010$ & 9.77 & 13.43 & 7.24 & 10.89 \\
\hline
\end{tabular}

Table 5-21: Averaged magnitude (accumulated severity in SPEI values) of droughts and wet events for the whole Iberian Peninsula (IP), for the South-western pattern (SWP), for the North-western pattern (NWP) and for the Mediterranean pattern (MedP) using the periods 1921-1950, 1951-1980 and 1981-2010.

\begin{tabular}{|c|c|c|c|c|c|}
\hline & Periods & IP & SWP & NWP & MedP \\
\hline \multirow{3}{*}{ 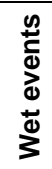 } & $1921-1950$ & 6.3 & 7.6 & 7.4 & 6.5 \\
\hline & $1951-1980$ & 10.5 & 14.4 & 11.2 & 11.2 \\
\hline & $1981-2010$ & 5.4 & 6.8 & 5.9 & 4.7 \\
\hline \multirow{3}{*}{$\begin{array}{l}\text { on } \\
\text { to } \\
\text { 옴 }\end{array}$} & $1921-1950$ & 7.6 & 7.6 & 7.0 & 6.1 \\
\hline & $1951-1980$ & 5.8 & 12.2 & 6.8 & 7.2 \\
\hline & $1981-2010$ & 13.2 & 15.1 & 8.4 & 9.8 \\
\hline
\end{tabular}

Table 5-22: Averaged duration (in months) of droughts and wet events for the whole Iberian Peninsula (IP), for the South-western pattern (SWP), for the North-western pattern (NWP) and for the Mediterranean pattern (MedP) using the periods 1921-1950, 1951-1980 and 1981-2010.

The averaged severity of droughts has experienced a clear increase in all regions for the period 1981-2010 relative to other periods. The South-western area already had a considerably increase in drought severity for the period 1951-1980 relative to 19211950 while the other regions have shown similar severity of droughts among both periods, although the Mediterranean region experienced a slight increase.

The averaged magnitude of droughts have had different behaviour than severity however they have coincided showing the highest rates of average magnitude of droughts for the period 1981-2010. This parameter has decreased in the whole Iberian Peninsula and in the North-western area in 1951-1980 relative to 1921-1950. In opposite, the South-western Iberia and the Mediterranean region have had an increase of magnitude for the period 1951-1980 that was more prominent during 1981-2010. 


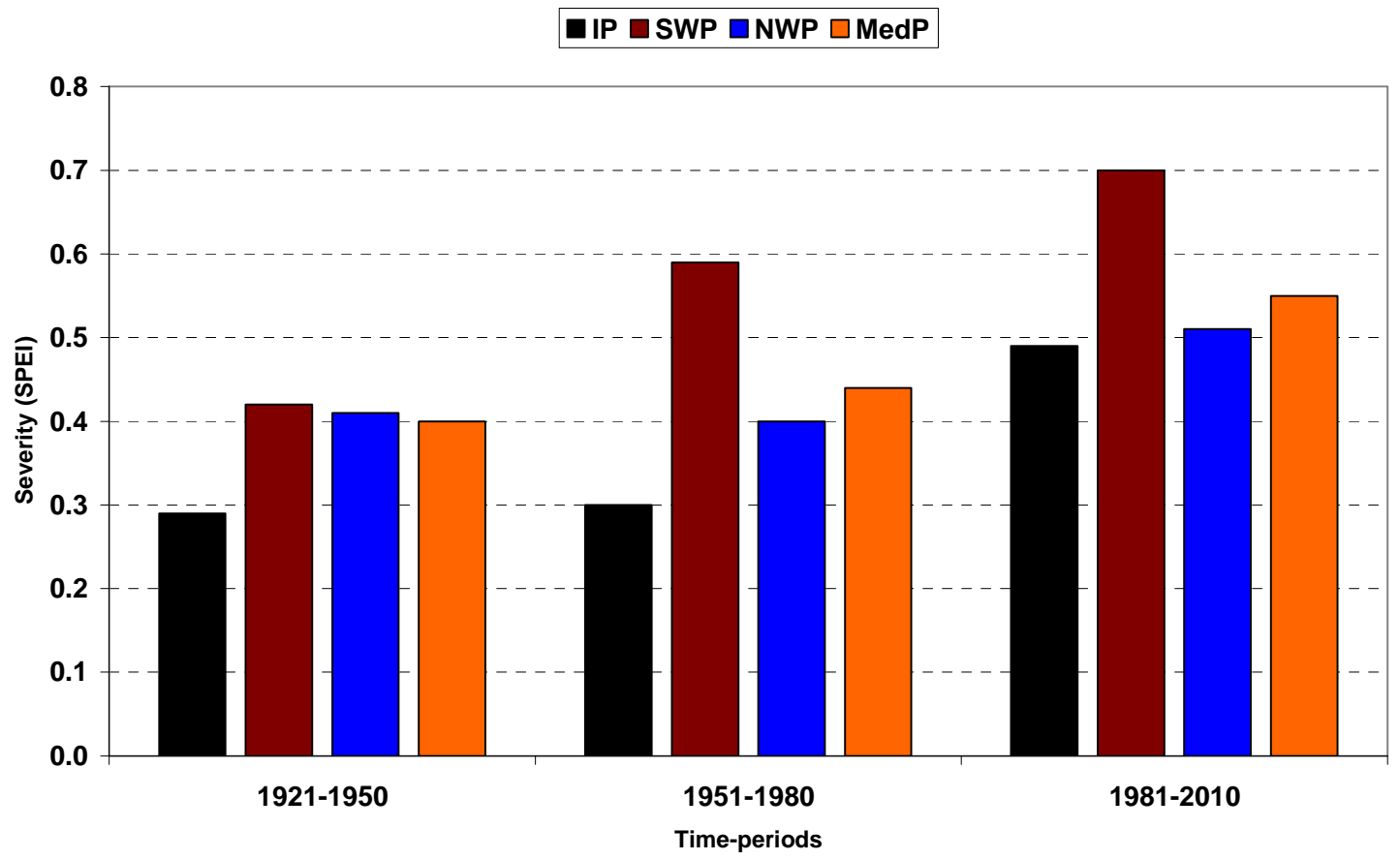

Figure 5-52: Averaged drought severity (in SPEI values) for the whole Iberian Peninsula (IP), for the South-western pattern (SWP), for the North-western pattern (NWP) and for the Mediterranean pattern (MedP) using the periods 1921-1950, 1951-1980 and 1981-2010.

$\square$ IP $\square$ SWP $\square$ NWP $\square$ MedP

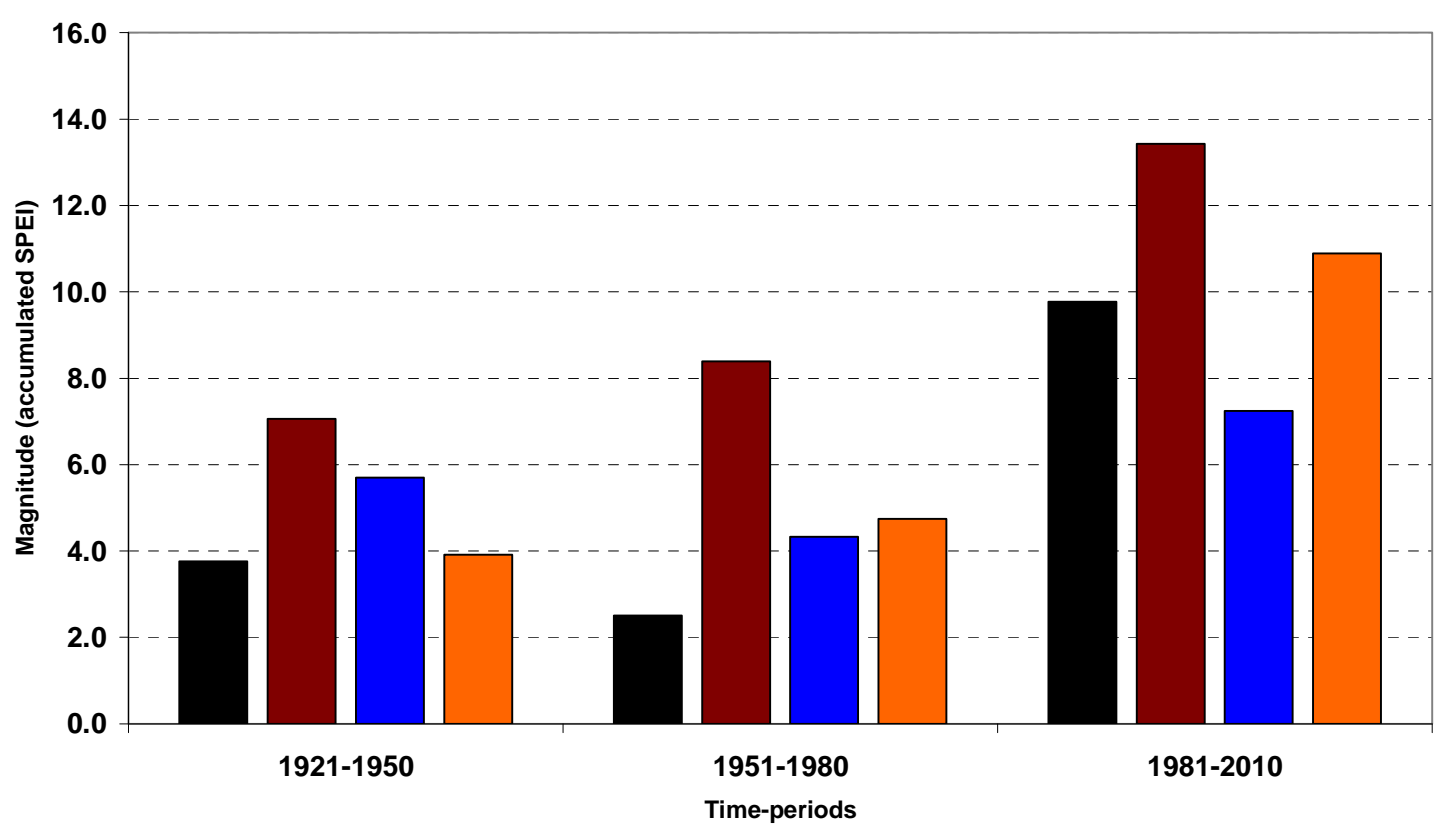

Figure 5-53: Averaged drought magnitude ( accumulated severity in SPEI values) for the whole Iberian Peninsula (IP), for the South-western pattern (SWP), for the North-western pattern (NWP) and for the Mediterranean pattern (MedP) using the periods 1921-1950, 1951-1980 and 19812010 . 
QIP —SWP —NWP $\square$ MedP

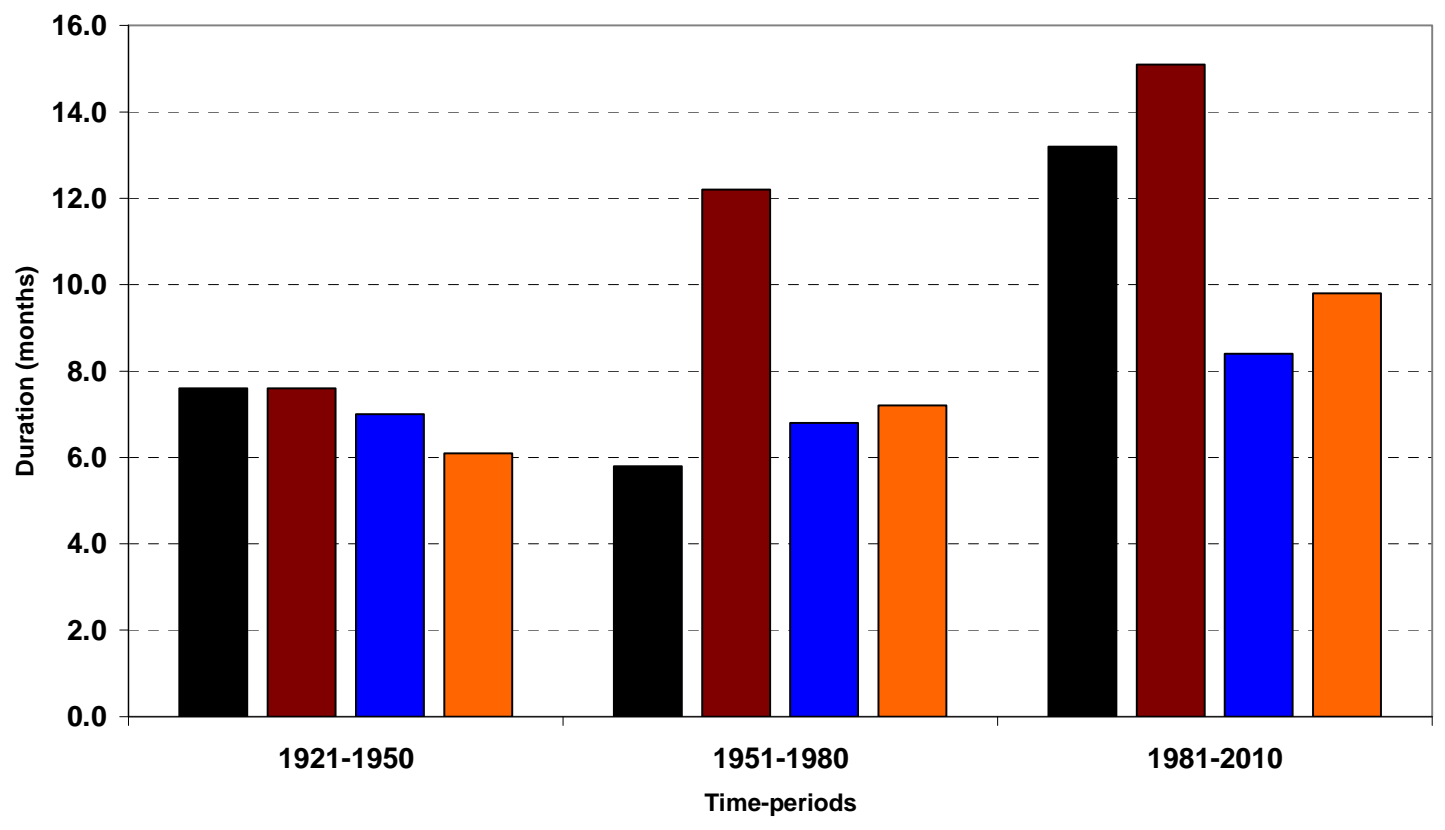

Figure 5-54: Averaged drought duration (in months) for the whole Iberian Peninsula (IP), for the Southwestern pattern (SWP), for the North-western pattern (NWP) and for the Mediterranean pattern (MedP) using the periods 1921-1950, 1951-1980 and 1981-2010.

The averaged duration of droughts has shown similar behaviour rather than magnitude with a remarkable increase in the South-western area in 1951-1980 that continued during the last three decades of the time-series. In fact, droughts lasted almost twice in average for 1981-2010 relative to 1921-1950. Moreover, figure 6-50 shows that the duration of droughts for the period 1981-2010 lasted more than twice relative to 19511980 for the whole Iberian Peninsula. The duration also increased in the North-western area and in the Mediterranean region, but with lower rates of change.

In summary, the drought severity, magnitude and duration have experienced a remarkable increase in the entire Iberian Peninsula but especially in the south-western area for the period 1981-2010 relative to 1951-1980 while the same parameters for wet events have not experienced significantly changes. 


\subsubsection{Summary}

Severity, magnitude and duration of droughts and wet events are analyzed for the whole Iberian Peninsula and also for the spatial-temporal patterns found at annual time-scale for the period 1906-2010 in this section. Moreover, other interesting parameters are also studied, such as the seasonal distribution of the onset, offset and the period of the maximum severity reached by dry or wet events.

From the results, we can conclude that the severity, magnitude and duration of droughts are having a remarkable increase over the entire Iberian Peninsula and also in the southwestern region while only drought magnitude is changing significantly in the Mediterranean region mainly related with the major droughts occurred in the last decades. The North-western Iberia is the exception of the drying trend found in most of the studied area, since the behaviour of drought parameters is not changing across time. The same parameters computed for wet events have not shown significantly changes over the Iberian Peninsula along the $20^{\text {th }}$ century and the first decade of the $21^{\text {st }}$ century. From the joint analysis of severity-duration and magnitude-duration of droughts, we can affirm that the accumulative character of droughts can be identified by noting that when the duration of a given drought event increases so does its severity and, consequently, its drought magnitude too.

The onset, offset and maximum severity of droughts and wet events are mostly produced in winter, autumn and spring while summer shows a much lower number of starts/ends. The same results are found related to the South-western pattern and the North-western pattern while the equinoccial seasons have a major role in the Mediterranean pattern in detriment of winter and summer to produce an onset, offset and maximum severity reached in dry or wet events indistintely.

Finally, after the comparisons between the averaged drought severity, magnitude and duration for the common periods 1921-1950, 1951-1980 and 1981-2010, we can conclude that drought parameters mentioned above have experienced a clear increasing for the entire Iberian Peninsula, but especially in the south-western area, for the period 1981-2010 relative to 1951-1980, while the same parameters analyzed for wet events have not been affected significantly according to the established 30 -year periods. 
UNIVERSITAT ROVIRA I VIRGILI
DROUGHT VARIABILITY AND CHANG

DROUGHT VARIABILITY AND CHANGE ACROSS THE IBERIAN PENINSULA

Joan Ramon Coll Benages

DL: T 955-2014

\begin{abstract}
DL: T 955-2014
\end{abstract}




\section{Chapter 6}

\section{SUMMARY}

After the exposition of our results, this chapter will discuss them. At the end of the Chapter, final conclusions will be drafted.

\subsection{Discussion}

This study provides a comprehensive analysis about drought variability and trends over the Iberian Peninsula across the $20^{\text {th }}$ century and the first decade of the $21^{\text {st }}$ century. The Sc-PDSI, 12-month SPI and 12-month SPEI are computed in a monthly basis using a high quality dataset to assess the spatial-temporal evolution of hydrological droughts and wet events at annual and seasonal time-scales, taking into account the severity, magnitude and duration of these extreme events. From the results, a drying trend is detected for most of the Iberian Peninsula along the $20^{\text {th }}$ century except in the western and in the north-western area, where a wetting trend is identified.

For this study, the compilation and use of the Monthly Iberian Temperature and Precipitation Series (MITPS) ensures consistency and reliability on the identified drought conditions over the area of interest. A dataset of 24 long temperature and precipitation time series regularly spread over the Iberian Peninsula and extending from the mid-nineteenth century to the present is used. Monthly means derived from the Spanish Daily Adjusted Temperature/Precipitation Series (SDATS, SDAPS Brunet et al. 2006, 2007) and 2 Portuguese time series obtained from Climatology and Climate Change Research Group of the Instituto Dom Luiz (Lisbon University) are required.

The use of a limited number of observatories could produce some uncertainties in terms of data representativeness for the whole region. However, this study is focused in a regional perspective since drought is considered as a regional phenomenon because the main causes that can produce it also affect a regional scale (Hayes et al., 2011). Prolonged droughts occur when large-scale anomalies in atmospheric circulation patterns persist for months or seasons (or longer) extending the persistence of high pressure beyond 
their climatological normals. This is most prominent when we are referred to hydrological droughts because the fluctuations of this kind of drought are highly dependent on regional climate patterns among other anthropogenic causes (LorenzoLacruz et al., 2012). Some studies of drought variability used a few observatories to detect drought conditions across wide regions highlighting the longevity and the quality of the time-series prior to the density of the network. For example, Szinell et al., (1999) analyzed drought trends in Hungary using 15 long-term stations spread over the country; Briffa et al., (2009) detected dry and wet summers in Europe using 22 longterm series to explain the evidence of increasing drought; Laux et al., (2009) used 29 observatories to demonstrate the precipitation variability in Volta Basin (West Africa); and Potop (2011) assessed drought variability in the Czech Republic using 15 meteorological stations. Moreover, it is crucial to have time-series as long as possible since this study is focused on drought evolution across time. The temporal character of droughts requires long-term series to quantify reliable observed trends. For example, van der Schrier et al., (2011) computed global drought trends for the period 1901-2006, while Sousa et al., (2011) did it across the Mediterranean region for the period 19012000. Furthermore, the difficulty of having a great number of long-term and high quality precipitation and temperature series must be considered. A quality controlled and homogenized dataset can provide robust climate results temporally and spatially comparables among other regions. For this reason, projects focused on data rescue, quality control and time-series homogenisation are crucial to ensure high-quality results on climate analysis.

The selected dataset fulfils the main requirements to be potentially used for drought analysis over the region under study; it is a high quality dataset, long-term records of temperature and precipitation are provided to get reliable trends, and a great spatial coverage over the region is ensured involving the main climate characteristics found in the Iberian Peninsula. Unfortunately, most of the long-term climatological time series are affected by a number of non-climatic factors that make these data unrepresentative of the actual climate variation across time. All of these inhomogeneities can bias a time series and lead to misinterpretations of the studied climate. It is important, therefore, to remove the inhomogeneities or at least determine the possible error they may cause (Aguilar et al., 2003). Thus, Daily maximum, minimum, derived daily mean temperatures and daily precipitation of mainland Spain had been adjusted by the Centre for Climate Change (C3) for the period 1850-2005 (Brunet et al., 2006). The series were quality 
controlled (QC) following Aguilar et al., (2002) and were homogenized applying the Standard Normal Homogeneity Test (SNHT) (Alexandersson and Moberg, 1997). Moreover, SDATS and SDAPS have been updated to 2010 directly from the AEMET servers, after applying the pertinent QC procedures. Updated SDATS and SDAPS are pending of rehomogenisation for the period 2005-2010, although basic data analysis suggest that no large homogeneity problems were present in this segment. The two Portuguese series (Lisboa and Porto) were subjected to quality control procedure of raw data and tested in a monthly scale using SNHT to maintain spatial and temporal consistency with SDATS/SDAPS time-series for the whole period. As example, Brázdil et al., (2009) used SNHT method to homogenize monthly temperature and precipitation time-series before detecting drought variability in the Czech Republic.

But, time-series of observed data are often affected by missing values due to directly non-observation or gaps produced by removed outliers during the QC procedure among others. In this study was crucial to fill these gaps to ensure temporal continuity in timeseries avoiding drought indices interruption. Thus, punctual monthly missing values were completed using multiple linear regressions with respective reference series. Vicente-Serrano et al., (2005) and (2006) applied this method to complete missing values in 51 Iberian precipitation series from 1910 to 2000 in order to provide continuity in time-series before computing SPI to detect drought conditions over the Iberian Peninsula. Unfortunately, Pamplona and San Sebastián observatories could not be included in our study due to excessive missing data found in both time-series. The results confirm that the low percentage of monthly missing data filled on the original dataset has an inappreciable impact on temperature and precipitation time-series in the Iberian Peninsula.

However, the analysis of the time-series using various lengths of records could affect negatively the reliability of the results taking into account the regional character of this work. Therefore, the comparisons between different regions under study could be erroneous. Furthermore, the needed to have simultaneous temperature and precipitation records to compute drought indices for each location is crucial to obtain drought conditions. For all these reasons, it is needed to fix the common period 1906-2010 in all dataset to solve this issue according to the availability and continuity of the records.

The creation of MITPS dataset ensures maximum continuity and reliability in monthly temperature and precipitation for the 22 time-series across Iberian Peninsula using the 
common period 1906-2010. Thus, the simultaneous availability of monthly long-term temperature and precipitation data guarantees the continuity of drought severity values across time, which affects positively the final quality and reliability of the results related to drought detection in the Iberian Peninsula.

The variability and trends of temperature and precipitation data are computed for the whole Iberian Peninsula (1906-2010) at annual and seasonal time-scale. This climate analysis provides crucial information related to the behaviour of the main climate variables under climate change conditions. From the results, annual temperature anomalies computed for the whole Iberian Peninsula (1906-2010) shows a clear increase of $0.13^{\circ} \mathrm{C} /$ decade while seasonal temperature anomalies also increase significantly. This is consistent with the Spanish temperature increase described by Brunet et al., 2006 for the period 1850-2003. Other regional studies show a qualitative concordance with this one (e.g. for the interior of Valencia, Miró et al., 2006; CastillaLeón, del Río et al., 2005; Andalucía, Castro-Díez et al., 2007 and Catalonia, Martínez et al., 2009).

Otherwise, annual precipitation anomalies are dominated by a high inter-annual variability accompanied by a slight non-significant increase. Seasonal precipitation anomalies show a slight increasing trend in winter and autumn precipitation while a slight decreasing trend is detected in spring and summer precipitation. These findings are consistent with Trenberth et al., (2007), who did not detect a generalized and significant decrease of precipitation in the Mediterranean basin including the Iberian Peninsula. Other studies which dealt the evolution of the precipitation during the $20^{\text {th }}$ century or before concluded that annual precipitation do not show appreciable changes in a secular time scale (Lana and Burgueño, 2000; Llasat and Quintas, 2004; Saladié, 2004; BarreraEscoda, 2008; CLIVAR, 2010). Being consistent with the observed trends, climate models project a large increase in temperatures and also a decrease in precipitation of roughly $20 \%$ in southern Europe at the end of $21^{\text {st }}$ century (Salomon et al., 2007), including the whole Iberian Peninsula (Sanchez, 2009; Gómez-Navarro et al., 2010; Rodríguez-Puebla et al., 2010; Alvarez et al., 2011; Jerez et al., 2012a and 2012c).

The most widely used drought indices (the Sc-PDSI (Wells et al., 2004), the SPI (McKee et al., 1993) and the SPEI (Vicente-Serrano et al., 2010)) are computed to identify hydrological droughts across Iberian Peninsula using the common period 1906-2010. A wide temporal window of analysis in SPI and SPEI (12 months) is preferred for this study, since it is more suited to identify hydrological than agricultural droughts in the Iberian 
Peninsula (Hayes et al., 1999 and Vicente-Serrano, 2006). The Sc-PDSI is used instead the original PDSI because it is more appropriate for geographical comparison of climate in diverse regions (van der Schrier et al., 2006a).

The estimation of Potential Evapotranspiration (PET) is required to compute the ScPDSI and the SPEI drought indices. There are various methods to compute potential evapotranspiration (Thornthwaite, Penman-Monteith, Hargreaves,...) and multiple algorithms and variables can be implied depending on the selected method. The use of one or another PET estimation method strongly depends on the long-term available data to compute them. Generally, PET estimation methods that require greater amount of data to compute PET are physically more realistic than others which less amount of data are needed (Dai, 2012 and Sheffield et al., 2012). For this study, the unique method to be applied to estimate PET is Thornthwaite (Thornthwaite, 1948) since there are not available long-term series of observed wind speed, relative humidity, solar radiation and cloud cover for the period under study (1906-2010). Therefore, other more robust methods like Penman-Monteith unfortunately cannot be applied in this case. As is shown, Thornthwaite's method was formulated in 1948 and it is based on the assumption that radiation is the main driver of temperature variability. Therefore, the Thornthwaite's method estimates the radiation based on the temperature. This assumption could be valid under the climate conditions in 1948, but under the current global warming conditions, the temperature increase is not driven by increased radiation but it is caused by increased greenhouse gasses emissions (Solomon et al., 2007; Field et al., 2012). In this way, the Thornthwaite's approach is currently overestimating PET since the method is overestimating solar radiation, which is not increasing in parallel to the temperature increase. Thus, the PET estimation method chosen here could introduce possible limitations on drought detection, especially when computing observed drought trends, which could be affected in some way by the method applied.

The results related to drought time-series show that the three drought indices represent similar variability of wet and dry conditions for the whole Iberian Peninsula across time. The decades of 1940 and 1950 were abnormally dry in average while the decades of 1910, 1930, 1960 and 1970 were abnormally wet in all drought indices. A high variability of wet and dry conditions were found in 1920s while mostly dry conditions were detected in 1980s, 1990s and 2000s, especially using the Sc-PDSI and the 12month SPEI due to the impact of the evapotranspiration rate on the drought series under 
global warming. Furthermore, all drought indices identified clearly the most important droughts in 1945, 1995 and 2005, which were thoroughly validated using documental sources. Similar results were found for the entire Mediterranean basin (Xoplaki et al., 2004; Trigo et al., 2006; and Sousa et al., 2011), whom detected severe droughts in 1920s, 1940s and mostly dry conditions since 1980s while Vicente-Serrano et al., (2006) found similar drought variability using SPI in the Iberian Peninsula. It means that 12-month SPEI and 12-month SPI are able to provide similar results rather than Sc-PDSI with less data requirements (just monthly precipitation (in the case of 12-month SPI) and monthly precipitation and temperature (using 12-month SPEI)). Otherwise, Sc-PDSI computation requires monthly precipitation, temperature and Available Water Content of the soil. Available information on soil water content is not easy to find in most regions around the world and it is often a local and fixed value normally associated with current soil conditions, knowing that soil properties may change across time (VicenteSerrano et al., 2011). It could lead the use of inaccurate values when applying Sc-PDSI in the Iberian Peninsula.

Nevertheless, 12-month SPEI and 12-month SPI show better calibration in terms of the frequency distribution of values into drought categories than the Sc-PDSI over the Iberian Peninsula. Despite Wells et al., (2004) solved most of the calibration problems from the original PDSI, making the index more suitable for drought quantification and monitoring (Sc-PDSI), some calibration problems appear in the computation of ScPDSI over the Iberian Peninsula. The 12-month SPEI maintain robust units with statistical consistency obtained from cumulative antecedent climate conditions and it provides more drought reliability than Sc-PDSI in the region under study. These differences in drought index calibration could be explained knowing that SPI and SPEI are purely statistical, and their purpose is not related to reproduce the water balance of any particular system as Sc-PDSI (Vicente-Serrano et al., 2011).

Otherwise, all drought indices are able to identify similar surface area affected by dry conditions in the Iberian Peninsula across time. Moreover, the driest periods detected before in terms of severity are found again as the driest periods in terms of affected area too. All drought indices coincide to attribute the driest conditions (in terms of severity and area affected by drought) to years 1945, 1995 and 2005 over the Iberian Peninsula along the $20^{\text {th }}$ century. These findings are in good agreement with Vicente-Serrano et $a l$., (2006), whom found a high inverse correlation between severity and area affected by drought over the Iberian Peninsula. 
Despite the similar results found in terms of drought variability and area affected by drought among all drought indices, some differences in trends are identified in both; individual and regional time-series. In general, all drought indices identify a drying trend in the Pyrenees, Ebro basin, central Iberia and in the south, south-western and south-eastern area while a wetting trend is focused in the western and north-western of the Iberian Peninsula. These results are consistent with Sousa et al., (2011) using the Sc-PDSI, Vicente-Serrano et al., (2011), using SPI and SPEI indices, and LorenzoLacruz et al., (2012) using stream-flow data, whom detected that droughts increased over most of the Iberian Peninsula with the exception of the north-west area of the region for the $20^{\text {th }}$ century. Sc-PDSI and 12-month-SPEI show a non-statistically significant drying trend while a non-significant wetting trend is obtained using 12month SPI (all at the 95\% level) for the whole Iberian Peninsula. The results obtained are in good agreement with other drying trends found using the Sc-PDSI across southern-Europe (Dai, 2011 and 2012; Sheffield et al., 2012), (Brázdil et al., 2008 (for the Czech Republic), Mavromatis 2007 (for Greece), Briffa et al., 2009 (for Europe in summer), and Sousa et al., 2011 (for the Mediterranean basin). In fact, an increase of drought conditions can be expected in the Mediterranean basin (Blekinsop et al., 2007; Planton et al., 2008; Mariotti et al., 2008; Mata, 2008; Dai, 2011 and 2012; Field et al., 2012) and also over the Iberian Peninsula under climate change conditions (Beniston et al., 2007; Rodríguez-Puebla et al., 2010; Alvarez et al., 2011; Sanchez et al., 2012).

The annual trends are larger in drought indices which include temperature in their computation (the Sc-PDSI and 12-month SPEI) than in those where the only driver is precipitation (such as 12-month SPI). The Sc-PDSI and SPEI indices represent better drought conditions under global warming than other indices since evapotranspiration process is included in their algorithms (Vicente-Serrano et al., 2010 and 2011, Dai 2004 and 2011, Van der Schrier et al., 2006 and 2011). There is general agreement on the importance of precipitation in explaining drought variability, but the observed and predicted global warming by IPCC AR4 (Solomon et al., 2007) have important implications for evapotranspiration processes, increasing the influence of this parameter on drought severity (Vicente-Serrano et al., 2010). Nevertheless, the use of Thornthwaite PET estimation method could have exacerbated the drying trends found in the Sc-PDSI and 12-month SPEI across Iberian Peninsula since this parameterization tends to overestimate PET. Multiple studies tested the effect of the PET on the Sc-PDSI (van der Schrier et al., 2011; Dai, 2010, 2011 and 2012) showing similar results in global drought trends 
using different PET estimation methods, however, a current study showed that Thornthwaite PET estimation produces higher rates of PET than other parameterizations as Penman-Monteith around the world (Sheffield et al., 2012). This study reported that the increase in global drought was overestimated because the PDSI used a simplified model of PET (referred to Thornthwaite method) causing large uncertainties on drought conditions under global warming. More realistic estimations of PET (referred to Penman-Monteith method) suggested a little change in drought over the past 60 years. For this reason it is interesting to assess the role of temperature in drought indices (between SPI and SPEI) and the impact of global warming on drought trends (in the case of Sc-PDSI and SPEI) over the Iberian Peninsula.

The results confirm that the Sc-PDSI and the 12-month SPEI-all forcing show higher severity of droughts compared with the Sc-PDSI and the 12-month SPEI-without temperature changes due to the increase of PET caused by global warming. Moreover, 12-month SPEI-all forcing shows higher severity of droughts compared with the 12month SPI due to the role of temperature, which enhances the role of PET leading an increase of drought severity under global warming. As mentioned before, a nonsignificant drying trend (at the 95\% level) is found for the whole Iberian Peninsula (1906-2010) using the Sc-PDSI-all forcing and 12-month SPEI-all forcing, but these trends become slightly wetter when using drought indices without temperature changes (Sc-PDSI and 12-month SPEI) or without temperature in its algorithm (12-month SPI). All wetting trends are statistically non-significant at the $95 \%$ level. The results suggest that precipitation variability is the main driver of droughts, but temperature (and derived PET) has an important role (in terms of drought severity) to explain drought trends over the whole Iberian Peninsula. Moreover, the increase in PET during last decades reinforces the drying trend found under climate change conditions. The high probability that PET is overestimated in this study caused by the use of Thornthwaite method instead other more realistic PET estimation methods must be considered. Thus, the drought trends computed for Sc-PDSI and 12-month SPEI could also be affected by PET overestimation. Van der Schrier et al., (2011) and Dai, (2011) assessed the role of PET in the global Sc-PDSI finding slight differences in drought trends when comparing both PET estimation methods. This statement is not in agreement with those studies probably caused by the geographical location of the Iberian Peninsula in a subtropical climate where the evapotranspiration rate has a major role than in other regions. From the results, it is crucial to use an accurate PET estimation method in drought indices 
when computing them in the Iberian Peninsula due to the importance of PET on drought trends in this region. Nevertheless, the indices and PET estimations used to monitor droughts are still affected by large uncertainties leaded by the complexity of drought phenomenon and by the multiple factors and feedbacks implied in it (Sheffield et al., 2012). Therefore, short-term temperature anomalies are likely to be a response to drought rather than a factor in forcing drought.

From the main results obtained using different drought indices, we can conclude that the 12-month SPEI is the most suited drought index to identify wet and dry conditions over the Iberian Peninsula along the $20^{\text {th }}$ century. This drought index is able to show similar drought conditions (both in terms of severity and area affected by drought) rather than other more complex drought index (such as Sc-PDSI) has fewer data requirements and includes the role of evapotranspiration in its algorithm (in detriment of SPI). Moreover, 12-month SPEI shows statistical consistency and robustness thanks to better calibration than the other indices allowing the detection of a drying trend in most of the Iberian Peninsula also observed by other studies already mentioned. Thus, the analysis of the spatial-temporal patterns of droughts and the univariate performing of severity, duration and magnitude of droughts and wet events are carried out using only the 12-month SPEI.

But, before that, drought conditions are inspected since the mid-nineteenth century using 12-month SPEI for only a few observatories which data are available for this period (Cadiz, Madrid, Lisboa, Murcia and Huesca). The results show wet conditions in mid-1850s, mid-1860s, all the 1880s and in most of the 1910s while dry conditions are focused in early-1870s, late-1890s and in most of the 1900s. Briffa et al., (2009) analyzed 22 long-term time-series for Europe using the Sc-PDSI to detect drier or wetter summers across time. Unfortunately, the results from that study cannot be compared to the time-series mentioned above because there is not any station located in the Iberian Peninsula, only the summer drought variability detected in Marseille is similar to the Iberian drought variability found in late- $19^{\text {th }}$ century.

In this study, Principal Component Analysis (PCA) is applied at annual and seasonal time-scale to the 12-month SPEI time-series for the common period 1906-2010 in order to detect spatial-temporal variations of droughts across the $20^{\text {th }}$ century. The regionalization shows three different spatial-temporal drought behaviours in the Iberian Peninsula called as the South-western pattern, the North-western pattern and the 
Mediterranean pattern. A clear drying trend is found in the South-western pattern and in the Mediterranean pattern while the North-western pattern does not show a significant trend in drought conditions. It means that the south and south-west of the Iberian Peninsula (South-western pattern) are suffering drier conditions currently than before, but the Mediterranean region does it duplicating the drying trend, caused basically by the driest last decades observed in this region. Similar behaviour of drought patterns is also found at seasonal time-scale. These results are in good agreement with VicenteSerrano et al., (2011) whom found that dry conditions did not increase in the north-west of the Iberian Peninsula between 1930 and 2006 using SPI and SPEI drought indices. Sousa et al., (2011) have also shown that the north-west of the Iberian Peninsula is an exception to the predominant trend in the $20^{\text {th }}$ century towards drier conditions using PDSI, which were detected for most of the western Mediterranean. In the same way, Lorenzo-Lacruz et al., 2012 showed a drying trend over most of the Iberian Peninsula analyzing stream-flow data, while a wetting trend was detected in the north-west area from the Iberian regionalization (Lorenzo-Lacruz et al., 2013). This contrasts with the general trends found in other Iberian regions, in which dry conditions have increased (Vicente-Serrano 2006a and Lorenzo-Lacruz et al., 2012). On a regional scale, there is evidence of a significant increase in the severity of drought in the Ebro basin (Vicente-Serrano \& Cuadrat-Prats 2006, Vicente-Serrano \& López-Moreno 2006), some areas of the Valencia region (Vicente-Serrano et al., 2004) and in the Tagus basin (Lorenzo-Lacruz et al., 2010).

Otherwise, the characteristics and trends of the main parameters related to dry and wet events (severity, duration and magnitude) are analyzed for the whole Iberian Peninsula and for the spatial-temporal patterns found at annual time-scale. The accumulative character of droughts can be identified by noting that when the duration of the drought increases so does the severity drawing a logarithmic distribution. In summary, droughts have changed their behaviour in terms of severity, duration and magnitude over the whole Iberian Peninsula from 1906 to 2010, while wet events do not present significantly variations over the analysed parameters. The time-series associated to the South-western pattern shows significant changes on the behaviour of all main parameters related to droughts, while wet events do not present significantly variations. The results demonstrate that the time-series associated to the North-western pattern is not experienced changes on the behaviour of wet and dry events, but the fluctuations of drought time-series is only the result of the temporal variability without clearly trends observed in the main drought parameters. Finally, the Mediterranean pattern shows a 
non-significant increase of severity and duration of droughts, but a clear increase of drought magnitude. Otherwise, the evolution of main parameters of wet events experiences a non-significant decrease. Furthermore, the severity, magnitude and duration of droughts have a remarkable increase especially in the entire Iberian Peninsula and in the south-western area for the period 1981-2010 relative to 1951-1980 while the same parameters for wet events do not experience significantly changes. These findings are consistent with Lorenzo-Lacruz et al., (2013), whom found a clear increase in drought duration and magnitude in the central-eastern Iberian Peninsula for the period 1975-2005 relative to 1945-1974 while a decrease of the same drought parameters were found in the north-west area of the region using stream-flow data. However, a clear decrease in drought duration and magnitude was detected in the northwest of the Iberian Peninsula for the period 1980-2005 relative to 1930-1955 using SPI and SPEI (Vicente-Serrano et al., 2011).

Finally, winter, autumn and spring are the seasons in which most of droughts and wet events began, reached their maximum severity and ended for the whole Iberian Peninsula while summer has a low weight related to this kind of parameters. Therefore, winter and autumn are the seasons in which most of droughts and wet events began, ended and reached the maximum severity in the South-western and North-western pattern. Otherwise, the season which has the most important role related to the parameters analyzed is unquestionably in autumn. However, winter is the season in which the beginning and ending of droughts and wet events is less prominent in the Mediterranean region. These less relevant findings are strongly related with the seasonal precipitation variability across Iberian Peninsula.

As mentioned above, a clear increase in drought conditions can be expected in most of the Iberian Peninsula along the $21^{\text {st }}$ century according to the future projections since the drying trend detected across the $20^{\text {th }}$ century not only in this study. Therefore, the availability of water resources for consumption, irrigation and tourism among others could be worsening in this area leading unknown socio-economical and environmental impacts actually not easy to solve. Nevertheless, the application of effective water management strategies, strongly related to water policies, together with a general consensus about saving water will be crucial to minimize the impact of the hydrological droughts over the Iberian Peninsula across time. 


\subsection{Further work}

The robustness of the results obtained about drought variability and trends in the Iberian Peninsula along the $20^{\text {th }}$ century could surely get more reliability including more observatories in this analysis. Despite the station network selected for this study represents the main climate characteristics of the region, an extended station network could produce more accurate results especially in terms of spatial drought distribution and impact over the region of interest. Nevertheless, the crucial importance of long and high quality time-series must be prior to the increase of the network density.

There are many homogeneity tests that could be applied to the dataset used in this study in order to improve the consistency of the main variables related to drought. The field related to data treatment is in constant progress in climatology and new robust homogeneity software packages were developed during the last years. It will be interesting to test them together with the SNHT to ensure that the evolution of climate variables is only influenced by the climate variability. This experiment would probably provide more reliability on drought results.

Unfortunately, the uncertainties on results not only depend on the quality of the input data, but the drought index computations are still affected by some limitations. It is widely known that drought indices are not able to reproduce accurately the actual drought conditions of any region since drought is a complex phenomenon in which many distinct variables and feedbacks are involved. Thus, the improvements in drought indices are highly required to monitor more reliable drought variability especially under climate change conditions.

Moreover, the results related to drought variability and trends carried out in this study are strongly influenced by the use of a weak PET estimation method (Thornthwaite). The known limitations of this method to compute PET should be considered in future works and the results obtained through this method should be compared to other drought results computed using more physically realistic PET estimation methods. This is a great issue to solve in the case of the Iberian Peninsula, where the evapotranspiration rate could have an important role on drought worsening under global warming.

This study could be complemented analyzing various kinds of drought (meteorological and agricultural drought) because only the hydrological drought is assessed here. This 
could be figured out using different time-scales on drought index computation. This experiment could provide more information about the behaviour of short-term and midterm droughts over the region of interest. Furthermore, once the univariate analysis of the main parameters related to drought (severity, duration and magnitude) is carried out in this study, it could be interesting to analise all these parameters together to get an accurate characterization of droughts. The multi-variate analysis could be computed using Copulas model method in order to figure out the return periods for various categories of drought taking into account a given magnitude and/or duration using the severity-frequency-duration curves.

Finally, it might be worth to project precipitation, temperature and derived drought conditions over the Iberian Peninsula across the $21^{\text {st }}$ century taking into account various IPCC climate change scenarios. The temporal evolution of the main variables that explain drought could be analyzed using drought indices from different Regional Climate Models across the $21^{\text {st }}$ century to give us an approach about drought variability and change into the future. 


\subsection{Conclusions}

The evaluation and analysis of the spatial and temporal variability of hydrological droughts are carried out across the Iberian Peninsula along the $20^{\text {th }}$ century and the first decade of the $21^{\text {st }}$ century in this study. The Sc-PDSI, 12-month SPI and 12-month SPEI are computed in a monthly basis by using a long-term high quality and adjusted dataset (MITPS) to assess the evolution of hydrological droughts and wet events in terms of severity, magnitude and duration at annual and seasonal time-scales.

Once the results have been thoroughly described and analyzed, the main conclusion of this Ph.D. Thesis can be summarized as:

- A drying trend is found for most of the Iberian Peninsula, especially in the south and south-eastern region, but a wetting trend is identified in the western and in the north-western area.

But other specific conclusions are also extracted:

- Annual and seasonal temperature anomalies computed for the whole Iberian Peninsula (1906-2010) show a significantly increase while annual precipitation anomalies are dominated by a high inter-annual variability accompanied by a slight non-significant increase. Seasonal precipitation anomalies show a slight increasing trend in winter and autumn precipitation while a slight decreasing trend is identified in spring and summer precipitation.

- The three drought indices tested in this study represent similar variability of wet and dry conditions for the whole Iberian Peninsula across time. The analysis of temporal evolution of droughts confirms that dry conditions dominated in 1920s, 1940s and in 1950s while wet conditions were present in 1930s, 1960s and in 1970s. The last three decades of the time-period (1980-2010) were abnormally dry mainly due to less precipitation than normal.

- Drought conditions inspected since the mid-nineteenth century show wet conditions in mid-1850s, mid-1860s, all the 1880s and in most of the 1910s 
while dry conditions are focused in early-1870s, late-1890s and in most of the 1900s.

- The most important droughts occurred in 1945, 1995 and 2005 in terms of drought severity and area affected by drought, which were thoroughly validated using documental sources.

- All drought indices identify a drying trend in the Pyrenees, Ebro basin, central Iberia and in the south and south-eastern area while a wetting trend is focused in the western and north-western of the Iberian Peninsula.

- Annual trends are larger in drought indices which temperature is included in their computation than in which the main driver of drought variability is only precipitation. Nevertheless, the use of Thornthwaite PET estimation method must be considered because it could have exacerbated the drying trends found across the Iberian Peninsula since this parameterization tends to overestimate PET.

- Precipitation variability is the main driver of droughts, but temperature (and derived PET) has an important role (in terms of drought severity) to explain drought trends over the whole Iberian Peninsula. This fact highlights the importance of including evapotranspiration in the evaluation of droughts while, at the same time, it warns that the use of unsuitable methods to estimate PET could compromise the final results.

- The severity and duration of dry conditions were reinforced during the last three decades caused by the increase of the evapotranspiration rate coinciding with the maximum increase of temperatures in the Iberian Peninsula in a climate change context.

- The 12-month SPEI is the most favoured drought index to identify hydrological wet and dry events over the Iberian Peninsula. This drought index is able to show similar drought conditions rather than other more complex drought index 
(as Sc-PDSI) with less data requirements and also including the role of evapotranspiration in their algorithm (in detriment of SPI). Moreover, 12-month SPEI shows statistical consistency and robustness thanks to better calibration than the other indices allowing the identification of a drying trend in most of the Iberian Peninsula.

- Three different drought patterns have been found in the Iberian Peninsula. A clear drying trend is identified in the south and south-western Iberian Peninsula and also in the Mediterranean region while the north-western area does not show a significant trend in drought conditions. Similar behaviour of drought patterns is also found at seasonal time-scale.

- The accumulative character of droughts can be identified by noting that when the duration of the drought increases so does the severity.

- The severity, magnitude and duration of droughts have a remarkable increase especially in the entire Iberian Peninsula and in the south-western area for the period 1981-2010 relative to 1951-1980 while the same parameters for wet events do not experience significantly changes.

- The onset, offset and maximum severity of droughts and wet events are mostly produced in winter, autumn and spring while summer has a less role related to this kind of parameters for the whole Iberian Peninsula. The same results are found related to the south-western Iberia and the north-western area while the equinoccial seasons have a major role in the Mediterranean region in detriment of winter and summer to produce an onset, offset and maximum severity reached in dry or wet events indistintely.

Future projections indicate a clear increase in hydrological drought conditions in most of the Iberian Peninsula along the $21^{\text {st }}$ century mainly caused by a decrease of precipitation together with an increase of water demand for consumption or human activities among others. Thus, water saving and the application of effective water management strategies will be crucial to minimize the impact of the hydrological droughts over the Iberian Peninsula across time. 


\section{Chapter 7}

\section{REFERENCES}

AEMET and Instituto de Meteorologia (Portugal). 2011. Iberian Climate Atlas. www.aemet.es

Agnew C. T., 2000. Using the SPI to identify drought. Drought Netw News 12:6-12

Aguilar E., Auer, I., Brunet, M., Peterson, T.C. and Wieringa, J., 2003: WCDMP No. 53, WMD/TD No. 1186: Guidelines on climate metadata and homogenization. World Meteorological Organization, Geneva, Switzerland.

Aguilar E., Brunet M, Saladié O, Sigró J, López D. 2002. Hacia una aplicación optima del standard normal homogeneity test para la homogeneización de series de temperatura. In La Información Climática Como Herramienta de Gestión Ambiental, VII Reunión Nacional de Climatología, Grupo de Climatología de la AGE, Cuadrat JM, Vicente SM, SAZ MA (eds). Universidad de Zaragoza: Zaragoza, 17-33.

Alexandersson H., and A. Moberg. 1997. Homogenisation of Swedish temperature data, Part I: Homogeneity test for linear trends, International Journal of Climatology 17:25-34.

Alley W. M. 1984. The Palmer drought severity index: limitations and applications. Journal of Applied Meteorology, 23, 1100-1109.

Barrera-Escoda, A., 2008. Evolución de los extremos hídricos en Catalunya en los últimos 500 años y su modelización regional (Evolution of hydric extremes in Catalonia during the last 500 years and its regional modelling), Ph.D. Thesis, Internal Publication, University of Barcelona, Barcelona, Spain.

Begueria, S., S.M. Vicente-Serrano, and M. Angulo-Martinez, 2010: A multiscalar global drought dataset: The SPEIbase: A new gridded product for the analysis of drought variability and impacts. Bulletin of the American Meteorological Society, 91(10), 1351-1354.

Blenkinsop, S. and H.J. Fowler, 2007a: Changes in drought frequency, severity and duration for the British Isles projected by the PRUDENCE regional climate models. Journal of Hydrology, 342, 50-71.

Blenkinsop, S. and H.J. Fowler, 2007b: Changes in European drought characteristics projected by the PRUDENCE regional climate models. International Journal of Climatology, 27(12), 1595-1610. 
Bordi, I., Fraedrich, K., Petitta, M., Sutera, A., 2006. Large-scale assessment of drought variability based on ncep/ncar and era-40 re-analyses. Water Resources Management (20), 899-915.

Boroneant C., Ionita M, Brunet M, Rimbu N, 2011. CLIVAR-SPAIN Contributions: Seasonal drought variability over Iberian Peninsula and its relationship to global seas surface temperature and large scale atmospheric circulation. Poster presentation at WCRP OSC: Climate Research in Service to Society, 24-28 October 2011, Denver, USA.

Brazdil R., Trnka M, Dobrovolny P, Chromá K. 2009. Variability of droughts in the Czech Republic, 1881-2006. Theory and Applied Climatology 97:297-315. doi: 10.1007/s00704-008-0065-x.

Briffa K. R., Van der Schrier G., and Jones P.D., 2009. Wet and dry summers in Europe since 1750: evidence of increasing drought. International Journal of Climatology. 29:1894-1905, doi: 10.1002/joc.1836.

Briffa K. R., Joes P. D., and Hulme, M.: Summer moisture variability across Europe, 1892-1991: an analysis based on the Palmer drought severity index. 1994. Int. J. Climatol., 14, 475-506.

Brunet M. P.D. Jones, J. Sigró, O. Saladié, E. Aguilar, A. Moberg, P.M. Della-Marta, D. Lister, A.Walther and D. López. 2007a. Temporal and spatial temperature variability and change over Spain during 1850-2005. Journal of Geophysical Research-Atmospheres 112:D12117, doi:10.1029/2006JD008249.

Brunet M., O. Saladié, P.D. Jones, J. Sigró E. Aguilar, A. Moberg, A. Walther, D. Lister, D. López, and C. Almarza. 2006. The development of a new daily adjusted temperature dataset for Spain (1850-2003), International Journal of Climatology 26:1777-1802.

Burke, E. J.: Understanding the sensitivity of different drought metrics to the drivers of drought under increased atmospheric CO2. 2011. J. Hydrometeorol. 12, 13781394.

Burke, E. J., Brown S. J.: Evaluating uncertainties in the projection of future drought. 2008. J. Hydrometeorol. 9, 292-299.

Burton I., Kates R.W. and White G.F. 1978. The environment as a hazard. Oxford University Press. Nueva York, 240 pp.

Cancelliere, A., and J. D. Salas, 2004. Drought length properties for periodic-stochastic hydrologic data, Water Resour. Res., 40, W02503, doi:10.1029/2002WR001750.

Capel Molina, J. J., 2000: El Clima de la Península Ibérica. Ed. Ariel, Barcelona

Castro-Díez Y., Esteban-Parra M. J., Staudt M., Gámiz-Fortis S. 2007. Temperature and precipitation changes in Andalusia in the Iberian Peninsula and northern hemisphere context. In: Sousa A., García-Barrón L., Jurado V., editors. Climate 
Change in Andalusia: Trends and Environmental Consequences. Seville: Consejería de Medio Ambiente de la Junta de Andalucía. p. 57-77. 332.

Causapé J., Clavería I, 2007. Drought as an agri-environmental determinant of irrigation land, the case of Bardenas Spain. Env. Geol. 51, 1213-1220.

Christensen, J. H., and O.B. Christensen, 2007: A summary of the PRUDENCE model projections of changes in European climate by the end of this century. Climatic Change, 81(S1), 7-30.

CLIVAR Assessment 2010: Clima en España: Pasado presente y futuro. In Pérez F, Boscolo R, eds. www.clivar.es

Contreras S. C., 2003. Importancia de las sequías en el clima de México. Pp. 1-7 http://www.uaslp.mx/Docs/CCSYH/Programas/publicaciones/sequia.pdf

Collins, R., Kristensen, P., and Thyssen, N.: Water resources across Europeconfronting water scarcity and drought. 2009. European Environmental Agency.

Dae Ha K., Chulsang Y, Tae Woong K, 2011. Application of spatial EOF and multivariate time series model for evaluating agricultural drought vulnerability in Korea. Advances in Water Resources 34 (2011) 340-350.

Dai A., 2012. Increasing drought under global warming in observations and models. Nature Climate Change. DOI: 10.1038/NCLIMATE1633.

Dai A., 2011b. Characteristics and trends in various forms of Palmer Drought Severity Index during 1900-2008. J. Geophys. Res., 116, D12115, doi:10.1029/2010JD015541.

Dai A., 2011. Drought under global warming: A review. Wiley Interdisciplinary reviews: Climate Change 2: 45-65. doi: 10.1002/wcc.81.

Dai, A., T.T. Qian, K.E. Trenberth, and J.D. Milliman, 2009: Changes in continental freshwater discharge from 1948 to 2004. Journal of Climate, 22(10), 2773-2792.

Dai A., Trenberth KE, Qian T, 2004. A global dataset oh palmer drought severity index for 1870-2002: Relationship with soil moisture and effects of surface warming. Journal of Hydrometeorology 5: 1117-1130.

de Castro M., Lorenzo N, Taboada JJ, Sarmiento M, Alvarez I, Gomez-Gesteira M. 2006. Influence of teleconnection patterns on precipitation variability and on river flow regimes in the Mino River basin (NW Iberian Peninsula). Climate Research 32:63-73.

de Castro M., Martín-Vide, J., and Alonso, S.: El clima de España: pasado, presente y escenarios de clima para el siglo XXI. 2005. Impactos del cambio climático en España, Ministerio de Medio Ambiente: Madrid. 
del Moral L., Van der Werff, P., Bakker, K. \& Handmer, J., 2003. Global trends and water policy in Spain. Water International. 28, 3: 358-366.

del Río S., Penas A, Fraile R. 2005. Analysis of recent climatic variations in Castile and Leon (Spain). Atmospheric Research 73(1-2): 69-85.

Donohue, R. J., McVicar, T. R., and Roderick M. L.: Assessing the ability of potential evaporation formulations to capture the dynamics in evaporative demand within a changing climate. 2010. J. Hydol. 386, 186-197.

Dracup J. A., Lee KS., Paulson EG. 1980. On the statistical characteristics of drought events. Water Resources Res., 16, 289-296.

Dubrovsky M., Svoboda M.D., Trnka M.J., Hayes M.J., Wilhite D.A., Zalud Z. and Hlavinka P. 2008. Application of relative drought indices in assessing climatechange impacts on drought conditions in Czechia. Theoretical and Applied Climatology, 96, 155-171.

Entekhabi D., Rodríguez-Iturbe I, Bras RL, 1992. Variability in large-scale water balance with land surface-atmosphere interaction. J. Climate 5(8) 798-813

Estrada P. M., 2001. Cambio climático global: causas y consecuencias. http://www.inigi.gob.mx/inegi/contenidos/espanol/prensa/contenidos/articulos/a mbientales/climatico.pdf

European Parliament Assessment, 2005. Risk and crisis management in agriculture. IP/B/AGRI/ST/2005-30. European Parliament, Brussels

FAO/IISA/ISRIC/ISSCAS/JRC. 2009. Harmonized World Soil Database (version 1.2). FAO, Rome, Italy and IISA, Laxenburg, Austria.

Feyen L., and R. Dankers, 2009: Impact of global warming on streamflow drought in Europe. Journal of Geophysical Research - Atmospheres, 114, D17116.

Font Tullot I., 1988: Historia del clima de España. I.N.M., Madrid.

Gallego M., C., R. M. Trigo, J. M. Vaquero, M. Brunet, J. A. García, J. Sigró, and M. A. Valente, 2011. Trends in frequency indices of daily precipitation over the Iberian Peninsula during the last century, J. Geophys. Res., 116, D02109, doi:10.1029/2010JD014255.

Gibbs W. J. and J. V. Maher, 1967. Rainfall deciles as drought indicators. Bureau of Meteorology Bulletin, No. 48, Commonwealth of Australia, Melbourne.

Gomez-Navarro JJ, Montavez JP, Jimenez-Guerrero P, Jerez S, Garcia-Valero JA, Gonzalez-Rouco JF (2010) Warming patterns in regional climate change projections over the Iberian Peninsula. Meteorol Z 19(3):275-285.

Great Britain Meteorological Office, 1951. The meteorological glossary. Chemical publishing Co., New York, USA. 
Groisman P.Y., and R.W. Knight, 2008: Prolonged dry episodes over the conterminous United States: New tendencies emerging during the last 40 years. Journal of Climate, 21(9), 1850-1862.

Guttman, N. B.: Comparing the Palmer drought index and the Standardized Precipitation Index. 1998. J. Am. Water Resour. Assoc. 34, 113-121. doi: 10.1111/j.1752-1688.1998.tb05964.x.

Hayes, M., Svoboda, M., Wall, N., Wildhalm, M.: The Lincoln Declaration on Drought Indices: Universal Meteorological Drought Index recommended. 2011. Bull. Am. Meteorol. Soc., 92, 485-488, doi: 10.1175/2010BAMS30103.1.

Hayes M. J., Svoboda, M. D., Wilhite, D. A., and Vanyarkho, O.V., 1999, 'Monitoring the 1996 drought using the standardized precipitation index', Bulletin of the American Meteorological Society 80(3), 429-438.

Hayes M., 1997. Drought Indices. National Drought Mitigation Center (NDMC) http://www.drought.unl.edu/

Heim R.R., 2002. A review of twentieth-century drought indices used in United States. Bulletin of the American Meteorological Society, 83, 1149-1165.

Heinrich, G., Andreas Gobiet, 2012. The future of dru and wet spells in Europe: A comprehensive study based on the ENSEMBLES regional climate models. International Journal of Climatology 32: 1951-1970.

Herrera S, Fita L, Fernandez J, Gutierrez JM (2010) Evaluation of the mean and extreme precipitation regimes from the ENSEMBLES regional climate multimodel simulations over Spain. J Geophys Res 115:D21.

Hirabayashi Y., S. Kanae, S. Emori, T. Oki, and M. Kimoto, 2008b: Global projections of changing risks of floods and droughts in a changing climate. Hydrological Sciences Journal, 53(4), 754-772.

Hisdal H, Tallaksen LM, Clausen B, Peters E, Gustard A., 2004. Hydrological drought characteristics. In: Tallaksen LM, Van Lanen HAJ (eds) Hydrological droughtprocesses and estimation methods for streamflow and groundwater. Developments in Water Sciences 48, Elsevier B.V., 139-198

Hisdal H, Stahl K, Tallaksen LM, Demuth S, 2001. Have droughts in Europe become more severe or frequent? Int J Climatol 21:317-333

Hudson H. E., Hazen R., 1964: Droughts and low streamflow. In "Handbook of Applied Hydrology”, section 18; Ven Te Chow, editor-in-Chief; New York: McGraw-Hill Book Company.

Iglesias A., Garrote L, Martin-Carrasco F. 2009. Drought risk management in Mediterranean river basins. Integr Environ Assess Manag 5:11-16. 
Iglesias A., Garrote L., Flores F., Moneo M.: Challenges to manage the risk of water scarcity and climate in the Mediterranean. 2007. Water resour. Manage., 21, 775-788.

IPCC climate change 2012: Managing the Risks of Extreme Events and Disasters to Advance Climate Change Adaptation. A Special Report of Working Groups I and II of the Intergovernmental Panel on Climate Change [Field, C.B., V. Barros, T.F. Stocker, D. Qin, D.J. Dokken, K.L. Ebi, M.D. Mastrandrea, K.J. Mach, G.-K. Plattner, S.K. Allen, M. Tignor, and P.M. Midgley (eds.)]. Cambridge University Press, Cambridge, UK, and New York, NY, USA, 582 pp.

IPCC climate change 2007: the physical science basis. In: Salomon S, Qin D, Manning M, Chen Z, Marquis M, Averyt KB, Tignor M, Miler HL, eds. Contribution of Working Group I to the Fourth Assessment Report of the International Panel on Climate Change Program. Cambridge, UK/New York, USA: Cambridge University Press; 2007, 996.

Jáuregui O. E., 1979. Algunos aspectos de las fluctuaciones pluviométricas en México, en los últimos cien años. Boletín de Geografía. Instituto de Geografía de la UNAM. México. 9: 39-64.

Jerez S, Montavez JP, Gomez-Navarro JJ, Jimenez PA, Jimenez-Guerrero P, LorentePlazas R, Gonzalez-Rouco JF (2012a) The role of the land-surface model for climate change projections over the Iberian Peninsula. J Geophys Res 117:D01,109.

Jerez, S., Montavez, J.P. 2012c. A multi-physics ensemble of regional climate change projections over the Iberian Peninsula. Climate Dynamics. DOI: 10.1007/s00382012-1551-5.

Jones P. D., and M. Hulme. 1996. Calculating regional climatic time series for temperature and precipitation: methods and illustrations, International Journal of Climatology 16:361-377.

Jolliffe I. T., 2002. Principal Component Analysis, 2nd Ed. Springer, 487pp.

Jolliffe I. T., 1990, Principal Component Analysis: A beginner's guide. Part I: Introduction and application. Weather, 45, 375-382.

Jolliffe I. T., 1986, Principal Component Analysis, Springer, New York, 271 pp.

Kaiser H. F., 1958, The Varimax criterion for analytic rotation in factor analysis. Psychometrika, 23, 187-200.

Kaiser H. F., 1960, The application of electronic computers to factor analysis. Educational and Psychological Measurement, 20, 141-151. 
Karl T. R., 1986. The sensitivity of the Palmer drought severity index and the Palmer z-index to their calibration coefficients including potencial evapotranspiration. Journal of Climate and Applied Meteorology, 25, 77-86.

Keetch J. J., and Byram GM. 1968. A drought index for forest fire control. USDA Forest Service Research Paper SE-38, Southeastern forest Experiment Station, Asheville, NC, 33pp.

Kendall M. G., 1970. Rank Correlation Methods (4th ed). Griffin and Co. Ltd.

Keyantash J., Dracup JA. 2002. The quantification of drought: an evaluation of drought indices. Bulletin of the American Meteorological Society 83: 11671180 .

Kingtse C., Mo, Schemm J.K.E., Soo-Hyun Y. 2009. Influence of ENSO and the Atlantic Multidecadal Oscillation on drought over United States. Journal of Climate, 592.

Kingtse C., Mo, Schemm J.K.E. 2008. Droughts and persistent wet spells over the United States and Mexico. Journal of Climate, 980.

Komuscu A. U., 1999. Using the SPI to analyze spatial and temporal patterns of drought in Turkey. Drought Network New, 11 (1): 7-13

Kulik M. S., 1962, "Agroclimatic indices of droughts", in Agrometeorological problems (eds.) Davitaya, F.F. 1958 and Kulik, M.S., Met. Transl., No. 7, Dept. of Transport. Toronto, pp. 71-74.

Lana X., Burgueño A. 2000. Some statistical characteristics of monthly and annual pluviometric irregularity for the Spanish Mediterranean coast. Theoretical and Applied Climatolology 65(1-2): 75-97.

Lehner B., P. Doll, J. Alcamo, T. Henrichs, and F. Kaspar, 2006: Estimating the impact of global change on flood and drought risks in Europe: A continental, integrated analysis. Climatic Change, 75(3), 273-299.

López-Moreno, J.I., Vicente-Serrano S. M., Zabalza, J., Beguería S., Lorenzo-Lacruz J., Azorín-Molina, C., Morán-Tejeda, E.: Hydrological response to climate variability at different time-scales: A study in the Ebro basin. 2013. J. Hydrol., 477, 175-188.

Lorenzo-Lacruz J., Morán-Tejeda E, Vicente-Serrano S.M. and López-Moreno J.I., 2013. Streamflow droughts in the Iberian Peninsula between 1945 and 2005: spatial and temporal patterns. Hydrol. Earth Syst. Sci., 17, 119-134, 2013.

Lorenzo-Lacruz J., Vicente-Serrano SM, López-Moreno JI, Morán-Tejeda E, Zabalza J, 2012. Recent trends in Iberian streamflows (1945-2005). Journal of Hydrology 414-415 (2012) 463-475 
Lorenzo-Lacruz J., Vicente-Serrano SM, López-Moreno JI, González-Hidalgo JC, Morán-Tejeda E, 2011. The response of Iberian rivers to the North Atlantic Oscillation. Hydrol. Earth Syst. Sci. 15, 2581-2597

Lorenzo-Lacruz J., Vicente-Serrano SM, López-Moreno JI, Beguería S, García-Ruiz JM, Cuadrat JM, 2010. The impact of droughts and water management on various hydrological systems in the headwaters of the Tagus River (central Spain). J Hydrol (Amst) 386:13-26

Loukas A., and Vasiliades, L., 2004: Probabilistic analysis of drought spatio-temporal characteristics in Thessaly region, Greece, Nat. Hazards Earth Syst. Sci., 4, 719731.

Llamas M. R., 1995. Consideraciones sobre la sequía de 1991 a 1995 en Espanya. Manuscript.

Llasat M. C.; Quintas, XXX. 2004. Stationarity of Monthly Rainfall Series since the Middle of the XIXth Century. Application to the Case of Penin sular Spain. Natural Hazards. No 31. pp. 613-622.

Lloyd-Hughes B., and M.D. Saunders, 2002: A drought climatology for Europe. International Journal of Climatology, 22(13), 1571-1592.

Magaña R. J., Pérez L, Conde C, Gay C, Medina S, 1997. El fenómeno de El Niño y la Oscilación del Sur (ENOS) y sus impactos en México. Departamento de Meteorología General. Centro de Ciencias de la Atmosfera. UNAM

Mariotti, A., N. Zeng, J.H. Yoon, V. Artale, A. Navarra, P. Alpert, and L.Z.X. Li, 2008: Mediterranean water cycle changes: transition to drier 21st century conditions in observations and CMIP3 simulations. Environmental Research Letters, 3(4), 044001.

Marcos Valiente O., 2001. "Sequía: definiciones, tipologías y métodos de cuantificación". Investigaciones geográficas, n 26 pp59-80.

Martín-Vide J., Olcina J., 2001. Climas y tiempos de España. Alianza Editorial: Madrid.

Martínez M. D., Serra C., Burgueño A., Lana X., 2009. Time trends of daily maximum and minimum temperatures in Catalonia (NE Spain) for the period 1975-2004. International Journal of Climatology. Doi: 10.1002/joc.1884.

Mastrandrea, M. D., C.B. Field, T.F. Stocker, O. Edenhofer, K.L. Ebi, D.J. Frame, H. Held, E. Kriegler, K.J. Mach, P.R. Matschoss, G.-K. Plattner, G.W. Yohe, and F.W. Zwiers, 2010: Guidance Note for Lead Authors of the IPCC Fifth Assessment Report on Consistent Treatment of Uncertainties. Intergovernmental Panel on Climate Change (IPCC). Available at 〈http://www.ipcc.ch $\rangle$. 
Mavromatis T., 2009. Use of drought indices in climate change impact assessment studies: an application to Greece. International Journal of Climatology. Doi: 10.1002/joc.1976.

Mavromatis T., 2007. Drought index evaluation for assessing future wheat production in Greece. International Journal of Climatology, 27, 911-924.

McKee T. B. N. and Kleist J, 1995. Drought monitoring with multiple scales. Preprint. 9th Conference on Applied Climatology, January, 15-20. Dallas, Texas. Pp. 233236

McKee T. B. N., Doesken J. and Kleist J. 1993. The relationship of drought frequency and duration to time scales. Eight Conf. On Applied Climatology. Anaheim, CA, Amer. Meteor. Soc. 179-184.

Mirakbari M., Ganji A, Fallah SR. 2010. Regional bivariate frequency analysis of meteorological droughts. Journal of Hydrologic Engineering 15(12): 985-1000.

Miró J. J., M. J. Estrela, and M. Milló. 2006, Summer temperature trends in a Mediterranean area (Valencia region), International Journal of Climatology 26:1051-1073.

Mishra, A. K., Singh, V. P. 2011. Drought modeling-A review. Journal of Hydrology 403: $157-175$.

Mishra, A. K., and Singh, V. P.: A review of drought concepts. 2010. J. Hydrol., 391, 202-216.

Monteith, J. L. Evaporation and environment. 1964. Symp. Soc. Exp. Biol. 19, 205234.

Morán-Tejeda, E., López-Moreno J. I., Ceballos-Barbancho, A., and Vicente-Serrano, J. M.: River regimes and recent hydrological changes in the Duero basin (Spain). 2011. J. Hydrol., 404, 241-258.

Mourato S., Moreira M., Corte-Real J., 2009. Interannual variability of precipitation distribution patterns in Southern Portugal. Int. J. Climatol. 30, 1784-1794.

Mueller B., Seneviratne S., 2012. Hot days induced by precipitation deficits at the global scale. PNAS. Doi: 10.1073/pnas.1204330109.

New M., Todd M, Hulme M, Jones P. 2001. Precipitation measurements and trends in the twentieth century. International Journal of Climatology 21: 1899-1922.

Olcina Cantos J., 1994. Riesgos climáticos en la Península Ibérica. Madrid, Penthalón, 440pp.

Osborn T. J., Briffa K.R., Jones P.D. 1997. Adjusting variance for sample-size in treering chronologies and other regional-mean time-series. Dendrochronologia 15:8999. 
Palmer W.C., 1965. Meteorological droughts. U.S. Department of Commerce Weather Bureau Research Paper 45,58 pp.

Potop V., Mozny M, 2011. The application a new drought index-standardized precipitation evapotranspiration index in the Czech Republic. Středová, H., Rožnovský, J., Litschmann, T. (eds): Mikroklima a mezoklima krajinných struktur a antropogenních prostředí. Skalní mlýn, 2. - 4.2. 2011, ISBN 978-80$86690-87-2$

Potop V., 2011. Evolution of drought severity and its impact on corn in the Republic of Moldova. Theor. Appl. Climatol. DOI 10.1007/s00704-011-0403-2

Pita-López M. F., 1995. Las sequías: anàlisis y tratamiento. Consejería de Medio ambiente. Junta de Andalucía. Sevilla. 56pp.

Rammukainen, M., 2010. State-of-the-art with regional climate models. Wiley Interdisciplinary Reviews: Climate Change 1: 82-96.

Rasmussen E. M., 1987. Global climate change and variability: effects on drought and desertification in Africa. En: Glantz M, (Ed.): Drought and hunger in Africa. Cambridge University Press.

Rebetez M., Mayer H, Dupont O, Schindler D, Gartner K, Kropp J, Menzel A., 2006. Heat and drought 2003 in Europe: a climate synthesis. Ann For Sc 63: 569-577

Richman M. B., 1986. Rotation of Principal Components. Journal of Climatology, 6, 293-335.

Rodrigo F. S., Trigo M, 2007. Trends in daily rainfall in the Iberian Peninsula from 1951 to 2002. Int. J. Climatol. 27, 513-529.

Rodríguez-Puebla C., Nieto S., 2010. Trends of precipitation over Iberian Peninsula and the North Atlantic Oscillation under climate change conditions. Int. J. Climatol. 30, 1807-1815

Saladié O., 2004. Variaciones y tendencia secular de la precipitación en el Sector Nororiental de la Penísnula Ibérica (1850-2000), Tesis de Doctorado Inédita, Universitat de Barcelona, Barcelona, 496 pp.

Sánchez, E., Domínguez, M., Romera, R., López de la Franca, N., Gaertner, MA., Gallardo, C., Castro, M., 2012. Modelización regional de períodos secos sobre la Península Ibérica en clima presente y condiciones de cambio climático. Física de la Tierra.

Sánchez, E., Gaertner, MA., Gallardo, C., 2009. Regionalización diaria de la precipitación diaria sobre la Península Ibérica: análisis de la resolución espacial en la descripción del clima actual y clima futuro. Física de la Tierra 21: 207-218. 
Santos J., Pulido-Calvo I., Portela M. M., 2010. Spatial and temporal variability of droughts in Portugal. Water Resources Research. Doi: 10.1029/2009WR008071, 2010 .

Schär C., and G. Jendritzky, 2004: Climate change: Hot news from summer 2003. Nature, 432(7017), 559-560.

Seneviratne S., Corti T., Davin L., Hirschi M., Jaeger E., Lehner I., Orlowsky B., Teuling A. 2010. Investigating soil moisture-climate interactions in a changing climate: a review. Manuscript. Universitätsstrasse 16, 8092 Zurich, Switzerland.

Seneviratne, S. I., R.D. Koster, Z.C. Guo, P.A. Dirmeyer, E. Kowalczyk, D. Lawrence, P. Liu, C.H. Lu, D. Mocko, K.W. Oleson, and D. Verseghy, 2006b: Soil moisture memory in AGCM simulations: Analysis of global land-atmosphere coupling experiment (GLACE) data. Journal of Hydrometeorology, 7(5), 10901112.

Serra C., Burgueño A., martinez MD., Lana X. 2006. Trenes in dry spells across Catalonia (NE Spain) during the second half of the $20^{\text {th }}$ century. Theoretical and Applied Climatology. Doi: 10.1007/s00704-005-0184-6.

Shafer B. A., and L. E. Dezman, 1982. Development of a Surface Water Supply Index (SWSI) to assess the severity of drought conditions in snowpack runoff areas. Proceedings of the Western Snow Conference, pp. 164-175.

Sheffield J., Wood, EF., Roderick ML., 2012. Little change in global drought over the past 60 years. LETTER DOI: 10.1038/nature11575.

Sheffield, J., and E. F. Wood: Drought: Past Problems and Future Scenarios, Earthscan, to be published in 2011 .

Sheffield, J., K. M. Andreadis, E. F. Wood, and D. P. Lettenmaier, 2009: Global and continental drought in the second half of the 20th century: severity-area-duration analysis and temporal variability of large-scale events, J. Climate, 22(8), 19621981.

Shiau J. T., Modarres R. 2009. Copula-based drought severity-duration-frequency analysis in Iran. Meteorological Applications 16(4): 481-489. DOI: 10.1002/met.145.

Shiau J. T., 2006. Fitting drought duration and severity with two-dimensional copulas. Water Resources Management 20: 795-815.

Shiau J. T., 2003, 'Return period of bivariate distributed hydrological events', Stochastic Environmental Research and Risk Assessment 17(1-2), 42-57.

Shiau J. T., and Shen, H.W., 2001, 'Recurrence analysis of hydrologic droughts of differing severity', Journal of Water Resources Planning and Management ASCE 127(1), 30-40. 
Simpson, I., 2011. PhD Dissertation. Precipitation variability across the UK: Observations and model simulations. Climatic Research Unit, School of Environmental Sciences, University of East Anglia, Norwich NR47TJ, UK.

Sivakumar M., Wilhite DA., Svoboda D., Hayes M., Motha R., 2011. Drought risk and meteorological droughts. Global Assessment Report on Disaster Risk Reduction. GAR 2011.

Smith T. M., Reynolds RW, 2005. A Global Merged land-air-Sea surface temperature reconstruction based on Historical Observations (1880-1997). Journal of Climate $18 ; 2021-2036$

Smith D. I., Hutchinson MF, and McArthur RJ, 1993. Australian climatic and agricultural drought: payments and policy. Drought Network News, 5(3): 11-12

Sousa P., R.M. Trigo, P. Aizpurua, R. Nieto, L. Gimeno, R. Garcia-Herrera, 2011. Trends and extremes of drought indices throughout the 20th century in the Mediterranean, NHESS, Special Issue "Understanding dynamics and current developments of climate extremes in the Mediterranean region", 11, 33-51; doi:10.5194/nhess-11-33-2011

Stahl K., H. Hisdal, J. Hannaford, L.M. Tallaksen, H.A.J. van Lanen, E. Sauquet, S. Demuth, M. Fendekova, and J. Jódar, 2010: Streamflow trends in Europe: evidence from a dataset of near-natural catchments. Hydrology and Earth System Sciences Discussion, 7(4), 5769-5804.

Strenberg, T. Regional drought has a global impact. 2011. Nature 472, 169.

Svoboda M., 2000. An introduction to the Drought Monitor. Drought Network News, $12,15-20$.

Subash N., Ram Mohan HS, 2010. Trend detection in rainfall and evaluations of standardized precipitation index as a drought assessment index for rice-wheat productivity over IGR in India. Int. J. Climatol. Doi: 10.1002/joc.2188

Szalai S., and Szinell, Cs., 2000, Comparison of two drought indices for drought monitoring in Hungary - a case study, In: J. V. Vogt and F. Somma (eds), Drought and Drought Mitigation in Europe, Kluwer, Dordrecht, pp. 161-166.

Szinell Cs., Bussay, A., and Szentimrey, T., 1998, Drought tendencies in Hungary. Int. J. Climatol. 18, 1479-1491.

Thornthwaite C. W., 1948. An approach toward a rational classification of climate. Geographical Review, 38, 55-94.

Trenberth, K. E., 2007. Observations: Surface and Atmospheric Climate Change. In: Climate Change 2007: The Physical Science Basis. Contribution of Working Group I to the Fourth Assessment Report of the Intergovernmental Panel on Climate Change [Solomon, S., D. Qin, M. Manning, Z. Chen, M. Marquis, K.B. 
Averyt, M. Tignor and H.L. Miller (eds.)]. Cambridge University Press, Cambridge, United Kingdom and New York, NY, USA.

Trigo R. M., Pozo-Vázquez D, Osborn TJ, Castro-Díez Y, Gámiz-Fortis S, EstebanParra MJ, 2004. North Atlantic Oscillation influence on precipitation, river flow and water resources in the Iberian Peninsula. Int. J. Climatol. 24, 925-944.

van der Linden and Mitchell J.F.B. 2009. ENSEMBLES: Climate Change and its Impacts: Summary of research and results from the ENSEMBLES project. Met Office Hadley Centre, FitzRoy Road, Exeter EX1 3PB, UK. 160pp.

van der Schrier G., Jones PD, Briffa KR, 2011. The sensitivity of the PDSI to the Thorthwaite and Penman-Monteith parameterizations for potential evapotranspiration, J. Geophys. Res., 116, D03106, doi:10.1029/2010JD015001

van der Schrier G., Efthymiadis D., Briffa KR., Jones PD. 2007. European alpine moisture variability for 1800-2003. International Journal of Climatology. 27: 415427, Doi: 10.1002/joc.1411.

van der Schrier G., Efthymiadis D., Briffa KR., Jones PD., 2006b. Summer moisture variability across Europe. Journal of Climate. 19(12): 2828-2834.

Vautard, R., P. Yiou, F. D’Andrea, N. de Noblet, N. Viovy, C. Cassou, J. Polcher, P. Ciais, M. Kageyama, and Y. Fan, 2007: Summertime European heat and drought waves induced by wintertime Mediterranean rainfall deficit. Geophysical Research Letters, 34, L07711.

Vicente-Serrano, S. M., Gouveia, C., Camarero, J. J., Beguería, S., Trigo, R., LópezMoreno, J. I., Azorín-Molina, C., Pasho, E., Lorenzo-Lacruz, J., Revuelto, J., Morán-Tejeda, E., Sánchez-Lorenzo, A. 2013. Response of vegetation to drought time-scales across global land biomes. PNAS. 110, 52-57.

Vicente-Serrano, S. M., Beguería, S., Lorenzo-Lacruz, J., Camarero, J. J., LópezMoreno, J. I., Azorín-Molina, C., Revuelto, J., Morán-Tejeda, E., SánchezLorenzo, A. 2012. Performance of Drought Indices for Ecological, Agricultural, and Hydrological Applications. Earth Interactions. Volume 16, paper 10.

Vicente-Serrano S. M., Beguería S, López-Moreno JI., 2011. Comment on "Characteristics and trends in various forms of the Palmer Drought Severity Index (PDSI) during 1900-2008” by Aiguo Dai, J. Geophys. Res., 116, D19112, doi:10.1029/2011JD016410

Vicente-Serrano S. M., Lópea-Moreno JI, Beguería S, Lorenzo-Lacruz J, AzorínMolina C, Morán-Tejeda E, 2011a. Accurate computation of a streamflow index. J Hydrolog Eng. Doi: 10.1061/(ASCE)HE.1943-5584.0000433

Vicente-Serrano S. M., López-Moreno JI, Drumond A, Gimeno L, Nieto R, MoránTejeda E, Lorenzo-Lacruz J, Beguería S, Zabalza J, 2011b. Effects of warming processes on droughts and water resources in the NW Iberian Peninsula (19302006). Climate Research. 48: 203-212. 
Vicente-Serrano S. M., Beguería S., López-Moreno JI., 2010. A multi-scalar drought index sensitive to global warming: the standardized precipitation evapotranspiration index-SPEI. Submitted.

Vicente-Serrano S. M., Cuadrat JM., Romo A., 2007. Early prediction of crop productions using drought indices at different time scales and remote sensing data: application in the Ebro valley (North-east Spain). International Journal of Remote Sensing, 27, 511-518.

Vicente-Serrano S. M., 2006b. Spatial and temporal analysis of droughts in the Iberian Peninsula. Hydrological Sci-J-des Sciences Hydrologiques 51(1):83-97. doi:10.1623/hysj.51.1.83

Vicente-Serrano S. M., López-Moreno J. I. 2006. Differences in spatial patterns of drought on different time scales: an analysis of the Iberian Peninsula. Water Resources management, 20, 37-60.

Vicente-Serrano S. M., Cuadrat-Prats, 2006. Trends in drought intensity and variability in the middle Ebro valley (NE Spain) during the second half of the twentieth century. Theor Appl Climatol 88:247-258.

Vicente-Serrano S. M., González-Hidalgo JC, de Luis M, Raventós J, 2004. Spatial and temporal patterns of droughts in the Mediterranean area: the Valencia region (eastern Spain). Clim Res 26:1427-1456.

Wang X. L., Swail, V. R., 2001. Changes of extreme wave height in Northern Hemisphere oceans and related atmospheric circulation regimes. Journal of Climate. Volume 14, 12-45.

Wells N., Goddard S, Hayes MJ. 2004. A self-calibrating Palmer Drought Severity Index. J Clim, 17:2335-2351.

White, D., Richman, H., and Yarnal, B.: Climate regionalization and rotation of principal components. 1991. Int. J. Climatol., 11, 1-25.

White D. A., and O'Meagher B, 1995. Coping with exceptional droughts in Australia. DA Whilhite (Eds.) Drought Network News, Volume 7. University of Nebraska, pp. 13-17

Wilhite D. A., and Glantz MH, 1985. Understanding the drought phenomenon: the role of definitions. Water International, 10: 111-120

Wilks D. S., 2006. Statistical Methods in the Atmospheric Sciences, International Geophysics Series, Academic Press.

World Meteorological Organization (WMO). 1992. International Meteorological Vocabulary. 2d ed. WMO No. 182, WMO, 784pp. 
Wu R., Kinter JL, 2009. Analysis of the relationship of U.S. Droughts with SST and Soil Moisture: Distinguishing the time scale of droughts. Journal of Climate. Volume 22. Pp. 4520-4538.

Xoplaki, E., González-Rouco, J. F., Luterbacher, J., and Wanner, H.: Wet season Mediterranean precipitation variability: influence of large-scale dynamics and trends. 2004. Clim. Dynam., 23, 63-78. 